Claremont Colleges

Scholarship@ Claremont

2012

\title{
Authoring Authority: The Apostle Paul and the Prophet Joseph Smith--A Critical Comparison of Texts and Power in the Generation of Religious Community
}

Alonzo Huntsman

Claremont Graduate University

\section{Recommended Citation}

Huntsman, Alonzo, "Authoring Authority: The Apostle Paul and the Prophet Joseph Smith--A Critical Comparison of Texts and Power in the Generation of Religious Community" (2012). CGU Theses \& Dissertations. Paper 28.

http://scholarship.claremont.edu/cgu_etd/28

DOI: $10.5642 / \operatorname{cguetd} / 28$

This Open Access Dissertation is brought to you for free and open access by the CGU Student Scholarship at Scholarship @ Claremont. It has been accepted for inclusion in CGU Theses \& Dissertations by an authorized administrator of Scholarship @ Claremont. For more information, please contact scholarship@cuc.claremont.edu. 
Authoring Authority: The Apostle Paul and the Prophet Joseph SmithA Critical Comparison of Texts and Power in the Generation of Religious Community

\author{
by \\ Alonzo Huntsman
}

\title{
Claremont Graduate University
}

May, 2012

Approved by

Vincent L. Wimbush

Committee Chair

(C) Copyright Alonzo Huntsman, 2012

All Rights Reserved 


\section{APPROVAL OF THE REVIEW COMMITTEE}

This dissertation has been duly read, reviewed, and critiqued by the Committee listed below, which hereby approves the manuscript of Alonzo Huntsman as fulfilling the scope and quality requirements for meriting the degree of

Doctor of Philosophy.

Vincent L. Wimbush

Claremont Graduate University

Chair

Richard L. Bushman

Columbia University, Emeritus, and Claremont Graduate University

Committee Member

Lori Anne Ferrell

Claremont Graduate University

Committee Member

Armand Mauss

Washington State University, Emeritus; Claremont Graduate University, Adjunct Visiting Examiner 


\title{
ABSTRACT \\ Authoring Authority: The Apostle Paul and the Prophet Joseph Smith- A Critical Comparison of Texts and Power in the Generation of Religious Community
}

\author{
by \\ Alonzo Huntsman \\ Claremont Graduate University: 2012 \\ ... believe in God, believe also in me... \\ -John 14.1
}

"Authoring Authority" analyzes the ways texts function to generate social cohesion while at the same time advancing the power interests of their authors. The study is a comparative, critical, and interdisciplinary/transdisciplinary excavation of the religion-making efforts of the first-century Christian Apostle Paul and the nineteenth-century Mormon Prophet Joseph Smith.

This comparison defamiliarizes and recharacterizes the heroes and originstories of the dominant (and my own) tradition to force important questions about scholarly perspectives, interests and deferences (protection, exceptionalization), self-reflexivity, and politics. The project's critical orientation deploys insights and models from a range of disciplines to "read" these texts for what they signify and how they function in nascent social formations. The texts of these men were presented as if their contents were other than the products of embedded social 
actors (e.g. "it really is God's word" 1 Thes 2.13) contending for limited resources such as discursive authority and social power. These charismatic narrators harnessed the authority of pre-existing texts and traditions and integrated them with contemporary perspectives and sentiment. Their texts and performances offered a contingent construal of reality as ultimate reality-which served the power needs of their authors and the existential needs of their communities of subscribers.

The dissertation begins with the articulation of an analytical framework appropriate for the critical and comparative academic study of religion. Chapter two contextualizes the lives of these men within cultural settings that provided motivation, made available vocational training and, ultimately provisioned social opportunities for them as adept charismatics. Chapter three directly illuminates the range of techniques embedded in texts, both implicit and explicit, of claiming power and developing a following. The final chapter wrestles with the functional role of deception in social formation and human life. 


\section{CONTENTS}

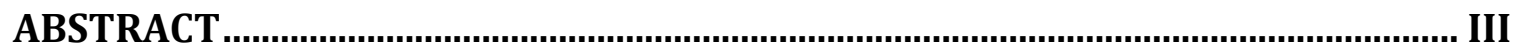

TABLES

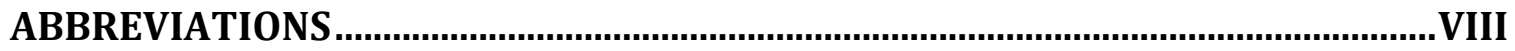

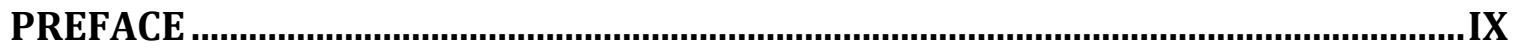

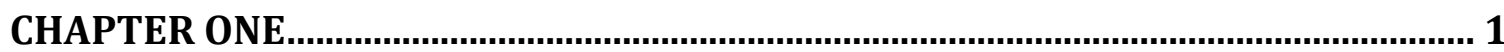

INTRODUCTION AND CRITICAL FRAMEWORK …................................................ 1

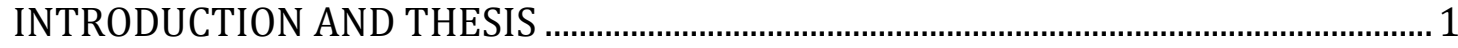

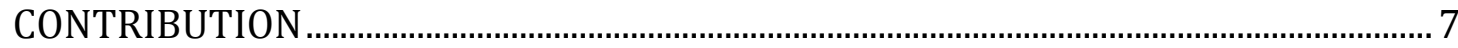

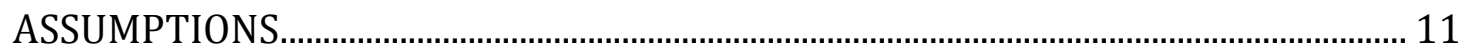

The Relentless Meaning-Making Enterprise ……………………………………... 13

Relationships: Self-Interest and Sociality, Knowledge and Power....................... 24

Scripture and Scripturalization.............................................................................. 30

Discourse as Mediator of Social Relationships........................................................ 37

Discourse Internalized - a final assumption ............................................................... 39

APPROACH—COMPARATIVE AND CRITICAL ……………………………………..... 43

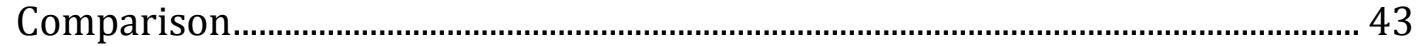

Critical Approach............................................................................................................. 46

Acknowledging the Human Motivations That Drive Behavior .............................................. 47

Meaning is Dynamic......................................................................................................................51

Texts and Power-The Mandate to Excavate...........................................................................53

Personal Stake-Author's Location ............................................................................. 57

CHAPTER TWO

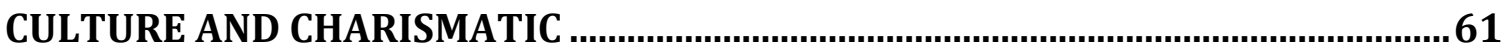

CHARACTER ATTRIBUTES AND SOCIO-CULTURAL LOCATION N................................. 61

Charismatic Characteristics ......................................................................................... 64

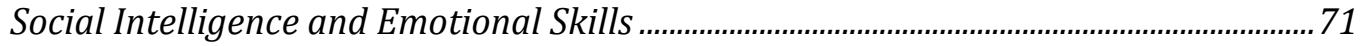

Confidence and Persuasion.................................................................................................................77

Recognizing Gifts..........................................................................................................................

THE LIFE-STAGES OF A PROPHET .................................................................................. 93

The Sense of Not Belonging to Any Group ................................................................ 96

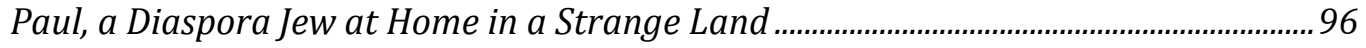

Smith: Poverty, Itinerancy and Longing for Belonging.........................................................107

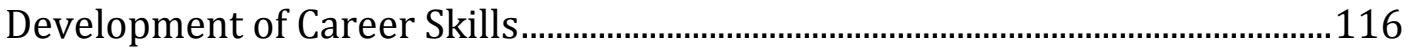

Paul: Partisan Persecutor, Partisan Promoter....................................................................116

Smith: Seeker of Hidden Treasures, Golden and Spiritual .....................................................124

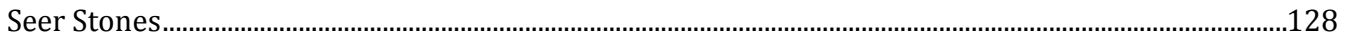

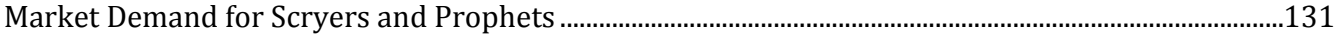

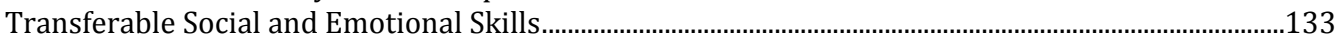

Skill Sets and Improvisation: The Alchemist Entrepreneur...……………………………………………....137 
AUTHORING AUTHORITY ......................................................................... 143

THE POWER OF WRITING REALITY ..........................................................................143

The Subtle Power of Texts (in context) ..................................................................146

Revelations Reveal Reality..................................................................................157

Texts Articulate the Social Contract........................................................................166

CLAIMING POWER: THE SELF-PROMOTER ARGUES HIS CASE ...............................173

Supernatural Sanction: Chosen Messengers and the Claims of Packaging .....175

Paul: Explicit Claims of a Divine Commission ............................................................................175

Smith: The Implicit Claims of Packaging .................................................................................183

Claiming Authority Over Men:..................................................................................196

Paul: Pursuing Dominance in a Competitive Market Place...................................................198

Smith: Power and Disempowerment..................................................................................................210

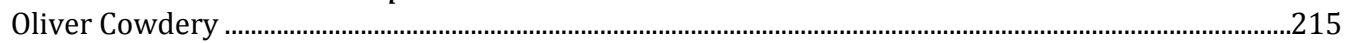

The Work of the Lord as Financial Extortion: Martin Harris and Philemon ...............227

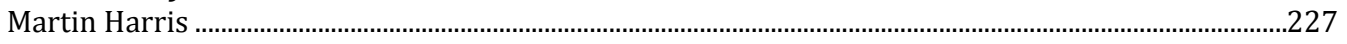

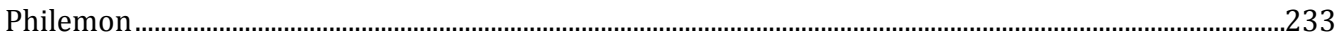

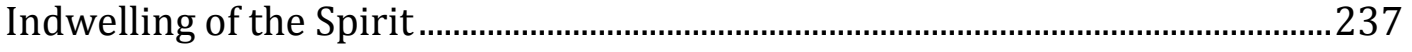

Authority and Lineage.......................................................................................24

Called Before They Were Born, kata taV grafaV ..................................................243

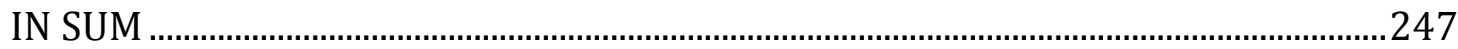

Determined Social Actors ...........................................................................................252

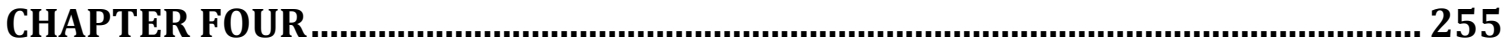

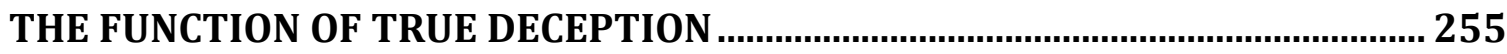

SUMMARY, CONCLUSION, INTEGRATION …………………………………….......25

The Grace of Guile........................................................................................257

CUNNING INTELLIGENCE IN THE WORLDS OF PAUL AND SMITH.........................265

Sanctioned Deception in the Ancient World ............................................................265

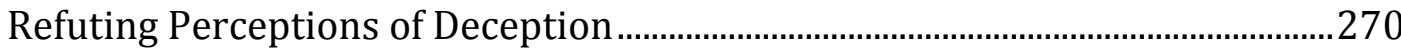

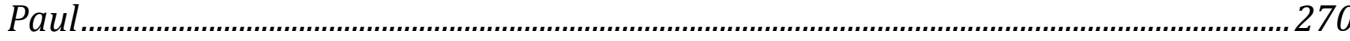

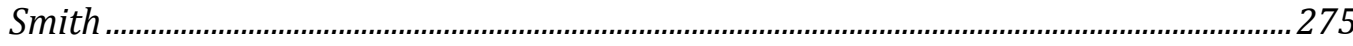

Epistemology and Evidence.....................................................................................22

Deceiving Demons Must Be Deceived ....................................................................224

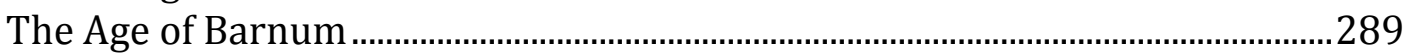

A TREE BUY ITS FRUITS? ………………………………………………………...29

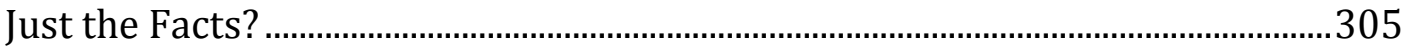

WORKS CITED AND CONSULTED 


\section{TABLES}

Table

Title

Page

2.1 Summary Overview of Oakes' Analytical Framework

65

2.2 Smith's Developing Skills

127

3.1 Smith: Ambiguity Regarding Textual Authority

152

3.2 Paul: Ambiguity Regarding Textual Authority

153

3.3 Analysis of Paul's Introduction to the Galatians

181

3.4 Texts: Comparative Claims, Characteristics and Packaging

185

3.5 Smith's Downgrading of Cowdery

227

4.1 Perceptions of Deception: Paul's Defense

272

4.2 Smith: Extrapolated Attitude Toward Deception

277

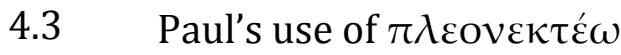

286

4.4 Paul's Challenge to Social Theorists

300 


\section{ABBREVIATIONS}

\begin{tabular}{|c|c|c|}
\hline$B o A$ & & Book of Abraham \\
\hline BoC & & Book of Commandments \\
\hline 1830 BoM & & Original, pre-versified, Book of Mormon \\
\hline BoM & & Book of Mormon \\
\hline BoMs & & Book of Moses \\
\hline$D \& C$ & & Doctrine and Covenants \\
\hline KJV & & King James Version \\
\hline$N E B$ & & New English Bible \\
\hline NRSV & .......... & New Revised Standard Version \\
\hline$A B D$ & & $\begin{array}{l}\text { Anchor Bible Dictionary, David Noel } \\
\text { Freedman, editor. }\end{array}$ \\
\hline$B D A G$ & & $\begin{array}{l}\text { Bauer, Danker: A Greek-English Lexicon of } \\
\text { the New Testament and other Early } \\
\text { Christian Literature }\end{array}$ \\
\hline$E M D$ & $\ldots$. & $\begin{array}{l}\text { Early Mormon Documents, Dan Vogel, } \\
\text { editor. }\end{array}$ \\
\hline$L S J$ & .......... & Liddell and Scott Greek-English Lexicon \\
\hline OTP & .......... & $\begin{array}{l}\text { Old Testament Pseudepigrapha } \\
\text { (2 Volumes) James H. Charlesworth, editor. }\end{array}$ \\
\hline
\end{tabular}




\section{PREFACE}

Evangelical Texas Pastor, Richard Jeffers, recently introduced Governor of Texas, fellow Evangelical and Republican presidential candidate, Rick Perry, to a crowd of conservative Republicans as "a genuine follower of Jesus Christ.” ${ }^{1}$ The comment was not simply to extol Perry’s piety; it was an implicit and direct attack on the less-thangenuine-Christian belief system of Republican presidential rival Mitt Romney, a Mormon. ${ }^{2}$ Following the speeches, Jeffers made himself available to the press where he continued to deride the Mormon church as a "cult” and Romney as "not a Christian.”3 To Southern Baptists and other Evangelicals, such rhetoric smugly reinforces the legitimacy of Jeffers' brand of Christianity at the delegitimizing expense of the "other," that of Romney's. One of the attendees of the Perry rally summarized the sentiment of many of his co-religionist when he reported to CNN contributor James Moore, "We think a them Mormons as bein' in kind of a cult . . . . I couldn't vote for one a them when we got a real Christian like Governor Perry runnin'."4

Polls indicate that the suspicions and contempt of Jeffers' and other “real Christians” for Mormons are not isolated to Texas. In a recent Gallup poll nearly one of

\footnotetext{
${ }^{1}$ New York Times, Oct. 7, 2011, http://www.nytimes.com/2011/10/08/us/politics/prominentpastor-calls-romneys-church-a-cult.html, accessed Nov 10, 2011.

2 "The Church of Jesus Christ of Latter-day Saints" is the preferred institutional title of the largest of the religious sects that claim Smith as their founder.

${ }^{3}$ New York Times, Oct. 7, 2011, http://www.nytimes.com/2011/10/08/us/politics/prominentpastor-calls-romneys-church-a-cult.html, accessed Nov 10, 2011.

4 James Moore, "Why Rick Perry is headed to the White House" http://www.cnn.com/2011/OPINION/08/11/moore.perry.candidate/index.html?hpt=hp_t1, accessed Nov 11, 2011. Moore's reproduction of his interviewee's dialect and less than perfect grammar conveys his own political message about the general intelligence of Evangelicals.
} 
five Republicans indicated that they would not vote for their party's nominee "if that person happens to be a Mormon.” 5 Such findings seem odd given that a higher percentage of Mormons self identify as “conservative” and/or Republican than any other subgroup measured by Gallup in a recent poll. ${ }^{6}$ The negative perception of Mormons is even more acute in the eyes of those on the other side of the political aisle. There, twenty-seven percent of Democrats would not vote for a Mormon for president. Given the self-expressed conservatism of so many Mormons, perhaps this reflexive response by those oriented towards the left is no surprise. But why do so many conservativesindeed Americans and American Christians in general—show such suspicion and distrust for Mormons? I believe that much of the distrust stems from two related points: the relative youth of the Mormon movement, and the person and claims of Joseph Smith. The aggressive missionary effort and rapid growth of the LDS Church perhaps fuels outsider fear and suspicion, but the basis of the animus resides squarely on Smith and his story. $^{7}$

${ }^{5}$ Lydia Saad, "In U.S., 22\% are Hesitant to Support a Mormon in 2012" Gallup, http://www.gallup.com/poll/148100/hesitant-support-mormon-2012.aspx, accessed Nov 11, 2011. A CNN/ORC poll taken in mid October of 2011 corroborates this basic sentiment. To the question: "Would you be more likely or less likely to vote for a candidate for president who is a Mormon, or wouldn't that matter to you one way or the other?" 17\% responded "less likely." http://www.pollingreport.com/politics.htm accessed Nov 11, 2011.

6 "Mormons are both the most Republican and the most conservative of any of the major religious groups in the U.S. today." Frank Newport, "Mormons Most Conservative Major Religious Group in U.S." Gallup, http://www.gallup.com/poll/125021/Mormons-Conservative-MajorReligious-Group.aspx, accessed Nov 11, 2011.

7 The largest denomination of the movement that Smith founded prefers to be recognized by its full name, The Church of Jesus Christ of Latter-day Saints, from which comes the acronym "LDS." In the contemporary discourse, the terms are generally used (I believe wrongly) interchangeably. I suggest that the term LDS is most appropriately used to describe contemporary orthodoxy and active membership in the institutional Church of Jesus Christ of Latter-day Saints. In contrast, the cultures, communities and all of the people who hail from the movement Smith started-from Strangite to RLDS/Community of Christ to FLDS to apostate LDS—can be understood as Mormons. "Church of Jesus Christ of Latter-day Saints" or "LDS" designates institutional membership while "Mormon" designates a cultural heritage. All LDS are Mormons but not all Mormons are LDS. However, as the vast majority of sectarian differentiation began after the death of Smith, the distinction between 
Contemporary, non-denominational sentiment further documents these suspicions. Journalist Jacob Weisberg ${ }^{8}$ of the online publications Slate recently wrote that he "would not, under most imaginable circumstances, vote for a fanatic or fundamentalist" or "for someone who truly believed in the founding whoppers of Mormonism.” He continues that Joseph Smith "was an obvious con man.” ${ }^{9}$ Weisberg’s justification for disparaging Mitt Romney’s belief in Smith’s “seer stones” and other “founding whoppers” while exempting the virgin birth and the parting of the Red Sea is based solely on chronological proximity. He writes that "Mormonism is different because it is based on such a transparent and recent fraud" ${ }^{10}$ and that "a few eons make a big difference" in terms of allowing a religion to moderate and turn its myths into metaphor. Weisberg's blatant ignorance regarding the general factors that motivate religious affiliation will be ignored here in order to focus on his specific discernment of, and bias towards, Mormons and Mormonism as an indicative representation of perceptions held by many Americans.

Visceral sentiments concerning religious founders and their followers suggest that these are important issues. Selecting—or deselecting—a president based on religious affiliation half a century after the United States elected its first Catholic seems eerily anachronistic not to mention bigoted and shallow. Do "a couple of eons" really make

Mormon and LDS is not significant in the time period covered in this dissertation.

${ }^{8}$ Weisberg is the chairman and editor-in-chief of the Slate Group, a unit of the Washington Post dedicated to developing Web-based publications. http://www.slate.com/articles/briefing/staff/2001/10/who_we_are.html, accessed Nov 11, 2011.

9 "Romney's Religion: A Mormon President? No Way." Posted December 20, 2006, http://www.slate.com/articles/news_and_politics/the_big_idea/2006/12/romneys_religion.html, accessed November 2, 2011.

10 Weisberg's implicit assumption is that individuals who live within and embrace a social formation based on what he calls a "fraud" (i.e. foundational stories that make use of the supernatural, are historically problematic and generally implausible) are somehow automatically devoid of intelligence, competence or integrity as an entire people is bigoted, shallow and baseless. 
foundational stories any more plausible or just more palatable due to familiarity and cultural acceptance? ${ }^{11}$ As a cultural phenomenon, Mormonism arose on the edge ${ }^{12}$ of American society (theologically, socially, politically and geographically), just as Christianity itself developed on the margins of Ancient Mediterranean society (socially and politically). Belief in the foundational stories of each require that one engage in a proverbial leap of faith. But most critics of Smith and Mormonism will exempt the ancient foundational traditions of Christianity from the same type of critical scrutiny showered upon Smith and the nineteenth century events leading to the founding of the Mormon movement. ${ }^{13}$

As is the case with most traditions or institutions, the presentation of the past is one that reflects favorably on the tradition. Insiders create a history they want to see, one that conforms to deeply held convictions and sacred traditions. So too with Christianity, the tradition-based story of Christian origins has become normative history for many. ${ }^{14}$

${ }^{11}$ Foundation stories, or "[b] eginnings are often nothing but what inventors of traditions, whether modern or premodern, choose to turn into beginnings. They may remember selectively, erasing one beginning in favor of another; or they may deny the possibility of beginnings altogether" Sheldon Pollock, The Language of the Gods in the World of Men: Sanskrit, Culture, and Power in Premodern India (Berkeley: University of California Press, 2009), 285.

12 The imagery of the periphery is rich. Those on the forefront of movement and change are the innovators and leaders. Those on the tailing edge get left behind. Those on the lateral periphery are "marginalized."

${ }^{13}$ Notorious Mormon apostates gone Evangelical, Jerald (d. 2006) and Sandra Tanner of Utah Lighthouse Ministry, are excellent examples of individuals who apply one set historical methods and critical criteria to the study of early Mormonism and a different set when examining the beginnings of their own beloved variety of "Christianity." Pastor Jeffers is another.

${ }^{14}$ Mann writes, "most skeptics over the last centuries .... have ignored ecclesiastical history, leaving it to the clerics.... The consequence is an uneven literature on the power of Christianity." Michael Mann, The Sources of Social Power: Volume 1, A history of power from the beginning to A.D. 1760, (Cambridge, UK: Cambridge University Press, 1986), 302-3. Luke's Acts is a sacred fiction presented as history and Eusebius was a "court historian" dedicated to presenting Christian history as a "social instrument" that shapes the world view of all who encounter it. The "clerics" since then have little latitude in how they present the traditional saga. See Roger D. Launius, "Mormon Memory, Mormon Myth, and Mormon History", Journal of Mormon History, Presidential Address, Spring 1995, 1-24. See also, Tazim R. Kassam, "Signifying Revelation in Islam" in Vincent Wimbush, editor, 
The creation of a cogent historical narrative aides the group’s “task of self-definition.”15

The paucity of sources from the first Christian centuries provides great latitude for mythmaking. Christian history has privileged its mythological roots as sacred history. Its conventions and traditions are deeply entrenched, naturalized and virtually immune to critical investigation.

The foundational story behind the modern social formation of Mormonism is no less plausible and no more bizarre than its ancient Christian, specifically Pauline, counterpart. Mormonism's relatively recent arrival in the shadows of the dominant tradition, however, has subjected it to the criticisms one should expect by any dominant tradition that has an interest in preserving its unique and authoritative status. Analyzing the power dynamics of Mormon origins from a sociological, social-theoretical and discursive perspective can shed light on equivalent dynamics of the murkier, more remote roots of Christianity itself. Undoubtedly a multitude of modern new religious movements (NRMs) could profitably be compared to better illuminate the NRMs initiated by Paul and Smith.

With this foregrounding of an emergent religious tradition competing for legitimacy in the public political arena dominated by more traditional notions of Christianity, this dissertation compares the foundational claims upon which the dominant

Theorizing Scriptures: New Critical Orientations to a Cultural Phenomenon (New Brunswick, N): Rutgers University Press, 2008), "Signifying Revelation in Islam," 29-40, 38.

15 Launius, "Mormon Memory, Mormon Myth, and Mormon History," 19. "This official consensus amounts to an official effort to construct memory for the Saints and to create an identity with specific attributes," 5. While creation of a past to suit the present is a common endeavor, sometimes it is explicitly hijacked by the interested party. LDS Apostle Boyd K. Packer has advocated to Church educators that their "objective should be that they [those who study Mormon history] will see the hand of the Lord in every hour and every moment of the Church from its beginning till now," 12. Those within traditions who approach history less selectively may find themselves labeled as a "traitor" and may receive formal Church discipline. The excommunication and marginalization of Mormon Historian D. Michael Quinn, is a poignant example, 19. 
forms of Christianity themselves emerged. Specifically, the focus is on the life, claims and text of the Apostle Paul, the only individual from the first generation of (what has become known as) Christianity ${ }^{16}$ that we can identify as an actual person; one who committed his thinking to text. ${ }^{17}$ His efforts to build a community—as documented by

${ }^{16}$ Paul himself never uses the term "Christianity". Most scholars (the general exception would be committed Christian scholars) see Paul as engaged in a reform of his native belief system (itself a complex amalgam of traditional Jewish piety as interpreted and shaped by the ubiquitous and dominant Hellenistic world) rather than conscientiously promoting a completely new religion. See for example Pamela Eisenbaum, Paul Was Not a Christian: The Original Message of a Misunderstood Apostle (New York: HarperOne, 2009); Daniel Boyarin, Border Lines: The Partition of JudaeoChristianity (Philadelphia: University of Pennsylvania Press, 2004) and A Radical Jew: Paul and the Politics of Identity (Berkeley: University of California Press, 1994); Alan Segal, Paul the Convert: The Apostolate and Apostasy of Saul the Pharisee (New Haven: Yale University Press, 1990); and, John Ashton, The Religion of Paul the Apostle (New Haven: Yale University Press, 2000). Of course the line that demarks what constitutes a "reform" versus an innovative break is both subjective and relative, and can be harnessed for one's discursive needs.

17 Paul is the only major recoverable historical figure from the earliest decades of the Christian era. His seven authentic letters serve as primary source documentation of his leadership within the context of developing communities. Wayne Meeks writes that Paul's efforts represent "the bestdocumented segment of the early Christian movement." He would be still more correct to say "the only documented segment of the early Christian movement." Wayne Meeks, The First Urban Christians (New Haven, CT: Yale University Press, 1983), 7.

Whether of the Roman, Coptic, Orthodox, Protestant or another variety, what has become known as Christianity was as influenced by Paul—or at least the legacy of Paul-as anyone else. Paul's tremendous influence relies on a couple of basic facts. The first is that Paul's writings are the earliest texts we have from the Christian movement. They precede the creation of the canonical gospels by two to five decades. In fact, the next earliest Christian writings that carry the authentic name of the individual who wrote them are the letters of Ignatius written on his way to martyrdom in the second century CE. We do not have a single text attributable to Jesus or any of the first generation of followers. The Gospel of Thomas and the reconstructed Q have been dated as early as $50 \mathrm{CE}$, but the actual authorship of these documents is far from certain. Richard Valantasis writes that "the oldest core of sayings suggests an early date of 60-70 CE, The Gospel of Thomas, New Testament Readings (London: Routledge, 2000), 13. Canonical and non canonical gospel accounts of Jesus are chronologically late, anonymous, contradictory and written to promote belief rather than document history. e.g., "Now Jesus did many other signs in the presence of his disciples, which are not written in this book. But these are written so that you may come to believe that Jesus is the Messiah, the Son of God and that through believing you may have life in his name," John 20.30-31, (emphasis added). In sum, Paul's seven authentic letters are the only texts in the New Testament written by an individual whose actual identity we have. Mediterranean religions scholar Einar Thomassen writes that of the twenty-seven writings that came to form the New Testament, "only seven are unanimously accepted by modern scholars as genuinely carrying the name of their original author." These seven are Paul's authentic letters. "Forgery in the New Testament" in James R. Lewis and Olav Hammer, editors, The Invention of Sacred Tradition (Cambridge: Cambridge University Press, 2011), 141-157, 141.

This study will not attribute the "founding of Christianity" exclusively to Paul, but it will rely on the assumption that Paul was central to establishing a number of geographically dispersed, ideologically connected communities. These communities understood Paul's specific Christ-crucified message as the central and centering message that fostered communal identity, meaning and 
his claims, texts and actions-are compared with those of the nineteenth century Mormon prophet and community builder, Joseph Smith Jr. Both presented themselves as possessing the required knowledge and authority to spawn distinct movements; both successfully engaged in innovative — though contextually bound—world-building and meaning-making.

As a product of Mormon culture and heritage,${ }^{18}$ I have an interest in excavating Smith's assertion of power that facilitated the rise of Mormonism within the same analytical framework as one would investigate the Paul's claims of authority and privilege in the earliest years of the dominant Western religious tradition. As a scholar, I am obligated to do so with critical tools and within naturalistic framework based on clearly stated assumptions. This study critically examines some of the dynamics involved in this socio-historical process.

purpose. Paul preached in person, but his texted exhortations preserved and transmitted his message well beyond the range of his voice and the length of his life. The oral traditions espoused by his competitors have not endured in the same way as his letters have. Communities solidified around his letters. Eventually his letters were collected and circulated as a group. See Harry Y. Gamble, Books and Readers in the Early Church: A History of Early Christian Texts (New Haven: Yale University Press, 1995), 58, 63. See also Lee Martin McDonald, The Biblical Canon: Its Origin, Transmission, and Authority (Peabody, MA: Hendrickson Publishers, 2007), 266-270.

${ }^{18}$ See more personal disclosure in "Author's Location" at the end of chapter one. 


\section{CHAPTER ONE}

\section{INTRODUCTION AND CRITICAL FRAMEWORK}

\section{INTRODUCTION AND THESIS}

This dissertation analyzes the relationships between charismatic leader, text, and follower in the generation of power and authority in novel communities. To do so, it interrogates dynamics behind the construction of authority, community, meaning and reality itself by critically analyzing the discursive strategies-texts, claims, behaviors and trappings—of the first century Christian Apostle and his nineteenth century Mormon counterpart. For both, the process of religion-making and community-building was a dialectic one between leader and led. Through the interface, shepherd and flock emerged simultaneously; each needed the other for coherence, meaning and success. Paul and Smith's personal characteristics combined with their claims of revealed knowledge and divine sanction vested their textual productions with enormous power in the minds of their followers. Their texts in turn served as integral, centering and meaning-making components for their respective movements. This study interrogates the relationship between texts and power in the earliest phases of the enormously successful and still thriving religious communities left in the wake of these men.

It is the thesis of this study that the same texts and discourses that purport to reveal the will of the heavens and serve as the basis for the construction of new 
social formations also function to authorize, legitimize and even naturalize an asymmetric power relationship between their author and their followers, between power claimant and those seeking leadership, between narrator and subscriber. Texts make both implicit and explicit authoritative claims for their authors.

In this sense, and in keeping with the notions of theorists such as Peter Berger, ${ }^{19}$ William Cantwell Smith, ${ }^{20}$ Vincent Wimbush ${ }^{21}$ and Bruce Lincoln, ${ }^{22}$ these texts are no less than effective instruments in the construction of reality for those who embrace them. This study will examine the multiple natures of these texts, with a specific focus on the inherent functionality of the seldom-analyzed power strata.

When framed appropriately, the similarities between Paul and Smith that provide grounds for comparison are broad and compelling. The study of one begs questions of, and provides understanding regarding, the other. Mormonism and Paul's Christianity both originated as fringe movements. They developed derivative understandings of the prevailing or dominant discourses that proved compelling to many. Although distinctly different individuals in radically different times and places, Paul and Smith both presented themselves as authorized mouthpieces of a

${ }_{19}$ Peter L. Berger, The Sacred Canopy: Elements of a Sociological Theory of Religion (New York: Anchor Books, 1990).

20 Wilfred Cantwell Smith, What Is Scripture? A Comparative Approach (Minneapolis, MN: Fortress Press, 2005).

21 Vincent L. Wimbush, Theorizing Scripture, and, The Bible and the American Myth: A Symposium on the Bible and Constructions of Meaning, Studies in American Biblical Hermeneutics 16 (Macon, GA: Mercer University Press, 1999).

22 Bruce Lincoln, Discourse and the Construction of Society: Comparative Studies of Myth, Ritual, and Classification (New York: Oxford University Press, 1989); Authority: Construction and Corrosion (Chicago: University of Chicago Press, 1994); Theorizing Myth: Narrative, Ideology, and Scholarship (Chicago: University of Chicago Press, 1999). 
divine message and as vehicles of social and religious change. Both engendered social formations centered on an integration of ancient traditions, contemporary ideas and imaginative teachings. ${ }^{23}$ Both emerged as potent leaders of their respective communities in their own lifetimes and left powerful legacies after their respective deaths. As the claims of neither went uncontested during their lifetimes, they were forced to reiterate their arguments for why they should be considered credible, legitimate, and compelling. It is these claims that are analyzed here. For both Smith and Paul, the rhetorical appropriation of a divine commission to speak for the unchallengeable, unseen—but broadly believed-in—divine powers provided the authoritative basis of their words. Claims of a supernatural calling were rendered credible by charismatic and dynamic personalities and the texted discourses they crafted.

Given the structural and functional similarities, one should not be fooled into thinking that the different titles "Apostle" 24 and "Prophet" embraced by these two

${ }^{23}$ While this assertion is easy to understand for Smith, it is perhaps more difficult with respect to Paul. New Testament scholar Wayne Meeks writes that the "pseudonymous letters [of Paul] provide evidence that the Pauline association was a self-conscious movement which accorded to Paul the position of 'founder' or leading authority." The First Urban Christians: The Social World of the Apostle Paul (New Haven, CT: Yale University Press, 2003), 8.

${ }^{24}$ Wolfgang A Bienert argues that based on the usage in the Didache 11.3-6, within the context of determining criteria for itinerant "true" and "false prophets," the term "apostle" is used in opposition to false prophet (yeudoprofhvthV) rather than "false apostle." Beinert concludes that "apostle and prophet are here evidently understood as equivalent." Wolfgang A. Bienert, "The Picture of the Apostle in Early Christian Tradition" in Wilhelm Schneemelcher, editor, New Testament Apocrypha: Volume Two: Writings Relating to the Apostles; Apocalypses and Related Subjects, Revised Edition, English translation edited by R. McL. Wilson (Louisville and London: James Clarke \& Co. and Westminster John Knox Press, 2003), 5-27, 9. Alternatively, Bengt Holmberg argues that Paul takes as a given the existence of what he calls "prophets" in the Corinthian congregation (1 Cor 12.28; 14.1 5, 27-33) in addition to Thessalonika (1 Thess, 5.20) and Rome (Rom 12.6). Paul and Power: The Structure of Authority in the Primitive Church as Reflected in the Pauline Epistles (Eugene, Oregon: Wipf \& Stock Publishers, 2004) (Fortress Press, 1978), 96-98. The function of these many congregational "prophets," however, appears subordinate to Paul's "apostolic" role. Paul's coded emulation of the prophets of Israelite scripture is unpacked below. See also, Alan Segal, Paul the 
individuals somehow render them incomparable. ${ }^{25}$ The titles themselves are part of a contextual, self-promotional taxonomy. Each moniker claims for the bearer the divinely appointed task of delivering and mediating the will of the heavens to humanity. In practice, a mediating appointment functions to support leadership claims, entice followers, and provide a common narrative framework upon which social formation can be established. Irrespective of the range of religious attributes these titles might imply, this study incorporates the social and rhetorical functionality of these roles and monikers into the analysis.

Moreover, given the similarities of the two movements and yet the cultural and chronological disparity between their foundings, this project serves as a model for understanding the phenomenon of texts as they relate to leadership, culture and power. ${ }^{26}$ Some committed Christians will instantly recoil from such a comparison as it destabilizes the entrenched view of "Saint" Paul and casts him in the light of a modern founder of a new religious movement. Comparison has the potential to undermine the uniqueness of one's own belief system. ${ }^{27}$ Moreover, it puts the (biblically) canonical works of Paul on the same analytical footing as the extra-

Convert, 30.

${ }^{25}$ See Michael Quinn's comments on the changes and development of the terms and offices of "apostle" and "prophet" within the early Mormon context in, D. Michael Quinn, The Mormon Hierarchy: Origins of Power (Salt Lake City: Signature Books, 1994), 7-14.

${ }^{26}$ Sheldon Pollock writes of his own intellectual endeavor, "I am interested in establishing, in a spirit as open as possible to historical difference, the specific contours of culture's place in power," Sheldon Pollock, The Language of the Gods in the World of Men: Sanskrit, Culture, and Power in Premodern India (Berkeley: University of California Press, 2006) (paperback, 2009), 8 (emphasis added).

27 Whereas non-Mormon Christians might recoil at comparing Paul to Smith, Mormons might welcome such a comparison (depending on the level of criticality) as it bolsters the perception of Smith as comparable to that of a broadly recognized Christian hero. On the other hand, I can not imagine Mormons warmly receiving a comparison of Smith with L. Ron Hubbard, David Koresh, or Sun Myung Moon-all of which would be considered destabilizing. 
canonical works produced by Smith. It defamiliarizes the familiar in an attempt to force critical thinking about deeply ingrained perceptions and structures that otherwise appear normative.

The very existence of writings regarded as authoritative implicitly acted as a strategy of power in that the texts tangibly supported the claims of who was authorized to communicate with the supernatural realm and thus who was commissioned to speak the words that should be considered authoritative. Not everyone who claims to speak for God can find a following. Not everyone who claims revelations is hailed as a prophet. Not everyone who commits the revealed words of the gods ${ }^{28}$ to a permanent format is considered a divine mediator. This study lays bare the human dynamics inherent in the authority-claiming and scripturalizing ${ }^{29}$ process that facilitated the success of Paul and Smith.

Texts in isolation, however, will not suffice. Individual character and social context is often determinative of appeal. The power believed to reside in the content of texts is in part a function of the compelling personality dynamics of their authors in addition to the authors' attunement to the contexts and needs of those whom they seek to lead. Text and author, message and messenger, can become confused.

\footnotetext{
${ }^{28}$ In this analysis, I use the terms "the gods" and "God" somewhat interchangeably. "The gods" has the advantage of rendering reference to specific deities more generic and less personal. It is simply a reference to the relevant member(s) of the supernatural pantheon. Moreover, "the gods" facilitates dealing with Paul's pre-Nicean christology where God and Jesus are distinct beings. Smith's christology is also confused, alternating between an early Trinitarian understanding in the $B o M$ and that of a Godhead composed of different, distinct beings - which ultimately became LDS doctrine.

${ }^{29}$ For elaboration on this term, see the discussion under "Scripture and Scripturalization" in this chapter below.
} 
The comparative analysis centers on the respective discursive strategies through which Paul and Smith create fields of knowledge which in turn serve to construct a new reality and their own authoritative position within that novel construction. They author their own authority. The flock's acceptance of the power and truth-claims is the seal of the social relationship. New Testament scholar Elizabeth Castelli writes that "power is not a thing; rather, power relations are ultimately coterminous with social relations." Paul provides data for Castelli's perspective when he writes to his community in Corinth, "you are the seal $\left[\right.$ sfragi $\left.\mathrm{V}^{30}\right]$ of my apostleship in the Lord, (1 Cor 9.2). ${ }^{31}$

30 With $B D A G$, "that which confirms or authenticates, attestation, confirmation, certification." In 2 Cor 1.21-22 Paul uses the term $\sigma \phi \varrho \alpha \gamma \iota \sigma \alpha \dot{\mu} \varepsilon v 0 \varsigma$ to claim that God has put "his seal on us."

${ }^{31}$ See also the reciprocal "boasting" of 2 Cor 1.14 . Biblical citations generally come from the NRSV. Other sources or my own translations will be identified explicitly. 


\section{CONTRIBUTION}

The transdisciplinary nature of this dissertation requires insights from a number of scholarly discourses, including the study of religion, New Religious Movements (NRM's), social theory, sociology, history, anthropology, literary criticism and cultural studies. ${ }^{32}$ The primary thrust of the work, however, is a response to the call for a different orientation to the study of "scripture," one promoted by Vincent Wimbush and the Institute for Signifying Scriptures at Claremont Graduate University. ${ }^{33}$ This call seeks to shed light on the relationships between human power, meaning-making, community formation, ${ }^{34}$ and material artifacts, usually texts. ${ }^{35}$ The focus on texts is not for exegetical purposes, ${ }^{36}$ nor to determine meaning(s) or a history of interpretation. Instead, the textual focus is on the political and power implications embedded in certain texts which are "pressed into service" by their authors, interpreters and communities. ${ }^{37}$ Critical analysis illuminates "the nature and consequences of interpretative practices ... especially in terms of power relations." ${ }^{38}$

\footnotetext{
32 Study of "the phenomenon must not even be limited to the purview of scholars of religion!" Wimbush, Theorizing Scripture, 16.

33 In particular, see Wimbush's Introduction to Theorizing Scripture, 1-20. See also the ISS website http://www.signifyingscriptures.org.

34 Including the (re)formation and (de)formation of various communities. See Wimbush, Theorizing Scripture, 115, and http://www.cgu.edu/pages/7394.asp, Accessed Jan. 18, 2012.

${ }^{35}$ Rituals and other unscripted gestures would also be included.

${ }^{36}$ Exegetical analysis is based on a vast complex of unexplored assumptions that underlie why the text to be exegeted is considered authoritative in the first place. The very nature of the sacrosanct status enjoyed by scriptures and their authors is in need of interrogation and analysis. Given that scripture's of various stripes are put to work to achieve an assortment of social and political ends, an analysis of how they came to be and how they were used by their authors is instructive in understanding human social practices-if not humanity-itself. See Wimbush, Theorizing Scripture, 14.

37 Wimbush, Theorizing Scriptures, 13.

${ }^{38}$ Wimbush, Theorizing Scriptures, 5.
} 
This study embraces Wimbush’s critical orientation within a comparative "history of religions” framework. Smith’s development of Mormonism has much in common with the foundational dynamics of Paul's Christianity—only Smith's work was conducted in North America less than two hundred years ago in broad daylight. Suspicion and resentment evoked by his texts and prophetic claims remain alive in some circles of today's world and fuel the cultural and ideological conflicts between different Christian denominations. Current events ${ }^{39}$ have raised the visibility of tensions many Christians, and even secularists, hold towards Mormons. While Mormons see themselves as Christians and use the heavily Pauline-influenced New Testament as part of their canon, widespread popular sentiment remains suspicious of Mormons on a national level. $^{40}$

In light of these tensions, the comparative component that juxtaposes the assumption of power by the sole identifiable founding figure of the dominant tradition of the Western world against a tremendously successful—yet often demonized—modern equivalent is intended to destabilize and provoke. The freighted examples are intended to challenge those within dominant traditions to reconsider how they assess and analyze the "other," and how they privilege their own assumptions and traditions in the process.

The comparison makes use of a expansive range of scholarly work to bring theoretical abstractions to life with actual examples from comparable historical scenarios. It relies upon a combination of textual, critical-historical, and social-theoretical

\footnotetext{
${ }^{39}$ Current presidential politics, high profile Fundamentalist Latter-day Saint (FLDS) polygamy and sexual abuse cases in Texas, Arizona and Utah, and institutional LDS opposition to same sex marriage in California ("Prop 8") all contribute in one way or another to the ideological and cultural wars that are a current component of American life.

${ }^{40}$ See the various polling data cited in the footnotes of the preface, above.
} 
considerations—as argued by sociologists, anthropologists, psychologists, historians, textual critics, and social theorists—-to place two of Western history's more significant religious movements within a comparative framework that forces otherwise unasked question. One goal is to illuminate patterns of behavior surrounding the phenomena of social power and "scripture." Another is to provide a plausible explanatory model of human behavior that may also find applications in the study of other high-commitment, social formations, be they political, national, ethnic, affinity-based or other. Overall, the project is a contribution to the development of an integrated theory of religion.

As part of the "wider significance of [Wimbush's critical] orientation," ${ }^{41}$ the historical and cultural contextualizing that is part of this project answers the call to examine the "settings, situations and practices" ${ }^{42}$ —in which the phenomena of scripture, and their human producers, arise. The textual and historical analysis that illuminates how scripture functions to create and maintain the asymmetrical power relationships between a prophet and her flock is a response to Wimbush’s call to analyze the "psychosocial-cultural/power needs and dynamics” of scripture and scripturalizing.

The project also seeks to reinforce the analytical approach suggested by religious studies scholar Russell McCutcheon in his Critics NOT Caretakers ${ }^{43}$ whereby one’s critical assumptions and framework are clearly articulated to make clear the difference between a "religious study of religion" and an "academic study of religion." ${ }^{44}$ This

\footnotetext{
${ }^{41}$ Wimbush, Theorizing Scripture, 14-15

${ }^{42}$ See Wimbush, Theorizing Scriptures, 15 where Wimbush lays out possible directions of study under a number of inter-related categories.

${ }^{43}$ Russell T. McCutcheon, Critics NOT Caretakers: Redescribing the Public Study of Religion (Albany, NY: State University of New York Press, 2001).

${ }^{44}$ See differentiation and elaboration under "Assumptions" below.
} 
project falls within the latter category and as such will provide neither refuge nor sanctuary to the venerable figures under analytical scrutiny.

The analysis also finds motivation in the "Redescribing Christian Origins" 45 project in that it analyzes the "myth-making" component that so frequently attends social formation. The "redescribing" project seeks human, social, and historical reconstruction of the earliest Christian social formations that are not blatant products of two thousand years of Christian story-telling and apologetics. Traditional legends should not be treated as "history" irrespective of how frequently they are repeated. ${ }^{46}$ The stakes are high. Both traditional New Testament scholarship and insider accounts of Mormon beginnings want to hold on to their respective received stories, those that match the broadly embraced "sacred histories" that have been propagated at an institutional level. The "received stories" have acquired substantial theological value in their own right and most partisans (even professional historians) want their tradition’s “received story to be validated as a critically reconstructed history." ${ }^{47}$ Paul and Smith are analyzed in the way founders of modern New Religious Movements (NRMs) are analyzed, yet accorded the dignity of being the founder of a "religion" as opposed to a "cult". (Taxonomy is never neutral.) Rather than engage in the game of verifying or debunking truth claims, the preaching and writings of both are treated on the basis of their functionality in constructing of novel social formations.

\footnotetext{
${ }^{45}$ See the product of the Society of Biblical Literature's "Ancient Myths and Modern Theories of Christian Origins" seminar as aggregated and edited by Ron Cameron and Merrill P. Miller, editors, Redescribing Christian Origins, Society of Biblical Literature Symposium Series, No. 28 (Atlanta: Society of Biblical Literature, 2004).

46 Burton Mack as cited in Cameron and Miller, Redescribing Christian Origins, 2.

${ }^{47}$ Cameron and Miller, Redescribing Christian Origins, citing Davis, 4.
} 


\section{ASSUMPTIONS}

By never spelling out the big picture we have become unconscious of our ultimate assumptions, and in the end confused about them

—Charles Taylor ${ }^{48}$

I not only grant but insist that scholarship - like human speech in general - is interested, perspectival, and partial and that its ideological dimensions must be acknowledged, ferreted out where necessary and critically cross-examined

-Bruce Lincoln ${ }^{49}$

The nature, stakes and approach of this project, demand that I begin with an overview of the primary assumptions operative in the humanistic study of history, sociality and religion. As these individuals are freighted examples of social formation and as the history of scholarship surrounding them has often been partisan, emotionally charged, and prone to denominational exceptionalization, I believe it is imperative to articulate my assumptions and methods explicitly and clearly as they govern my work ${ }^{50}$ and provide a platform from which to proceed with the historical, literary and socialtheoretical excavation. The approach is critical. The assumptions are naturalistic ${ }^{51}$ and

${ }^{48}$ As found in the Forward of Marcel Gauchet, The Disenchantment of the World: A Political History of Religion, Foreword by Charles Taylor (Princeton, NJ: New French Thought/Princeton University Press, 1999), ix.

${ }^{49}$ Theorizing Myth, 208. Lincoln's observation of course applies to me too-which is why I have endeavored to clearly articulate my own assumptions, methods and approach. Moreover, the reader will find information on my personal "location" and background at the end of this chapter. Critics are free to cross-examine as they please-but should be reflexively aware of their own interests in the process.

${ }^{50}$ See Jonathan Z. Smith, Drudgery Divine: On the Comparison of Early Christianities and the Religions of Late Antiquity (Chicago, IL: University of Chicago Press, 1994), 35.

51 “'Naturalism' names a modest position. It serves primarily to mark my orientation off from non-naturalistic and especially supernaturalistic views," Owen Flanagan, The Really Hard Problem: Meaning in a Material World (Cambridge, MA: The MIT Press, 2007) (paperback, 2009), 2.

In keeping with the assumption and perspectives, mundane, naturalistic, explanations will be used to interpret claims or accounts of otherwise non-empirical, non-obvious beings and phenomena such as visions, apparitions and revelations. Studying religion on "naturalistic grounds" is "the decisive feature which distinguishes the study of religion from theology," Samuel Preus, Explaining Religion: Criticism and Theory from Bodin to Freud (Yale University Press, 1987), xxi, 205.

Descriptions or accounts of the supernatural or supernatural events-whether provided by prophet, 
guided by the work of Russell McCutcheon and a host of others engaged in the academic $^{52}$ study of religion, ${ }^{53}$ social theory, history ${ }^{54}$ and related areas.

apostle or devotee-will be taken seriously in this study, but probably not in the way that many religious practitioners would see fit. Private, religious experiences-whether they come in the form of a vision, revelation, apparition or special, private feeling - so often interpreted by the devotee as evidence of intangible supernatural forces and as proof of the epistemic regime to which these supernatural forces are believed to be connected, can not be accepted at face value as described by the insider. It should be said that while these experiences, and the non-obvious beings, powers and forces thought to be behind them, are not verifiable empirically, neither are they-as is the case with Bertrand Russell's posited orbiting tea pot-falsifiable.

These experiences will simply be interpreted as private, culturally informed, and emotional. William James writes that "there are moments of sentimental and mystical experience ... that carry an enormous sense of inner authority." But these powerful moments of transcendence, spiritual rapture, ecstasy, anguish or of simply "feeling good" (to use James' term) do not necessarily equate with what is "true." James writes that "what immediately feels most 'good' is not always most 'true' . . .. If 'feeling good' could decide, drunkenness would be the supremely valid human experience," William James, The Varieties of Religious Experiences: A Study in Human Nature (New York: Modern Library, 2002), 19. My use of James' language "feeling good" is not to trivialize these powerful emotional experiences, it is rather to frame spiritual ecstasy and its cognates as one of many types of epistemic verification processes - none of which should be exempt from interrogation. The efficacy of thought systems that contain and promote their own epistemological verification techniques is explored comparatively in detail in the latter section of chapter three.

Here, claims to knowledge based on what amounts to a private, individual feeling, i.e. the "experience" or manifestation of God, will be treated as "the product rather than the cause of other human beliefs, behaviors, and institutions," McCutcheon, Critics NOT Caretakers, 6. The supernatural account itself will be treated as "data in need of explanation," Russell McCutcheon, Manufacturing Religion: The Discourse on Sui Generis Religion and The Politics of Nostalgia (Oxford: Oxford University Press, 1997), vii-xi.

Social actors perceive reality within a contingent explanatory framework that differs from the analytical, explanatory framework embraced by outside observers, David Swartz, Culture and Power: The Sociology of Pierre Bourdieu (Chicago: University of Chicago Press, 1997), 58-9. Social critics, scholars and dissertation writers are of course bound by their own location, and their own constructed reality--which is why I believe it is imperative to clearly state my assumptions, approach and operating parameters, McCutcheon, Critics NOT Caretakers, 73-4. See the disclosure of my own background under "Author's Location" below. In addition, McCutcheon writes,

As scholars of social authorizing practices, we fail to fulfill our role as public intellectuals when we decline to demonstrate consistently that such a thing as society, text, nation, ethnicity, tradition, intuition, gender, myth or even religion, is 'not a natural or god-given entity, but is a constructed, manufactured, even in some cases invented object, with a history of struggle and conquest behind it,' Critics NOT Caretakers, 140. McCutcheon references the work of Edward Said, Representations of the Intellectual (New York: Vintage Books, 1996), 33.

In sum, systems of meaning, constructions of reality, and truth verification processes are all human in origin. The combination of (posited) meaning within a (posited) reality confirmed by a circular and self-fulfilling epistemic process not only construct one's view of the world, it provides an internal logic to support and verify the views embraced.

52 Bruce Lincoln writes,

When one permits those whom one studies to define the terms in which they will be 


\section{The Relentless Meaning-Making Enterprise}

The first basic analytical assumption is that "religion” is an ordinary part of human cultural production and that even ostensibly radical religious innovation is in fact an ordinary aspect of the dynamic social world in which we live. S. N. Eisenstadt well articulates this point in his introduction to a collection of Max Weber's papers. He writes,

understood, suspends one's interest in the temporal and contingent, or fails to distinguish between "truths", "truth-claims", and "regimes of truth", one has ceased to function as historian or scholar. In that moment, a variety of roles are available: some perfectly respectable (amanuensis, collector, friend and advocate), and some less appealing (cheerleader, voyeur, retailer of import goods). None, however, should be confused with scholarship. Method \& Theory in the Study of Religion vol. 8 (1996): 225-27.

\section{Classicist and historian Peter Green writes,}

The fact of faith, as a datum, conflicts with normal historical criticism, presupposes what Eliot called "the intersection of the timeless with time." The historian, who is required to study the secular genesis of events rather than their divine revelation, cannot in any open sense work sub specie aeternitatis: though he must, and does, recognize the force of faith as a major historical determinant, he can only evaluate it in linear, temporal terms. If he accepts its presuppositions, he becomes, strictly speaking, a propagandist-which means that for the highest of nonhistorical motives, he has betrayed his calling, Alexander to Actium: The Historical Evolution of the Hellenistic Age (Berkeley: University of California Press, 1990), 497.

53 This is in contrast to the "religious study of religion-itself a religious pursuit," so often subtly cloaked in the guise of secular scholarship. For a critique and explanation of the differentiation between the academic study of religion and the religious study of religion (even as conducted by scholars), see Russell T. McCutcheon, Critics Not Caretakers: Redescribing the Public Study of Religion (Albany: State University of New York Press, 2001), 3-20, esp. 16. Similarly, scholars of religion Tim Jensen and Mikael Rothstein write, "[w]e have to recognise that the academic study of religion-be it history of religions, sociology of religions, anthropological studies of religion or something else-is not at all as emancipated from religion, not least Christian theology, as one might think." Tim Jensen and Mikael Rothstein, Editors, Secular Theories on Religion: Current Perspectives (Copenhagen:

Museum Tusculanum Press, 2000), 7. Given the "entrenched naturalization" of the dominant belief system, the basic questions that are allowed to be asked within the field of biblical studies and often even religious studies are often severely limited in the "service of and to protect God and church and academy." See Vincent Wimbush, Editor, The Bible and the American Myth: A Symposium on the Bible and Constructions of Meaning (Macon Georgia: Mercer University Press, 1999), 2.

${ }^{54}$ Non Mormon historian of Mormonism, Jan Shipps, writes:

History making ... leads to a struggle over control of the past. In the religious arena, the arguments are deeper and more complex because they have to do with supernatural as well as natural things .... [if] perceptions of reality are social constructions, ... then history making is not an inconsequential enterprise..." Sojourner in the Promised Land: Forty Years among the Mormons (Urbana, IL: University of Illinois Press, 2000), 224-225. 
The search for meaning, consistency, and order is not always something extraordinary, something which exists only in extreme disruptive situations or among pathological personalities, but also in all stable social situations. . . . such situations do not arise only in catastrophic conditions, but that they constitute part of any orderly social life. ${ }^{55}$

Along these lines, anthropologist Pascal Boyer has written,

... at all times and all the time, indefinitely many variants of religious notions were and are created inside individual minds. Not all these variants are equally successful in cultural transmission. What we call a cultural phenomenon is the result of a selection that is taking place all the time and everywhere (emphasis in original). ${ }^{56}$

In one sense, the history of culture is little more than the tracking of the more enduring of these socio-religious innovations. This notion of individual or small group creativity is a subset of a larger assumption that culture itself is a human production and that notions of "reality" are culturally informed and ultimately socially created along the lines of thinking articulated by Peter Berger in his Sacred Canopy. ${ }^{57}$

To summarize Berger’s view, human society perpetually engages in the collective enterprise of "world building” in which it projects or pours itself out into the world both physically and mentally. Berger calls this process “externalization.” The next step is

\footnotetext{
${ }^{55}$ S. N. Eisenstadt, editor, Max Weber: On Charisma and Institution Building, The Heritage of Sociology Series (Chicago and London: University of Chicago Press, 1968), xxvi, xxviii. Other scholars see the meaning making enterprise as a human mandate. Regarding an individual's attempt to make sense of the unexplainable events of the world, Walter Burkert writes that an individual will always "seek to orient himself within his own world, he may—indeed, he must—take the risk of projecting a model of his situation and reducing a confusing multiplicity into a comprehensible form." Homo Necans, The Anthropology of Ancient Greek Sacrificial Ritual and Myth (Berkeley: University of California Press, 1983), xix. Such sentiments resonate with the theoretical work of Peter Berger and William Cantwell Smith, briefly discussed below.

56 Pascal Boyer, Religion Explained: The Evolutionary Origins of Religious Thought, (New York: Basic Books, 2001), 33. Rodney Stark begins one article with, "This year, hundreds of new religious movements will appear on earth ... [most of which] will become no more than a footnote in the history of religions." Rodney Stark, "Why Religious Movements Succeed of Fail: A Revised General Model" \ournal of Contemporary Religion, Vol. 11, No. 2, 1996, 133-146.

${ }^{57}$ Peter Berger, The Sacred Canopy: Elements of a Sociological Theory of Religion (New York: Anchor Books, 1990) (1967). See also Peter L. Berger and Thomas Luckmann, The Social Construction of Reality: A Treatise in the Sociology of Knowledge (New York: Anchor Books, 1967) (1966).
} 
what Berger calls “objectivation” in which the immaterial, projected external world becomes in fact a reality that confronts its original producers as a "thing" or a system that is capable of standing on its own. It rests outside of the individual even though constructed by society. ${ }^{58}$ It is the process by which human societies locate authority outside of themselves.

These repositories of cultural meaning and authority can take the form of material artifacts, frequently texts, which enjoy the status of "scripture" in the major traditions of the Near East and West, a notion that connects the work of Berger and Wimbush. The final component of the social construction of reality is called "internalization" whereby the external construction—-here reified and embodied in "scripture"—is appropriated and internalized by the collective and the individual. The external/reified thing that was shaped by society now has the power to shape the individual and even society as a whole. This is the process of scripturalization, which is addressed more comprehensively below. In keeping with Berger’s perspective, early Christianity scholar John Gager has proposed a brief summary of religion that is helpful. He writes:

Religion, then, is that particular mode of world-building that seeks to ground its world in a sacred order, a realm that justifies and explains the arena of human existence in terms of the eternal nature of things. Whether this transcendent realm is the mythic world of remote ancestors, an ideal universe existing in some remote "heaven," or an order of reality utterly unlike anything known in the present, it is what gives meaning and value - whether positive or negative - to human affairs in "this world." 59

${ }^{58}$ Berger, Sacred Canopy, summary from the first two chapters of The Sacred Canopy, 3-51.

${ }^{59}$ John Gager, Kingdom and Community: The Social World of Early Christianity (Englewood Cliffs, NJ: Prentice-Hall, Inc. 1975), 10. 
Prior to Gager, Berger had written already that "[']this world['], of course, is culture.”60 Pushing one step further, while affirming the place of religion as but one aspect of the phenomenon we recognize as culture, one of Russell McCutcheon’s summary definitions of the study of religion is useful in articulating the approach taken in this study. He writes that,

the study of religion is but one instance of the wider, cross disciplinary study of how human beliefs, behaviors, and institutions construct and contest enduring social identity—-talk about gods and talk about mythic origins are but two strategies for doing this. ${ }^{61}$

Importantly for this study, "talk about gods . . . and mythic origins” has been committed to text by Paul and Smith.

In addition to, or rather as part of, the meaning-making and identity-construction enterprise, this study's focus is on the power dimensions that reside within the meaningmaking process. The analysis takes aim at the cultural icons of Christendom and Mormondom and analyzes them as self-interested social actors in the same manner one would assess the life and actions of other less exalted religion-makers and founders of new religious movements (NRMs) who have emerged in the millennia since Paul's life. The task at hand is to "unveil [the] hidden dimension of power relations"62

The second basic assumption is that social formations prove successful as a result of the meaning and functionality they provide to their participants, individually and communally; not because of the irresistible "truth" they espouse, ${ }^{63}$ the will of the gods or

\footnotetext{
60 Berger, The Sacred Canopy, 6.

61 McCutcheon, Critics Not Caretakers, 16.

62 Swartz, Culture and Power, 10.

63 Mann, Sources of Social Power, 302.
} 
any other self-serving, propagandistic claims made by insiders. ${ }^{64}$ The stakes at play in the meaning-making exercise are high. They are critical to individual and group identity, and ultimately personal wholeness and social cohesion. As such, social formations will generally resist attempts to cast their meaning-making enterprise as something ordinary, as a manufactured component of human culture. In many social formations, the charter narrative explicitly depicts the group’s foundational events as unique and divinely sanctioned and as such as extraordinary in the history of humankind. To undermine this notion of being exceptional can be inherently destabilizing and corrosive to the selfperception of the community as a whole.

The third assumption presupposes a complex of individual and social factors that provides for some degree of human volition within a cultural framework that offers a limited range ${ }^{65}$ of opportunities for humans to alter their basic existential circumstances. ${ }^{66}$ As entrenched social actors, people make decisions and act within this limited and contingent framework. Human volition also suggests that social formations (absent coercive force) are most robust when leaders and followers are all—at least at some level—willing participants in the new social endeavor.

Bourdieu, with Weber, holds that within this contingent framework, "all action is interested.”67 Moreover, action can be seen as strategy "to emphasize the interested

64 This sentiment has not always been recognized by scholars. For example some scholars have not only assumed but have explicitly stated that "no religion persists by its falsehood, but by its truth." S. Angus, The Mystery Religions: A Study in the Religious Background of Early Christianity (New York: Dover Publications, Inc., 1975) (Unabridged and unaltered from its second printing by John Murray in London, as The Mystery-Religions and Christianity in 1928), vii-viii.

${ }^{65}$ Social "norms" will inherently "constrain behavior." Rodney Stark and Roger Finke, Acts of Faith: Explaining the Human Side of Religion (Berkeley: University of California Press, 2000), 45.

${ }^{66}$ One method of describing this process is through the acquisition of various types of capital: economic, social, and symbolic, which will be briefly discussed in the pages below.

${ }^{67}$ Swartz, Culture and Power, 67. Neuroscientists Patricia Churchland writes concerning self- 
orientation of human conduct. ${ }^{\text {} 68}$ Individual human beings as social actors, whether leader or led, act in ways that promote their interest. They will attempt to "derive advantages ${ }^{, 69}$ from various socio-political and economic interactions with their fellow human beings. The complex of opportunity and volition will determine not just what community to join (or generate, or remain within) but where the individual will residein terms of contribution, activity/passivity and status-within that community. The notion of individual volition suggests that people will seek the community that maximizes the satisfaction of their needs.

Sociologist Rodney Stark has written a great deal on what he calls "rational choice theory” as it relates to individuals and their religious preferences. He posits a "theory of religious economy”,70 which builds upon a basic "supply and demand” model as traditionally used by economists. Despite the model's flaws—-beginning with the connotations suggested by the term "rational" to describe human actions-it provides a useful explanatory model in which to consider the human actions explored in this study. ${ }^{71}$

As with any market for material goods, Stark's posited spiritual marketplace is filled with vibrant and competitive suppliers of religious systems, world-views, routes to

preservation,

[a]ll nervous systems are organized to take care of basic survival of the body they are part of. From an evolutionary perspective, the general point is straightforward: self-caring is selected over self-neglect. Animals that fail at self-preserving behavior have no chance to pass on their genes. Patricia S. Churchland, Braintrust: What Neuroscience Tells Us about Morality (Princeton, NJ: Princeton University Press, 2011), 27.

${ }^{68}$ Swartz, Culture and Power, 67. Human "self-interest" must be understood within a framework that allows acts of charity and philanthropy to be understood as ultimately beneficial (psychologically satisfying and rewarding) to the giving party. Giving to charity makes one feel good, or at least mitigates the guilt of not-giving.

${ }^{69}$ Swartz, Culture and Power, 67.

70 Stark and Finke, Acts of Faith, 35-41, 85.

${ }^{71}$ See Stark and Finke, Acts of Faith, 44-45. 
salvation, steps to personal well-being and a host of others. Purveyors range from

established ecclesiastical systems to innovative NRMs, from august institution to bare-

footed guru, from biblical exegetes to writers of self-help manuals. ${ }^{72}$ The demand side of the equation represents individuals who seek such systems, philosophies and sociality whether to establish meaning in life, to generate emotional well being or to simply find a community in which to interact. As "[h]umans seek what they perceive to be rewards and avoid what they perceive to be costs,"73 demand-side seekers patronize the suppliers that best address their needs. ${ }^{74}$ On the other side of the market equation, purveyors ${ }^{75}$ will seek to develop spiritual systems that best suit the needs of, and prove enticing to, seekers - that is, provided that the provisioning of such systems also satisfies the needs of the spiritual entrepreneur herself. ${ }^{76}$

${ }^{72}$ Reflecting the range of options in antiquity, one scholar of early Christianity has written, "at the beginning, the Christian faith had to assert itself among the rival religious views which literally competed with one another on the market-place for the favour of the public." Hans-Josef Klauck, Magic and Paganism in Early Christianity: The World of the Acts of the Apostles (Minneapolis, MN: Fortress Press, 2000), 1-2. See also, Shayne Lee and Phillip Luke Sinitiere, Holy Mavericks: Evangelical Innovators and the Spiritual Marketplace (New York: New York University Press, 2009).

${ }^{73}$ Stark posits this statement as an axiom. He then defines rewards as "anything humans will incur costs to obtain" and costs as "whatever humans attempt to avoid." Rodney Stark and Williams Sims Bainbridge, A Theory of Religion (New Brunswick, NJ: Rutgers University Press, 1996), 27.

${ }^{74}$ This statement fails to account for what financial market analysts call "imperfect information." In other words, markets reflect individual risk preferences given the amount of information available. In religious or social systems, obtaining "information" regarding comparative thought systems and their communal make-up is costly as it demands a degree of personal interaction with various communities to find the right fit.

75 One might also refer to this competitive environment as a market for "spiritual authority" that competes with the authority claimed by more traditional notions of religion. About Smith's era, historian John Brooke has written that he has isolated "four distinctly different spiritual authorities competing for popular allegiance ... church reformers, utopian prophets, cunning folk, and Christianhermetic magi," John L. Brooke, The Refiner's Fire: The Making of Mormon Cosmology, 1644-1844 (Cambridge, UK: Cambridge University Press, 2001), 5. Paul's era saw competition for social allegiance among various types of associations, philosophical schools, and ancient mysteries (although these were generally not exclusivist systems). Individuals clearly have a tremendous range of choices categorized under a broad range of terms.

${ }^{76}$ On the leadership side of the social formation, and contrary to how most leaders represent themselves (e.g. public servants, God's servant, etc.), this study holds that "the struggle for social distinction, whatever its symbolic form is ... a fundamental dimension of all social life," Swartz, 
As preferences vary by individual and situation, and as costs and rewards are entirely subjective components that prove resistant to meaningful quantification, human decision making will always be relative and contingent. What appears "rational” to one individual might appear entirely irrational to another. Human decision making can not be abstracted from its social context and there is no absolute or universal set of criteria that determines what constitutes rationality.

If humans act in ways that serve their interests, the decision to join a NRM is made of one's own free will which will often include the willing acquiescence to the group’s leadership claims and organizational structure. Authority is freely ceded to the leader as followers reckon to gain something from submitting to the dominant component of the power relationship. ${ }^{77}$ The rationale for doing so will vary by individual, (e.g. spiritual quest, metaphysical adventure, social experiment, membership in a meaningful community, a quest for truth, salvation, tranquility, a good time, etc.) but the decision to join is made freely ${ }^{78}$ — given the available possibilities and inherent limitations in the individual's contingent framework.

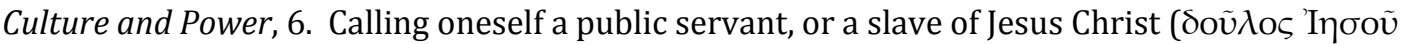

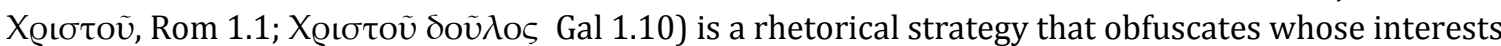
are really being served.

77 In a passage that summarizes the divided nature of new religious movements scholarship, Zablocki and Robbins write, "Cults [i.e. NRMs] are a genuine expression of religious freedom deserving toleration." The very next line reads, "At the same time they are opportunities for unchecked exploitation of followers by leaders deserving civic scrutiny." Benjamin Zablocki and Thomas Robbins, Misunderstanding Cults: Searching for Objectivity in a Controversial Field (Toronto: University of Toronto Press, 2001), x.

78 This is contrary to the thoroughly discredited theory of "brainwashing" espoused by modern day anti-cult movements. Stark writes that "'brainwashing' has been thoroughly discredited by careful research," Acts of Faith, 137. The term "brainwashing" derives from a cold war era book by Edward Hunter, Brainwashing in Red China: The Calculated Destruction of Men's Minds (New York: Vanguard, 1953). "Brainwashing" is a translation of the Chinese hsi nao, which means "to cleanse the mind" i.e. of non-Maoist, non-communist thoughts. The term is a blatant metaphor (not a physiological process) which attempts to describe "the replacing of old attitudes and beliefs with new ones." According to David Bromley and Anson D. Shupe, the reorientation can take place through 
If one accepts that each of us, as nominally autonomous beings, ${ }^{79}$ has a say as to where we want to reside in (an often limited range of) the human pecking order, our actions will determine where we sit in the inevitable hierarchy of social status and power whether local, communal, legally recognized, informal, de facto, or otherwise. Some humans are more active, others more passive in terms of self determination and the achievement of goals.

Paul and Smith exhibit and act upon the desire to be leaders rather than followers. They seize the opportunities present in their culture to accomplish this. Claiming mandates from divine sources is but one effective strategy. Their very lives are a testament to their human inclinations and their texts document their discursive techniques.

“Rationality,” however, in its enlightenment sense of dispassionate, calculated and objective reason, is a problematic misnomer. ${ }^{80}$ The contingent factors behind individual choices do not easily lend themselves to mathematical models. Most decisions involve tradeoffs or costs that are impossible to quantify. The point here is that human decision making is rarely free of emotional influence. ${ }^{81}$ In fact, it is a specifically

"spontaneous voluntary participation" or by the use of "terror and coercion." David Bromely and Anson Shupe, Strange Gods: The Great American Cult Scare (Boston: Beacon Press, 1981), 95-96, 230. "The replacing of old attitudes and beliefs with new ones" is also known as conversion.

79 This is not the place to enter a debate on the relative amount of human free will versus determinism, structural or otherwise. For the purpose of this dissertation we will assume that whatever free will we humans possess, it is heavily influenced-and in some sense partially determined-by location and circumstance. The absolute positions of either side are rejected.

${ }^{80}$ Stark somewhat unhelpfully defines rationality as "marked by consistent goal-oriented activity." Rodney Stark and William Sims Bainbridge, A Theory of Religion, 328. See also, Stark and Finke, Acts of Faith.

${ }^{81}$ Scottish Philosopher David Hume wrote "reason is and ought to be the slave of the passions" as quoted in Patricia Churchland, Braintrust, 5. Churchland continues that by "passions" Hume meant "any practical orientation toward performing an action in the social or physical world," 5. Philosopher Julian Baggini writes, 
emotional component that functions so powerfully as a persuasive technique in the epistemic regimes preached by Paul and Smith. ${ }^{82}$

Transaction are not solely determined on the superficial characteristics of issue or product. Those who join new communities often do so less for the ideology and more for the sociality. Stark's sociological research indicates that "doctrine usually plays a secondary role when people initially make their choices.”83 ${ }^{23 a r k e t-b a s e d ~ c h o i c e ~ m o d e l s ~}$ must acknowledge that externalities, such as the desire for sociality or community, are no more, and no less, rational than strict economic decision centered on price and quality (or strict "rational" decisions based on the soundness and plausibility of the doctrine posited)— they are just more difficult to identify, analyze and quantify.

Acknowledging the range of externalities and emotional influences that accompany human decision making, one should be judicious in assessing how and where the term "rational" applies in his theory. It is certainly rational for an individual to profess faith in the religion of one's family and one's community if professing atheism or faith in a different thought system means that she would lose or seriously compromise her entire social network. ${ }^{84}$ At the same time, professing belief in a system with historical, foundational and doctrinal components that are problematic from a "rational" perspective may seem like the antithesis of rationality. The key to understanding Stark's rational

We human beings often claim that it is our ability to think which distinguishes us from other animals. We are homo sapiens - thinking hominids .... Yet we are not purely rational. It is not just that we are often in the grip of irrational or non-rational forces and desires, it is that our thinking is itself infused with emotion. These feelings shape our thought, often without us realizing it. Atheism, A Very Short Introduction (Oxford: Oxford University Press, 2003), 2.

82 Epistemic regimes are analyzed at the end of chapter three.

83 "Subsequently, doctrine often becomes a central aspect of commitment," Stark and Finke, Acts of Faith, 115-118, 137.

${ }^{84}$ E.g., the penalty for apostasy in some forms of Islam is death. 
choice theory is that the rational part of the choice applies to the choice to believe or not to believe, to participate in the religious community or not to participate. Rational choice has nothing to do with the inherent rationality of the system to be embraced. As such, it may be entirely rational to embrace an entirely irrational system. It may be entirely rational on personal, social, social-psychological and cultural grounds to choose to embrace a system that is entirely irrational on historical, philosophical, scientific or even theological grounds.

From a different disciplinary angle, Lincoln helps us focus Stark’s observations. Lincoln writes that the persuasive power of a discourse resides only partially in its "logical and ideological coherence." ${ }^{85}$ He argues that persuasion is a result of a range of factors including "rhetoric, performance, timing, and the positioning of a given discourse vis-à-vis those others with which it is in active or potential competition.” A given discourse is ultimately successful only if it is capable of eliciting an emotional response from the audience it seeks to persuade. ${ }^{86}$

Human beings have a tremendous range of ideological options from which to choose. Relatively few (if any) of these choices, however, are made without significant emotional influence. Bourdieu goes even further to claim that human action need not "assume conscious, rational calculation" as much of human behavior is "prereflective rather than conscious." ${ }^{87}$ Whether the locus of the impulse to act is in the (higher order, deliberate and conscious) cerebral cortex or the (lower order, reflexive and stimuli-

\footnotetext{
${ }^{85}$ Lincoln, Discourse and the Construction of Society, 8.

${ }^{86}$ Lincoln, Discourse and the Construction of Society, 8.

87 Swartz, Culture and Power, 70.
} 
driven) brain stem, human conduct is oriented towards self-preservation and self-

interest. $^{88}$

\section{Relationships: Self-Interest and Sociality, Knowledge and Power}

if one accepts the biological axiom of universal self-interest[,] then the central task of social theory is to show by what means a plurality of individuals who are independently self-interested are able to achieve sociality - Loyal Rue ${ }^{89}$

you are the seal [sfragi $\left.i V^{90}\right]$ of my apostleship in the Lord

- Paul $^{91}$

The two epigraphs frame — without explicitly addressing —a central issue

addressed in this dissertation: social power. On the one hand, Loyal Rue adroitly articulates the central theoretical problem that underlies human sociality. On the other hand, Paul's confirmation of his relationship with his Corinthian flock implicitly acknowledges that it is his followers that make him a leader. Both passages assume a

${ }^{88}$ Risking one's life to rescue a child from a burning building is in a significant sense a selfinterested action-provided one could not live with oneself if one failed to act to save the child. Moreover, philanthropic actions such as giving to charity allows one to feel good-or at least avoid the gnawing guilt of not giving. An intriguing problematizing of this conjecture is presented by Dostoyevsky's "underground man" who seeks to assert his volition by acting in ways which are calculated to run contrary to his ostensible self interest, contrary to what "rational" calculation would suggest. In defying expected behavior he is able to satisfy himself existentially by proving his ability to act according to his own whims and not the norms expected of him. "Life is life and not merely extracting square roots!" His ability to prove his humanity to himself by acting against his surface self-interest provides a deeper human satisfaction which is ultimately self-interested. "the whole work of man really seems to consist in nothing but proving to himself every minute that he is a man and not a piano-key" (i.e. that when struck he will not respond with a predictable, calculated, response). "What sort of free will is left when we come to tabulation and arithmetic, when it will all be a case of twice two makes four?" As in, Walter Kaufmann, Existentialism from Dostoevsky to Sartre, Revised and Expanded (New York: A Meridian Book, New American Library, 1975), 52-82, 76.

${ }^{89}$ By the Grace of Guile: The Role of Deception in Natural History and Human Affairs (Oxford: Oxford University Press, 1994), 184.

${ }^{90}$ With $B D A G$, "that which confirms or authenticates, attestation, confirmation, certification." In 2 Cor 1.21-22 Paul uses the same term $\sigma \phi \varrho \alpha \gamma \iota \sigma \alpha \dot{\mu} \mu \varepsilon v o \varsigma$ to claim that God has put "his seal on us."

911 Corinthians 9.2. See also the reciprocal "boasting" of 2 Cor 1.12. Biblical citations generally come from the NRSV. Other sources or the author's own translations will be identified explicitly. 
type of social relationship between leader and led, between author and subscriber that facilitates a functional collective of human beings.

Within human collectivities, power thus manifests itself in the formation of social hierarchy. Truly egalitarian societies simply do not exist as hierarchical political structures are normative. Social power is a scarce resource; vigorously and competitively pursued by many, obtained by few, and notoriously difficult to quantify in terms of economic value.

Expressions of power are often so subtle and so entrenched that they appear to be natural. Culture itself is implicated in the naturalization of power as it provides vehicles through which political ideas—-those that serve the "interests" ${ }^{92}$ of dominants ${ }^{93}$ —are expressed as normative. $^{94}$

In the situations considered here, the expressions of power manifest in social hierarchy are based on the possession of specific, constructed knowledge. The analysis of power is based on the interaction between those who claim to speak for-and indeed know the desires of — the gods, the physical text that proclaims and documents this intermediation, and the followers who accept these claims of divine insight, anointed mediation, and godly knowledge. This "knowledge" — which claims for itself the

\footnotetext{
${ }^{92}$ Here "interests" should not be construed narrowly in material, economic, or crass Marxist terms. "Interests" denotes a broad array of individual and social goals that extend beyond the material and tangible. "Interests" include psychic and social components such as emotional wellbeing, sociality, community involvement, meaningful relationships, social status and power.

${ }^{93}$ Swartz writes that "social systems of hierarchy and domination persist and reproduce intergenerationally without powerful resistance and without the conscious recognition of their members." Swartz, Culture and Power, 6. See also Weber, Sociology of Religion, 28-31. The term "intergenerational" suggests blind historical replication of entrenched systems and structures, but innovated leaders who can harness the human disposition (which is to say the familiarity and comfort with) towards these entrenched cultural structures in the creation of new social movements whose hierarchical structures bear similar patterns to traditional structures. Justification for the innovation relies upon the charismatic's claims of uniquely possessing a special knowledge or calling.

${ }^{94}$ Swartz, Culture and Power, 7. Also Pollock, The Language of the Gods in the World of Men, 1-36.
} 
exclusive ownership of "truth"-is the creation of, and in the sole possession of, Smith and Paul. It resides in the form of constructed truth that one party possesses vis-à-vis another party.

The constructed nature of knowledge need not imply a completely novel production carved out of un-hewn stone, but instead an assemblage of existing ideas cobbled together or interpreted in an innovative manner that resonates powerfully in its time and place. Moreover, "constructed” knowledge should not be dismissed as a worthless fabrication. On the contrary, it is precisely the constructed nature of the novel, exclusive knowledge that, when presented authoritatively, renders it enticing and explains its efficacy to powerfully address the human needs of the time and place. Texts contain, preserve, and disseminate this knowledge and, as such, themselves become vested with tremendous power — but only so long as they are perceived to be authoritative themselves.

Social theorist Michael Mann provides one summary of the power/ knowledge relationship as it pertains to early Christianity when he writes,

Christianity was a form of ideological power. It did not spread through force of arms; it was not for several centuries institutionalized and buttressed by the power of state; it offered few economic inducements or sanctions. It claimed a monopoly of, and divine authority for, knowledge of the ultimate "meaning" and "purpose" of life, and it spread when people believed this to be true. ${ }^{95}$

Lincoln's nuanced work on authority describes power as residing in a carefully negotiated space between coercion and persuasion. ${ }^{96} \mathrm{~A}$ compelling pitch is generally little better than its promoter. Lincoln repeatedly stresses that "the authority of the

\footnotetext{
95 Mann, The Sources of Social Power, 302.

${ }^{96}$ Bruce Lincoln, Authority, 3-4.
} 
speaker depends on the trust ${ }^{97}$ of the audience,” and notes that authority is undermined when too much persuasion is required, or once force is threatened—force being seen as but "a fig leaf" for legitimacy. ${ }^{98}$ Lincoln understands power not as a thing in itself, but as something relational, as an

effect of a posited, perceived, or institutionally ascribed asymmetry between speaker and audience that permits certain speakers to command not just the attention but the confidence, respect and trust of the audience, or-an important proviso - to make audiences act as if this were so. ${ }^{99}$

Bourdieu argues that Lincoln’s “posited, perceived, or institutionally ascribed asymmetry" of social relationships can be based on the acquisition and possession of various kinds of "capital.” He has suggested four primary forms: "economic capital (money and property), cultural capital (cultural goods and services including education credentials), social capital (acquaintances and networks,) and symbolic capital (legitimation)." 100 Social actors then “capitalize” on their accumulated resources—both material and symbolic. Sociologist David Swartz writes that a

central focus [of Bourdieu's work is] the study of how and under what conditions individuals and groups employ strategies of capital accumulation, investing, and converting various kinds of capital in order to maintain or enhance their positions in the social order. ${ }^{101}$

\footnotetext{
${ }^{97}$ Building trust in itself is a complicated issue as it serves as a fundamental component of social relationships. Some neuroscientists argue that the ability to build trust is rooted in anatomical structures of the brain and influenced by chemical and physiological functioning. Patricia Churchland analyzes the role of oxytocin and vasopressin as requisite chemical ingredients in the establishment of trust. The ability to trust in turn facilitates sociality. The implication is that the species that exhibit these anatomical structures and produce the right amount of oxytocin and vasopressin are more reliant on (and more able to engage in) sociality for survival than are similar species without these structures. Patricia S. Churchland, Braintrust. See also Pascal Boyer, Religion Explained for a study of the interaction between religious belief and the structures of the human brain.

98 Lincoln, Authority, 4, 6, 10 (emphasis added).

${ }_{99}$ Lincoln, Authority, 4, 8. Also, Pollock, "power is always relative," The Language of the Gods, 35.

100 Swartz, Culture and Power, 74.

${ }^{101}$ Swartz, Culture and Power, 75.
} 
Bourdieu's takes individual human power interests as a given. Neither Smith nor Paul simply maintained a position of power into which they were born. Each engaged in strategies that facilitated the accumulation of social, cultural and especially symbolic capital. Authoring texts was a major component of their respective "capital-acquisition" strategy.

Those who posses various types of capital, especially (in these situations) symbolic capital, are recognized as those who should be relied upon for leadership and direction. Symbolic capital can be a function of the perception of a divine calling or the perceived possession of special knowledge. Symbolic capital, however, only exists to the degree to which it is considered legitimate by other social actors. Authority rests on the assumption that the individual claiming power uniquely possesses some form of (constructed) truth, some field of special knowledge that is out of the reach of those he who aspires to power seeks to lead. "Legitimation” recognizes the difference between "knowledge" and mere "ideas."102 Authority, and its construction, are aspects of discourse. ${ }^{103}$

Discourse itself is neither purely verbal nor purely textual. It is a combination of these in addition to a multi-vocal array of gestures, events and acts—all within a particular context. It is here that the notion of charisma comes into play, as the personal skills possessed by the proclaimers greatly aid promotion of, and receptivity to, the

\footnotetext{
102 Berger, Sacred Canopy, 31.

103 This sentiment follows Lincoln-who himself acknowledges his debts to the work of both contemporary and earlier theorists, including: Michel Foucault, Pierre Bourdieu, Mikhail Bakhtin, Maurice Bloch and James Scott. Bruce Lincoln, Authority: Construction and Corrosion, (Chicago: University of Chicago Press, 1994), 2.
} 
message and vision. The proclaimers themselves become part of what is proclaimed. ${ }^{104}$

Paul and Smith both assert themselves as critical to the fulfillment of an overarching divine plan which they alone ${ }^{105}$ have been chosen by the gods to correctly articulate. There texts embody their divine designations and messages. ${ }^{106}$ Smith as prophet and proclaimer himself becomes the proclaimed as his followers celebrate the return of divine mediation to the earth. His Book of Mormon was promoted as proof of prophets living in contemporary times. Early Mormon leader Brigham Young even referred to himself as “an apostle of Joseph Smith.”107 The possession of subject matter presumed worthy to proclaim implies the possession of specific knowledge not available to others.

104 This language of proclaimer becoming the proclaimed was earlier used by one of the twentieth century's most influential analysts of the New Testament, Rudolf Bultmann, to describe the transformation of Jesus as represented in the gospels of the Christian New Testament as one where the "proclaimer" (Jesus of the synoptic gospel accounts, as a teacher and prophet, proclaimed the kingdom of heaven) becomes the "proclaimed" (Jesus as the Messiah, "Christ crucified" in the letters of Paul, e.g. 1 Cor 1.23). Bultmann writes, "He who formerly had been the bearer of the message was drawn into it and became its essential content. "Rudolf Bultmann, Theology of the New Testament, Volume I, (New York: Charles Scribner's Sons, 1951), 33-34. While "the proclaimer becoming the proclaimed" is perhaps an apt condensation of one set of problematics that New Testament study entails, it is one that completely ignores the important implications of the fact that the historical development of the gospels as texts were chronologically several decades later than, and thus plausibly influenced by, Paul's epistles. In other words, the textual occurrence of the "proclaimed" preceded the textual occurrence of the "proclaimer." A strict historical chronology of the texts would suggest that the "proclaimed" was later portrayed also as a "proclaimer."

105 E.g. Gal 1.7-9; and Smith's published claim that he was told by a divine personage in a vision that "all [other] creeds were an abomination in his sight; that those professors were all corrupt," "Extracts from the History of Joseph Smith, the Prophet," 2.19.

106 Paul's letters were collected and circulated as a group. Paul and his letters were not only central to the development of Christian New Testament, but were also central to competing interests such as Marcion's second century canon. See Harry Y. Gamble, Books and Readers in the Early Church: A History of Early Christian Texts (New Haven: Yale University Press, 1995), 58, 63. See also Lee Martin McDonald, The Biblical Canon: Its Origin, Transmission, and Authority (Peabody, MA: Hendrickson Publishers, 2007), 266-270.

107 D. Michael Quinn, Early Mormonism and the Magic World View (Salt Lake City, UT: Signature Books, 1998), 194 who cites Journal of Discourses 3:212; and also, "Whosoever confesseth that Joseph Smith was sent of God to reveal the holy Gospel to the children of men, and lay the foundation for gathering Israel, and building up the Kingdom of God on the earth, that spirit is of God, and every spirit that does not confess that God has sent Joseph Smith, and revealed the everlasting Gospel to and through him, is of Antichrist, no matter whether it is found in a pulpit or on a throne" (Discourses of Brigham Young, p.435), http://www.mrm.org/brigham-young, accessed Jan. 10, 2012. 


\section{Scripture and Scripturalization}

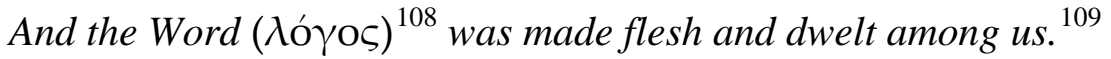

—John $1.14(\mathrm{KJV})$

The truth of the holy book is an axiom, not the end product of a process of reasoning. The book is true, and if the evidence seems to contradict it, it is the evidence that must be thrown out, not the book.

- Richard Dawkins ${ }^{110}$

The concepts of “scripture” and "scripturalization” are integral components of the meaning-making process. Texts become "scripture” when they, as material objects, are invested with sentiment and authority such that they then signify a "reality" that, although a construction of humanity, is thought to reside beyond the reach of human creation and manipulation. The phenomenon of certain texts being recognized as "scripture," is an implicit recognition of the scripturalizing process whereby specific texts become effective instruments in the psychosocial and sociopolitical constructions of reality on both the individual human and collective level. ${ }^{111}$

Scripture thus becomes the group's central and centering material object. ${ }^{112}$ It is the cultural artifact that provides a physical repository for human projections. Although entirely a product of human experience, interpretation and projection, "scripture" - the

108 The semantic range of $\lambda$ ó $\gamma$ os/logos is broad, ranging from a simple "word" used in communication to a more formal reckoning to a reasoned discourse, to the cosmic ordering system of the universe. Its use in John is as the "independent personified expression of God, the Logos," BDAG 598-601. Transcendent reality can take on material form, whether in the person of prophets, or in their texts.

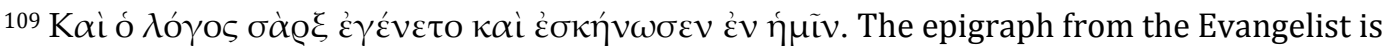
instructive. It refers to the process by which the $\lambda$ ó $\gamma$ o "word" (here "word of God" in the sense of divine reason, the cosmic ordering process and as an expression of ultimate reality) claims embodiment in a material thing.

110 The God Delusion (Boston: A Mariner Book, Houghton Mifflin Company, 2008), 319.

111 Compare Theorizing Scriptures, 16.

112 Berger uses "religion" as the centering component. Scripture is the physical object that serves as a place holder for religion, 35. Some religions base their authority on a text just as some countries base their authority on their texted "constitution." See also Martin, Religion and Republic, 152. 
objectivation of these projections—obtains the perception of facticity in itself, ${ }^{113}$ a status that is bolstered (in the case of texts) by the materiality of ink on paper. Scripture in this sense is the vessel into which humans pour meaning and authority. ${ }^{114}$ "Scripture" becomes "objective reality" "by virtue of collective recognition." 115 Completing the "scripturalization" cycle, scripture then serves to inform if not define the nature of reality itself for its human subscribers.

Once perceived as objective reality, scripture is made to sanction the whole of the human meaning-making enterprise. “Scriptures” provide a basis from which the cosmic order and life within it are explained. They bring clarity to the world and provide meaning. Scriptural interpretations provide social groups with identity and purpose. They provide a logic and an authorization that justifies human existence and can be made to regulate daily life, codes of conduct and behavioral expectations. Scriptures shape human development on both an individual and communal basis. They are deployed to support human social structures and are harnessed to provide a legitimization of leadership claims. They can support, or subvert, asymmetrical power relationships.

It is here that Berger's imagery of the sacred canopy is helpful. Scripturalization, like the sacred canopy, encapsulates the full extent of human vision, perception and awareness — even though the cosmos extends infinitely beyond it. The canopy lets in rays of the sun, but never its full light. Some light shines through the leaves of the canopy as

\footnotetext{
113 Berger, Sacred Canopy, 3-10.

${ }^{114}$ Here, see also W. C. Smith, What is Scripture?, 16.

115 Berger, Sacred Canopy, 10-12. Elisabeth Schussler Fiorenza summarizes "scripture" as a "cross-culture and relational category" which (citing Barbara Holdrege who appears to use W.C. Smith's formulation) "'refers not simply to a text' but to a text 'in relationship to a religious community for whom it is sacred and authoritative."' Fiorenza, "Powerful Words: The SocialIntellectual Location of the International Signifying Scriptures Project" in Wimbush, Theorizing Scriptures, 256-267, 258.
} 
if they were panes of stained glass, showering the community below with illuminated images of their own (or their ancestor's, or their community's) construction. The entire community looks up to, is informed, nurtured and sheltered by, the same canopy. The canopy as a structure occludes the astral bodies and infinite possibilities beyond it—but it provides a plausible, workable, familiar habitus for those who live under it.

“Scriptures” function as a sacred canopy. They are perceived as "objective reality," and are made to delineate a world for humanity to inhabit. ${ }^{116}$ The reabsorption of this constructed reality into the consciousness of a collection of human actors determines not only social structures, but "the subjective structures of consciousness itself." ${ }^{117}$ Its perceived location as outside of, and beyond the reach of, humanity is internalized and becomes an effective mechanism through which the world is understood, actions are justified, and authority resides. The basic, root ideas signified by scriptures are "beyond question" by the mere fact that they are in accordance with social convention. ${ }^{118}$

The process serves an important anthropological purpose. Human communities can not function without some form of organizing structure, customs, traditions, a legal code, the ways of the ancestors, etc. As an analogy, traffic flows best when everyone understands the rules of engagement: stop at a red light, proceed at green. ${ }^{119}$ There is

116 Berger, Sacred Canopy, 13.

117 Berger, Sacred Canopy, 15. This notion is further explored in chapters three and four.

118 Pierre Bourdieu, Outline of a Theory of Practice, Cambridge Studies in Social and Cultural Anthropology, 16. Translated by Richard Nice (Cambridge: Cambridge University Press, 2008) (1977), 169.

119 The rules of engagement in the game of rugby (fittingly, "laws" in rugby vernacular) literally allow the game to be played. The "laws" were purposely constructed by humans to facilitate the game which flows only when both teams abide by them. That the laws of the game are in some sense arbitrary is irrelevant. They need no sanction "from the gods" and their inherent "truth" is irrelevant. The laws of the game are merely recognized as a human production that facilitates ninety minutes of 
nothing inherently or morally good or bad behind the colors red and green; rather they serve as simple codes that facilitate one type of social interaction-the efficient and safe flow of traffic.

Martin Marty provides some imagery that is helpful to the discussion at hand, the carapace. He defines a carapace, in its native zoological context, as "a hard boney or chitinous outer covering, such as fused dorsal plates of a turtle, or the portion of the exoskeleton covering the head and thorax of a crustacean.” He goes on to qualify that the term can also refer to “any similar protective covering.”120 Where Berger’s canopy informs the entire community, Marty's carapace functions more on the individual level while still a product of socialization. Marty’s carapace has “great anthropological and psychic significance” as it is composed of what Jose Ortega y Gasset calls creencias (ideas and beliefs that are so deeply ingrained that we are unaware we hold them) and vigencias (the "binding customs of culture, customs that have a hold much stronger than that which law itself can impose”). ${ }^{121}$ Marty writes that “a carapace of images is necessary in order for individuals and society to function cognitively or morally,” and that "without such carapaces people would likely go mad."122 These fundamental ideas reside in coded form in traditions, rituals, laws, and for the purposes here, texts.

rewarding play. Violations of the laws merit penalties. Serial or egregious violators can be "sent off," i.e. "excommunicated."

120 Martin E. Marty, Religion and Republic: The American Circumstance (Boston: Beacon Press, 1989), 146.

${ }^{121}$ Marty, Religion and Republic: The American Circumstance, 141. For Ortega y Gasett's work, Marty cites Karl J. Weintraub, Visions of Culture (Chicago: University of Chicago Press, 1966), 261, 263; and Harold C. Raley, Jose Ortega y Gasset: Philosopher of European Unity (University of Alabama Press, 1967), 81.

122 Marty, Religion and Republic, 152, 146. Such a description provides parallels, on a more comprehensive basis, to the laws of rugby described in the note above. 
In relation to his carapace imagery, Marty takes the step of speaking of the bible as an American icon. The connection is that Americans to this day overwhelmingly believe that the bible is either the "actual" or "inspired word of God"123 and yet biblical literacy is appallingly low. ${ }^{124}$ The point is that people believe the bible to be the word of God without knowing what is actually in the bible. ${ }^{125}$ This assumption that the bible contains — and thus, as God's word, legitimizes —individual creencias and vigencias is the core phenomenon behind scripturalization. ${ }^{126}$

On the other end of this "scripturalizing" phenomenon is the prohibition against interrogating the object, text, or icon held up as scripture. The phenomenon of scripturalization protects itself by establishing "taboos against applying various sets of

\footnotetext{
123 Seventy-nine percent of Americans who have graduated from college believe the bible to be the actual or the inspired "word of God" according to a May 2011 Gallup Poll. The number of believers increases as education levels decrease. http://www.gallup.com/poll/148427/say-bibleliterally.aspx, accessed Dec. 5, 2011. Marty used earlier iterations of the same basic Gallup Poll in his research.

124 Stephen Prothero, Religious Literacy: What Every American Needs to Know-And Doesn't (New York: HarperCollins, 2008).

${ }^{125} \mathrm{~A}$ favorite quip of atheists is that the best way to make a Christian convert to atheism is simply to ask them to read the Bible. See also the argument for why non-believers too should know what is in the Bible, Jacques Berlinerblau, The Secular Bible: Why Nonbelievers Must Take Religion Seriously (Cambridge: Cambridge University Press, 2005).

${ }^{126} \mathrm{~A}$ poignant example of a text considered authoritative on specific topics that are not within its contents comes from the "Book of Mormon" musical (winner of nine Tony awards) when the Mormon missionaries are challenged to produce the page, chapter and verse in the Book of Mormon that prohibits rape as a prophylactic against AIDS.

Middala: "The story I've been told is that the way to cure AIDS is by sleeping with a virgin. I am going to go and rape....

Elder Cunningham: What!?!! OH MY - NO! You can't do that! NO!!!!

Middala: Why not?

Elder Cunningham: Because that is DEFINITELY against God's will!

Middala: Says who? Where in that book of yours does it say ANYTHING about sleeping with a [virgin]?

Nowhere!"

Track ten from The Book of Mormon soundtrack, "Making It Up Again" by Trey Parker, Robert Lopez and Matt Stone. Dialogue as printed in soundtrack liner notes.
} 
[disruptive] discursive practices” to objects, actions and people considered holy. ${ }^{127}$ Such restrictions are part of the group’s “world-maintenance” activities. As critical analysis can subvert the "plausibility structure” of a group’s constructed world, keepers of scripture will act to "hide, as much as possible, its constructed character." 128

Importantly however, “scriptures” need not be the aggregate production of humanity through the ages as is the case of the Bible. ${ }^{129}$ They can be manufactured by individual human hands guided by human interests. Pseudepigraphy is a powerful, authorizing ruse. Manufactured texts - whether they are produced in an afternoon or the collective product of a culture-will always reflect components of the environment that produced them. Moreover, they will generally serve the specific interests of those who pen them. They may arise from vernacular traditions to contest the hegemony of the dominant tradition, to “deconstruct or de-center [destabilize] normative structures while at the same time weav[ing] new social textures and identities.” ${ }^{130}$ In such cases claims of revelation serve to legitimize the authority of the revealed word-provided such claims are accepted and embraced by those who hear the revelations.

These human projections are thus perceived as transcending human origin and existence as the ultimate source of explaining how and why things are as they are. The process is self reinforcing because what prior generations have projected (based on the constructed nature of their own context, shaped by their own predecessors, location and

127 Kassam, "Signifying Revelation in Islam," 38.

128 Berger, Sacred Canopy, 33 (emphasis added).

${ }^{129}$ As a broad, diachronic collection of texts, the bible includes a range of genres and an expansive range of ideologies-all of which can be pressed into serving contemporary agendas. 39.

130 Tazim R. Kassam, "Signifying Revelation in Islam” in Wimbush, Theorizing Scriptures, 29-40, 
contingencies) has become the objective reality that shapes the present generation and their own projections.

The development of a closed canon may stop the addition of new material to the body of sacred writings, but by no means will it slow the interpretive process nor the process by which meaning is produced and sanctioned by these culturally laden objects. $^{131}$

Visceral belief often shields sacred objects from the sort of critical questions asked of other human productions. ${ }^{132}$ And yet scripture tells the critical analyst more

\footnotetext{
${ }^{131}$ Perhaps as important as the explanations, meanings, histories and ethical guidelines conveyed by these sets of scriptures is their capacity to provide a self-serving method of epistemological verification. When deployed as instructed, this methodology has the capability of powerfully confirming all the claims and meanings derived from scripture. As such the methodology is circular, self-reinforcing and as such ultimately self-serving. The "self" that is served is not limited to the spiritual or social benefits achieved by the believer. The self-serving nature of the power agenda is implicitly promoted by texts that she produces. Unpacking the discursive techniques which facilitate the self being served by the production of texts is an important component of this project.

Providing an example of this latter function, early Mormon convert and Book of Mormon witness David Whitmer writes that,

When God had given us the Book of Mormon, and a few revelations in 1829 ... commanding us to rely upon the written word in establishing the church, He did His part; and left us to do our part and to be guided by the Holy Ghost as we walked worthy to receive. (David Whitmer, An Address to All Believers in Christ: By a Witness to the Divine Authenticity of the Book of Mormon (Richmond,
} MO: David Whitmer, 1887), 30.

Texts are read within a certain epistemic framework. Changing that interpretive framework radically alters one's understanding of a given text. Whitmer's reading is within an epistemological framework that allows the text to function in a certain way. The texts promoted by both Paul and Smith provide rather explicitly the type of epistemology one should bring to the reading. Given this interpretive framework, what Whitmer perceives as a mandate to be guided by the Holy Ghost is understood by the critical analyst as license to create (within certain parameters) a system suitable to the gods as Whitmer understands them-which is to say as Whitmer's convictions and interests dictate. This is not really different from other epistemologies, even those that fly the authorizing flag of "reason." Some say "Holy Ghost," others say "Reason." In either case people arrive at conclusions according to their assumptions, "convictions and interests." The interesting question is the difference it makes to situate one's perception of reality within a religious framework where the source of authority is located beyond the pale of empirical analysis. Locating the source of authority in the supernatural realm allows one to advocate a social, ethical, and institutional order in which people could live their lives without feeling the need to challenge the source of the authority, or of the authority's mediator.

132 This reticence of critical inquiry, the taboo against treating the "sacred" as mundane are features that indicate a given material object has been scripturalized. Kassam, 38. 
about humanity than divinity. Scripture and scripturalizing are where people create gods in their own image.

\section{Discourse as Mediator of Social Relationships}

Lincoln's writings consider the work done by the various “modes” of discourse recognized as myth, ritual and taxonomy in the shaping and maintenance of society and certain social institutions. ${ }^{133}$ He refers to the use of these modes as nothing less than "effective instruments" in the "construction of society itself."134 The modes of discourse deployed by Smith and Paul (“prophetic,” “inspired,” "revelatory,” “mediating” discourse) are themselves no less effective instruments in the construction of specific, tangible social formations. ${ }^{135}$ Components of Paul and Smith’s revelatory discourses became enshrined in texts. In addition to explicitly texted claims to power, Sheldon Pollock writes that "writing claims an authority the oral cannot. The authorization to write ... is no natural entitlement, like the ability to speak, but is typically related to social and political and even epistemological privileges.”136 In effect, circulating one’s ideas in texted form is an implicit claim to a privileged position, especially if the source of the content is promoted as divine. The promulgation of these texts effectively disseminates these claims in a format that better resists alteration than oral transmission. Moreover, "the construction of the text . . . can lead to its contemplation, to the

\footnotetext{
${ }^{133}$ Bruce Lincoln, Discourse and the Construction of Society: Comparative Studies of Myth, Ritual, and Classification (New York and Oxford: Oxford University Press, 1989), 3.

134 Bruce Lincoln, Discourse and the Construction of Society, 3.

135 "The central idea behind discourse analysis is to conceive of language as a communicative set of interactions, through which social and cultural beliefs and understandings are shaped and circulated," Michael Freeden, Ideology: A Very Short Introduction (Oxford: Oxford University Press, 2003), 103.

${ }^{136}$ Sheldon Pollock, The Language of the Gods in the World of Men: Sanskrit, Culture, and Power in Premodern India, 4.
} 
development of thoughts about thoughts." ${ }^{137}$ These are precisely the texts that function to construct and center ${ }^{138}$ novel social formations. The claim to have been selected by the gods to spread their words is no less than a claim to an authoritative social position. The intentionally texted discourse presented by Paul and Smith to their communities documents one side of the dialectic between leader and community.

In these situations the social formation's novel or experimental endeavor is the mission or vision for the future as articulated by the community leader. In the dialectic relationship between leader and follower, the quest to participate in the mission or vision of the leader must prove compelling to followers — even if the leader and his vision are difficult to distinguish from each other. Sociologist Janja Lalich writes,

without the leader, there would be no draw, no call, no promise of an ideal. And without devotees responding to that call, there would be no group, no set of coordinated activities, and no followers granting the leader the authority to rule. ${ }^{139}$

The "willing participants" in some scenarios may also be described as leader and follower, or narrator and subscriber "locked together in a relationship of [mutual] interdependence.” ${ }^{140}$ This should not suggest that each of these social formations is a dictatorship—but neither are they egalitarian or classless. ${ }^{141}$ Dialectic interaction between

137 Jack Goody, The Logic of Writing and the Organization of Society, Studies in Literacy, Family, Culture and the State (Cambridge: Cambridge University Press, 1996), 38. Text "renders the discourse itself a subject for discourse," Pollock, The Language of the Gods, 4.

138 Martin E. Marty, Religion and Republic, 152.

139 Janja Lalich Bounded Choice: True Believers and Charismatic Cults (Berkeley, CA: University of California Press, 1988), 226 (emphasis added).

140 Alan Bryman, Charisma and Leadership in Organizations (London: SAGE Publications, 1992), 51. See also Lorne Dawson, Comprehending Cults: The Sociology of New Religious Movements (Toronto: Oxford University Press, 1998), 72-101; and Eileen Barker, The Making of a Moonie: Choice or Brainwashing? (Oxford: Basil Blackwell, 1984).

${ }^{141}$ Despite any rhetoric or claims to the contrary, and just as was the case with twentieth century Soviet rhetoric, contemporary America is far from a classless society. Freeden writes that not all "articulated discourses are hegemonic," Ideology, 113. 
leader, council of elders, boule, and followers is the interplay by which leadership and power are established and community is formed.

The factors are social and human, as it is living, breathing people that negotiate and acquire—and conversely, choose to accept and acquiesce to—positions of leadership and authority. The negotiation of authority is especially dynamic within the development of new social formations. Within such an emergent social setting, few if any specific institutionalized practices have been put in place. There is considerable latitude available to each social actor, limited perhaps only by the recognized practices of much larger and more entrenched circles of traditional social practice. Those who seek authority in innovative settings do not have legal forms to file, certificates or degrees to post, or formal campaigns to run. They do not possess the components of physical power. They have no militia and no apparatus for physical coercion with which to enforce compliance or obedience. Rather, they rely on discourse. Simple rhetoric has its limitations unless the discourse in which it participates evokes ${ }^{142}$ something much larger.

\section{Discourse Internalized - a final assumption}

The social world intends, as far as possible, to be taken for granted. Socialization achieves success to the degree that this taken-for-granted quality is internalized

$$
\text { -Peter Berger }{ }^{143}
$$

McCutcheon writes that some analytical models overlook "the diverse ways in which members of a hegemonic system participate in the definition, coordination,

\footnotetext{
142 This is the sentiment evocation spoken of by Lincoln in Authority 3. The extent to which certain sentiments evoke powerful feelings are in large part influenced by one's location within a culture and the charismatic's ability to harness the powerful images and sentiments important in that culture.

143 Berger, Sacred Canopy, 24.
} 
articulation and experience of dominance." ${ }^{144}$ One of these tools is socialization. One tool of socialization is the authoritative nature attributed to the ideas thought to reside in specific texts. Once the community's rules of behavior are established they become internalized by the individual. Once internalized, expectations become self-enforcing. The coercive tools of discourse are subtle as they are creep into the mind of the individual at the personal, psychological level. The constructed reality of the group becomes normative for the properly socialized individual. Foucault argues that coercive power can be deployed via discourse into elements of human thought and behavior where they then form a self-governing mechanism. He writes,

We must not understand the exercise of power as pure violence or strict coercion. Power consists in complex relations: these relations involve a set of rational techniques, and the efficiency of those techniques is due to a subtle integration of coercion-technologies and self technologies. ${ }^{145}$

It is when the rules of social engagement and behavior have been internalized that they become most effective. Once internalized the rules of social engagement that guide behavior and thought do so without the individuals cognitive recognition. They have become normative and essentially invisible to reproach or challenge. The rhetoric originating from the top of the social formation's hierarchy—especially when it rearticulates the "reality of the world as socially defined"-guides the actions of the rest involved. "[R]eality maintenance" depends in part upon "the way by which the individual apprehends the world within his [or her] own consciousness.” ${ }^{146}$ Community

\footnotetext{
${ }^{144}$ Russell McCutcheon, Manufacturing Religion: The Discourse on Sui Generis Religion and the Politics of Nostalgia (Oxford: Oxford University Press, 1997), ix. See also Lorne L. Dawson, Comprehending Cults: The Sociology of New Religious Movements (Toronto: Oxford University Press, 1998), 11; and "Charismatic Leadership," 23.

145 Michel Foucault, "The Hermeneutics of the Self" in Religion and Culture, selected and edited by Jeremy R. Carrette (New York: Routledge, 1999), 162.

146 Berger, Sacred Canopy, 32.
} 
members, having internalized the codes of conduct themselves, participate in

enforcement. A simple glance or reproving glare from a community member serves to reinforce behavioral expectations.

Lalich discusses the ramifications of such collective and internalized behaviors in her life as a member of a politically oriented, totalizing social formation, the Democratic Workers Party (DWP). As members of many totalizing communities can attest, the individual is often subjected to coercive force, even if non-violent and non-physical. She writes,

[Once] a person identifies and unites with the bounded reality of the group and its belief system, becoming a devotee by making that charismatic commitment to the self-sealing worldview, another process begins to take place. That is, individual perspective and personal decision making become limited and constrained, and that restriction comes from within as much as from without. ${ }^{147}$

Paul appears to be familiar with the power and efficacy of an internalized framework for self monitoring behavior when he counsels his Corinthian community regarding the ritual consumption of the bread and wine. His directives are not clear. He speaks only of eating the bread or drinking "the cup of the Lord" in an "unworthy" manner under the assumption that the community is aware of what constitutes "worthy" and "unworthy". He does, however, advise his followers to "Examine yourselves ... if we judged ourselves, we would not be judged" (1 Cor $11.28,31) .{ }^{148}$ Paul also speaks of the Corinthian community's obligation to reject and not associate with those who are sexually immoral, greedy, thieves or drunkards. Such a rejection of course requires discernment. The ultimate judgment of those excluded from the community will come

\footnotetext{
147 Lalich, 21.

148 Earlier in the same letter, as Paul boasts of his indifference to human judgment, he exempts himself from the onus of self judgment as it is "the Lord who judges me" (1 Cor 4.4).
} 
from the gods, but the onus of the passage is to remind the community to judge one another. Paul queries, "is it not those who are inside [the community] that you are to judge?” (1 Cor 5.12). Once internalized, this advice of inward assessment promotes an effective internal mechanism for controlling individual behavior. It also serves to maintain the group's particular construction of reality.

The coercive power of conformity therefore becomes not solely a function of adhering to the dictates of the charismatic leader, and not just a matter of meeting the expectations of one's community. The coercive power now resides within the individual human being so that they induce themselves to abide closely to the behavioral and belief requirements of the group. When adherents police themselves, the socialization process is complete, the sacred canopy has been reinscribed within the individual human psyche. 


\section{APPROACH-COMPARATIVE AND CRITICAL}

The critical orientation operative here is based on the premise that the texts that shape a new community's sense of self, cosmology, ethics, and mission are simultaneously critical to the building and supporting of their respective author's dominant, authoritative, social position. The texts that reveal the ways and the wills of the gods also reveal the authorized spokesperson of the gods. In this way, texts generate tremendous power for their authors, or equivalently, authors forge social power through their texts. Such a thesis carries with it two fundamental methodological obligations. The first, in keeping with the assumptions outlined above, is to acknowledge that human interests motivate the production of texts such as these. The second is to acknowledge the array of social uses these texts are made to serve, both implicitly and explicitly, that extend well beyond the realm of theology. Comparing these men and their texts illuminates the concurrent processes of developing a community and acquiring power. Comparison highlights, elucidates and differentiates the human behaviors that facilitate social formation.

\section{Comparison}

In the broadest of terms, this analysis compares the similarities and differences of Smith and Paul as divine mediators, preachers, writers and community leaders. The comparison takes place within two analytical frameworks designed to complement each other. Each has discrete subcategories. The first framework of comparison, the subject of chapter two, "Culture and Charismatic,” is based upon historical and sociological analysis that is organized by a model of "prophetic charismatics" produced by 
psychologist Len Oakes. ${ }^{149}$ Neither individual is forced into Oakes’ model, rather the model serves as a platform from which select issues can be compared. His framework allows for the illumination and analysis of these individuals as human beings who develop specific skills, located within a particular cultural setting. Describing the personality traits and sociocultural location of each allows first for an analysis of the relationships between human motivations and sociocultural opportunities and, second, the development of specific skill sets that facilitate the acquisition of power.

The second comparative framework, the subject of chapter three, relies heavily on Bruce Lincoln's work that exposes the inherent political dimensions ${ }^{150}$ of texted discourse. Both Smith and Paul harnessed literary traditions, claimed divine sanction and ultimately garnered a following through the use of texts. The analysis provides a critical assessment of the implications and effects of these discursive strategies and the human behaviors that construct, authorize and facilitate the social relationship between leader and led, between entrepreneurial ${ }^{151}$ religious innovator and the spiritually adventurous community founded on the claims of this leader. ${ }^{152}$ Texts are analyzed not for exegetical

\footnotetext{
${ }^{149}$ Len Oakes, Prophetic Charisma: The Psychology of Revolutionary Religious Personalities (Syracuse, NY: Syracuse University Press, 1993).

150 By "political" I mean, in the words of Terry Eagleton, "no more than the way we organize our social life together, and the power-relations which this involves." Literary Theory: An Introduction (Minneapolis, MN: University of Minnesota Press, 1984), 194.

151 "Entrepreneurs are persons who start and promote new enterprises in order to obtain rewards through profitable exchanges." Stark and Bainbridge, $A$ Theory of Religion, 172 (emphasis in original). Stark also uses this citation as "Definition 76" on page 329. Here "profitable" is not restricted to exchanges quantifiably in monetary terms. Psychic income, power, joy and other unquantifiables are all part of the equation.

152 Continuing the market metaphor, financial investment in start-up, entrepreneurial business ventures is risky. Investors expect to be compensated for this risk, that is they expect a high-return for taking big risks. The same risk profile applies to seekers who join high-risk ventures, they anticipate high rewards.
} 
purposes, but based on how they functioned as part of the dialectic involved in community building.

This second comparative framework confronts the powerful place of texts in culture. Once recognized as authoritative, texts present a version of reality that expresses—either symbolically or explicitly—a social contract. In addition to delineating expectations of followers, the texted social contract clearly states who is to be vested with the authority and power to lead the community. The process of claiming power is broken into three basic subcategories: 1) claims themselves (whether blatant or subtle, implicit or explicit); 2) a circular authorizing component where the text promotes and authorizes its author at the same time the author promotes the text, and; 3) the presentation and promotion of specific epistemic regimes which are conducive to verifying the claims made by these men and their texts.

As with so many great characters of history, both Paul and Smith engage in tactics of deception to advance their interests. The final chapter confronts the role of deception in 1) biological life; 2) in terms of evolutionary fitness, 3) in human history, and 4) in terms of its ability to generate personal wholeness and social cohesion. As the term “deception” has obvious, negative taxonomical baggage, the reader is urged to think in terms of "narrator" and "subscriber" rather than "deceiver" and "dupe," respectively.

Comparison provides examples of human behavioral patterns which can have similar contours while remaining unique. The interest is not in drawing simplistic, positivistic conclusions about Paul or Smith being similar or different from each other. Rather, the exercise of comparing one against the other serves to facilitate the analysis of power, hallowed texts and the formation of religious communities at hand. Comparison 
highlights distinctions as much as similarities. ${ }^{153}$ Not everyone who claims to speak for the gods ${ }^{154}$ finds success — and yet Smith and Paul developed substantial and thriving communities in their own lifetimes. These social formations are now enormous institutions that operate under a different set of social relationships. This dissertation attempts to analyze the discursive techniques that contributed to their initial development, the seeds and sprouts that gave rise to the mighty trunks.

\section{Critical Approach}

A historical reconstruction of past practices, if considered apart from their potential to effect future practices, is an empty enterprise . . . The past will not go away by ignoring it or pretending it is past: either we master it through critical historical analysis or it will continue to master us -Sheldon Pollock ${ }^{155}$

Here, the reading of scripture, as articulated by Vincent Wimbush, “is and ought to be the study of . . . power relations.”" ${ }^{156}$ Wimbush’s work is directed towards analyzing the dynamics involved in (and ramifications of) investing texts and other objects with meaning to support contemporary paradigms of power and notions of identity.

\footnotetext{
153 See Jonathan Z. Smith, Drudgery Divine: On the Comparison of Early Christianities and the Religions of Late Antiquity (Chicago: University of Chicago Press, 1990), 47, 53; and Imagining Religion: From Babylon to Jonestown (Chicago and London: University of Chicago Press, 1982), 1. Smith has been a long-time proponent of the comparative enterprise as well as critic of the way religious comparisons have been mis-handled in the past. See also Fitz John Porter Poole, "Metaphors and Maps: Towards Comparison in the Anthropology of Religion" in the Journal of the American Academy of Religion, vol. 54, no.3 (Autumn 1986), 411-457, 417.

154 The use of "the gods" here rather than the more standard monotheistic rendering of "God" serves two purposes. The first is an attempt to render the comparison somewhat more universal in that "the gods" is perhaps a less theologically charged handle for a reference to posited divine powers that resides outside of the realm of empirical understanding. The second is that Paul speaks of both Christ and God as deities. His "ditheistic" discourse preceded the Trinitarian controversy by three centuries. Smith while frequently treating God and Christ as the same entity in the 1830 Book of Mormon, later insists on separate and distinct personages and identities within the Godhead.

155 Pollock, Language of the Gods in the World of Men, 35, 36.

156 Wimbush, Theorizing Scripture, 6.
} 
Scholars from other disciplines have also promoted a power-oriented approach regarding the study of religion. David Bromley argues that the study of new religious movements (NRMs) should be one "that facilitates the exploration of power relations." A study of power relations with respect to the Apostle Paul was modeled by New Testament scholar Elizabeth Castelli in her analysis of the role of imitation in the rhetoric of Paul. ${ }^{157}$

\section{Acknowledging the Human Motivations That Drive Behavior}

The implications of the author's interestedness, the writer's motivation, and the material stakes at play are questions that resist being asked of cultural icons. ${ }^{158}$ The resistance is itself evidence of sacrosanct status of the texts and humans under consideration. ${ }^{159}$ Above, I have made the simple argument that humans act in ways that advance their interests ${ }^{160}$ and yet a "personal agenda" is rarely assumed of those who claim to bear the words of God. That a human and ultimately self-interested agenda implicitly exists for the prophetic speaker or writer need not imply insincerity on behalf

157 David Bromley, "Perspective: Whither New Religious Studies? Defining and Shaping a New Area of Study" in Nova Religio, vol. 8, no. 2, 83-97, 2004, 89, 92. Elizabeth Castelli, Imitating Paul: A Discourse of Power (Lousiville, KY: Westminster/John Knox Press, 1991).

158 It is difficult to subject the heroes of our culture or simply those we admire to this type of analysis. William James makes the point of the difficulty in treating great men as ordinary humans with respect to what he considered the psychopathological aspects of Quaker founder George Fox, a man for whom James expresses sincere respect and admiration. Having cited a bizarre passage from the diary of Fox, James writes,

Bent as we are on studying religion's existential conditions, we cannot possibly ignore [the] pathological aspects of the subject. We must describe and name them just as if they occurred in non-religious men. [Even though] it is true that we instinctively recoil from seeing an object to which our emotions and affections are committed handled by the intellect as any other object is handled, William James, The Varieties of Religious Experience: A Study in Human Nature (New York: Modern Library, 2002), 11.

159 Kassam, 38.

${ }^{160}$ Recall the work of Pierre Bourdieu, David Swartz and Rodney Stark as presented in the "Assumptions" section above. 
of the prophet. Nor should a human agenda suggest that the prophet's message is somehow devoid of real meaning for those disposed to embrace it.

To state that people who claim to speak for the gods do so only to advance their own interests does less than full service to the complex set of relations that attend each prophetic utterance. In contrast, however, the notion that one who claims to speak for the gods automatically has nothing personal at stake in the proclamation of her message is either simply naïve- or is the product of partisan thinking where uncritical exceptionalization of prophets and their work is normative.

Challenging the basic motivations that underlie the missions and proclamations of revered or holy men is generally avoided by scholars inside the traditions under examination. ${ }^{161}$ This point is especially noteworthy given that biblical studies and Christian history has been in the hands of the Christian partisans since its formation. Add to this the fact that, since the beginning, the "gospel” ( $\varepsilon \dot{v} \alpha \gamma \gamma \varepsilon \dot{\lambda} \lambda$ เov, euangelion: "good news," "good message”) preached by Christians has been treated as history rather than as a "good message” which promotes a sectarian ideology. Challenging this long established portrayal is often simply beyond what the reigning cultural assumptions, political expediency, or even conventional courtesy, will allow. ${ }^{162}$

${ }^{161} \mathrm{~A}$ great example of this tendency is confessed by the scholar of Isis and ancient mystery religions who freely admits that, "For the orthodox reader, however, the biographical validity of the Acts and the [Pauline] Epistles must remain unquestioned, the latter indeed being treated as genuinely autobiographical. Such is the standpoint to be adopted here." R.E. Witt, Isis in the Ancient World (Baltimore and London: The Johns Hopkins University Press, 1997) (1971) 255. While this approach is common in the world of biblical and ancient studies, Witt is honest enough to disclose his perspective and location forthrightly and honestly.

162 In an important article focused on the "nature of diversification in the history of early Christianity," Harvard's well respected Helmut Koester urges that the "conventional picture of early Christian history.... [must be] called into question." He notes the problems with terminology (e.g. the "ambiguous and vague ... use of the term gnostic"), the rhetorical distinctions of heresy and orthodoxy, the political and other problems with the canonical New Testament, and many other problematic issues. He refers to Christianity as "a religious movement which is syncretistic in 
Moreover, while many scholars show no reluctance in analyzing the "intangible skill sets and talents” that help entrepreneurs or entertainers capture market share, "they are often reluctant to exercise the same curiosity to explore how spiritual leaders carve out unique niches in the religious marketplace.”163 Traditional accounts of a religion’s origins, as generally interpreted by committed scholars, rarely consider the external stakes motivating the prophets or founders to act as they have. And if some of the externalities are considered, they generally render invisible the human interests that motivate the prophet to speak.

Along these lines, Bruce Lincoln writes,

Although critical inquiry has become commonplace in other disciplines, it still offends many students of religion, who denounce it as "reductionism". This charge is meant to silence critique. The failure to treat religion "as religion"-that is, the refusal to ratify its claim of transcendent nature and sacrosanct status-may be regarded as heresy and sacrilege by those who construct themselves as religious, but it is the starting point for those who construct themselves as historians. ${ }^{164}$

appearance and conspicuously marked by diversification from the very beginning," (italics added). Having noted these problematic issues and having urged re-evaluation of the "conventional picture" Koester then re-asserts the crux of the "conventional picture" by writing that "it is beyond dispute that the historical origin of Christianity lies in Jesus of Nazareth, his life, preaching, and fate." He does so without providing a single bit of supporting evidence or reason for the proposed sacrosanct nature of this foundational component. In other words, Koester's challenge to the "conventional picture" has its boundaries when it comes to faith in Jesus-a topic still frequently off limits to critical scrutiny. Even the most renowned of scholars from the most eminent universities will push things only so far when to do so challenges their deepest convictions and sympathies. Helmut Koester, GNOMAI DIAPHOROI: The Origin and Nature of Diversification in the History of Early Christianity, in James M. Robinson and Helmut Koester, Trajectories through Early Christianity (Philadelphia: Fortress Press, 1971), 114-157, 114-117. Within the Mormon tradition, those who depart from the LDS Church's viewpoint in a critical way are branded not as independent historians or critical thinkers, but as anti Mormons.

163 Lee and Sinitiere, Holy Mavericks, 159.

164 Bruce Lincoln, "Theses on Method" Method \& Theory in the Study of Religion vol. 8 (1996): 225-27. From the critical standpoint, religious practitioners who understand their experiences as some form of contact with the divine have already made an interpretation of their experience which is at odds with other secular explanations. In this analysis, I want to preserve the right of the analyst to describe, name and perhaps explain the experience, even if it is at odds with those who have experienced it. I have undergone my own "experiences" in my life. My subsequent change of analytical perspective does not change the physical reality of the experience, but it does change the interpretation of the experience. Moreover, as an analyst of religion, I am not about to allow the 
Scholars must choose the criteria and rubrics under which they analyze their data. McCutcheon raises the point that in no other field of study are the objects of study allowed to determine the rules and criteria of analysis. ${ }^{165}$ Although many religions and religious people believe that their (or their denomination's) belief system is unique and not to be confused with other religions, it invariably is not as unique as insider rhetoric posits. William James writes "a crab would be filled with a sense of personal outrage if it could hear us class it without ado or apology as a crustacean, and thus dispose of it. 'I am no such thing,' it [the crab] would say; 'I am MYSELF, MYSELF alone.’”166 Such positioning makes for effective insider rhetoric and perhaps provides the quintessential example of “exceptionalization.” For religious scholars of religion to hold that religion is somehow exempt or apart from social historical analysis is a "highly useful discursive as well as political strategy."167 Such protective rhetoric often prevents some of the most basic questions from being raised.

objects of study to dictate the terms under which they will be studied-an argument made by James, McCutcheon and JZ Smith. The richness and complexity of these experiences should take the myriad of social, psychological, and neuroscientific factors into account.

165 Wayne Meeks writes that there is "no reason to let the theologian legislate what questions the interpreter is allowed to ask." The First Urban Christians: The Social World of the Apostle Paul, 4.

166 William James, Varieties of Religious Experience, 11-12, (emphasis in original). To those who would argue that the crab is correct, one must in return query whether or not the crab has any useful or meaningful anatomical, morphological, evolutionary or behavioral similarities with other crustaceans? Is the crab as an individual species unique and able to defy any analytical categories proposed by those uninterested in preserving the unique status of crabs vis-à-vis other crustaceans or critters of similar ilk? Should we put "Mormonism" or "Christianity" in an the unique crab category and relegate all others to inferior crustaceans, crab-devils that emulate real crabs for demonic purposes? Or should we put all religions in the unique category? What about religions that look more like clubs, or those that look more like political systems, or those that look more like "selfhelp" ideologies? The critical analyst should understand the crab's rhetoric for what it is - a selfinterested plea designed to promote the unique status of the crab. In the end, any description of the crab is partial and perspectival.

167 McCutcheon, Manufacturing Religion: The Discourse on Sui Generis Religion and the Politics of Nostalgia, (Oxford: Oxford University Press, 1997), xi. 


\section{Meaning is Dynamic}

The approach here also assumes that irrespective of the dictionary definition of some words or the physical and material stability of ink on a page, the meaning of the words themselves is neither inherent nor stable. Words, "signifiers," symbols on a page (be they images, letters, words or pictographs) have no inherent meaning and must be invested with meaning by the reader. ${ }^{168}$ In keeping with the basic assumption above that reality is a social construction, meaning is a human construction that reflects the culture - and location within that culture — of the signifier. Words can only possess the meaning that is attributed to them, which will vary with time, location and reader. ${ }^{169}$ Textual meaning is rarely stable. Social formations will point to "scripture" as an external and unchallengeable justification for its perspectives and beliefs. There is a long tradition of human meaning-making which sources its interpretive practices on culturally significant texts - even if interpretations stray far from the superficial (and ostensibly literal) textual content. Examples of this meaning-creating exegetical tendency are found throughout history. ${ }^{170}$

\footnotetext{
168 "Neither language nor meaning is stable," J.Z Smith, Drudgery Divine, 18. "The meaning of meanings is not a firm foundation, but an oppressive illusion," Terry Eagleton, The Meaning of Life: A Very Short Introduction, (Oxford: Oxford University Press, 2007) 56-57, 58. See also Catherine Belsey, Poststructuralism: A Very Short Introduction (Oxford: Oxford University Press, 2002) 1-22.

169 "There is no such thing as presuppositionless thought," Terry Eagleton, What is Ideology, 3.

170 E.g. the Stoics used allegorization of Homer's works to provide support for their system of ethics. "The method by which [Jews] discovered Greek wisdom in the Old Testament was by the use of allegory. This art of interpretation had reached its zenith in Stoicism, where it was employed to read philosophical doctrines into the myths and poetry of ancient Greece." Rudolf Bultmann, Primitive Christianity: in its Contemporary Setting, Translated by the Reverend R. H. Fuller (New York: Meridian Books, 1956), 95.

Another example is the allegorization of the bible by Philo that exhibited the wisdom of Greek philosophy and sought to harmonize the bible with Plato. See Philo's On the Creation of the World for an excellent example. Speaking of Moses, Aristobulos writes "it seems to me that Pythagoras, Socrates, and Plato with great care follow him [Moses] in all respects. They copy him when they say they hear the voice of God" in Charlesworth, OTP, vol 2:840, frag. 4.3.
} 
As a comparative contemporary example, today's political discourse is full of refrains that reinscribed the sola scripture rhetoric of the Reformation. A broad range of political ideologies support their perspectives by pointing to the U.S. Constitution. People on all sides of the political realm (from the Tea Party to the ACLU) call forth the "original intention" of the Founding Fathers, and look to the U.S. Constitution as an inspired and inerrant document that contains all of the answers needed to address today's social and political ills. One must wonder what kind of "reading" or meaning-making methodologies were used by ancient East Asian readers of tea leaves or by the broad Mediterranean practice of reading the entrails of sacrificial victims or the appearance of birds in various quadrants of the sky, (the haruspices and auspices, respectively). Meaning will evolve as material and psychological conditions dictate. Evolving political, economic and social circumstances force alterations, often subtle, in human conceptions of reality. Neither texts nor "meaning" are ever stable and "no text is selfinterpreting." ${ }^{171}$ People interpret, understand and deploy texts in a manner that serves their present needs which implies perpetually evolving interpretations of the "classics," political documents, great philosophical works and holy writ.

I do not pretend that my reading of Smith and Paul is the only valid reading. Rather, my reading of Paul and Smith is one that is in keeping with the assumptions and methodological approach articulated here and reflects my interests and orientation. The

Aristobulos, a Jew with a Greek name endeavored to show, among other things, that the Greek poets thought in line with the Hebrews in recognizing the seventh day as holy. Aristobulos wrote that "both Homer and Hesiod, having taken information from our books, say clearly that the seventh day is holy," Charlesworth, OTP, vol 2:842 frag. 5.13. See also Bultmann, Primitive Christianity, 95-96.

"Spiritual readings" of biblical texts by Augustine were used to confirm what the catholic church taught, and many Christians today still read passages of the Hebrew bible as prophecies of Jesus (Christ). See W. C. Smith's discussion of the various readings, perspectives and uses of the biblical Song of Songs, What Is Scripture, 21-44.

${ }^{171}$ Calvin Roetzel, Paul: The Man and the Myth (Minneapolis: Fortress Press, 1999), 1. 
notion that I am discovering what Paul or Smith "really meant" when they wrote $x$ or $y$ does not serve my interests. Rather my intention is to develop a reading that is plausible, given the parameters I have established, the assumptions made and the methodology deployed. ${ }^{172}$ This dissertation is an excavation of the power relationships that are at the root of social organization and community building. Paul and Smith are but two examples of many who have performed in this arena.

\section{Texts and Power-The Mandate to Excavate}

but even if it were true, it should be passed over in silence . . yes, such stories are hard to deal with, and they shouldn't be told in our city

_Plato, Republic, 378a, b

The functionality of a text in a social setting need not even rely upon the textual content. For many early Mormons, the very fact that the Book of Mormon was produced by the leader of their enterprise signified that a prophet lived in their midst. While content—with its ever changing significations_-is not unimportant, what is of greater interest is how and why these texts were written and construed in the ways that they were.

The dynamics that allow texts or other cultural productions to claim and reinforce power for their producers and interpreters needs to be critically assessed. Authoritative claims of this nature become circular and mutually reinforcing. An author's status elevates the credibility of the text and the text's status promotes the authority of its author. It becomes difficult to differentiate with certainty between the authoritative chicken and the authoritative egg as the spiral of mutual authorization eventually

${ }^{172}$ Castelli, Imitating Paul, 121; McCutcheon, Critics Not Caretakers, ix-xx, 3-20. 
produces texts that become holy canon and authors who are revered as direct mediators between humankind and a divine realm.

The texts considered here are read for how they functioned and function, ${ }^{173}$ how they operated and operate in the development of power and community. They are read to understand how they both implicitly and explicitly set their authors apart with a special status—one that endorses and underwrites the legitimacy of the writers' now-texted claims and the status inherent therein. Read in this way, the same texts that provided the centering element of Paul and Joseph’s early communities and that continue to provide the theological basis and spiritual direction of Christians and Mormons, ${ }^{174}$ also amply document Paul and Joseph's quest for and acquisition of leadership power constructed on claims of divine authority.

Paul and Smith are not the only worthwhile examples. Many, many others could conceivably be introduced into the mix, specifically the host of contemporary leaders that have led revolutions, led their nations in times of crisis or spawned new religious movements over the past couple of centuries. ${ }^{175}$ They might range from Martin Luther King Jr. or Franklin Delano Roosevelt to the Ayatollah Ruhollah Khomeini of Iran,

\footnotetext{
${ }^{173}$ Elizabeth Castelli's Imitating Paul provides an excellent model for this type of approach and orientation, 18. The "work that we make scriptures do for us" is the oft repeated maxim of the Institute for Signifying Scriptures at Claremont Graduate University, (ISS), e.g. Wimbush, Theorizing Scripture, 13 and http://www.signifyingscriptures.org/index.php?option=com_content\&task=section\&id=1\&Itemid=2 accessed on May 6, 2009.

174 The usage here, "Christians and Mormons" is not to suggest that Mormons are not Christians, only that they are a Christian denomination that is distinguishable from the amalgam of mainstream Christian denominations as they have formed their own, tightly knit, idiosyncratic and insular, community.

175 The criteria of who belongs here is tricky and politically charged. Arguably many more modern charismatics have been considered evil rather than good. Examples of such would included The Reverend Jim Jones, Vladimir Lenin and Adolf Hitler. Abraham Lincoln and Winston Churchill might counterbalance this somewhat. Founders of NRM's are a highly politicized lot, referred to by many with the implicitly pejorative term "cult" leaders. As was the case with early Christianity, these groups and their leaders are routinely demonized by "mainstream" or "normative" society.
} 
David Koresh of the Branch Davidians, India's Ghandi, or Apollonius of Tyana of the first century Mediterranean. The choice to analyze these two is neither random nor unimportant. To begin with, both Mormonism and Christianity have been highly successful in terms of growth and longevity. Another is that Christianity is the dominant tradition within the Western world ${ }^{176}$ and hence within Western scholarship. Dominant traditions beg for critique—especially when they seek to dismiss the legitimacy of competing discourses such as in the case in current American presidential politics.

Projects that interrogate the sacred ways of the ancestors are generally not popular within those cultures. Bengt Homberg remarks on the obvious impact of a writer's location when he writes that "even scholarly studies in this field are often marked by the particular theological background of the scholar.” He continues that "every ecclesiastical tradition wishes to find its own church order confirmed by the New Testament.”177 The other side of this sentiment is that the strange, unfamiliar, unflattering or disconcerting will not receive much critical attention. McCutcheon cites a passage from Noam Chomsky which is relevant here-especially in light of the fact that both Smith and Paul document outside accusations of deceit in their writings (see chapter four and Table 4.1). Linguist and social critic, Noam Chomsky writes,

The system protects itself with indignation against a challenge to the right of deceit in the service of power, and the very idea of subjecting the ideological system to rational inquiry elicits incomprehension or outrage, though it is often masked in other terms. ${ }^{178}$

\footnotetext{
${ }^{176}$ Daniel Boyarin calls Christianity "the most powerful of hegemonic cultural systems in the history of the world." Daniel Boyarin, A Radical Jew, 9.

177 Bengt Holmberg, Paul and Power, 1.

${ }^{178}$ McCutcheon cites Noam Chomsky, Necessary Illusions: Thought Control in Democratic Societies (Concord, Ontario: Anansi Press, 1991), 9 in Manufacturing Religion, viii. Chomsky's observation accords well with the definition of "Scripturalization" provided by Kassam, 38, and as discussed above.
} 
The scenario depicting the treatment of Paul within the dominant tradition applies to the treatment of Joseph within Mormon circles, too. Just as with the traditions and writings of earliest Christianity in which the story the church has told about itself has come to be considered historical, so too the story of Mormon beginnings has been shaped by institutional interests and is treated with an uncritical reverence by most insiders. But as Mormonism is far from today’s dominant system, and as many in traditional Christian camps view Mormonism’s founder as a shamelessly transparent imposter, if not the modern incarnation of a dangerous heretic, some analysis on Smith’s work has been done-albeit frequently polemic or apologetic in nature. The critiques are often motivated by competing theological interests. The discourse which surrounds Smith is full of raw energy — devotional and antagonistic — much of which is less than productive. Unvarnished vitriol, while capable of provoking challenging questions, is generally of little benefit to an understanding of the varieties and patterns of the human construction of culture, the dynamics of successful social formation and the phenomena of scripturalization. 


\section{Personal Stake-Author's Location}

In more instances than not, the path through a maze of conflicting interpretations is paved with knowledge about the religious, emotional, or philosophical commitment of the historian

$$
\text { -Jan Shipps }{ }^{179}
$$

Theories about social behavior [are themselves] culture-bound

$$
\text { -Peter Burke }{ }^{180}
$$

There is a personal interest involved with comparing these particular two men which necessitates some disclosure regarding my background and location as they are not without relevance to this project. ${ }^{181}$ I am the product of Utah Mormon belief, practice, geography and culture. (I am also the son of an academic.) All but one of my greatgrandparents were born into "the Church" and at least two forebears joined Smith's movement in its first year, $1830 .{ }^{182}$ I have since relocated outside of the sacred canopy of LDS thought, belief and practice. My interests are neither to privilege nor belittle the

179 Jan Shipps, Sojourner in the Promised Land: Forty Years among the Mormons (Urbana, IL: University of Illinois Press, 2000), 55.

180 Peter Burke, History and Social Theory, Second Edition (Ithaca, NY: Cornell University Press, 2005), 46.

${ }^{181}$ Discourse analyst Ruth Wodak writes that scholars who engage in what she calls "critical discourse analysis" should attempt to make their own positions and interests explicit while retaining their respective scientific methodologies and while remaining self-reflective of their own research process." And moreover that,

researchers have to be aware that their own work is driven by social, economic and political motives like any other academic work and that they are not in any privileged position. Naming oneself 'critical' only implies specific ethical standards: an intention to make their position, research interests and values explicit and their criteria as transparent as possible, without feeling the need to apologize for the critical stance of their work.

Ruth Wodak and Michael Meyer, Methods of Critical Discourse Analysis, Second Edition (Los Angeles: SAGE Publishing, 2009), 3, 7.

182 Parley P. Pratt, an early 1830 convert and a member of the first council of The Twelve Apostles, is my great, great, great grandfather. The sixth of his twelve wives, Belinda Marden, gave birth to Isabella Eleanor Marden Pratt who married Franklin Alonzo Robison. In addition to MardenPratt, Robison married a pair of sisters. His three wives produced twenty-nine children, including the father of my maternal grandmother, Kathleen Robison Huntsman. In addition, James Huntsman is a patrilineal great, great, great, great grandfather who was converted by Sidney Rigdon in 1830 . 
roots of my heritage, rather to better understand the dynamics that foster and propel movements like the one that proved so enticing to my ancestors, and played the central socializing, world-building and meaning-making role in my childhood development. Moreover, I am fascinated by the very notion of a “constructed reality," its power, its malleability and its efficacy to unify a community of people. The LDS thought-world still governs the lives of many of my extended family and friends. It remains powerful in today's world, especially in the politics of my home state, Utah, and the "Book of Mormon-belt” that is the Mormon cultural region of the intermountain West.

I would like to characterize my own interest and motivation as a desire to understand human behavior, identity formation (tribalism) and the ideological narrative and ritual components that make for strong social bonds—especially as it relates to the venerable, but not beyond reproach, culture of my ancestors and youth. ${ }^{183}$ Strong social bonds based on ideological homogeneity are the crux of a tight knit community—which has as its obverse phenomenon the rejection and delegitimization of those who do not conform. This position as a quasi-insider brings additional sympathy and criticality to the study, inclinations which will be managed conscientiously and self-reflexively.

My rearing within a devoutly Mormon family and community and my subsequent departure has provided a tremendous influence in shaping the way I view the world. Other social formations of which I have been a part—and of which I have been a conscious, irrepressible internal analyst and critic—include a college fraternity, and

${ }^{183}$ JZ Smith reminds us that questions we as scholars ask are our questions. 
men’s rugby clubs in Salt Lake City, Boulder, Colorado; New York City, Philadelphia

and Sydney, Australia. ${ }^{184}$

As a member or observer of these diverse communities, I have found patterns, behaviors and other commonalities that simply seem to be intrinsic parts of human behavior and social formation. All of these extra-curricular and communal activities have been measured against experiences in the professional world of finance in New York City, Los Angels, Seattle and an MBA program at the University of Pennsylvania’s Wharton School of Business in Philadelphia. These perspectives provide real insights

184 The social dynamics within the fraternity were instructive. Pledgeship, initiation and full membership within a group with a clear identity and established boundaries has plenty of analogues in other types of social formation. The rugby subculture is strong and supportive, at times providing jobs, housing and a complete social infrastructure for its members and even for complete strangers interested in the game. The rules of engagement off the field are less explicit than those on, but an unspoken code of general behavior exists. The colors one wears on game day clearly identify one's tribal affiliation.

I've also been a participant and informal social critic of musical communities which have distinctive subcultures of their own, including the Grateful Dead and the band Phish. Beyond a common bond of music, fans of these bands tend to espouse similar politics and embrace similar styles of dress and behavior, especially when gathering with other fans for a performance-which in many cases is much like a pilgrimage. Hearing someone criticize the performance of (Grateful Dead lead singer and guitarist) Jerry Garcia (no matter how justly deserved) in a social setting after a performance is about as likely as hearing someone criticize Ronald Reagan at a gathering of conservative Republicans or hearing someone reject Jesus at an evangelical gathering. Such criticism of Garcia would never be verbalized, even if merited.

Most recently, I've twice made a pilgrimage to an event (part arts festival, part rave, part camping trip) called Burningman held in the Black Rock desert nearly 100 miles north of Reno, Nevada. A study of the spontaneous community that emerges in the Black Rock desert is worthy of its own monograph. The gathering numbers between forty and fifty thousand people, mostly "alternative" types, most of whom seem to enjoy flouting the rules of conventional living while at the same time closely abiding by the rules of the Burningman event [See the Survival Guide which is presented as "mandatory reading" for all participants, http://www.burningman.com/preparation/event_survival/ accessed Jan 29, 2011]. These rulesseventeen pages of idealistic text-demand such things as leaving no human trace in the salt desert and forbid the purchase or sale of any good or service. Radical self sufficiency, "gifting" and open friendliness is an expected part of the ethos. "Radical inclusivity" and a responsibility to participate in and contribute to the week-long spectacle are expected of participants. The rules of behavior for Burningman were penned by anonymous individuals but hold the force of institutional and communal sanction. Burningman participants can be seen going out of their way to appear to be obeying these rules [Compare, "Beware of practicing your piety before others in order to be seen by them ... And whenever you pray, do not be like the hypocrites; for they love to stand and pray in the synagogues and at the street corners, so that they may be seen by others" Matt 6.1,5]. 
into human social behavior and in turn influence my work. To borrow some phrasing from New Testament scholar, Vernon Robbins; critical, historical and social-theoretical analysis “is my answer to what I must do to perform biblical interpretation in a manner that embodies who I am.”185

185 Vernon Robbins, The Tapestry of Christian Discourse: Rhetoric, Society and Ideology (London: Routledge, 1996), 26. 


\title{
CHAPTER TWO
}

\section{CULTURE AND CHARISMATIC}

\section{CHARACTER ATTRIBUTES AND SOCIO-CULTURAL LOCATION}

\author{
This chapter uses psychologist Len Oakes' analysis ${ }^{1}$ of prophetic charisma ${ }^{2}$
}

as a point of departure from which to excavate the character development of the

\begin{abstract}
${ }^{1}$ Len Oakes, Prophetic Charisma: The Psychology of Revolutionary Religious Personalities (Syracuse, NY: Syracuse University Press, 1997).

${ }^{2}$ Despite the wide use of the term "charisma," many who endeavor to employ it conceptually in their research are frustrated with the paucity of specific research conducted that is directly related to their own field. Sociologist S. N. Eisenstadt, in introducing a volume of Max Weber's papers that specifically addressed the topic of charisma and institution building, laments "[w]e know as yet very little either about conditions of development of such entrepreneurial, charismatic people, of their psychological and behavioral attributes, and about the conditions under which they may be capable of implementing their vision.” S. N. Eisenstadt, Max Weber, On Charisma and Institution Building: Selected Papers, Edited and with an Introduction by S. N. Eisenstadt (Chicago and London: University of Chicago Press, 1968), xl.
\end{abstract}

Along these lines, historian Lawrence Foster writes that, "[d]espite the interest that the phenomenon of charisma has generated over the years, surprisingly few serious efforts have been made to reconstruct and analyze systematically the psychological dynamics and social interactions of charismatic individuals. Lawrence Foster, "The Psychology of Prophetic Charisma: New Approaches to Understanding Joseph Smith and the Development of Charismatic Leadership," Dialogue, A Journal of Mormon Thought, Vol. 36, No. 4/Winter 2003, 1-14, 2 (italics added).

Similarly, sociologist and scholar of new religious movements, Lorne Dawson, writes that "[s]ystematic and comparative investigation of how authority is achieved, exercised, developed, sustained, or lost in millennial groups is still in its infancy. The lacunae is strange, given the tremendous emphasis on the study of leadership in the worlds of business, politics and social activism, and the near universal association of new religions, especially apocalyptic ones, with strong forms of charismatic authority," Lorne Dawson, "Charismatic Leadership in Millennial Movements: Its Nature, Origins and Development" [forthcoming in Cathy Wessinger, ed., The Oxford Handbook of Millennialism (New York: Oxford University Press), 2]. Advance article kindly provided by Professor Dawson. Also of note in this passage is the way Dawson relates the terms "leadership," "authority" and "charisma."

Given that Weber himself based a number of his notions of charisma on the material contained in the bible-including the prophets of the "Old" Testament (sociologist Peter Berger has written on how Weber's notion of biblical prophets - which itself was based on the biblical scholarship of Weber's time would be modified based on more recent biblical scholarship, that of Berger's time. See Peter L. Berger, "Charisma and Religious Innovation: The Social Location of Israelite Prophecy," American Sociological Review, Vol. 28, No. 6 (Dec., 1963) 940-950.) and Jesus of the "New"-one would think that studies of charisma and charismatic leadership would be much more prevalent. Joseph Bansman and Michael Givant write that as a result of Weber's analysis being based on how biblical literature represented Jesus and the Israelite prophets that preceeded him, the literary tropes of antiquity have become a reified theory of Weber's world. Joseph Bansman and Michael Givant, "Charisma and Modernity: The Use and Abuse of a Concept,” in Ronald M. Glassman and William H. Swatos, Jr., Charisma, History and Social Structure, Contributions in Sociology, Number 58 (New York: Greenwood Press, 1986) 28.

In sum, many sociologists, psychologists and historians lament the lack of good research on charisma 
messengers and the cultural environment from which they and their messages

emerged. ${ }^{3}$ The intention is not to diagnose either Paul or Smith with some type of

behavioral pathology, nor is it to "prove" that either definitively does or does not fit

Oakes' criteria of prophetic charisma (although both do fit rather nicely in many

respects). Instead, the purpose is to illuminate and compare the conditions that

impacted character development, provided personal motivation and provisioned

social opportunities for these men as developing prophets.

Oakes provides a descriptive psychological ${ }^{4}$ framework that identifies and

describes a range of personality attributes associated with charismatics. ${ }^{5}$ These

as it relates to new social formations or new religious movements. And yet, modern research on charisma does exist. It merely has yet to be integrated into other academic disciplines.

${ }^{3}$ Neither Paul nor Smith emerged from a cultural vacuum, neither individual nor their respective system was entirely revolutionary, unique or sui generis. See Russell McCutcheon, Critics NOT Caretakers and Manufacturing Religion, for a critique of the persistent notion that the rise of Christianity (and here by implication, Mormonism too) was an event unlike any other in the history of human kind, unique, born of themselves without any influence from the outside world.

${ }^{4}$ Stark and Finke argue that "many of the most interesting and pressing questions facing the social scientific study of religion require that religion be conceived of as social rather than as psychological, as a property of groups or even whole societies,” Acts of Faith, 35. Oakes’ psychological framework allows a segue into the social components of power relationships.

${ }^{5}$ As one might expect from a psychologist, Oakes goes beyond the term charisma to suggest the clinical condition for the people he studies: narcissism. However accurately or inaccurately narcissism might describe this category of individuals within the realm of psychology, neither the diagnosis nor the term will be used in this broader, transdisciplinary project. There is little to be gained in labeling Smith and Paul with a psychological condition that is rarely, if ever, used without suggesting or implying a rather unsavory personality disorder. Psychiatrist Robert D. Anderson, whose book Inside the Mind of Joseph Smith: Psychobiography and the Book of Mormon (Salt Lake City, UT: Signature Books, 1999) provides a perfect example of an analysis conducted under such a loaded, taxonomically problematic category. In this book, Anderson endeavors to "examine Joseph Smith as a narcissistic personality” xxxviii. When Anderson writes that "most have viewed the narcissistic personality as the severest form of character pathology that may not have a significant genetic component and is potentially treatable," it is hard to disentangle the diagnosis from the moralizing, xlv n.57. Analyzing the traits and skills exhibited by these two does not require attributing moral judgment. Narcissism, whether used clinically or colloquially, has too much negative baggage and too little explanatory value to be deployed here usefully. As always, taxonomy is not a neutral enterprise. Jan Shipps, a sympathetic historian, describes Joseph in terms that exactly fit one of Oakes' criteria for narcissism without attributing a diagnosis. She writes, "His subjective recognition of separateness may well account for the apparently compulsive need for acceptance," "The Prophet Puzzle,” Journal of Mormon History, vol 1, 1974, 3-20, 11. 
personality traits are generally positive and conducive to successful leadership. ${ }^{6}$

Examples applicable to Smith and Paul are provided. The second frame of reference uses one of Oakes' five "life stages" that chronicle a "natural history" of the charismatic's development, specifically the "incubation" stage (see Table 2.1 below). ${ }^{7}$ Oakes' study is far from definitive, but its use here facilitates; 1 ) an analysis of the budding prophet's interaction with—and alienation from-his environment, and, 2) the practical skills developed that ultimately contributed to the ability to successfully lead. The latter component, the practical importance of developing career tools should be obvious. The former component presumes that certain individuals who experience or perceive alienation in their youth and developmental stages, will seek a social role in life that counters those early experiences. Scholar David Aberbach writes, “[b]y becoming a public being, the charismatic may find the resolution, the love and wholeness which were lost, attenuated or never had in private life."8

Analyzing and comparing the socio-cultural locations of each of these men contributes to Wimbush's call to examine the situations and settings that incubate scripturalizing phenomenon.

\footnotetext{
${ }^{6}$ Academic psychiatrist Nassir Ghaemi argues that "in times of crisis, we are better off being led by mentally ill leaders than by mentally normal ones.” Part of Ghaemi’s approach (in contrast to that of Anderson's as in the note above) is his reluctance to "pathologize" mental dispositions. One's mental status as “'[a]bnormal' is not necessarily a problem” just as “"normal' in not inherently a benefit,” A FirstRate Madness: Uncovering the Links Between Leadership and Mental Illness (New York: The Penguin Press, 2011), 2, 266.

${ }^{7}$ Oakes, 21, 42.

${ }^{8}$ David Aberbach, Charisma in Politics, Religion and the Media: Private Trauma, Public Ideals (New York: New York University Press, 1996), 10.
} 


\section{Charismatic Characteristics}

Oakes argues that charismatics are not simply "constructed" by their

followers. ${ }^{9}$ His assertion is based on extensive research and fieldwork that included

personally meeting and interviewing a number of charismatic sect leaders. Oakes

has observed that charismatics possess qualities or personality traits that often

prove compelling to those they meet. He writes,

[i]t simply beggars the imagination to suggest that men such as L. Ron Hubbard, Fritz Perls, Werner Erhard, Bhagwan Shree Rajneesh and Sun Myung Moon are not really, objectively, unusual people possessing exceptional abilities to inspire the kinds of mass followings they have achieved. 10

Despite the "stunning variety of forms," Oakes lists specific traits that he believes exemplifies the "basic behaviors of the leaders."11 He begins with a recognition of the extraordinary energy ${ }^{12}$ most prophets exhibit. Oakes posits that this energy is connected to and feeds their enormous self-confidence which he asserts is "legendary." Consequently, in many situations this self-confidence appears as a type of fearlessness if not grandiosity, the combination of which "makes everything they say seem authoritative." 13 Rodney Stark writes that "the universal

\footnotetext{
${ }^{9}$ Len Oakes Prophetic Charisma where he cites the study by W. D. Wallis, Messiahs: Their Role in Civilisation (Washington D.C.: American Council on Public Affairs, 1943).

${ }^{10}$ He further qualifies this statement in that "all behaviors occur in a social context, and this needs to be considered when attempting to explain conduct,” Len Oakes, Prophetic Charisma, 2.

${ }^{11}$ Oakes, 12.

${ }^{12}$ Oakes, 13. The terms italicized in this section are those which Oakes italicized in the original.

${ }^{13}$ Oakes, 12-3. Compare this observation against research from the legal realm, i.e. the effects of witness confidence as researched by Tenney, et al. cited in the discussion below. There is a downside to over confidence which Oakes describes as "delusions of omnipotence and refusal to compromise or hear criticisms" in addition to the appearance of being dogmatic, "an inability to admit error, to apologize, or to recognize the hurtful effects their behaviors have on others." Dawson too writes of the characteristic energy found in charismatics who "exude self-confidence and determination," "Charismatic Leadership," 6. Historian Richard Bushman cites his inspired translation of the Bible as "a striking demonstration of his outrageous confidence,” Richard L. Bushman, Joseph Smith: Rough Stone Rolling, A cultural biography of
} 
problem of religion is one of confidence" as "people contemplating religious

commitments will seek assurance."14 Self-assured charismatics are adept at

providing just this type of confidence. The characteristics and behaviors that

generate the appearance of authority in the analysis of Oakes complement Lincoln's

theoretical analysis of the discursive strategies deployed in the construction of an

authoritative discourse.

Table 2.1

Summary Overview of Oakes' Analytical Framework

\begin{tabular}{|c|c|c|}
\hline $\begin{array}{c}\text { Specific Personality Traits of } \\
\text { Charismatics }\end{array}$ & $\begin{array}{l}\text { "Life Stages" of } \\
\text { Charismatic }\end{array}$ & $\begin{array}{l}\text { Components of } \\
\text { “incubation" stage }\end{array}$ \\
\hline $\begin{array}{l}\text { 1. extraordinary energy ("not beset } \\
\text { by the fears, shame and guilt that limits } \\
\text { others") } \\
\text { 2. self-confidence15 } \\
\text { 3. revolutionary vision } \\
\text { 4. inspirational rhetoric } \\
\text { 5. manipulativeness/ability to } \\
\text { influence others } 16 \\
\text { (prophets are natural actors) } \\
\text { 6. aloof (disciplined, self contained) } \\
\text { 7. strength (endurance, strong will) } \\
\text { 8. congruence (personify their truths) } \\
\text { a. tendency to reflect other people's } \\
\quad \text { behaviors back to them } \\
\text { b. a personal style that others find } \\
\text { nourishing } \\
\text { 9. social insight (ability to read the } \\
\text { audience, to say precisely those things } \\
\text { which strike a chord)("all things to all } \\
\text { people") } \\
\text { 10. detached availability (inner calm) } \\
\text { 11. acceptance of others } \\
\text { 12. unrefined quality (classless, earthy, } \\
\text { ordinary, plain speaking) } \\
\text { In Sum: profound sense of utter } \\
\text { otherness of the prophet }\end{array}$ & $\begin{array}{l}\text { 1. } \\
\text { 2. Incurly narcissism } \\
\text { 3. } \\
\text { 4. } \text { Awakening } \\
\text { followers, the leader } \\
\text { advances a bold claim } \\
\text { to be the source of } \\
\text { ultimate good for } \\
\text { others) } \\
\text { 5. Decline or fall } \\
\\
\text { a natural history of } \\
\text { prophetic development }\end{array}$ & $\begin{array}{ll}\text { a. } & \begin{array}{l}\text { Sense of not } \\
\text { belonging to any } \\
\text { group }\end{array} \\
\text { b. } & \begin{array}{l}\text { Construction of a } \\
\text { personal "myth of }\end{array} \\
\text { calling" } \\
\text { c. }\end{array}$ \\
\hline
\end{tabular}

Mormonism's founder (New York: Alfred A. Knopf, 2006), 132.

${ }^{14}$ Stark and Finke, Acts of Faith, 106-7.

15 "I had full confidence in obtaining a divine manifestation, as I previously had one.” Writings of Joseph Smith, 2.29. Smith's expression of confidence in itself exudes confidence.

${ }^{16}$ The latter half of this component is my attempt to take the sinister connotations down half a notch 
The next trait listed by Oakes is that of a revolutionary vision which Oakes claims is "opposed to convention and is focused on ultimate concerns and the reordering of the world." 18 I would like to nuance the preceding sentence by noting that the "opposition to convention" is relevant only on an important surface level that is strong enough to forge some level of tension ${ }^{19}$ against the outside world. If Paul and Smith oppose some components of "convention," they at the same time retain many of the larger assumptions and practices of society at large. For their movements to appeal broadly, they must allow new members the ability to preserve some degree of their existing social and religious capital. ${ }^{20}$ The new worlds they create are riffs off, or reforms of, existing culture and entrenched notions. Both Paul and Smith harnessed the culture in which they dwelt and presented a revision of the status quo that was by no means in complete opposition to the status quo. One can never completely remove oneself from the culture from which one has emerged. Perhaps more importantly, reform movements that make use of a society's cultural and religious capital—even if radically repackaged—are more likely to find success.

from Oakes' "manipulativeness." Ronald Riggio, whose work is overviewed below, writes that "socially skilled persons have an aptitude for influencing others, The Charisma Quotient: What It Is, How To Get It, How To Use It (New York: Dodd, Mead \& Company, 1987), 51.

${ }^{17}$ Certainly further developing one’s skill sets continues through the "awakening” and "mission" stages of the charismatic's life.

${ }^{18}$ Oakes, 13 (emphasis in original).

${ }^{19}$ Stark and Finke write that "tension refers to the degree of distinctiveness, separation, and antagonism between a religious group and the 'outside' world," Acts of Faith, 143.

${ }^{20}$ Stark and Finke write that as "people attempt to maximize gain" they will make religious choices that "will attempt to conserve their social capital," Acts of Faith, 118-119, and that "when people reaffiliate, they will tend to select an option that maximizes their conservation of religious capital." The same "proposition" regarding conserving religious capital is made for those who "convert," 121-123. Social capital "consists of interpersonal attachments" while "religious capital consists of the degree of mastery of and attachment to a particular religious culture," 280-281. 
Inspirational rhetoric, the next trait listed, includes a sense of "moral absoluteness" effective only if espoused with unblinking self confidence. This tactic in turn can be used to "amplify a sense of crisis." 21 Given the characters under examination here, one immediately thinks of the notion of the imminent "day of the Lord" and the last days of humanity in this dispensation as an impending crisis. Paul writes to the Thessalonians that "you yourselves know very well that the day of the Lord will come like a thief in the night ... then sudden destruction will come upon them, as labor pains come upon a pregnant woman, and there will be no escape!" (1 Thess 5.2-3). The importance of the notion of last days is implicit in the official name of Smith's church, the Church of Jesus Christ of Latter-day Saints. ${ }^{22}$ End time rhetoric is in itself a recurrent theme in human existence and at times a powerful, galvanizing social strategy. ${ }^{23}$

\footnotetext{
${ }^{21}$ Oakes, 14.

22 Emphasis added. The theme of the last days before impending doom also features prominently in the first revelation of Smith's Book of Commandments, dated April 6, 1830. It reads in part,

Hearken, O ye people of my church, saith the voice of Him who dwells on high . . . . there is none to escape ... . wherefore fear and tremble, O ye people for what I the Lord have decreed, in them, shall be fulfilled .... the day of the Lord shall come recompense unto every man according to his work . . . . wherefore I the Lord, knowing the calamity which should come upon the inhabitants of the earth, called upon my servant Joseph, and spake unto him from heaven, and gave him commandments . . . . Behold I am God and have spoken it: these commandments are of me. . . . the day speedily cometh, the hour is not yet, but is nigh at hand, BoC I.

This passage was written before the Church changed its name to "Church of Latter Day Saints” in 1834 and then to its current moniker, The Church of Jesus Christ of Latter-day Saints in 1838. The inclusion of "last days" reflects a broader movement in America. The year of the final name change preceded the "Great Disappointment[s]" experienced by the Millerites by five and six years. See Ronald L. Numbers and Jonathan M. Butler, eds., The Disappointed: Millerism and Millenarianism in the Nineteenth Century (Knoxville, TN: The University of Tennessee Press, 1993). Many other "last days" revelations exist in the modern Doctrine and Covenants, e.g. 33, 34, 39, 42, 45, 63.58.

${ }^{23}$ Oakes writes, "Groups facing threat may generate powerful levels of cohesion that were totally lacking before," 130. On the other hand, Aberbach argues that some "leaders . . created crisis in a struggle to master and resolve [their own] inner disabilities projected onto the public sphere," Charisma in Politics, Religion and the Media, xii. Citing Robespierre, Lincoln, Roosevelt and Churchill, he argues "that they have all been schooled in parallel, perhaps harder, crises in their inner lives and are, therefore, wellqualified, as it were, to deal with social, political or military crisis,” xii.
} 
Oakes also discusses the great physical and emotional strength of prophetic charismatics, their endurance and strong will which he believes is related to their need to continually keep up appearances. Sometimes, however, keeping up appearances will cause prophets to hold themselves somewhat "aloof" from others. Oakes has some personal insight into this phenomenon. Even after spending the better part of sixteen years in a charismatic community he felt that he never truly got to know the real thoughts of the community's leader any better than he did after first joining. The leader, he writes, "remained inexplicable to me."24 Oakes adds, disciplined and self-controlled, they [prophets] manage in even the most intimate encounters to signify something greater than what they are. The prophet always holds himself slightly apart from others, revealing little of his true feelings and seeming to be something of a mystery even to his long-term followers. ${ }^{25}$

The observed traits of personal mystery and aloofness might correspond to Paul's nearly perpetual physical absence from the communities that he fostered. To his congregation in Corinth he acknowledges that despite his "weighty" letters his bodily presence is weak, and his speech contemptible" (2 Cor 10.10)—hence the medium of letter writing for communication.

One historical and comparative study of longings for the paradise associated with the End of Time is John Ashton and Tom Whyte, The Quest for Paradise: Visions of Heaven and Eternity in the World's Myths and Religions (San Francisco: HarperSanFrancisco, 2001). Robert H. Abzug explores the various attempts in American society to lend "sacred significance to the issues of political and social life" in Cosmos Crumbling: American Reform and the Religious Imagination (New York: Oxford University Press, 1994); See also the first chapters of Grant Underwood, The Millenarian World of Early Mormonism (Urbana, IL: University of Illinois Press, 1999); Norman Cohn explores this theme through various cultures in ancient history in, Cosmos, Chaos and the World to Come (New Haven: Yale University Press, 1995) (paperback, 1999).

${ }^{24}$ Oakes, 4. "Prophets are self-contained and autonomous,” “aloof,” 16 (emphasis original).

${ }^{25}$ Oakes, 16. 
For his part, Smith acknowledged the ostensibly mysterious components of his background and true persona in some now infamous lines delivered at a funeral shortly before his death. In the April 7, 1844 funeral sermon he said,

You don't know me; you never knew my heart. No man knows my history. I cannot tell it; I shall never undertake it. I don't blame anyone for not believing my history. If I had not experienced what I have, I could not have believed it myself. ${ }^{26}$

Smith's biographer Fawn Brodie continues that

There are few men, however, who have written so much and told so little about themselves. To search in his six-volume autobiography for the inner springs of his character is to come away baffled. ${ }^{27}$

Of charismatics, Aberbach writes,

The charismatic is a public being, an open book, about whom much is known. At the same time, the inner world, the past, the motives, drives and hopes of the charismatic are mostly hidden. What is revealed is often extremely limited and distorted. Charisma involves a virtual state of amnesia towards the past, or suppression of the past. It is the charismatic's gift to make large numbers of people forget the past, forget themselves temporarily and live vividly in the spell of the present. The fact that the charismatic appears to slough off his past and private life and creates a new, public identity is a serious handicap as well as a source of fascination to biographers. ${ }^{28}$

Oakes writes that the sum of the character traits listed above leads to "a profound sense of the utter otherness of the prophet" and suggests that the

\footnotetext{
${ }^{26}$ As in Fawn M. Brodie, No Man Knows My History: The Life of Joseph Smith the Mormon Prophet, Second Edition, Revised and Enlarged (New York: Vintage Books, 1945) (1995), vii. Of interest is Smith's explicit connection between "experience" and "belief." The relationship between the two is a fundamental component of Smith’s (and Paul's) epistemic regime. Belief is supported by an interpretation of one's emotional experiences. Perhaps the most provocative line of the entire passage is Smith's statement that "you never knew my heart." It suggests, at least to this reader, that some part of Smith is trying to come clean. By this point in his life he is submerged far too deeply in his constructed reality to admit to any of the deceptive practices that facilitated his powerful status.

${ }^{27}$ Brodie, No Man Knows My History, vii. Quinn cites Joseph as boasting “I can keep a secret until Doomsday," Magic World View, 93.

${ }^{28}$ Aberbach, Charisma in Politics, Religion and the Media, 7. Aberbach continues, “[t]he biography of a great man is rarely, if ever, the revelation of the man as he was. It arises from a fascination with a largely fictional public image which he created and a consequent desire to find the 'real' man and his motives, despite the lack of conclusive documentation,” 7-8.
} 
aggregate of these personality traits could be perceived as a sort of magic. As Oakes limits himself to naturalistic explanations, this "magical quality" he defines as "charisma."29

According to Oakes, the powerful rhetoric and propaganda that support the prophet's vision in effect keep the prophet "on stage" all of the time. ${ }^{30}$ Charismatics tend to be "natural actors." 31 They possess rhetorical skills that facilitate their ability to influence actions and beliefs. ${ }^{32}$ Oakes includes the ability to register the needs and vulnerabilities of others ${ }^{33}$ as a component of what he calls social insight. ${ }^{34}$ By social insight, Oakes means the "ability of charismatic figures to read their audience, to say precisely those things which strike a chord, and to see into the hearts of others."35 The notion of social insight discussed by Oakes combined with what he calls "detached availability" transitions his work nicely into the concept of "social intelligence" found in another helpful study on charisma produced by Ronald Riggio.

${ }^{29}$ Oakes, 20, emphasis in original.

${ }^{30}$ Oakes, 14. Perhaps this sense of constantly being expected to perform is what led Smith to prophesy the location of the Garden of Eden in America, translate the Kinderhook plates, and his dubious discourse on Zelph, the "white Lamanite."

${ }^{31}$ Oakes 15. Aberbach writes, "[a]ll great charismatics are gifted entertainers. They have the power to uplift and inspire. [But f]or them ... 'entertainment' is no casual pastime. It is a vital means of a spiritual and physical survival, an expression of the will to live at a time when destruction or self-destruction may be imminent," Charisma in Politics, Religion and the Media, xii.

${ }^{32}$ Oakes' use of the term "manipulativeness" indicates little appreciation of the benefits followers enjoy from participating in the new community.

${ }^{33}$ Oakes, 14-5, 18.

${ }^{34}$ Oakes, 18.

${ }^{35}$ Oakes, 18. This perspective expressed by Oakes is broader than, and inclusive of, Lincoln's notion of sentiment evocation, see Discourse and the Construction of Society, 8-11, 20, 22-26, 172-174. Ronald Riggio writes that "charisma, by its very nature, involves an ability to arouse emotions in the hearts of others, The Charisma Quotient, 17. 


\section{Social Intelligence and Emotional Skills}

Organizational Psychologist Ronald E. Riggio, writes about a type of "social intelligence" that underpins communication and successful social interaction. ${ }^{36}$ Riggio understands charisma as "a composite of well-developed, basic social skillsa type of advanced social intelligence." 37 Riggio breaks down categories of human interaction in ways that can be described and even (imperfectly) measured. His basic categories explore and attempt to measure an individual's social skill set with respect to the subcategories of; 1) expressivity, 2) sensitivity and 3) control. Another category of emotional skills explores and makes use of the same three subcategories: expressivity, sensitivity and control. The primary difference between the social and the emotional categories is that the former is expressed verbally while the latter is primarily non-verbal. The sub-category of expressivity attempts to describe an individual's ability to express her emotions in ways that can be easily perceived by others whereas the category of sensitivity attempts to measure how sensitive one is to others' expression of emotions. Control refers to the ability to exude or withhold one's own emotions as is appropriate for the social circumstance, or personal interests, at hand. Said another way, control refers to the extent one is able to manage the "outward display of inner emotions." ${ }^{38}$ For Riggio, nonverbal communication, the role of body language, gesticulations and expressions, are critical as they are the primary means of communicating, or withholding, emotions

\footnotetext{
${ }^{36}$ Riggio, Charisma Quotient, 6.

${ }^{37}$ Riggio, Charisma Quotient, 49.

${ }^{38}$ Riggio, Charisma Quotient, 28.
} 
or emotional cues. ${ }^{39}$ Successful charismatics are adept at both verbal communication and the type of non-verbal communication that is generally perceived as communicating how one truly feels. ${ }^{40}$ In Riggio's schema, the ability to control one's own emotions ${ }^{41}$ as well as the ability to read and determine the emotions of others are not ancillary components of the successful charismatic's quiver, they are essential.

Scholar of religious studies and comparative anthropology, Thomas Overholt, illuminates Riggio's observation of the charismatic's "ability to read and determine the emotions of others," in his study of the social dynamics of prophetic activity. He writes, "at the level of what is said, one mark of prophetic authority is the ability to clarify and articulate what audience members themselves have begun to feel about their particular situation." 42 Such an ability requires the skill set proposed by Riggio, the social and emotional sensitivity to grasp the sentiments of his followers and at the same time the social and emotional expressivity to articulate these concerns.

\footnotetext{
${ }^{39}$ Riggio, Charisma Quotient, 12-15, “The truly charismatic individual is also a master of non-verbal communication,” 13.

${ }^{40}$ Riggio, 12. Dawson corroborates these notions when he writes of the charismatics' "seeming sensitivity to the needs of others," their "ability to make connections with those they meet" and their ability to prompt "people to feel more of a direct affinity with them," "Charismatic Leadership," 6.

${ }^{41}$ Emotional control has had other applications as well. James W. Cook writes of mid-nineteenth century confidence men: "what made confidence criminals particularly unsettling was their ability to defy visual interpretation, to maintain an impenetrable façade which gave no clue about the actual person or criminal agenda behind the misleading appearances," The Arts of Deception: Playing with Fraud in the Age of Barnum (Cambridge, MA: Harvard University Press, 2001), 201.

${ }^{42}$ Thomas W. Overholt, Channels of Prophecy: The Social Dynamics of Prophetic Activity (Eugene, OR: Wipf and Stock Publishers, 2003), 71.
} 
In his study of the role and function of the seer in ancient Greece, and adjusting for differing social constructions of reality, classicist and ancient historian Michael Flower expresses this sentiment when he writes,

it was the seer who acted as the critical bridge between the limited and partial knowledge of mortals and the superior knowledge of the gods. Regardless of what type of divination was being enacted, it was up to the seer to recognize and to decode, and in some cases to transmit, the signs and messages that the gods were willing to vouchsafe to mortals. ${ }^{43}$

The charismatic senses what will resonate with his audience and responds to them in a manner that addresses their needs.

Sometimes seekers do not know exactly what it is they are seeking. They put their trust in one who appeals to them on a visceral level, or whose "values appear to coincide with their own." One of Oakes' interviewees flatly stated that "I needed him to tell me what it was I was seeking," 44 in which case the subscriber seeks a compelling narrator. The follower seeks to be led.

The seeker's "need" illustrates the "demand" side of the charismatic relationship. Both Stark and Overholt acknowledge that followers "choose their prophets," which is to say that "they attribute authority to them" based on the range of rhetoric and actions that epitomize the cultural expectations of what a prophet should be. ${ }^{45}$ But as prophets claim supernatural sanction and engage in the actions expected of a prophet, followers might more accurately be said to "confirm" the

\footnotetext{
${ }^{43}$ Michael Attyah Flower, The Seer in Ancient Greece (Berkeley, CA: University of California Press, 2009), 240.

${ }^{44}$ Oakes, 128.

${ }^{45}$ Stark and Finke, Acts of Faith, 85. 165-66; Overholt, Social Dynamics of Prophetic Activity, 71.
} 
prophet in his role. ${ }^{46}$ Paul acknowledges the role of communal expectations and communal approval when he writes,

Am I not an apostle? Have I not seen Jesus our Lord? Are you not my work in the Lord? If I am not an apostle to others, at least I am to you; for you are the seal of my apostleship in the Lord (1 Cor 9.1-2).

Paul's acknowledgement that he "is not an apostle to others" highlights his cognizance of the role of his own followers in determining his status. The nature of the relationship must be mutually recognized and beneficial. Oakes observes that the leader and the follower rely on each other to meet their respective needs. He writes that a "relationship of symbiosis or codependence, perhaps even of mutual exploitation, is set up." 47 As with Stark's discussion of exchange benefits in which both sides of the relationship gain, ${ }^{48}$ Oakes argues that "there is a far greater degree of reciprocity and mutuality involved in the leader-follower relationship than is commonly thought." 49

A prophet's social skills are also recognizable to those outside of the community of followers. Even the harshest of Smith's early critics could recognize his "natural genius, strong inventive powers of mind, a deep study, and an unusually correct estimate of the human passions and feelings" 50 which reinscribes Riggio's categories of social and emotional sensitivity. Smith himself realized the importance of social and emotional sensitivity and control, and was cognizant (in

\footnotetext{
${ }^{46}$ Overholt, Social Dynamics of Prophetic Activity, 72.

${ }^{47}$ Oakes, 129.

${ }^{48}$ Stark and Finke, Acts of Faith, 38.

${ }^{49}$ Oakes, 129.

${ }^{50}$ Eber D. Howe, Mormonism Unvailed (Painesville, OH: printed by the author, 1834), 12-13 (emphasis added).
} 
hindsight) that he was not always accurate with his early estimations. As an example-and within the context of losing the first 116 pages of BoM manuscript because he had allowed Martin Harris to show it to others-he implicitly acknowledged the importance of being able to judge the sentiments of others. In a somewhat self-reflective chastisement of himself recorded in the $B o C$, Smith wrote that he should not show his sacred work until it is complete and he has firmed up his publication and distribution plans. The reason Smith puts into the mouth of God for not showing his work is,

Behold I do not say that you shall not show it unto the righteous; but as you cannot always judge the righteous, or as you cannot always tell the wicked from the righteous: therefore, I say unto you, hold your peace until I shall see fit to make all things known unto the world concerning the matter $(B o C$ IX.8, emphasis added.)

Smith realizes the importance of "social sensitivity," specifically the ability to "judge the righteous" - which is code for assessing those more or less likely to accept his claims, propositions and message. Smith's disclosure regarding the import of this interpersonal and social skill is fascinating and illuminating. He gets better and better with his estimation of others as time goes on. ${ }^{51}$

Howe was not alone in recognizing these skills. A less-interested, first-hand source, John Reed - the attorney who defended Smith at his July 2, 1830 hearing in Colesville, Broome County, New York-some thirty years later, recollected Joseph's ability to control his expressions and emotions. Reed was struck by Joseph's calm self-possession in the face of the judicial machinery. He wrote that during the trial

\footnotetext{
${ }^{51}$ See Overholt's 'Model of the Prophetic Process,' in Social Dynamics of Prophetic Activity, 21-25, especially $24-25$.
} 
"that boy Joseph sat there apparently as unconcerned as if he was in his father's house."52 Reed's observation suggests that Smith was able to emanate self confidence while concealing anxiety as the situation required. In Riggio's schema, these physical behaviors would exemplify the concepts of emotional expressivity and emotional control. Reed's comments are not based on anything Joseph said, but on the non-verbal components of his physical conduct. His bodily comportment concealed fear and exuded calm self-assurance.

Riggio writes that effective non-verbal communication of emotions could include "dominance (to show and to know who is in charge), feelings of selfconfidence ${ }^{53}$ or anxiety, and liking for others." ${ }^{54}$ Certainly self-confidence and a masking of any anxiety are corroborated in Joseph's comportment in the courtroom example above. Riggio has documented that expressivity is critical to influencing others, and moreover; that expressive individuals are better able to persuade than are less expressive people even if the latter, less expressive group are "experts" who posses more or better information in the relevant field of knowledge. Riggio's analysis of these expressive dynamics implies that the delivery of a message influences its ability to persuade or compel more so than does the content itself. 55

\footnotetext{
${ }^{52}$ As recorded in a 6 Dec. 1861 letter from Reed to Brigham Young, Dan Vogel, Joseph Smith: The Making of a Prophet (Salt Lake City: Signature Books, 2004), 516; and Dan Vogel, Early Mormon Documents, Volume 1, compiled and edited by Dan Vogel (Salt Lake City: Signature Books, 1996) (five volume series, abbr. EMD) 4:122.

${ }^{53}$ Oakes writes that the confidence of charismatics is "legendary," 13; Dawson, "Charismatic Leadership,” 6. Jan Shipps writes of Joseph Smith's "self-confident, almost cocksure, personality," "The Prophet Puzzle," Journal of Mormon History (1974) vol 1. 3-20, 12.

${ }^{54}$ Riggio, 12. Dawson’s summary backs many of the observations made by Riggio. He writes that charismatics frequently have "superior rhetorical skills" and that they are quite adept at "manag[ing] impressions in face-to-face and larger group contexts,” Dawson, “Charismatic Leadership,” 7.

${ }^{55}$ Riggio, 13-26.
} 
As such, Riggio's research suggests that the social and emotional skill sets of the proclaimer ultimately prove to be more influential than the content of what is actually proclaimed. 56

\section{Confidence and Persuasion}

Corroborating the importance of an expression of confidence in oneself and one's claims are a host of studies that probe the psychological dimensions of juror reactions to witness testimony in the civil and criminal legal worlds. These studies suggest that "jurors, or mock jurors, rely on expressed confidence when evaluating eyewitnesses' credibility." 57 Other studies have shown "that the correlation between eyewitnesses' confidence and accuracy is weak." 58 In other words, confident witnesses are not necessarily more credible on a factual basis than witnesses that lack confidence although they are often perceived as such. The expression of confidence from the witness box increases the perception of the credibility in the eyes of the average juror even if the accuracy for the statements made is no better. A confident narrator attracts subscribers. Of course there is much to nuance here. The study "Calibration Trumps Confidence" by Teney et al.

\footnotetext{
${ }^{56}$ In some ways this dovetails into Stark's research on the type of religious conversions that accompany those that join new religious movements. They join because they like the people and the community, which would include the leader. They get comfortable with the doctrinal requirements later. Stark writes: "Conversion to new, deviant religious groups occurs when, other things being equal, people have or develop stronger attachments to members of the group than they have to nonmembers," Stark, The Rise of Christianity, 18 (emphasis in original).

${ }^{57}$ Elizabeth R. Tenney, Robert J. MacCoun, Barbara A Spellman, and Reid Hastie, “Calibration Trumps Confidence as a Basis for Witness Credibility” Psychological Science vol. 18 no. 1. 46-50. The authors of this study in Psychological Science cited seven previous studies that indicated that confident witnesses were more persuasive than those lacking confidence: Brewer and Burke, 2002; Penrod \& Cutler, 1995; Wells, Ferguson, \& Lindsay, 1981; Whitley \& Greenberg, 1986; Deffenbacher, 1980; Kassin, 1984; Shaw \& McClure, 1996, 46-47.

${ }^{58}$ Tenney, et al., 46.
} 
(cited above) indicates robust confidence is not all there is to determining a witness's credibility. Witnesses who expressed a lack of confidence on details of which they were less than certain were judged to be more credible than those uniformly and unhesitatingly confident on all answers irrespective of their actual certainty of the facts, i.e. calibrated responses trumped overly-confident responses. The adept charismatic is able to sense the right amount of confidence needed for maximum persuasion. Riggio calls this ability "self monitoring." 59 Withholding expressions on the one hand and being expressive on the other are examples of the charismatic's "ability to wear appropriate emotional masks." 60

Smith's ability to self-monitor and to calibrate his confidence is expressed in a number of his revelations where he shows contrition, confesses his shortcomings and errors at the same time he reasserts his calling. An excellent example of Smith's self-monitoring is provided in Smith's earliest recorded revelation, $B O C$ II. ${ }^{61}$ There he tries to right himself after allowing Martin Harris to take, and subsequently lose, the first 116 pages of the Book of Mormon manuscript. He has God remind him,

for although a man may have many revelations, and have power to do many mighty works, yet, if he boasts in his own strength, and sets at nought the counsels of God, and follows after the dictates of his own will, and carnal desires, he must fall and incur the vengeance of a just God upon him $(B o C$ II.2).

The revelation continues,

Behold, you have been intrusted [sic] with these things, but how strict were your commandments; and remember, also, the promises which were made to

\footnotetext{
${ }^{59}$ Riggio, 24-5, 29-30.

${ }^{60}$ Riggio, 30.

${ }^{61}$ H. Michael Marquardt, The Joseph Smith Revelations: Text and Commentary (Salt Lake City, UT: Signature Books, 1999), 23. The $B o C$ dates the revelation to July of 1828.
} 
you, if you did not transgress them; and behold, how oft you have transgressed the commandments and the laws of God, and have gone on in the persuasions of men (BoC II.3).

Smith, having confessed that he had "transgressed" and as such was

vulnerable to losing favor in the sight of God, goes on to reassure himself and readers that,

thou art Joseph, and thou wast chosen to do the work of the Lord .... therefore repent of that which thou hast done .... and thou are still chosen, and wilt again be called to the work; and except thou do this, thou shalt be delivered up and become as other men, ${ }^{62}$ and have no more gift (BoC II.4, emphasis added).

In sum, Smith has confessed his errors in front of Harris and any other readers this revelation may have had. He has confessed his human shortcomings and at the same time reaffirmed his chosen status. Not only is this revelation a fitting example of Joseph's ability to calibrate his confidence and actions, it also reestablishes his strategy of doing only those things which he has the gods command him. He presents his range of possible actions as constrained by intangible forces beyond the domain of the perceptions of other, ordinary, humans. His ability to communicate with the gods is his "gift" which renders him different from "other men" (BoC II.4).

Like a good trial witness—or perhaps as a witness "to the Lord" — the role and level of the charismatic's expressivity varies as the situation demands. The adept charismatic is able to quickly identify and understand the emotional messages that others express-whether or not the latter do so intentionally or unknowingly.

\footnotetext{
${ }^{62}$ The implication is that Smith, despite his foibles, is currently "not as other men.” He has a special calling and special skills.
} 
The skilled charismatic has the sensitivity and ability to hold his or her expressivity in check as the situation requires-which is in keeping with Riggio's notion that the successful charismatic leader is able to control or hold back emotions or identifying expressions. Riggio's notions of "self monitoring" and of "wearing the appropriate emotional masks" correspond directly to the claims of Aberbach and Oakes that charismatic prophets are "natural actors." The ability to empathize and the psychological skills needed to successfully convince others that one has their best interests at heart are important components of one's ability to engender confidence, and to presenting a successful sales pitch.

Paul recognized the roles of self-monitoring, masking emotions and tailoring his actions to appeal to a particular audience as components of a successful persuasion technique. He even boasted of his ability to wear the appropriate social or emotional mask and alter his persona when it served his missionary goals. He has presented his gospel to a broad range of people with differing interests and expectations. His ministry has been successful due to his ability to relate to, and endear himself to, an assortment of constituents. To the Corinthians he writes:

To the Jews I became as a Jew, in order to win Jews. To those under the law I became as one under the law (though I myself am not under the law) so that I might win those under the law. To those outside the law I became as one outside the law (though I am not free from God's law but am under Christ's law) so that I might win those outside the law. To the weak I became weak, so that I might win the weak. I have become all things to all people, that I might by all means save some. I do it all for the sake of the gospel, so that I may share in its blessings (1 Cor 9.20-23). ${ }^{63}$

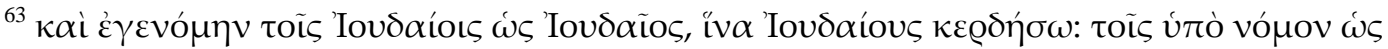

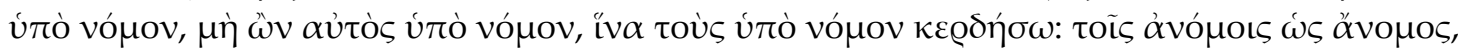

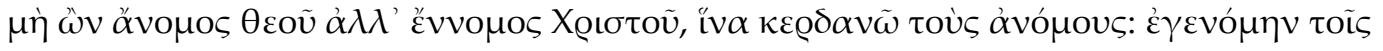

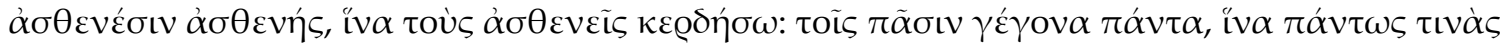

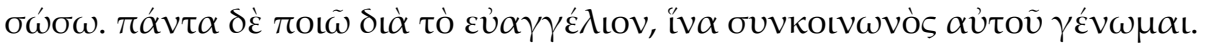


Overholt argues that the audience's acceptance of a prophet is based on the grounding of the prophet and his message "in their [the audience's] cultural and religious traditions," and on relevance "to the current sociopolitical situation." In each of the situations Paul encounters (Jew, law-bound, outside the law, or weak, 1 Cor 9.20-23), he boasts that he conscientiously alters his persona to fulfill the prophetic role expected by—or at least most likely to be embraced by-his audience. His decision to do so is based on efficacy. Paul justifies his mask-wearing means by his conversion ends. ${ }^{64}$ His success in "sav[ing] some" allows him to rationalize changing his behavior as circumstances demand. This is a practice he allows - even boasts of-for himself; yet he will publicly attack and criticize others who operate in the same manner. ${ }^{65}$

While the synopses of Oakes' and Riggio's work is by necessity selective and somewhat superficial, it does provide some useful observations and criteria with which to specify the types of human behavioral and emotional components that lend plausibility to the claims made by certain individuals. These observations

Paul here perhaps tips his hand to an implicitly selfish—and fundamentally human—motivation. The phrase "so that I may share in its blessings" can be interpreted as the spiritual blessings received from multiple conversions. It also suggests that Paul's social status, power and prestige increased as a result of his successful missionary efforts. Another plausible interpretive angle is that since his community has grown, so too has the size and number of the blessings captured on the collection plates. There are multiple

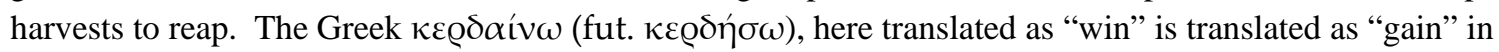
the KJV, a translation that is more in keeping with its archaic sense. BDAG defines $\kappa \varepsilon \varrho \delta \alpha i v \omega$ as "to acquire by effort or investment, to gain. Paul "invests" in acting in alternative ways so that he might "gain" converts to his ministry.

${ }^{64}$ Paul's reliance on the ability of praiseworthy “ends" to justify dubious "means” is considered in more detail in chapter four.

${ }^{65}$ In Galatians 2.11-14, Paul rebukes Cephas for attempting to be all things to all people. He writes, "But when Cephas came to Antioch, I opposed him to his face, because he stood self-condemned; for until certain people came from James, he used to eat with the Gentiles. But after they came he drew back and kept himself separate for fear of the circumcision faction,” Gal 2.11-12. 
concerning the believability of court-room witnesses are certainly relevant to understanding the believability of charismatics as they contend for followers and leadership. Riggio's research highlights the relational role between leaders and led, or more boldly, the dynamics of asserting power within an emerging community.

So when Max Weber, in his widely cited passage that describes "charisma," 66 speaks of a "certain quality," we can now fill in some of the blanks with Riggio's ideas concerning social and emotional skill sets.

Here, once again, the specifics and content are important. One may recognize "charismatic" attributes without accepting the claims made by the charismatic. One can often recognize the talents of a gifted sales person and yet not be interested in what he is hawking. Certainly many Republicans recognize the compelling oratorical performances of President Obama without being swayed by his rhetorical skills to adopt his policy positions. The charismatic's words are not irresistible. Not all will hear the call. The type of person that recognizes the charismatic as a viable leader is not entirely random. Human dispositions vary. The process depends on the orientation of both speaker and hearer, potential leader and potential follower, all located in a particular social setting. Followers must evaluate both messenger

\footnotetext{
${ }^{66}$ Weber writes,

The term 'charisma' will be applied to a certain quality of an individual personality by virtue of which he is set apart from ordinary men and treated as endowed with supernatural, superhuman, or at least specifically exceptional powers or qualities. These are such as are not accessible to the ordinary person, but are regarded as of divine origin or as exemplary, and on the basis of them the individual concerned is treated as a leader.
}

Weber describes a range of social relationships but his definition of charisma does little more than mystify entrepreneurial leadership qualities. No explanation of the interactive human dynamics is provided, nor are illuminating historical examples of the phenomena given. In emphasizing the acquiescence or acceptance side of the power relationship (e.g. Weber uses "treated as" twice and "regarded as" to emphasize the perceptions of those willing to be led), Weber passes over in silence the compelling personal, human qualities that persuade followers to "treat" or "regard" the individual as a leader. Weber, TSEO, 358-9. 
and message, both proclaimer and proclamation. Decisions by followers are not made without social influence as the benefits of participation in existing versus new socio-religious networks are weighed against the costs. The host of influential factors indicates that these types of decisions are rarely made on a purely rational basis-that is, if rational is to be understood as a reasoned, cognitive, assessment and methodical analysis of the facts of the case presented. If rationality is to be interpreted as being emotionally swayed by the trappings and persuasive confidence of the most dynamic leader, combined with the costs and benefits of existing in the most enticing community, then these decisions are entirely rational. Ignoring the semantic range and connotations of the term "rational," these important choices are exercised by autonomous beings who will be influenced by a wide range of social, emotional, personal and factual components.

\section{Recognizing Gifts}

The basic relational concept of the charismatic bond holds under a variety of terms and in a variety of cultures. Consider briefly one scholar's summary of the "essence of shamanhood." After reviewing anthropological research on the subject, New Testament scholar John Ashton summarizes:

The essence of shamanhood is twofold: it has an individual aspect insofar as it involves the shaman's own experience (which is always frighteningly solitary) and a social aspect, for the shaman's authority depends upon an ability to persuade other people of his or her exceptional gifts. ${ }^{67}$

Ashton's summary of a shaman's relationship with his people concisely states the basic charismatic power relationship: "authority depends upon an ability to

\footnotetext{
${ }^{67}$ John Ashton, The Religion of Paul the Apostle (New Haven and London: Yale University Press, 2000) 33 (emphasis added).
} 
persuade other people of [one's] exceptional gift."68 The persuasion takes place within a particular context. It may or may not rely on deception, theatrics, transcendent experiences or other tactics. Persuading others of one's authority is in large part contingent on prevailing cultural norms and expectations. Those performances and claims that evoke the deep sentiments deeply ingrained in the cultural or religious capital of those hearing are more likely to find followers and success than those too far afield, too "foreign." Old Testament scholar Robert Wilson writes that for divine intermediaries to exist, "certain general conditions and attitudes must be present." The attitudes and conditions "create the supportive social environment which permits intermediation to occur." 69 While novel claims are important to gaining leadership, claims that do not resonate on some sort of deeper—and acceptable—level with the charismatic's hearers are more likely to be ignored. It is not necessary for society as a whole to embrace these individuals; a small group of devoted supporters provides a sufficient micro-context for the intermediary's endeavors. ${ }^{70}$ A hearer's network of relations, family and friends, is

\footnotetext{
${ }^{68}$ Ashton, The Religion of Paul, 33.

${ }^{69}$ Robert R. Wilson, Prophecy and Society in Ancient Israel (Philadelphia: Fortress Press, 1984) (1946), 28. Wilson cites required attitudes such as "belief in the reality of the supernatural power or powers," the belief that these powers will interact with human agents, an environment where intermediation is tolerated and finally an environment in which "social conditions require the services of an intermediary" such as those experiencing "rapid [social] change" and the stress that accompanies it, 28-31. See also Overholt, The Social Dynamics of Prophecy, 70, where he writes,

To speak of authority in terms of acceptance is to acknowledge that the audience judges every instance of prophetic activity on the basis of certain tangible marks; that is to say, it knows in general what to expect of its intermediaries. Put differently, a stereotypical conception of what constitutes authentic prophetic behavior operates in each situation.

${ }^{70}$ Wilson, Prophecy and Society in Ancient Israel, 51.
} 
also critical to receiving the charismatic and his claims favorably, as "social networks make religious beliefs plausible."71

Overholt writes, perhaps axiomatically, "charisma is thus a function of recognition." 72 Later in his work, Overholt pushes his theme of recognition further when he writes "[d]espite revelatory experiences, intermediaries cannot effectively exercise their roles unless at least some of their audience responds positively." ${ }^{73}$ As with almost any human interaction, an individual's response to an opportunity will be based upon how the individual is compelled and what that individual expects to gain from such a response-weighed against the "costs"74 of the response. If an individual's existing social network is reluctant to embrace the prophet's message, he or she may find that the new social network, those who have already embraced the prophet's claims, provide a social group that make the "new religious beliefs plausible." 75 Acceptance of the prophet's claims is thus a function of a combination of factors: the intermixture of message and messenger and the social and emotional needs of the spiritual aspirant(s) within a particular community, whether existing or new.

Social context is important on a number of fronts. Simple knowledge of the charismatic's personal roots as firmly grounded in the mundane world might be enough to inoculate potential followers against the grandiose claims of a local kid.

\footnotetext{
${ }^{71}$ Stark and Finke, Acts of Faith, 114-138, 117.

${ }^{72}$ Overholt cites the origin of this particular phrasing in P. Worsley's work on so-called "cargo cults," The Trumpet Shall Sound, xii as in Channels of Prophecy, 24.

${ }^{73}$ Thomas W. Overholt, Channels of Prophecy, 69.

${ }^{74}$ See Stark and Finke, Acts of Faith for a definition of costs and benefits. Costs and benefits are only rarely quantifiable in terms of material currency.

${ }^{75}$ Stark and Finke, Acts of Faith, 114-138, 117-118. Also, Overholt, Social Dynamics of Prophecy, 23.
} 
We have no evidence that Paul founded a community in his hometown of Tarsus and Smith fled his New York home only a few months after his church was founded. ${ }^{76}$

An individual's charisma is simply not compelling to all people. The possession of the "certain quality" as something "of divine origin" is undermined, discounted, or rendered invisible when the local carpenter's kid,77 or the county money-digger, seems to have it.

A couple of years after the Smith family moved from Palmyra, New York, to Kirkland, Ohio, former Smith family Palymra neighbor Peter Ingersoll said he was

\footnotetext{
${ }^{76}$ See H. Michael Marquardt, Inventing Mormonism: Tradition and the Historical Record (Smith Research Associates, 1998), 153-172, for the problematics surrounding the actual date and location of the formal legal founding of the church.

Escaping debt obligations and moving to a recently established, supportive community seems to have been the primary motivating factors. According to the BoC XXXIX, in December of 1830, Smith and Sidney Rigdon (a preacher from Ohio who had converted and been baptized into Smith's church the previous month) received a revelation in Canandaigua, New York, that “command[ed]" him and the nascent church to "assemble together at the Ohio" "because of the enemy and for your sakes," BoC XXXIX, verses 4 and 1. About this time in early December, Joseph Smith Sr. finished serving a thirty day prison sentence related to debt. A debt related warrant for the arrest of Smith's brother Hyrum had been issued just two months earlier, September 29, 1830. Lavina F. Anderson, Lucy's Book: A Critical Edition of Lucy Mack Smith’s Family Memoir (Salt Lake City, UT: Signature Book, 2001), 177-78. It is hard not to see escaping debts as a contributing factor to the move. Former neighbor Willard Chase accuses the family of having left "this part of the country without paying their just debts." Willard Chase Testimony in Howe, Mormonism Unvailed, 247. See Bushman, Rough Stone Rolling, 122-26. The unnamed “enemy” mentioned in the revelation may well be the debt collector. In addition, there were over 100 new converts in the Kirtland, Ohio, area where a large portion of Sidney Rigdon's congregation had recently converted to Joseph's Mormonism. The revelation to move to Ohio was eminently practical.

${ }^{77}$ Once again, textual passages from antiquity show some insight into a familiarity with this type of issue; consider:

He came to his hometown and began to teach the people in their synagogue, so that they were astounded and said, "Where did this man get this wisdom and these deeds of power? Is not this the carpenter's son? Is not his mother called Mary? And are not his brothers James and Joseph and Simon and Judas? And are not all his sisters with us? Where then did this man get all this?” And they took offense at him. But Jesus said to them, "Prophets are not without honor except in their own country and in their own house." And he did not do many deeds of power there, because of their unbelief. ${ }^{77}$ Matt 13.55-58 (emphasis added.)

The last sentence of the Matthew passage referenced above is instructive in itself when compared to

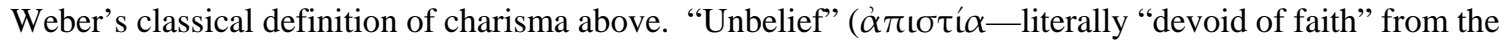
negated $\pi i ́ \sigma \tau \iota \varsigma$, pistis) is the equivalent recognition that (to use Weber's language) the prophet is neither regarded as nor "treated as a leader." This observation perhaps explains the fact that we have no letter from Paul to the people of Tarsus. It also provides one reason why Smith moved himself and his nascent community out of New York state well before the movement was even a year old.
} 
visited by Joseph's younger brother William. Upon Ingersoll's inquiry of "how they [the Smith's, his old neighbors] came on" William is said to have replied, "we do better there than here; we were too well known here to do much." ${ }^{78}$ The implication is that the Smith family was recognized in its home town as a family of which one should be wary, a fact of which William was cognizant.

Paul spends a considerable amount of time trying to distinguish and differentiate himself from other competing preachers. He wants his competitors to be recognized as evil, deceitful and to be avoided. To the Philippians he writes, "[b]eware of the dogs, beware of the evil workers, beware of those who mutilate the flesh!" (Phil 3.2); and to the Corinthians he writes, "such boasters are false apostles, deceitful workers, disguising themselves as apostles of Christ... even Satan disguises himself as an angel of light" (2 Cor 11.13). The market was full of competing preachers, many of whom were compelling proclaimers. The seeker was provided with a number of options - not all of which were equally compelling. Paul writes "the message about the cross is foolishness to those who are perishing, but to us who are being saved it is the power of God," (1 Cor 1.18). Those with ears to hear recognize the saving message and the integrity of its promulgator. Their receptivity is also influenced by the social network individual followers are a part of, or will soon join.

\footnotetext{
${ }^{78}$ Testimony of Peter Ingersoll, Howe, Mormon Unvailed, 237. Many other examples exist. One affidavit in particular, signed by fifty-one neighbors, concludes:

It was not supposed that any of them were possessed of sufficient character or influence to make any one believe their book or their sentiments, and we know not of a single individual in this vicinity that puts the least confidence in their pretended revelations.

Howe, Mormonism Unvailed, 262. To his Manchester neighbors, the prophet appeared to be without honor in his home town.
} 
A recollection by Edward Stevenson of a sermon delivered by Smith in 1834 expresses his confusion at the reality that not all charismatic seed falls on fertile ground. He writes,

I can very well remember many of the words of the boy Prophet as they were uttered in simplicity, but with a power which was irresistible to all present, although at the time I could not understand how it was that so few comparatively obeyed it. ${ }^{79}$

Stevenson's recollections simultaneously capture the sense of "power which was irresistible to all" and the enigma of why not all were swayed as he was. Stevenson's sentiments represent an example of the demand side of the religious market place while Smith represents one possibility on the supply side. In economic theory, a transaction takes place where supply meets demand as both sides agree to a suitable price for a mutually beneficial exchange. In the religious market place, the "price" at which a conversion takes place, despite the rhetoric from conversion narratives, is at the point where "interpersonal attachments to members overbalanced their attachments to nonmembers." 80 Individual perception of a leaders gifts is aided by a broader communal recognition. The benefits of the conversion include the significant tangible and intangible rewards of personal well being and communal membership. Stevenson's observation reiterates that not all products in the spiritual market place are universally compelling.

In his autobiography, Stevenson recalled what he perceived as the ubiquitous mood present during the prophet's preaching. He writes "I do believe that there

${ }^{79}$ Edward Stevenson Account, 1894, Vogel, EMD 1:39. Stevenson's account came from his Journal, 27 May 1883, EMD 1:36, and was a response to a sermon delivered by the prophet in Pontiac, Michigan, in October of 1834.

${ }^{80}$ Emphasized in the original, Stark and Finke, Acts of Faith, 117. This specific passage deals with Stark's research on the Unification church, but his observations have been corroborated by others. 
was not one person $<$ present $>$... who was not convicted of the truth of his vision of An Angel to him." Stevenson continued, "I do not wish to be understood that all present continued to feel the conviction abide with them, but while under its influence they were so deeply impressed that they could not gain-Say ...."81 Quite plausibly, Stevenson's discernment of Smith's power was influenced by his awareness that all involved felt it as he did.

Joseph Smith surely possessed an excess of native talents: raw intelligence, robust energy, creativity, charisma, and audacity to name only a few of the obvious. He was able to impress not only the downtrodden seeker, the enthusiastic primitivist, the uneducated and the credulous in search of salvation, but the sophisticated Yankee as well. As an example, the blue blood Josiah Quincy Jr., prior to being elected Mayor of Boston, met Joseph Smith in Nauvoo in 1844. He was both perplexed and favorably impressed by his encounter with the Mormon prophet. He would later write in his journal that "One could not resist the impression that capacity and resource were natural to his stalwart person." Smith reminded Quincy of U.S. Congressman Elisha R. Potter, a similarity which puzzled him. Quincy reckoned that such a man "would seem to be intellectually superior to so miserable a delusion." 82 Quincy could certainly recognize the persuasive and compelling nature of Smith, but was not predisposed to accept his claims at face value.

\footnotetext{
${ }^{81}$ Edward Stevenson, Autobiography, 1891, Vogel, EMD 1:38. Spelling, capitalization and grammar as in Vogel. Stevenson continues that "while we herd [sic] him tell in his plain and simple way ... I had a Testamony [sic] of the truth, for the Spirit of God witnessed and the Holy Ghost Sealed upon me his truthful words. . .” 1:39.

${ }^{82}$ Richard L. Bushman, Rough Stone Rolling, 2-5. Undoubtedly Smith, like his predecessor Paul, adjusted his behavior appropriately in his interaction with the skeptical Yankee blue-blood.
} 
Harold Bloom repeatedly refers to Joseph Smith as a religious genius in his book the American Religion ${ }^{83}$ and writes that he does "not find it possible to doubt that Joseph Smith was an authentic prophet." 84 He notes however that this genius is within the context of Smith's "innovations," his "religion making" and "myth-making imagination." 85 For Bloom it was Smith's charisma, imagination and "his intuitive understanding of the permanent religious dilemmas of our country" that made him a prophet. ${ }^{86}$ In this, Bloom's perspective on Smith's ability to "intuitive[ly] understand" the needs of people supports the notions of a charismatic's "social insight" as proposed by Oakes and "social intelligence" as proposed by Riggio. Smith was a perceptive and intuitive product of his times. He understood enough about the needs of the American religious seeker and was endowed with sufficient quantities of the American spirit of free innovation that he crafted a sacred history and a religion that gave many Americans precisely what they wanted. It was Smith's own success that reinforced in him the right to call himself a prophet. ${ }^{87}$ This success not only alarmed but generated hatred and fear in those who did not

\footnotetext{
${ }^{83}$ Bloom, 71, 73, 93, 95, 97, 103.

${ }^{84}$ Bloom, 89.

${ }^{85}$ Bloom, 92, 93, 95.

${ }^{86}$ Bloom, 130.

${ }^{87}$ For Overholt, "audience reaction" is one of the steps in his "model of the prophetic process." He writes that "[f]eedback from the audience addressed by the prophet may be positive, negative, or simply indifferent. In any case it is likely to exert an influence on the prophet's subsequent performances." See Social Dynamics of Prophetic Activity, 21-25, 27-68. Riggio writes,

as social skills develop, an individual also learns specific strategies of influence. The person learns that there are certain regularities to human behavior, that people tend to follow definite social rules. Knowing how these rules operate and how to manipulate them can be the key to unlocking the charisma potential and using it to affect others, Charisma Quotient, 51.
} 
subscribe to his story. Fear does not arise unless the threat perceived is compelling. Few heed the threats of those regarded as madmen. 


\section{THE LIFE-STAGES OF A PROPHET}

Going beyond personality characteristics and the notion of social intelligence, Oakes moves to another phase of analysis, where he posits a sequence of general patterns which he calls "life stages" or the "'natural history' of the prophet." 88 The second stage, and the only "life stage" to be considered here is that of "incubation," which examines the patterns of the embryonic prophetic charismatic's growth as influenced by various interactions with her environment. The full list of life stages was cursorily presented in Table 2.1. Of the incubation stage itself, only two components will be explored given their relevance and potential explanatory value: 1) "the sense of not belonging to any group," and 2) the "acquisition of practical skills appropriate to a later prophetic career." The first provides motivation, the second provisions fitting tools.

The assumption behind the first component is that one's adult life is a reaction to the experiences and trauma of one's youth. Later development and adulthood consists of attempts to redress the perceived voids of one's earlier life. ${ }^{89}$ In the case of prophetic charismatics, Oakes posits that those who seek to be the center of their own community in adulthood have experienced alienation from their larger community as a youth. For Aberbach, the notion that the "alien or alienated charismatic [who] at the same time becom[es] identified with a nation or people

\footnotetext{
${ }^{88}$ Oakes, 21. The first of these stages is "early narcissism” where the childhood of the charismatic to be is marked by an "excessively devoted yet conflicted parent" which protects the child from "external reality" and consequently "provides a flawed model for subsequent social development" 21. For Oakes, this stage is significant as it is the "uncritical devotion" provided by the primary caretaker of the prophet's early childhood that becomes a model which the prophet seeks to replicate in later life. This is done, Oakes posits, when the prophet “assumes a 'divine' role in order to get love from others," 21 . This category requires too much speculation to be of use in the analysis here.

${ }^{89}$ Aberbach, 10.
} 
towards whom he is in many ways an outsider, but who is nevertheless accepted by the nation [or people]" is both a "paradox" and a persistent theme in the study of charismatics. ${ }^{90}$

The second life-stage considered is more practical than speculative as it examines the development of specific tools and skills that facilitate one becoming central to a new community. The section that follows first examines the social and cultural context in which both Smith and Paul could have plausibly perceived themselves as marginalized and alienated. The argument then moves to document how each of these men developed a host of skill sets that would facilitate their success as prophetic community leaders. ${ }^{91}$

Oakes rounds out his "natural history" with the categories of "awakening," "mission," and "decline and fall." Awakening is often construed as a single, powerful event in one's life. The reality of "awakening," according to Oakes, is that it is more generally a combination of, or "series of[,] interconnected events rather than a single life-changing transformation." 92 Segal writes that "Paul's transformation could have been active questing in ways he could not recognize or acknowledge." 93 The discursive practices deployed by Smith and Paul during the "mission" phase are the subjects of chapters three and four, although not addressed with Oakes' framework in mind. The last life stage listed by Oakes, "decline and fall," is simply

\footnotetext{
${ }^{90}$ Aberbach, Charisma in Politics, Religion and the Media, 10. Aberbach argues that the charismatic has "already encountered [the alienation and uncertainty bred by crisis] on a private, psychological level, and has constructed defenses against them,” 10-11.

${ }^{91}$ Oakes, 21. See Table 2.1 above.

92 Oakes, 21-22, Aberbach, Charisma in Politics, Religion and the Media, 8-16.

${ }^{93}$ Segal, Paul the Convert, 29.
} 
less relevant to this study than the first four. Not only do we lack any information on Paul that might correspond to the theocratic experiment of Smith's Nauvoo (which ultimately led to his lynching), but the focus of the analysis in this study is on the development of an asymmetrical social relationship and not on an individual's decline.

The main function of the comparative analysis based on Oakes' model is not to generate data for a psychological diagnosis of either individual, nor is it to construct any sort of essentialist typology. The model simply suggests certain relationships to examine. Background and context illuminate plausible motivations relevant to future endeavors, and highlight the development of the skill sets that allowed these individuals to prosper as they did. In short, the idea presented is that the sense of alienation these individuals experienced in their own lives became the driving force behind developing a community in which they could be central. Quite simply, people comfortable within their own communities do not promote revolution (unless perhaps denied access to power). Additionally, those who ultimately thrive as cultural entrepreneurs will need some practical training to achieve success. 


\section{The Sense of Not Belonging to Any Group}

\section{Paul, a Diaspora Jew at Home in a Strange Land}

I am a debtor to both Greeks and to barbarians ${ }^{94}$

-Paul, Rom 1.14

Oakes' sub-category, "the sense of not belonging to any group," forces the question of the types of affiliations and social networks to which Paul, a selfproclaimed "member of the people of Israel"95 living in the Diaspora of Hellenistic times, could find attachment and meaning. Paul speaks and writes in Greek and hails from Tarsus, "no mean city" (Acts 21.39), which is in southeast Asia Minor. ${ }^{96}$ He describes himself as an "Israelite" (Rom 11.1) and "Hebrew from the tribe of Benjamin" (Phil 3.5). ${ }^{97}$ Assessing Paul's physical location in the Mediterranean

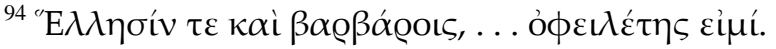

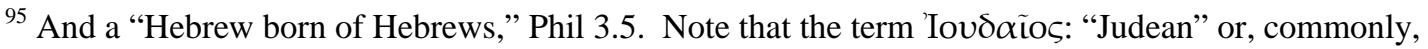
"Jew" is not used (e.g. Rom 1.16, Gal 2.14).

${ }^{96}$ Paul never mentions his homeland as Tarsus although Luke does three times, Acts 9.11; 21.39; 22.3. One biblical scholar has remarked that we can trust Luke's attribution of Paul's hailing from Tarsus as Luke has nothing to gain ideologically or rhetorically by making this his home town. See W. Ward Gasque, Tarsus, in David Noel Freedman, editor, Anchor Bible Dictionary, VI 334. See also Roetzel, The Letters of Paul, 6-7 and Paul: The Man and the Myth, 11.

${ }^{97}$ Caveat lector: these self identifications become highly suspect based on Paul's first letter to the

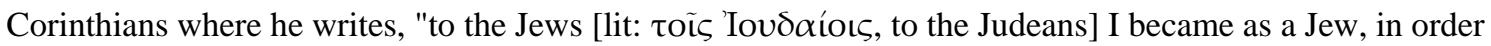

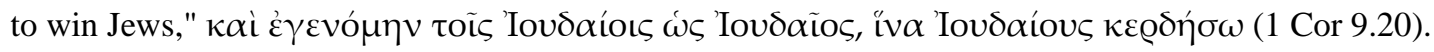

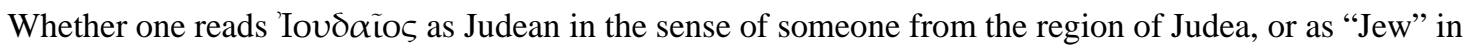
the more specific sense of following the customs attributed to Moses, this comment in which Paul freely discloses his "chameleon" conversion strategy of "becoming" like others "in order to win" them, can not but problematize every self identity claim that comes from Paul's pen. Given this statement, one has to wonder if Paul was really the Israelite or Hebrew that he claimed to be in Romans 11.1 and Philippians 3.5-or is he simply acting like a Jew to win Jews as he states he has done in 1 Cor 9.20. Contemporary Jewish scholars of Paul differ in their opinions. Alan Segal accepts Paul as a Pharisee, Paul the Convert, xi, xiii; as does Daniel Boyarin, "I see no a priori reason not to," A Radical Jew, 2. Representing a different opinion, Hyam Maccoby writes
}

[W]as Paul really from a genuine Pharisaic family, as he says to his correspondents, or was this just something that he said to increase his status in their eyes? The fact that this question is hardly ever asked shows how strong the influence of traditional religious attitudes still is in Pauline studies. Scholars feel that however objective their enquiry is supposed to be, they must always preserve an attitude of deep reverence towards Paul, and never say anything to suggest that he may have bent the 
culture of his time provides some understanding as to why Paul seemed so fixated

with incorporating Gentiles (eqnoi/ethnoi)—implicitly hailing from a host of

national, ethnic and geographical backgrounds that were not of Israelite heritage-

into communities centered on the promises made by the exclusive and explicitly

nationalistic—if not adamantly "Israelocentric"—God of Israel. ${ }^{98}$

Paul's version of "scripture," the Septuagint, was written in Greek to

accommodate the large number of Hellenized Jews ${ }^{99}$ who could read neither

truth at times, though the evidence is strong enough in various parts of his life-story that he was not above deception when he felt it warranted by circumstances. The Mythmaker: Paul and the Invention of Christianity (New York: Barnes and Noble, 1986), 6.

See also 14, 50-61. Eisenbaum asks the same question of Josephus's claim to be a Pharisee, implying that there was status to be gained in making such a claim, Paul Was Not a Christian, 131. Maccoby contends that anyone who reads Paul without preconceived notions of his being a Pharisee would see him as "a Hellenistic writer, deeply imbued with the Greek translation of the Bible," 64. Boyarin apparently does not see an inconsistency between being a Pharisee and a "Hellenistic writer" who is also a "cultural critic" of Jewish life and tradition. Calvin Roetzel expresses uncertainty about what Paul meant in Phil 3.5, Paul, 2.

${ }^{98}$ Despite the rhetorical claims otherwise of modern and ancient monotheists, it seems rather obvious at face value that the God of Israel, as portrayed in Hebrew scripture, is in fact the god of, well, "Israel"whether conceived of as place, progenitor, or people — and not the god of, say, Athens, nor of Agamemnon, nor of the Persians. For background and theories on this aggrandizing shift from the tribal to universal, see Gregory J. Riley, The River of God, 22-49 and Morton Smith "The Common Theology of the Ancient Near East,” Journal of Biblical Literature, 71 (1952), 135-47.

${ }^{99}$ The self-identification as a "Jew" or a "Greek" in a culture where observant, circumcised-in-theflesh, followers of the Torah might speak Greek but not Hebrew is problematic. The terms Greek and Hebrew are not mutually exclusive- and not only in Paul's spiritualized understanding (Rom 2.28-29). Elaboration on parties or sects such as the Pharisees, Sadducees, Maccabees, Essenes, Hasmoneans, etc. barely begins to describe the diversity of belief, practice and political affiliations that existed for Jews/Judeans in Paul's time period. Eusebius, citing the authority of Hegesippus, names "various groups among the Circumcision" which included "Essenes, Galileans, Hemerobaptists, Masbotheans, Samaritans, Sadducees, and Pharisees," Hist ecc. 4.22.5. History of the Church, translated by G. A. Williamson (London: Penguin Books, 1986), 129. Undoubtedly, numerous smaller and regional groups existed. These terms also fail to account for the sometimes radical diversity of communal identity and religious practice from one location to the next. See also Richard A. Horsley, Bandits, Prophets and Messiahs: Popular Movements in the Time of Jesus (Harrisburg, PA: Trinity Press International, 1985) (1999), for a history and analysis of the variety of religio-political movements, sentiments and leadership of first-century Palestine.

Moreover, labels tend to suggest more uniformity in thought and practice than was perhaps lived experience of various peoples who claimed to be heirs of the body of writings now recognized as the Hebrew Bible. See Karen L. King's What Is Gnosticism (Cambridge, MA: Harvard University Press, 2003) for how providing a single name for a broad collection of groups effectively reifies something that does not otherwise exist. Particularity and differentiation get lost in the process. What has become recognized as Rabbinic Judaism was the product of a lengthy process of emergence from the rubble of the 
Hebrew nor Aramaic. The translation altered the nature of Israel's Israelocentric divine patron. ${ }^{100}$ The entire corpus of writing was inherently colored by its translation into a language other than that of its original composition. Ideas and concepts do not translate as easily as words when different thought worlds are encountered. ${ }^{101}$ The fact that the textual tradition, the material artifact that transmitted the charter narrative of Israel and provided a center for Paul's world and power claims had already been embraced by Hellenized Jews and transformed into the language of the dominant culture, is not trivial. The linguistic and semiotic problems noted by the translator of Sirach would have obscured some of the tribal exclusivity and other important components of the Hebrew text. Paul's own corpus of holy writings already embodied Israelite integration into the "world" and bore the clear marks of Hellenism.

Temple’s destruction. The very identity of a “Judaism” was constructed in reaction to other communities that claimed that tradition of Israel as their own, including Christianity. This is a primary thesis of Boyarin's, Border Lines. Boyarin writes that “Judaism is not the 'mother' of Christianity; they are twins, joined at the hip,” 5. Christianity and Judaism are blanket terms for a bewildering diversity of sects, practices, theologies and behaviors, Walter Bauer, Orthodoxy and Heresy in Earliest Christianity. Also Robinson and Koester, Trajectories Through Early Christianity (Philadelphia: Fortress Press, 1971).

100 By Paul's time the Septuagint, translated over the course of the preceded three centuries, had rendered Yahweh’s self identification in Exodus 3.14 as “ó $\omega$ "” ("the being," "the existing one”). Whereas there is a play on words in the Hebrew (ehyeh asher ehyeh) between what is rendered in English as "I am"

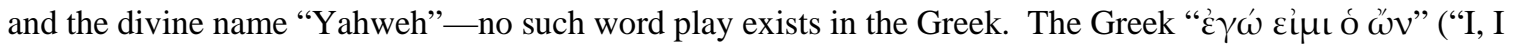
am [the] being” or "[the] existing”) is more reflective of Plato's "The One” than it is the proper name of the exclusivist tribal patron of Israel. "Paul was motivated by a Hellenistic desire for the One,” Daniel Boyarin, A Radical Jew, 7.

101 The translator of Sirach, was well aware of this problems. Before translating his grandfather's opus into Greek, he offered a prologue which contains the following:

You are invited ... to be indulgent in cases where, despite our diligent labor in translating, we may seem to have rendered some phrases imperfectly. For what was originally expressed in Hebrew does not have exactly the same sense when translated into another language. Not only this book, but even the Law itself, the Prophecies, and the rest of the books differ not a little when read in the original.

Paul's Septuagint already reflected Hellenistic Greek influence. 
In a remarkable study of social communities in the Asia Minor of Paul's era, Philip Harland documents a range of associations based on a number of social interests or commonalities including "familial, ethnic, occupational, cultic and other spheres of social ties." ${ }^{102}$ Each of these groups would have exhibited a somewhat similar range of social practices and each would have had their particular patron god. ${ }^{103}$ The ubiquity and diversity of associations, cults, synagogues, congregations and other communities in Paul's era attests to the human need for solidarity, sociality and a need to "feel a sense of belonging." 104 Beyond the identity forged by these types of associations, people were exposed to different ways of thinking and would engage in the (generally) non-exclusive worship of the patron gods of their ad hoc communities. Paul's communities, both before and after he recognized his call, should be seen as but one of these social formations.

Daniel Boyarin writes that "all of Palestinian Judaism was also Hellenized to [a] greater or lesser extent." 105 Another scholar even notes that "these Hellenistic

\footnotetext{
${ }^{102}$ Harland categorizes associations not on their "main purpose" whether "religious, funerary or otherwise," but on "the basis of an association's membership" and its self-understanding. Philip A. Harland, Associations, Synagogues, and Congregations: Claiming a Place in Ancient Mediterranean Society (Minneapolis, MN: Fortress Press, 2003), 25. In making this specific distinction, Harland moves his work beyond that of his teacher, John Kloppenborg, as presented in his work, "Collegia and Thiasoi: Issues in function, taxonomy and membership,” in John S. Kloppenborg and Stephen G. Wilson, Editors, Voluntary Associations in the Graeco-Roman World (London: Routledge, 1996), 16-30. Harland writes that "it is possible to distinguish five common types of associations according to their principal social network basis ... (1) household connections, (2) ethnic or geographic connections, (3) neighborhood connections, (4) occupational connections, and (5) cult or temple connections," 29.

${ }^{103}$ Harland's analysis of associations, cults and communities is based on the archeological record and thousands of ancient inscriptions. Features common to most of the associations he writes of include: (1) sociality, (2) feasting, (3) honoring the god(s) appropriately, (4) conducting proper burials which often reflect concerns of the afterlife. Associations (collegia), were often the categories in which outsiders placed Jews and Christians, Associations, 8, 31-87.

${ }^{104}$ Harland, Associations, 129.

${ }^{105}$ He adds that "it is also surely plausible that there were major cultural differences between Jews whose daily language was Semitic (Hebrew or Aramaic) and those whose daily language was Greek," and further that Rabbinic Judaism [wa]s also Hellenistic.” Boyarin, A Radical Jew, 6-7. "Rabbinic Judaism can
} 
Jews, who now lived in Palestine again, were everything but 'Hebrews'."106 Nor did all Jews share an identical understanding of what ancestral law required of them. Beliefs and practices varied widely as did educational status, trades, wealth and social status. Jews in Asia Minor interacted with gentiles in trade, were civic patrons and even attended the theaters. ${ }^{107}$ Not all communities peopled with Jews were as maniacally law-obsessed as those polemicized against in Matthew. Much like today's Jewry, what it meant to be a Jew varied. Boyarin repeats a concept from the Babylonian Talmud that "an Israelite, even if he [or she] sins, remains an Israelite." As a Jew of the Diaspora, ${ }^{108}$ in a metropolitan hub like Tarsus teaming with humanity from around the world, Paul would have witnessed a broad variety of both displaced peoples and deeply entrenched communities. ${ }^{109}$ These communities

be seen as a nativist reaction, a movement that imagines itself to be a community free of Hellenism, and therefore it is itself no less Hellenistic precisely because of its reaction,” 18, see also 235 n 73.

${ }^{106}$ Dieter Georgi, The Opponents of Paul in Second Corinthians (Philadelphia, PA: Fortress Press, 1986), 46.

${ }^{107}$ Evidence from stone inscriptions indicate that various guilds, e.g. the "emperor-loving goldsmiths," and associations, e.g. "Jews (Judaeans) and God-fearers," had seats reserved for themselves at the theater in Miletus. See Harland, Associations, 109. Theater attendance is a mark of social integration with the dominant Hellenistic culture.

${ }^{108}$ First century Judaism was never a monolithic entity. Rabbinic Judaism, irrespective of what it claims for itself, is a product of Jewish deliberation primarily in Jamnia in the decades if not centuries that followed Rome's sack of Jerusalem, Boyarin, Border Lines, 151-252. It is in this era that what is now recognized as both Judaism and Christianity emerged, albeit with tremendous diversity within each camp, e.g. Walter Bauer, Orthodoxy and Heresy in Earliest Christianity. Also Robinson and Koester, Trajectories; Gregory J. Riley, One Jesus, Many Christs: How Jesus Inspired Not One True Christianity But Many (Minneapolis, MN: Fortress Press, 2000). Given this backdrop, the notion that "Judaism"whether Hellenisitic or Palestinian — had always existed in a specific and recognizable form subject to facile categorization is impossible to substantiate. See Daniel Boyarin's Border Lines: The Partition of Judaeo Christianity, for an analysis that unpacks some of the problematics attached to defining Christianity and Judaism as distinct entities in this time period.

${ }^{109}$ Belaboring this point seems somewhat axiomatic to students of the ancient Mediterranean who are cognizant of the cultural trajectories that emerged in the wake of Alexander the Great. Let it suffice here to point out that Hellenistic influence had infiltrated much of Jewish culture by the turn of the era. The most obvious evidence is perhaps the Greek translation of Hebrew Scripture known as the Septuagint which was translated based on the needs of a robust Greek-speaking Jewish community in Alexandria, Egypt and elsewhere. Further evidence lies in the fact that nearly all early Christian literature was written in Greek. Whether by Jew or Gentile, those who have a facility for Greek are inevitably influenced by Hellenistic 
existed with varying levels of tension/integration in relation to the dominant culture. Virtually all of these groups would have facilitated a sense of belonging for its members. Many, if not most, of them would have displayed some level of distinctive, identity-marking behavior as part of the meaning-making exercise. The Pharisees were but one such group, which in itself no doubt experienced regional differences and sectarian schism. ${ }^{110}$ As a Pharisee, Paul was part of one of these groups, a tightly woven, exclusive community whose relationship to the world was mediated by sectarian interpretations of archaic Hebrew texts and the social and behavioral implications of these specific readings. His description of himself as Pharisee is within the context of his attitude and devotion regarding "the law"

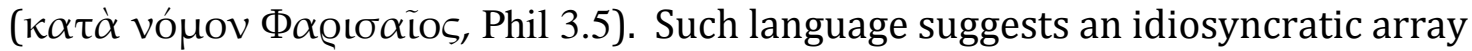
of meanings and conduct that marked and differentiated Pharisees from nonPharisees. Paul's presentation of himself in relationship to his respect for the law depicts him as an especially pious sectarian within an already highly committed group.

Stark and Finke's model of a religious economy provides a few helpful observations about the merits of exclusivity and commitment regarding social formation. They argue that due to the "reciprocal relationship between the degree of lay commitment and the degree of exclusivity," exclusive religious organizations

culture. See for example the preface to Sirach in the footnote above. See also John J. Collins, From Athens to Jerusalem: Jewish Identity in the Hellenistic Diaspora, Second Edition (Grand Rapids, MI: William B. Eerdmans Publishing Co., 2000).

${ }^{110}$ Pharisees were a "voluntary association," one that "functioned as a social movement . . . seeking to change society." The changes sought were "probably ... a new, communal commitment to a strict Jewish way of life based on adherence to the covenant" as part of the ongoing negotiation with the dominant Greco-Roman culture. Anthony J. Saldarini, "Pharisees,” ABD, V 289-303, 301-2. 
are inherently stronger than non-exclusive communities. ${ }^{111}$ Exclusive social formations survive by maintaining an optimal amount of tension ${ }^{112}$ with their surrounding environment. In turn, the higher the level of "tension with its surroundings, the more expensive it is to belong" to that religious group. The functional result of this increased tension and expense is more exclusivity and hence a higher level of commitment from participants. ${ }^{113}$ The high "price" of commitment and exclusivity is reflected in the high "value" of the rewards of commitment. 114 The Pharisees were a high-commitment group. Their interpretive practices and behaviors were intended to justify, strengthen and define their own sub-group over and against other types of Jews. From a sociological perspective, the practices of Pharisees are intended to alienate gentiles and non-Pharisaic Jews to some "optimal" degree. Paul essentially confessed his own partisan marginalizing practices when he spoke of his commitment ("zeal") to his "former life" as "a persecutor of the church" and that such a stance merited a status of righteous blamelessness under the law (Phil 3.5-6). Textual interpretation and various purity issues were the techniques deployed to maintain optimal tension and exclusivity. Paul's confessed

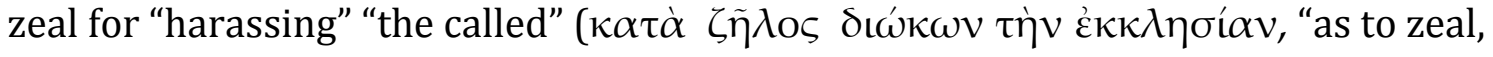
a persecutor of the church" Phil 3.6, NRSV).

${ }^{111}$ Stark and Finke, Acts of Faith, 142.

112 "Tension refers to the degree of distinctiveness, separation, and antagonism between a religious group and the 'outside' world," Stark and Finke, Acts of Faith, 143. Too much tension results in bloodshed, too little tension results in too little exclusivity and too little commitment from members, 142.

113 Stark and Finke, Acts of Faith, 141-146.

114 “Among religious organizations, there is a reciprocal relationship between expense and the value of the rewards of membership,” Stark and Finke, Acts of Faith, 145. 
When considering Paul's history as an inherently exclusivist Pharisee, his location in the Diaspora, his knowledge of Greek, and his reading of scripture that, by virtue of its translation, was already influenced by the dominant culture, it is not difficult to conceive of Paul wrestling with the pros and cons of the right amount of tension with other social formations, and the ramifications of exclusivity versus inclusivity in the communities to which he was a party. A location on the wrong side of a community's "tension" threshold is a type of alienation.

For Jews of the era, resolving these types of identity issues was an ongoing social phenomenon which is well documented in contemporary scholarship. ${ }^{115}$ Circumcision was one of these contentious, high cost(!), identity-marking strategies. In Paul's time and place there were a wide range of associations whose criteria for membership and relative exclusivity varied widely. The Pharisees are but one example. Paul's writings document his interest in forging a community that is, at least rhetorically, more oriented towards inclusivity than the Pharisaic traditions of

\footnotetext{
115 John M.G. Barclay, The Jews in the Mediterranean Diaspora: From Alexander to Trajan (323 BCE-117 CE) (Berkeley: University of California Press, 1996) for a study that endeavors to provide tools with which to measure and assess the amount of Jewish "assimilation" and "acculturation" in the era. Elias J. Bickerman asserts that the root of the problems with Antiochus leading to the Maccabean revolt was based on "Jews themselves ... who aimed at a reform of the ancestral faith. That reform was to lead to the rejection of the belief in the uniqueness of God, without, however, a complete rejection of the God of the fathers and without becoming entirely disloyal to Zion,” The God of the Maccabees: Studies on the Meaning and Origin of the Maccabean Revolt (Leiden: E. J. Brill, 1979), 1. In other words, the reform is evidence of significant assimilationist minded factions, including those in the most influential circles of society, embracing the ways of the dominant Hellenistic culture. See also, Erich S. Gruen, Diaspora: Jews Amidst Greeks and Romans (Cambridge, MA: Harvard University Press, 2002), and Heritage and Hellenism: The Reinvention of Jewish Tradition (Berkeley, CA: University of California Press, 1998); George W. E. Nickelsburg, Ancient Judaism and Christian Origins: Diversity, Continuity, and Transformation (Minneapolis, MN: Augsburg Fortress Publishers, 2003); Victor Tcherikover, Hellenistic Civilization and the Jews (New York: Atheneum, A Temple Book, 1959); Frederick C. Grant, Hellenistic Religions: The Age of Syncretism, The Library of Liberal Arts (Indianapolis, IN: Bobbs-Merrill, 1953); Martin Hengle, Judaism and Hellenism: Studies in their Encounter in Palestine during the Early Hellenistic Period (Philadelphia: Fortress Press, 1981); and Erwin R. Goodenough, Jewish Symbols in the Greco-Roman Period, edited and abridged by Jacob Neusner, Bollington Series (Princeton, NJ: Princeton University Press, 1992).
} 
his earlier life would allow. The social formations engendered by Paul's preaching were still exclusive, but the specific practices that denoted exclusivity had changed from those of his prior orientation. Gone, for non-Jews, was the practice of circumcision and the yoke of the law. Being recognized as a child of God is not based on genealogy (Rom 9.6-8), but on one's inner commitment (Rom 2.28-29), one’s recognition of a call (e.g. Rom 1.7), and fidelity to the code of conduct within the new community.

There are implications to such identity issues that may have impacted Paul's universalizing, boundary-crossing, community-forming work. If we are to assume that Paul was (formerly) the pious sectarian he claimed to be, we might be able to assume that such an identity delivered him a committed Pharisee community at the same time it alienated him from much of the rest of humanity, including Jews belonging to other, or lower tension communities. Ultimately, given the vast diversity of Diaspora Judaism, it is difficult to know what a Pharisaic Jew in Tarsus would look like. Did the Jews in Tarsus attend the Greek theater as was the practice of many Jews in contemporary Miletos? ${ }^{116}$

It is also difficult to know with any confidence how Paul's notions of piety aligned with the expectations and practices of his native community. Did Paul's zeal for the law alienate him from a community of more assimilated Jews? ${ }^{117}$ If one

\footnotetext{
${ }^{116}$ Harland cites inscriptional evidence that reserved seating for "Jews and God-fearers" at the Theater in Miletos, Associations, Synagogues, and Congregations, 110, 201. Interaction between Jews and Hellenistic civic society was common. He writes, "[t]here is clear evidence from Roman Asia (esp. epigraphic evidence) that being a member in a Jewish group did not mean the dissolution of all participation in conventions, institutions, and constituent groups of the polis," 201.

${ }^{117}$ E.g. thinking that paralleled "Christ is the end of the Law" (Rom 10.4) might not have been well received.
} 
imagines that Paul's notions of what it meant to be a Jew were rejected by his local Jewish community, certainly one could imagine that with this rejection came a profound sense of alienation. Providing this is a plausible scenario, one may be able to understand Paul's push for a version of Judaism that was inclusive to all who wanted to be included, which is to say, open to all who would believe (Rom 10.4). On the other hand, Paul's rigid Pharisaism might have so alienated him (in his own mind) from the Gentile community at large that he sought a reinterpretation of his tradition that changed the nature of the exclusive exchange-relationship in which he engaged as a Pharisee.

His claims of piety as a Jew (e.g. a Hebrew born of Hebrews, circumcised on the eighth day, a Pharisee, of the tribe of Benjamin, Phil 3.5-6) may better serve the rhetorical functions required by his letters than as an accurate biographical description. ${ }^{118}$ Paul worked to redefine what it meant to be a Jew in order to open up membership in his new Christ-centered community (Rom 2.28-29). He has also boasted of his ability to be all things to all people (1 Cor 9.20-23). Whether it is a means of redefining what is required to be considered a Jew or behaving inconsistently in order to maximize the breadth of his appeal, Paul shows himself to be working outside of a rigid framework fixed by tradition. ${ }^{119}$ Boyarin's notion of Paul as a "cultural critic" is helpful here as such individuals find themselves on the

\footnotetext{
${ }^{118}$ Paul would not be the first of us (nor will he be the last) to revise the ways of his youth for the needs of later times. O'Donnell's Augustine which analyzes Augustine's Confessions is a great example of an individual (re)construing and (re)presenting the piety of his youth in service of the needs of the present. James J. O’Donnell, Augustine: A New Biography (New York: HarperCollins, 2006). The evolving accounts of Smith's recollection of his own history is relevant here too.

${ }^{119}$ How "fixed" this tradition was would have varied widely throughout the "Hellenistic Jewish cultural koine,” Boyarin, A Radical Jew, 14.
} 
edge (or forefront, or margin) of their community's evolving ideas concerning acceptable behavior and practice. ${ }^{120}$ Paul's new communities developed specific notions of purity requirements just as the Pharisees developed theirs. ${ }^{121}$ Purity remained important, it was simply understood, practiced and expressed differently. ${ }^{122}$

Radically redefining what it meant to be a Jew in itself suggested a type of alienation from a Jewish community that had very specific ideas concerning identity. Israelites have marked their distinctiveness in the flesh for centuries (Gen 17.914). ${ }^{123}$ If Paul's new ideas about who gets to be called a Jew were not a result of his alienation from his Jewish community, certainly his promotion of them would earn him distain-and ultimately alienation — from the very community he claimed to represent.

120 "[T] he ultimate inadequacy of the Law stem[ed] from its ethnic exclusiveness,” Boyarin, A Radical Jew, 136.

${ }^{121}$ This was a simultaneous and ongoing process. Boyarin argues that as time went on different strands of thinking — in larger part based on one's primary language and attending thought world — became polarized and antagonistic, A Radical Jew, 14. See also, Border Lines.

${ }^{122}$ See Saldarini, "Pharisee” ABD, V 295.

${ }^{123}$ Daniel Boyarin sees Paul as “Jewish cultural critic," and “an internal critic of Jewish culture,” A Radical Jew: Paul and the Politics of Identity (Berkeley: University of California Press, 1994), 2, 12. Boyarin's perspectives are no doubt shaped by his self-perception as a "talmudist and postmodern Jewish cultural critic,” 1, 4, 8, 11, 12, 137, 262 n. 6. 


\section{Smith: Poverty, Itinerancy and Longing for Belonging}

all men try to avoid inheriting the poverty or sufferings or disgrace of their ancestors

-Justin, First Apology, 1.12

my circumstances in life [were] such as to make a boy of no consequences in the world

-J. Smith, History, 2.22

Contextual analysis also facilitates an exploration of the Smith family's background, its divided religious household, its location in a culture in which folk magic blended seamlessly with many nineteenth-century notions of Christianity, ${ }^{124}$ and their experiences of alienation in a number of contexts.

The Smith family's poverty and frequent moves were additional factors asserting a marginalizing status upon the young Joseph Smith Jr. Philastus Hurlbut's admittedly unfriendly documentation of the Smith family's relationships with its neighbors provides a tremendous source of data regarding the Smith's (in)ability to harmoniously coexist with their neighbors. ${ }^{125}$ All of these factors-itinerancy, poverty, penchant for magic, and strained relationships with neighbors - contribute to the way Smith perceived of himself in relationship to his environment. It is

\footnotetext{
${ }^{124}$ Catherine Albanese, A Republic of Mind and Spirit: A Cultural History of American Metaphysical Religion (New Haven, CT: Yale University Press, 2007), e.g. 6-7, 69, 75, 147. Bushman, Rough Stone Rolling, 26, 49-51; Dan Vogel, The Making of a Prophet; D. Michael Quinn, Early Mormonism and the Magic World View; John L. Brooke, The Refiner's Fire: The Making of Mormon Cosmology, 1644-1844 (Cambridge, UK: Cambridge University Press, 2001); "Mormonism emerged at the crossroads of magic and Christianity,” Robert D. Anderson, Inside the Mind of Joseph Smith: Psychobiography and the Book of Mormon (Salt Lake City: Signature Books, 1999) 217.

${ }^{125}$ As published in Eber Howe, Mormonism Unvailed [sic] (Painsville, OH: Eber Howe, 1834), 175277.
} 
certainly plausible to see Smith as one who did not feel himself a part of any community beyond that of his own family. ${ }^{126}$

It can be argued that Smith enjoyed little to no sense of social belonging beyond that of his immediate family and perhaps his money-digging friends. Joseph Sr.'s family struggled economically and moved frequently, never ultimately finding the financial stability it needed. From 1803 to 1816 the Smith family moved seven times, the last of which took them to New York and away from their network of family and friends. ${ }^{127}$ They had been "warned out" of Norwich, Vermont, in March of 1816 by neighbors who did not want the implicit responsibility of providing sustenance to the presumably impoverished family when they feared a poor harvest. ${ }^{128}$ Joseph's mother Lucy and her family arrived in Palmyra “destitute," clinging to a few personal possessions and "barely two cents in cash."129 The family endured a number of stressful events, ${ }^{130}$ which in addition to the numerous moves included an outbreak of typhoid in the area (1812-1813), ${ }^{131}$ a serious bone infection

\footnotetext{
${ }^{126}$ Even if only a third of the interactions attested to by Smith’s neighbors in Howe's Mormonism Unvailed, have basis in fact, one gets the idea that the entire Smith family often saw their fellow settlers as little more than human opportunities for financial exploitation.

${ }^{127}$ Bushman, Rough Stone Rolling, 19. Joseph would have been eleven years old in 1816.

${ }^{128}$ Vogel, The Making of a Prophet, 20. No doubt poverty may have been the main focus, but one might venture that had the family, Smith Sr. in particular, appeared industrious, eager for work, and able to get along with the rest of the community, no such "warning-out" would have happened. Perhaps the Vermont community had grown weary of the same behavioral patterns that filled the pages of their later Manchester neighbors' affidavits, those collected by Howe. The speculation of a "difficult harvest" seems to be Vogel's.

${ }^{129}$ Lucy Smith, Biographical Sketches of Joseph Smith the Prophet, and His Progenitors for Many Generations (Liverpool: S. W. Richards, 1852), 70. Bushman, Rough Stone Rolling, 29.

${ }^{130}$ Bushman Rough Stone Rolling, 20 and Vogel disagree on the amount and effects of this stress to the Smith family.

${ }^{131}$ Bushman, Rough Stone Rolling, 20.
} 
that left Joseph Jr. either in bed or on crutches from age seven to ten, ${ }^{132}$ "medical bills [that] had broken [the family] financially (1813-1814), ${ }^{133}$ fear of eviction, crop failures, and ultimately repossession of the house that they had built and the land they had worked hard to clear and farm. Shipps writes "he [Joseph] wanted to belong, but he could not; he did not fit the pattern of men whose worlds were limited by scant schooling, mortgaged homesteads, and revivalist religion. He was different and he knew it."134

Reports of interaction between the Smith family and their neighbors document very exploitative relations. ${ }^{135}$ Given the nature and frequency of the Smith family's attempts to take advantage of their neighbors economically, it is difficult to assume that they felt part of the area at large. The sentiments expressed in the affidavits written by Smith's neighbors depict a family that is clearly acting as if not belonging to the community. The views expressed by over fifty neighbors and acquaintances, as collected by Hurlbut, testify both to alienated behavior and behavior that would continue to alienate. On top of this the "family was marginalized religiously."136 Joseph Sr. worked as a shop keeper, a hired laborer and as a teacher. Poor judgment and bad luck stymied his attempts to own his own land. In 1830 he spent thirty days in jail for his debt obligations. ${ }^{137}$

\footnotetext{
${ }^{132}$ Bushman, Rough Stone Rolling, 21.

${ }^{133}$ Bushman, Rough Stone Rolling, 27.

${ }^{134}$ Jan Shipps, “The Prophet Puzzle,” Journal of Mormon History, vol 1, 1974, 3-20, 11.

${ }^{135}$ See collection of affidavits in Howe, Mormonism Unvailed, 231-290.

${ }^{136}$ Bushman, Rough Stone Rolling, 26, 40-41.

${ }^{137}$ L. F. Anderson, Lucy's Book, 177-78.
} 
While folk magic and even treasure chasing were embraced in many circles of this time and place, it certainly was not accepted by all circles. In fact, just being identified as a money-digger was enough to earn outright distain in the company of some. The Smith family's many moves during Joseph's youth, their poverty, their split and diverse religious affiliations and their tendency to support themselves financially by "alternative" means was likely to keep young Joseph bumping into distain and alienation ${ }^{138}$ in many parts of his life. His youthful religious experiences were rejected by the local Manchester pastor and he was considered a disruptive influence and a "disgrace to the church" by his in-laws in Harmony, Pennsylvania. ${ }^{139}$ Some of his own words, penned much later in life, speak to his rejection by his own community, especially the religious leaders whom he believed should have otherwise befriended and counseled him. He writes,

During the space of time which intervened between the time I had the vision and the year eighteen hundred and twenty-three-having been forbidden to join any of the religious sects of the day, and being of very tender years, and persecuted by those who ought to have been my friends and to have treated me kindly, and if they supposed me to be deluded to have endeavored in a proper and affectionate manner to have reclaimed me-I was left to all kinds of temptations; and, mingling with all kinds of society, I frequently fell into many foolish errors ... Joseph Smith, 2.28.140

The recollection is somewhat disingenuous and packed with feigned naiveté. Accounts of Smith's youth barely mention a breath about religious inclinations he

\footnotetext{
${ }^{138}$ Bushman, Rough Stone Rolling, 43.

${ }^{139}$ Vogel, The Making of a Prophet, 127; Richard L. Bushman, Joseph Smith and the Beginnings of Mormonism (Urbana, IL: University of Illinois Press, 1988), 94-95.

${ }^{140}$ Also cited as “Extracts for the History of Joseph Smith, The Prophet,” 2.28. As always, Smith’s autobiographical account must be read with caution as Smith is less interested in a strict documentary history than he is with a rhetorical presentation of his unlikely, implicitly divinely aided, rise to prophethood. In particular, his claim of being "forbidden to join any of the religious sects of the day" is designed to counter the notion that he was indifferent to religion as a youth.
} 
may have had. Moreover, Smith should not have been surprised at all that his claims of visionary encounters met with abuse and derision given his and his family's penchant for scrying and other types of scheming that involved supernatural manipulation. In any event, irrespective of the historical accuracy of Smith's reflections, one gets the sense that he felt ridiculed and ostracized.

In fact, it might be profitable to compare ${ }^{141}$ the behavior of the Smiths as perceived in the eyes of their neighbors to perceptions of Gypsies. The use of the term "gypsy" here is not meant to cast derision on either the Roma or the Smith family. Rather it is to illustrate, perhaps by an exaggeration, a conflict of cultures where Gypsies play the role of "outsiders" or the "other." Certainly just as with American frontier culture of the early nineteenth century, there are idiosyncratic notions of right and wrong, and honor and shame within Gypsy culture. ${ }^{142}$ The behaviors considered acceptable when dealing with those outside of one's own culture often differ substantially from those that govern insider interaction. One need look no further than the white European settlers' interaction with, and abusive, inequitable treatment of, "the other" of this time period, whether red man or the black man, to see this double standard. The double standard existed within Gypsy culture too. Gypsy and Western notions of appropriate behavior differed in significant ways. What Western culture may frown upon as a means to earn a living might be perfectly acceptable to the marginalized Gypsy on the threshold of

\footnotetext{
141 “A comparison is a disciplined exaggeration in the service of knowledge.” Jonathan Z. Smith, Drudgery Divine: On the Comparison of Early Christianities and the Religions of Late Antiquity (Chicago, IL: University of Chicago Press, 1994), 52 (emphasis added).

142 The biblical Ten Commandments are meant for insiders. The command "thou shalt not kill” lacks further qualification that was taken for granted in its own day. Thou shalt not kill another Israelite!
} 
existence. In fact, practices such as deception for gain and petty theft may be so normative within Gypsy culture that members of the community see no problem with it as a way to earn a living, especially when it comes at the expense of individuals who are part of the dominant, marginalizing and alienating, mainstream culture.

As an example of rationalizing marginal behavior, Roswell Nichols recalls Smith's father, Joseph Sr., saying "that it was sometimes necessary to tell an honest lie, in order to live."143 The attitude expressed by the elder Smith's comment would explain the rationalization behind the deceptive practices found so troublesome by Smith's neighbors as documented by Howe. The notion that a "lie" can be "honest" perhaps best exhibits itself as a small bit of deception that is undertaken for conceivably legitimate reasons. Perhaps the senior Smith meant "earnest" lie, or even an "I-need-to-feed-my-family" lie. The attitude towards deception as a plausible means to a justified end (survival) is one that seems to have been incorporated into Smith's practices as a treasure seeker and a promoter of God's word. This attitude, however noxious it may be to the ears of moderns, has biblical sanction and is analyzed more extensively in chapter four. Paul boasts of his ability to use deceptive practices as a method of bringing glory to God (Rom 3.5-7). It requires little imagination to understand why the impoverished might feel justified in using deception if it put food in the bellies of their family members at the expense of those better off. 144

\footnotetext{
${ }^{143}$ Roswell Nichols testimony, Howe, Mormonism Unvailed, 257.

${ }^{144}$ Dostoyevsky's Crime and Punishment is a classic example of an individual wrestling with the moral implications of a criminal act that serves personal and perhaps even-from a rationalized
} 
Later in his life, Martin Harris recalled a revelation in which an angel told Smith that in keeping with his (Smith's) new mission, "he must not lie nor swear, nor steal." 145 One of course might wonder if lying and stealing are the standard sins of the era from which a man of God must turn away, or if they were in fact were part of Smith's daily regimen of making his way through life by any means possible-and therefore in need of being explicitly renounced. Even if the Smith family was innocent of every scheme depicted in Howe's collection, the important point is that many in Smith's community perceived the behaviors and money-making endeavors of the Smith family as unacceptable, almost as if the Smiths belonged to their own micro culture where unorthodox ways of earning a living were acceptable. ${ }^{146}$ This perception no doubt registered with the Smith family and may have been mutually reinforcing. Neighbors who did not care for the broad range of the Smith family's money making schemes, especially those who were antagonistic and judgmental, would reinforce the sense of alienation the impoverished family would have felt. This in turn, in the minds of the Smiths, may have legitimized the deceptive practices documented in Howe's collection. When Wayne County resident G. W. Stodard recalled in 1833 that the Smith family "never made any pretentions [sic] to respectability" 147 we can take this to mean that the Smith family seemed to be either unaware of, or uninterested in, conducting themselves in a manner deemed

perspective—social needs.

${ }^{145}$ As found in Richard Bushman, Joseph Smith and the Beginnings of Mormonism, 74.

${ }^{146}$ Joseph Capron, a neighbor, recalled, "I might mention numerous schemes by which this young visionary and impostor had recourse to for the purpose of obtaining a livelihood. He, and indeed the whole of the family of Smiths, were notorious for indolence, foolery and falsehood," Howe, Mormonism Unvailed, 259.

${ }^{147}$ Vogel, EMD 2:30. 
appropriate by their neighbors. This is not to say that either side is right or wrong, rather to say that what was recognized as acceptable behavior differed between the Smiths and some of their neighbors.

"Acceptability" is of course culturally determined and will vary even by members of the same culture. Clearly some of the Smith family antics fell into a grey area. Peter Ingersoll, a Smith family neighbor and friend, recalled an instance in which "Jo ... exhibited true yankee wit."148 The story Ingersoll tells, however, is one in which Smith deceived a toll collector at the toll-gate near Ithaca, New York. On his way into town, Smith told the toll collector that he would "hand" him the full fare on his way back in a few days. When the time came on the return trip, Smith handed the toll-collector enough money to pay the toll in both directions. As the tollcollector did not recognize Joseph, he handed half of the fare back. Smith made no attempt to correct the error and Ingersoll found this a clever and permissible form of deception—even lauding it as "true yankee wit." The toll collector and some of Smith's other neighbors might not have agreed with Ingersoll's taxonomical characterization of this incident. The vignette does show that Ingersoll appreciated some of Joseph's cunning characteristics, even if deploring others. This simple recognition perhaps suggests Ingersoll's capability of offering a balanced and credible assessment of his former neighbor. What counts as deception versus ingenuity will vary from person to person. ${ }^{149}$

\footnotetext{
${ }^{148}$ Howe, Mormonism Unvailed, 235.

${ }^{149}$ James W. Cook, The Arts of Deception: Playing with Fraud in the Age of Barnum (Cambridge, MA: Harvard University Press, 2001), 1-29.

D. Michael Quinn picks up on this theme of a double standard of ethics—one standard for behavior to fellow Mormons, another standard for outsiders — as it manifest itself on an institutional level in the 1830s.
} 
Applying the same scrutiny to Paul, it is clear that he sought to legitimize his deception by asserting that it showered glory on God (Rom 3.7). In other words, Paul argues that his deceptive means are legitimized by his praiseworthy ends. The role of deception in human life and social formation is riddled with complexity, ambiguity and the tendency to moralize. There simply is no absolute behavioral standard. The important social role of deception is addressed at length in chapter four.

In light of Oakes' framework, it seems reasonable to assume that "the sense of not belonging" Smith must have experienced as a youth contributed to his desire to be the central focus of a new community. So the main consideration here is that it is entirely conceivable for Smith and Paul to be at the same time products of their culture while feeling alienated from the dominant or mainstream components of that culture. The groups they fostered thrived as responses to mainstream culture. ${ }^{150}$ Part of this success was that the critique of the dominant tradition, as articulated by the prophet, found purchase in the imagination of a number of followers. The grand narrators found subscribers. The prophet's message

Quinn calls it "theocratic ethics" which freed Mormons from obligations of civic law in a number of situations. Quinn lists not only the unusual marital and sexual relationships allowed within the Mormon community, but,

official denials of actual events, the alternating condemnation and tolerance for counterfeiting and stealing from non-Mormons, threats and physical attacks against dissenters or other alleged enemies, the killing and castration of sex offenders, the killing of anti-Mormons, the bribery of government officials, and business ethics at odds with church standards. ${ }^{149}$

The same practices and double standards that alienated the Smith family in New York state later alienated the Mormon community in Ohio, Missouri and Illinois. Providing alienation from the mainstream is indicative of some form of tension between two communities of people. We can see in this alienation a type of social glue that binds the alienated together against the outsiders who at the same time are the alienators, Stark, Acts of Faith, 193-276.

${ }^{150}$ Boyarin would describe such a "response" as the work of a "cultural critic," A Radical Jew, 2, 4, 8, 85, 135-7, 262 n.6. 
resonated with hearers, it articulated compelling solutions to the perceived problems inherent in the relevant time and place. In the process, Paul and Smith moved from the periphery of the larger cultural milieu to the center of their own inspired social formations. ${ }^{151}$ The world views espoused there were articulated, justified and legitimated by the texts these men produced.

\section{Development of Career Skills}

\section{Paul: Partisan Persecutor, Partisan Promoter}

I opposed him to his face

-Paul, Gal 2.11

In addition to theorizing about the impact early-life perceptions of alienation have on the subsequent motivations of a prophet, Oakes' model provides a starting point from which to explore the development of career skills (a component of the "incubation stage"), that prepare and serve the individual in their later prophetic vocation. ${ }^{152}$ In the case of Paul, his self-described background as a zealous "persecutor of the church" and his boast of unwavering orthodoxy-"as to righteousness under the law, blameless," (Phil 3.6)—provides significant insights into the type of skills Paul developed prior to his reorientation to preaching Christ and the cross.

\footnotetext{
151 Aberbach writes,

[C]harisma is defined as a dynamic force whose essence is the dialectic of paradox. It is the creative clash and embrace of inner fantasy and political reality. Though deeply personal and individual-at times dictatorial—charisma has nevertheless helped to shape most of the major modern democracies. It creates and is created by crisis. The charismatic is often an alien, from a broken or distorted family background, yet up to a point can create a group sense of familial harmony and unity, 16 .

152 Oakes, 21, 74-97.
} 
Oakes' notion regarding the importance of developing career skills reinscribes an important component of the sociological theorizing of Stark and Bainbridge. Stark and Bainbridge propose three related models that analyze the "formation of innovative religious movements." 153 The second of these, "The Entrepreneur Model" is based on the entrepreneur's ${ }^{154}$ possession of special and specific skills that facilitate success in the new endeavor. ${ }^{155}$ These skills are often achieved through "intimate participation in a successful, recently-founded [NRM]" or through "working closely with the leaders of a successful earlier cult."156 The need for practical skills is an obvious component behind the success of any new venture, but is generally overlooked in the world of religious innovation which emphasizes the divine guidance of the prophet. Paul's skills and aptitudes were acquired as a partisan promoter of (what is presumed to have been) his ancestral faith.

Paul reveals his career training amidst the rhetoric of his commitment, zeal, and the powerful nature of his call. He reminds his Galatian community of his "earlier life in Judaism" (Gal 1.13). He writes that because he was "more zealous for the traditions of [his] ancestors" than were his peers, he advanced beyond them (Gal 1.14). In making this claim, Paul emphasizes to his readers that his break with his

\footnotetext{
${ }^{153}$ Stark and Bainbridge, A Theory of Religion, 155-193. The three posited models are "The Psychopathology Model,” 158-168, “The Entrepreneur Model” 168-178, and “The Subcultural-Evolution Model” 179-187.

${ }^{154}$ Stark and Bainbridge define "entrepreneurs" as "persons who start and promote new enterprises in order to obtain rewards through profitable exchanges,” A Theory of Religion, 172. While Stark and Bainbridge allow that entrepreneurs "are motivated by the desire for profit” 169, it must be emphasized that “profitable exchanges” enjoyed by NRM leaders need not include material goods or tangible resources. Power and status alone will often suffice.

155 Stark and Bainbridge, A Theory of Religion, 170.

${ }^{156}$ Stark and Bainbridge, A Theory of Religion, 169, 172.
} 
past was not trivial. His claimed youthful zeal is intended to bear witness to the undeniably powerful nature of his call, and emphasized that any deviation from the practices of his native tradition would have been adamantly resisted. ${ }^{157}$ The implication is that the message Paul proclaims is so much more persuasive than the unaugmented, unmodified, unrevised, practices of his ancestors, that he had no choice but to break from the teachings of his people to promote the superior way revealed to him. Even if it took several years to materialize, Paul perceived his shift in orientation as dramatic.

Beneath the rhetoric that emphasizes the seriousness of his reorientation, and on a more subtle level, Paul informs us of his impassioned nature as a human being and the skills he has acquired as a serial promoter of related religious ideologies. Paul's writings project a sense of unhesitating confidence, a rigid commitment and total dedication. In sum, while Paul's rhetoric about his past devotion is intended to highlight the compelling nature of his call to preach Christcrucified, it also reveals a background of training to passionately promote sectarian causes.

Paul's preparation as a prophetic leader began when he was a devoted student of Pharisaic Judaism. ${ }^{158}$ His community involvement facilitated a context and outlet for his religious passion and provided a training ground for his promotional skills and his ability to denounce or "persecute" adherents of

\footnotetext{
${ }^{157}$ Segal writes that as Paul "was a success as a Jew, not a failure . . . it is the very unlikeliness of his conversion, the persecutor who became the latest apostle, that proves the power of the Holy Spirit" to his hearers and himself, Paul the Convert, 27.

${ }^{158}$ Providing such a claim accurately reflects Paul's past and is not self-serving rhetoric designed to conceal active participation in an alternative cultic or religious community that used the Hebrew writings as sanctioning and centering elements for their social formation.
} 
competing sects. This tendency is reflected in his repeated caution to the Galatians that "if anyone proclaims to you a gospel contrary to what you received [from us], let that one be accursed," (Gal 1.9). One can easily imagine Paul making the identical claim as a Pharisee harassing earlier iterations of "the called." The same zeal he exhibited as a putative Pharisee ${ }^{159}$ manifested itself in his self-designation as an apostle to the Gentiles.

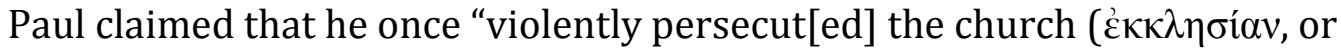
"the assembly," "the called") of God" to the point that he tried to "destroy it" (Gal 1.13). ${ }^{160}$ Later in his life, as a devoted believer in Christ crucified, Paul tries to destroy (at least rhetorically) any and all of those who preach a message different from his own. His admission of formerly persecuting competing sects is part of his effort to promote his own (Pharisaic) sectarian interests. The admission indicates Paul had already developed the requisite skill set. His call was perhaps little more than a self-realized sanction for him to conduct his religious business as usual—only he was to redirect his zeal from one social formation to another. "The one who formerly was persecuting us is now proclaiming the faith he once tried to destroy" (Gal 1.23). Paul has not altered his operating procedure, only his affiliation.

\footnotetext{
${ }^{159}$ Hyum Maccoby disputes the contention that Paul was a Pharisee as he claimed he was. Maccoby argues that the Diaspora communities to whom Paul wrote would have no understanding of the political situation in Palestine, and as such no idea of what it meant to be a Pharisee-which is why Paul could claim to be one even though he did not act, speak or argue as one. Maccoby continues that no one not already convinced that Paul was a Pharisee would become convinced by reading the evidence at hand-he would be "regarded as a Hellenistic writer." The Mythmaker, 61-64. As Maccoby has a palpable agenda to resurrect the dignity of the Pharisees of antiquity, much of his scholarship must be read with caution. Certainly, however, it would not be inconsistent for Paul to claim that he was, or was a heir to, something that he was not.

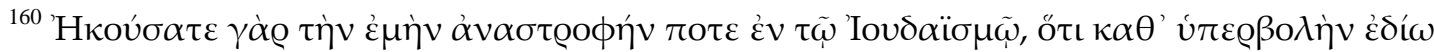

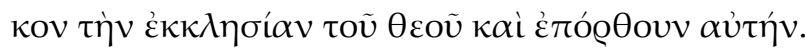


Paul's summary representation of his past persecution phase ${ }^{161}$ is a virtual synopsis of the basic operating procedures of a committed partisan promoting his own cause. What may have appeared as persecution to those receiving the brunt of it, might also be described as little more than harsh, competitive, partisan rhetoric.

An example of Paul's zealous promotional abilities is reflected in his recounting of his ruthless public rebuke of Cephas in Antioch. Paul boasts to his community in Galatia,

when Cephas came to Antioch, I opposed him to his face, because he stood self-condemned; for until certain people came from James, he used to eat with the Gentiles. But after they came, he drew back and kept himself separate for fear of the circumcision faction. And other Jews joined him in this hypocrisy .... But when I saw that they were not acting consistently with the truth of the gospel, I said to Cephas before them all, "If you, though a Jew, live like a Gentile and not like a Jew, how can you compel the Gentiles to live like Jews?" 162 (Gal 2.11-14, emphasis added).

Whether one sees Cephas as a member of a competing sect (Jesus-centered,

Jerusalem-based Judaism), or as a competing authority figure within Paul's social formation (Christ-centered, Gentile-focused Judaism), the rebuke with which Paul blasts Cephas reflects Paul's ability to publicly attack those with whom he competes or disagrees. ${ }^{163}$ In the passage above, Paul boasts of his direct face-to-face opposition. He wants his readers to know that his condemnation of Cephas' actions was public. ${ }^{164}$

161 "I advanced in Judaism beyond many among my people of the same age, for I was far more zealous for the traditions of my ancestors," Gal 1.14; “As to zeal, a persecutor” Phil 3.6 (all emphases added).

${ }^{162}$ Compare, 1 Cor 9.20-22 where Paul boasts in general about his ability to successfully conduct himself in the very same manner for which he attacks Cephas.

${ }^{163}$ This analysis takes Paul's version of events at face value as an historical account. Certainly, however, just as was the case with Smith's retrospectives, this account is presented rhetorically in a manner designed to serve Paul's image and political needs.

${ }^{164}$ Note the irony—or perhaps double standard or even hypocrisy—of Paul's boast to the Corinthians 
Had this exact interaction happened prior to Paul recognizing himself as ostensibly in alignment with the message promoted by Cephas, one would have very good reason to view Paul's rebuke of Cephas as the type of action of which he had boasted earlier in the same letter: "you have heard, no doubt... I was violently persecuting the church of God," (Gal 1.13, see also 1 Cor 15.9, Phil 3.3-6).

When Paul writes that anyone proclaiming a gospel other than his own should be "accursed" (Gal 1.8-9), he shows himself still to be a participant in the denouncement if not "persecution" of competing messages or claims. These behavioral practices often come with being a committed partisan. In sum, Paul has a history of zealously promoting one particular ideology at the expense of competing preachers and competing claims. The self-confident, brash, rhetorical skills that attend vigorous partisanship and facilitate promotion of one's own cause can also be deployed to delegitimize-if not persecute-opponents as well. He writes to the Galatians that "even if we or an angel from heaven should proclaim to you a gospel contrary to what we proclaimed to you, let that one be accursed!" (Gal 1.8). ${ }^{165}$

Whether Paul is "accursing" his competitors in the manner of Gal 1.8-9, or publicly attacking them in the manner he did Cephas in Antioch, Paul has clearly developed a certain level of competence in promoting sectarian causes.

Reading through Paul's claims is insightful for our purposes. Paul documents his conflicts with competing authority figures at the same time he attempts to undermine their status. Despite rejection by the unnamed leaders in Jerusalem (Gal

of being “all things to all people,” 1 Cor 9.20-23, and yet in Galatians he condemns Cephas for attempting to do the very same thing: trying to be all things to all people.

${ }^{165}$ For emphasis, Paul repeats this condemnation in the next verse, Gal 1.9. 
2.4-6), he writes that the named Jewish leaders of the Jesus movement-(James, Cephas and John (Gal 2.9)—extended to Paul (and his companion Barnabas), as he

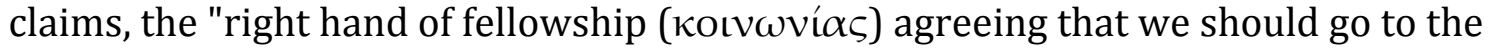
Gentiles" (Gal 2.9).166 This vignette is further unpacked for its power implications in chapter three.

It is not difficult to understand this encounter from more than one perspective. The first is the one generally understood by Christians, based on Luke's synthetic, whitewashed account, 167 in which Paul is officially embraced by the Jerusalem pillars and commissioned to spread his word to the Gentiles. My reading understands the encounter as concluding with the sectarian "pillars" adamantly remaining sectarian along the lines of the Gospel of Matthew 10.5-6 and 15.22 where Jesus issues the unambiguous directive to his designated Twelve: "'Go nowhere among the Gentiles, and enter no town of the Samaritans, but go rather to the lost sheep of the house of Israel." 168

These two passages that mandate avoiding Gentiles as converts are attributed to the living, pre-crucified Jesus. They are in flat contradiction to the socalled Great Commission delivered by the risen Christ in the penultimate verse of

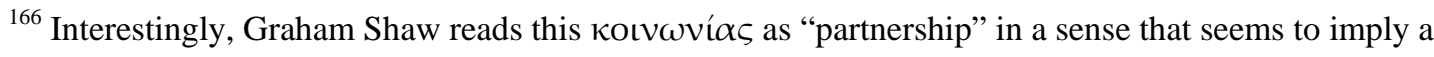
financial arrangement, "the gentile franchise." Graham Shaw, The Cost of Authority: Manipulation and Freedom in the New Testament (Philadelphia, PA: Fortress Press, 1983), 53.

${ }^{167}$ Acts 15.1-35.

168 Matt 10.5-6. This statement obviously conflicts with the "Great Commission" of Matthew 28.19 which, to this reader, by virtue of its placement at the very end of the text, and its contradiction of earlier passages (10.5-6, 15.22), appears to be a fairly transparent addendum that served the needs of a growing, more inclusive, perhaps now Pauline inflected, Christian movement.
} 


\section{Matthew. ${ }^{169}$ In my reading, the right hand that James, Cephas and John offered to}

\section{Paul was one of separation and departure. They eagerly encouraged him to take his}

message to the Gentiles as it was not their message and the Gentiles were not their

people. The pillars communicated that Paul should take his message to those who

were neither Jews nor part of the Jerusalem movement, something along the lines of

"keep that sectarian garbage off of our turf and away from our followers-but feel

free to poison the foreigners with it."170

${ }^{169}$ The Great Commission stands on dubious grounds not just because it is attributed to a dead man risen from the grave, but as it sits at the very end of the gospel, the easiest spot to augment. By virtue of its contradictory message and placement at the very end of the text, the Great Commission appears to be a fairly transparent addendum that served the needs of a growing, more inclusive, perhaps by this time Pauline inflected, Christian movement.

${ }^{170}$ Why would the pillars react in such a way? Because Paul's message was an innovation cut from the Greco-Roman world of Diaspora Tarsus which had little more than the name Jesus in common with the Jesus movements of Palestine. Paul's notion of Pharisaic Judaism certainly influenced the way he evolved into his modified views of what it means to be a "Jew." "Christ is the end of the law so that there may be righteousness for everyone who believes" (Rom. 10.4). The reality of his teachings, however, offers little overlap with what is presented as the teachings of Jesus in the earliest Christian gospels, especially Q and Thomas. So if things were as I am arguing, why would Paul even concern himself with other components of the Jesus movement? The answer, I believe, is that Paul's interests in doing so are somewhat akin to those of Luke's in both his gospel and Acts. Luke goes beyond Matthew and Mark to highlight Jesus' Jewishness. Luke is the only gospel writer to specify the newborn savior's circumcision on the eighth day (Luke 2.21) in keeping with traditional Jewish practice. Like Luke, Paul wants to locate and authenticate the message preached as originating in the traditions and texts of Israel. Both want to be seen as in alignment with the "true" trajectory of the perceived center of the ancient tradition.

Why would either of Luke or Paul write in a manner aimed at convincing readers of the Jewish origins of the movement if in fact there was not some question as to how "Jewish" the origins really were. Here David Ulansey's deconstruction of Mithraism is helpful, The Origins of the Mithraic Mysteries: Cosmology and Salvation in the Ancient World (New York: Oxford University Press, 1989). Rooting Mithraism in ancient Persia creates a trajectory with which Mithraic practitioners can boast of a noble legacy, even if that legacy is completely manufactured. Luke and Paul need others to see Christianity as a movement that legitimately originated within Israelite tradition and with the Jewish people. They want to avoid the appearance of being another imagined sect, another invented tradition with borrowed gods and a mythological heritage.

As a modern, comparative example, I was astounded to find that the fraternity to which I had pledged my freshman year of college claimed to have its roots in a secret society developed by university students in need of protection and community in Bologna, Italy of the $14^{\text {th }}$ century! These ancient roots had been dusted off and deployed by the "five founding friends and brothers" who founded the modern (putative) incarnation of the fraternity at the University of Virginia in the $19^{\text {th }}$ century. Having just debunked the claims of the culture of my youth, I was amazed that none of my fictive brothers were concerned about this obvious initiation-related fiction being passed off as legitimate history. On the other hand, the bogus nature of the history mattered little. It served to base the fraternal practices in deeper history and simply served as one component of an identity marking strategy. What was important was a bond generated through 
Galatians 2 documents Paul's alienation from one presumed center of the Jesus movement at the same he tries to claim sanction for his mission from three specific named members of that same community. He responds to his rejection from the center as a mandate to lead on the periphery.

\section{Smith: Seeker of Hidden Treasures, Golden and Spiritual}

It is not difficult to grasp how the skills Paul developed as a promoter of one religious sect are readily transferable to the promotion of another. Smith underwent a similar developmental process although modern distinctions between magic and religion, and their taxonomical baggage, tend to obscure the progression somewhat. The culture Smith inhabited as a youth was full of visions, ${ }^{171}$ angels, spirits, demons, and magical occurrences. Given the subjective and culturally contingent perceptions that create the supernatural realm, Smith's ability to convincingly posit and navigate its terrain is a skill that easily transfers from one of its subsets, magic, to another, religion. Both domains feature non-obvious, nonempirical beings that communicate with humans, hold important knowledge, and often require propitiation. They were related areas with related discursive practices. ${ }^{172}$ The thrust of the argument in this section is that the skills that

pledgeship, initiation, and joining a tight community of individuals. See also, James R. Lewis and Olav Hammer, editors, The Invention of Sacred Tradition (Cambridge: Cambridge University Press, 2007) and Terence Ranger and Eric Hobsbawn, editors, The Invention of Tradition (Cambridge: Cambridge University Press, 1992).

${ }^{171}$ Lawrence Foster writes that “far from being unique, Joseph Smith’s first vision and related experiences were almost a classic model of such phenomena in all times and culture," "First Visions: Personal Observations on Joseph Smith’s Religious Experience” Sunstone, 8.5 September-October, 1983, 39-43. See also Richard, L. Bushman, “The Visionary World of Joseph Smith” BYU Studies 37, no.1 (1997-98), 183-204; and, Ann Taves, Fits, Trances, and Visions: Experiencing Religion and Explaining Experience from Wesley to James (Princeton, NJ: Princeton University Press, 1999).

172 Just as one time science fiction writer L. Ron Hubbard's production of Dianetics was a product of a 
facilitated Smith's success in founding a new religion as a prophet were developed as an imaginative, entrepreneurial youth heavily engaged in the occult, receiving visions and pursuing material treasures buried in the ground. See Table 2.2.

Here, it is important to clearly state an important point. Smith's development of his personal and intellectual attributes was not methodically undertaken solely as a means to exploit humanity of their financial resources. It appears that Smith sincerely enjoyed interacting with the supernatural realm as an emotionally engaging, often social, activity in its own right. ${ }^{173}$ Yet while it earned him some status, scrying was generally not financially rewarding. Smith was a smart kid and undoubtedly enjoyed learning new things. His learning process was not limited to specialized, occult knowledge. He also developed the traits of a charismatic. He learned how to influence others, read emotions, manage expectations, conduct himself appropriately, entertain, cajole, conceal his pranks and so forth. Oakes writes that charismatics enjoy learning of this type "for its own sake" and that there is generally "no previously thought-out master plan for control." Instead, socially and emotionally "effective manipulators dream of a better

science fiction writer, so too was Smith's story of the golden plates-an ancient hoard of precious material stowed in the ground by ancients only to be discovered by a chosen adept - a product of someone steeped in the culture of the magic-world. Smith's magic-world was also influenced by contemporary Christian restorationist thinking which allowed his discovery of the plates to provide a basis for restoring "Christ's true church.” For Hubbard as a "moderately successful science-fiction writer," see Douglas E. Cowan and David G. Bromley, Cults and New Religions (Malden, MA: Blackwell Publishing, 2008), 26.

${ }^{173}$ He had followers that wanted him to "look in the stone” so, Peter Ingersoll in Howe, Mormonism Unvailed, 235. 
world, and some go on to become prophets." 174 Such is undoubtedly the case for Smith. ${ }^{175}$

Table 2.2 posits a number of highly related categories in which the youthful Joseph could develop and practice the skills he would need to be successful as a maturing prophet. The table is far from exhaustive, and the relationship between a number of the categories is significant. For instance, Smith's use of seer stones was not simply a ruse devoid of any practical substance. Seer stones allowed Smith a vehicle through which he could navigate the divine world, receive revelations, and gather his composure and thoughts while extemporaneously either divining digging instructions, ${ }^{176}$ or "translating." 177 Peering into a seer stone as a means of accessing supernatural information otherwise hidden from humanity provided Smith a functional basis from which to engage in his future prophetic, revelatory career. ${ }^{178}$ Importantly, Smith's ability to receive revelations and visions was quite plausibly due to his own conviction of the possibility—and reality—of communicating with the supernatural realm. The persuasive confidence he developed as a scryer served him well as a prophet.

\footnotetext{
${ }^{174}$ Oakes, 94.

${ }^{175}$ In the oft-cited passage where Smith claims that "no man knows my history" his admission that if he "had not experienced" it for himself he "could not have believed it" rings true in a certain way. I do not believe that Smith had any idea where his skills would take him, but as he became a master of convincing and influencing other people, opportunity after opportunity opened up to him. He was truly amazed by his own success. The human inclination to capitalize on the opportunities presented is not limited to entrepreneurs.

${ }^{176}$ E.g. scene at Stowell's where the "enchantment was so powerful that he could not see." Isaac Hale’s testimony, Howe, Mormonism Unvailed, 263.

${ }^{177}$ Putting his face into a hat, ostensibly to exclude the external light, provided a meditative microclimate for Smith to collect and articulate his thoughts; where he "could study it out in [his] mind, then ... . ask [God/Christ] if it be right” BoC VIII.3.

${ }^{178}$ Bushman, Rough Stone Rolling, 131.
} 
Table 2.2

Smith's Developing Skills

\begin{tabular}{|c|c|c|}
\hline Skill/Aptitude & Development & Mastery \\
\hline $\begin{array}{l}\text { Knowledge }=\text { Power } \\
\text { Knowledge of } \ldots . .\end{array}$ & $\begin{array}{l}\text { Expressions in Magic } \\
\text { World of Money Digger }\end{array}$ & $\begin{array}{l}\text { Expressions in Religious } \\
\text { World as Prophet }\end{array}$ \\
\hline Culture of magic & $\begin{array}{ll}> & \text { divining rod heritage } \\
& \text { scrying/peeping neighbors } \\
& \text { vast array of occult books } \\
& \text { in local shops and libraries } \\
& \text { "Scryer of Manchester" }\end{array}$ & $\begin{array}{ll}> & \text { visions } \\
> & \text { revelations } \\
> & \text { healings } \\
> & \text { prophecy } \\
& \text { alchemy (a book from gold) }\end{array}$ \\
\hline Props and trappings & \begin{tabular}{ll}
\multicolumn{2}{l}{ Seer Stones } \\
$>\quad$ navigate supernatural \\
$\quad$ world \\
$>\quad$ located spots to dig \\
$>\quad$ located golden plates
\end{tabular} & \begin{tabular}{ll}
\multicolumn{2}{l}{ Urim and Thummim } \\
$>\quad$ Receive Revelation \\
$>\quad$ Translate ancient records \\
$(B o M)$ \\
$>\quad$ re-write (translate) Bible \\
$>\quad$ create texts without a \\
& source, e.g. Book of Moses \\
\end{tabular} \\
\hline Visions & $\begin{array}{l}\text { Provide Direction } \\
>\quad \text { which church to join (or } \\
\text { not) } \\
>\quad \text { where to dig for plates }\end{array}$ & $\begin{array}{l}\text { Provide Direction } \\
\text { where to dig for plates } \\
\quad \text { restoration of priesthood } \\
\quad 3 \text { Witnesses, saw plates } \\
\quad \text { with "spiritual eyes" }\end{array}$ \\
\hline Revelations & $\begin{array}{l}\text { non-visual visions } \\
\text { process that unlocks } \\
\text { psyche? creativity? divine } \\
\text { madness? } \\
\text { perceptions of } \\
\text { enchantments } \\
>\text { where to dig } \\
>\text { when to abandon digs }\end{array}$ & $\begin{array}{l}\text { Provide Direction } \\
>\quad \text { Content of ancient } \\
\text { (pseudepigraphic) texts } \\
>\text { Book of Commandments } \\
>\text { practical direction } \\
>\text { Harris to pay for BoM } \\
>\text { gather in Ohio, etc. } \\
>\text { call me a prophet, seer } \\
\text { and revelator } \\
\text { Implies Power }\end{array}$ \\
\hline Extemporaneous Speech & $\begin{array}{ll}> & \text { story teller as child } \\
\text { negotiation of supernatural } & \text { during digs } \\
& \text { quick excuses for digging } \\
\text { failures } & \text { contingent revelations, i.e. } \\
& \text { "if" x, then y. } \\
\end{array}$ & $\begin{array}{l}>\begin{array}{l}\text { commanded not to show } \\
\text { the plates }\end{array} \\
\text { contents of revelations and } \\
\text { books. } \\
>\quad \text { Story of Zelph, the "white } \\
\text { Lamanite" }\end{array}$ \\
\hline Cunning Forethought & $\begin{array}{l}\text { Mitigates future hurdles } \\
\text { "hand" toll collector fair on } \\
\text { the way back } \\
>\text { plants feather at dig sight } \\
\end{array}$ & $\begin{array}{l}\text { Self fulfilling prophecies } \\
>\quad \text { prophesies himself as a } \\
\text { prophet \& three witnesses } \\
>\quad \text { plates not to be used for } \\
\text { "gain" }\end{array}$ \\
\hline Epistemology & must believe & must believe \\
\hline $\begin{array}{l}\text { Persuasive } \\
\text { "Convincing" }\end{array}$ & $\begin{array}{l}>\text { bags of white-sand/gold } \\
\quad \text { Stowell employment } \\
\text { "they want me to look in } \\
\text { the stone" (P. Ingersoll) }\end{array}$ & $\begin{array}{l}\text { "not to the bringing forth my } \\
\text { word only, saith the Lord, but to } \\
\text { the convincing them of my } \\
\text { word" } 1830 \text { BoM } 67 \text { = } 2 \text { Nephi } \\
3.11 \text {. }\end{array}$ \\
\hline
\end{tabular}


Whether termed "scrying" or "receiving revelations," the diviner's specialized knowledge of the occult, including the rituals required to locate places to dig for money and the spells needed to break enchantments or propitiate guardian spirits, is a contingent and culturally learned vocation. Moreover, the scryer must be careful to perform his trade only in front of those whom he senses are already open and receptive to this type of supernatural navigation-lest the swine trample his pearls into the mud. Beyond the social intelligence required to gauge an audience's receptivity, the diviner must have the ingenuity and quick, creative wit to craft, frame or dodge a response during the time he takes to consult the stone as it sits in the bottom of his hat, concealed from environmental light. 179 Much like Weber's proposition regarding the necessity of a follower's recognition of a charismatic leader, the proclivity to believe in—or recognize as valid—these types of tactics is important. As an example of Smith's recognition of the importance of a seeker's proper disposition, he concludes his first chapter of the Book of Moses with the admonition to "Show them not [the words spoken unto Moses in the mount and now unto you] unto any except them that believe," (BoMos 1.42).

\section{Seer Stones}

Smith's favorite tool for interacting with the supernatural realm was a seer stone. Smith owned at least four of them throughout his life ${ }^{180}$ and used them for a

\footnotetext{
${ }^{179}$ Whitmer, An Address to All Believers in Christ, 12.

${ }^{180}$ Quinn provides photos of a green and a sandy colored seer stones and refers to an additional white and brown seer stones. Magic World View, 57, figures 9 and 10 after page 320. Vogel counts only three stones from the evidence; a white stone cited in the March 1826 court hearing, the brown stone found in Chase's well and the green stone probably found in Harmony, PA in late October, 1825. "The Location of Joseph Smith’s Early Treasure Quests,” Dialogue: A Journal of Mormon Thought, 27 (3) 1994, 197-231, 202 n.11.
} 
variety of purposes, including 1) determining where to dig for buried treasure;181 2)

determining the location of the Golden Plates (arguably a subset of the previous

category); ${ }^{182}$ 3) finding lost or stolen property; ${ }^{183} 4$ ) translating the Book of

Mormon, ${ }^{184} 5$ ) receiving revelation which includes the production of the Book of

Moses, The Book of Commandments, The Doctrine and Covenants; 185 and 6)

“ascertain[ing] the approach of danger."186

\footnotetext{
${ }^{181}$ See Vogel, “The Location of Joseph Smith’s Early Treasure Quests.” Quinn, Mormon Hierarchy, 615.

182 Quinn writes that "both Mormon and non-Mormon sources agreed that Joseph Jr. used his brown
} treasure-seeking stone to discover the gold plates on this occasion” Magic World View, 145. Quinn details the evidence in the following pages, a number of which note Smith’s “pecuniary motivations.” Financial motives further blur the distinction of the first two categories, unearthing golden treasure versus unearthing a golden record of an ancient people that may bring riches. See also, Vogel, Making of a Prophet, 49, 66.

${ }^{183}$ Vogel, Making of a Prophet, 42-3, 82

${ }^{184}$ See the Wentworth Letter in Vogel, EMD 2:171 where the seer stone receives a lexical upgrade and is referred to as Urim and Thummim. There, Smith's reference to the Urim and Thummim as a "curious instrument" rings palpably false and is a conscientious attempt to distance himself from the trappings of folk magic that he had been using for years. In a letter dated 27 March 1870, Smith's wife Emma recalled "Now the first that my <husband $>$ translated, was translated by the use of the Urim, and Thummim, and that was the part that Martin Harris lost, after that he used a small stone, not exactly, black, but was rather a dark color,” as in Vogel, EMD 1:532. See also Quinn, Magic World View, 171. Book of Mormon witness David Whitmer related that the loss of the first 116 pages of the BoM "evoked the stormiest kind of chastisement from the Lord, who took from the prophet the urim and thummum [sic]." As a result of "fervent prayer" Smith was presented with an "oval-shaped, chocolate-colored stone about the size of an egg, only more flat, which, it was promised, should serve the same purpose as the missing urim and thummim. . . . With this stone all of the present Book of Mormon was translated.” David Whitmer Interview with the Omaha Herald, 10 October 1886, as in Vogel, EMD 5:179. "Smith used the same stone later to translate the Book of Mormon." Dan Vogel, “The 'Prophet Puzzle' Revisited," Dialogue A Journal of Mormon Thought, vol. 31, No. 3, Fall, 1998. Quinn asserts that "Urim and Thummim” was often used as a euphemism by Smith for mundane seer stones, Magic World View, 174, especially for his white stone, The Mormon Hierarchy, 616.

${ }^{185}$ Book of Mormon witness David Whitmer wrote "The revelations in the Book of Commandments up to June, 1829, were given through the "stone," through which the Book of Mormon was translated.” An Address to All Believers in Christ: By A Witness to the Divine Authenticity of the Book of Mormon (Richmond, MI:

Drav.ictwehi trferr, Wl18873)er became disgruntled with Smith's changing and publishing previously secret revelations, and was excommunicated in 1838, he remained a believer in the Book of Mormon. For Whitmer, being one of the Three Witnesses to the Book of Mormon was the equivalent of the status held by Matthew, Mark, Luke, John, Paul, Jude and Peter, 12-14. See also Bushman, Rough Stone Rolling, 132.

186 The words of Mother Lucy Smith, Lucy’s Book, 389. Lucy continues that Urim and Thummim could also warn Joseph of danger that approached the plates even when the plates where nowhere near his person. Quinn refers to this protective property as more properly within the domain of magic amulets than seer stones, Magic World View, 96. These could be worn around the neck. Quinn provides photo examples 
Smith's seer stones aided him in producing-recovering and translating-the Book of Mormon in addition to providing a medium through which he received his early revelations. Given these facts, it is clear that Smith's translation processwhich is to say his method of producing texts-relied on the trappings of folk magic. Smith's father-in-law Isaac Hale testified that "the manner in which he pretended to read and interpret [the Book of Mormon] was the same as when he looked for the money-diggers, with the stone in his hat, and his hat over his face, while the Book of Plates were at the same time hid in the woods!" 187 He held his seer stone up to his eye while placing a hat over his face to block out any environmental light. ${ }^{188}$ The source documents (golden plates) did not even need to be present for this to work. ${ }^{189}$ Through this method he was able to dictate enough to fill 588 typeset pages as printed in the 1830 version of the Book of Mormon. Michael Quinn's study of early Mormonism and the magic world view documents the deeply intertwined nature of folk religion and folk magic in Smith's time and place. He notes that "[e]ven according to friendly sources, both religion and magic were part of Joseph

of seer stones that could be worn as amulets after page 320 .

${ }^{187}$ Isaac Hale testimony, Howe, Mormonism Unvailed, 265.

${ }^{188}$ One account of his seer stone usage is from the court documents of his 1826 conviction as a disorderly person, where one of the witnesses "said [that] Joseph pretended to read from a book using his white stone" Bushman, Rough Stone, 590 n. 24. Howe, Mormonism Unvailed, 237. Book of Mormon witness David Whitmer, the third person baptized into the Church, writes "Joseph Smith would put the seer stone into a hat, and put his face in the hat, drawing it closely around his face to exclude the light; and in the darkness the spiritual light would shine." An Address to All Believers in Christ: By a Witness to the Divine Authenticity of the Book of Mormon (Richmond: MO: David Whitmer, 1887), 12. See also 30, 31, 37 and Elizabeth Ann Whitmer Cowdery Affidavit, 15 February, 1870, in Vogel, EMD 5:260

${ }^{189}$ Howe, Mormonism Unvailed, 265. The golden plates were often not in the vicinity of the translation project. The Book of Moses neither claimed nor needed a material source. 
Smith's early visions and his efforts to obtain gold plates buried by ancient people."190

\section{Market Demand for Scryers and Prophets}

The desire for leadership, spiritual guidance, sociality or just plain entertainment represents the demand side of the leadership marketplace. Strong demand provides enticement, offers positive feedback, and helps one generate confidence in one's abilities. One good example that illustrates the demand side of Smith's talents comes from Peter Ingersoll's testimony regarding Smith's promise to his new fatherin-law that he give up glass-looking. ${ }^{191}$ Ingersoll had been hired by Smith to help move the belongings of himself and his new wife from his father in-law's house near Harmony, PA, to Manchester, NY. Prior to leaving, Ingersoll witnesses a poignant ("truly affecting") scene where, as he tells it,

His father-in-law (Mr. Hale) addressed Joseph, in a flood of tears: "You have stolen my daughter and married her. I had much rather have followed her to her grave. You spend your time in digging for money-pretend to see in a stone, and thus try to deceive people." Joseph wept, and acknowledged he could not see in a stone now, nor never could; and that his former pretensions in that respect, were all false. He then promised to give up his old habits of digging for money and looking into stones. ${ }^{192}$

As Ingersoll drove the belongings of Smith and his bride to their home from his father in-law's home, Smith confided that, "he intended to keep the promise which he had made to his father-in-law but, said he [Smith], [']it will be hard for me,

\footnotetext{
${ }^{190}$ Quinn, Magic World View, 136. Bushman also notes that "as work on the Book of Mormon proceeded, a seer stone took the place of the Urim and Thummim as an aid in the work, blending magic with inspired translation," Rough Stone Rolling, 131.

191 “[G]lass-looking” was the term that Isaac Hale claimed Joseph used for his endeavors. Howe, Mormonism Unvailed, 264.

192 Howe, Mormonism Unvailed, 234-5.
} 
for they will all oppose, as they want me to look in the stone for them to dig money[']." 193 Ingersoll's recollection indicates a demand for Smith's skill sets within the markets of treasure-hunting and money-digging. Arguably the quest to find hidden treasure was as much about the quest itself as it was about finding riches. Questers need an inspiring leader. Irrespective of the motivations, Smith was well aware he had a persistent demand for his "gift."

The quest itself, where like-minded souls come together to seek tangible rewards such as treasure in the earth, indicates the important catalyst of leadership on sociality. Although treasure is never found, the adventure and comradery provide their own rewards. Changing domains only slightly, a collection of spiritual seekers who congregate in pursuit of spiritual rewards may or may not find salvation or transcendence. In the process, however, they likely will enjoy a supportive and re-affirming community of like minded souls, perhaps even a "kingdom of God" on earth (Luke 17.21). Under capable leadership, the purpose of the quest unites the community. Spiritual treasures are more easily found than buried gold. Participation in the community itself is inherently rewarding. Whether it is the warmth of the new community, or the promise of treasure to come in the afterlife, significant reward attends the community when guided by capable leadership. The market of religious seekers is considerably larger than that of money diggers, and tangible rewards are easier to provide.

As Smith developed still more confidence and further developed his prophetic skill set, he abandoned the use of his basic folk-magic prop. The use of a

\footnotetext{
${ }^{193}$ Howe, Mormonism Unvailed, 235.
} 
seer stone functioned as training wheels for the developing prophet. Over time he became adept at negotiating the divine realm without the use of his stone and the trappings of folk-magic. Bushman writes that "[n]either his education nor his Christian upbringing prepared Joseph to translate a book, but the magic culture may have. Treasure-seeking taught Joseph to look for the unseen in a stone."194

\section{Transferable Social and Emotional Skills}

The skills developed by Smith as a treasure seeker and scryer served him well beyond his ability to use a seer stone to locate places to dig for buried money. More importantly, he became adept at convincing people of his integrity-even when there was good reason to doubt it. Smith was good at not finding gold. That is to say that despite elaborate efforts, night time digs, the sacrifice of a "large fat sheep," 195 and other gimmicks and rituals, he found nothing but an improved ability to come up with excuses for the failure to find treasure. Despite the fact that Smith failed to actually find buried gold in the ground, he was widely regarded as proficient at his trade. ${ }^{196}$

His reputation ${ }^{197}$ was such that Josiah Stowell, a Presbyterian farmer with property in Chenango County, New York and Harmony, Pennsylvania, hired Joseph

\footnotetext{
${ }^{194}$ Bushman, Rough Stone Rolling, 131.

${ }^{195}$ The "large fat sheep" was "killed pursuant to commandment; but as there was some mistake in the process, it did not have the desired effect. This, I believe, is the only time they ever made money-digging a profitable business," William Stafford testimony in Howe, Mormonism Unvailed, 239.

${ }^{196}$ Vogel calls him "the famed seer of Manchester, New York,” The Making of a Prophet, 72.

${ }^{197}$ Quinn, citing BYU professor of Religion Bruce A. Van Orden, writes that "Stowell would not have hired Joseph in the first place had Joseph not already had the reputation of one who could find treasures deep in he earth.” Quinn continues that Smith had developed this reputation as early as 1821. Magic World View, 55. See Vogel, "Location of Early Treasure Digs" and Making of a Prophet for detailed analysis of Smith's treasure questing activity prior to employment by Stowell.
} 
and his father to travel nearly 100 miles ${ }^{198}$ to help him locate a "valuable mine of either gold or silver"199 that was supposed to be of Spanish origin and hidden on his Pennsylvania property. The digging under Stowell's employment continued for five months without material success. Finally, one of Stowell's nephews, convinced that his uncle was being defrauded, filed a complaint against Smith as a "disorderly person and an imposter." 200 Smith went to court in Bainbridge, Chenango County, New York, on March 20, 1826. The statement compiled for services rendered by presiding Justice of the Peace Albert Neely, referred to the case as "People vs. Joseph Smith The Glass Looker." ${ }^{201}$ Of interest here is not whether Smith violated either local or state ordinances against juggling, crafty sciences, or "pretending to tell fortunes, or to discover where lost goods may be found." 202 It is Smith's growing ability to convince people of his credibility and supernatural abilities that is important.

\footnotetext{
${ }^{198}$ Stowell had traveled up the Erie canal to visit his oldest son, Simpson, in Manchester NY. It was Simpson who set up the meeting and was evidently aware of Joseph's local reputation as a competent scryer. Vogel, The Making of a Prophet, 69. Joseph's mother would later remember that "He came for Joseph on account of having heard that he possessed certain keys, by which he could discern things invisible to the natural eye.” Lucy Smith, Biographical Sketches, 91-92. See also Lavina Anderson, Lucy's Book: A Critical Edition of Lucy Mack Smith's Family Memoir (Salt Lake City: Signature Books, 2001), 359-360.

${ }^{199}$ The trove was also thought "to contain coined money and bars or ingots of gold or silver" as reflected in the Articles of Agreement signed by the interested parties of the dig. "An Interesting Document: Articles of Agreement between Joe Smith, the Father of Mormonism, and Other Persons in 1825,” Salt Lake Daily Tribune (23 Apr. 1880), 4, http://www.sidneyrigdon.com/dbroadhu/UT/tribune2.htm\#042380, accessed November 30, 2010.

${ }^{200}$ Fawn Brodie, No Man Knows My History, 427; Vogel, The Making of a Prophet, 82.

${ }^{201}$ Vogel, The Making of a Prophet, 82.

${ }^{202}$ I.e. a partial description of what being a "disorderly person" entailed under the New York statue of that era. Vogel, The Making of a Prophet, 82.
} 
One witness for the defense was the alleged victim, Josiah Stowell, himself. ${ }^{203}$

Stowell, who employed Smith from November of 1825 to March of 1826 without so

much as finding a Spanish real testified on behalf of Joseph. As reported by Abram

W. Benton, who attended the trial, one line of questioning by the prosecution of

Stowell went as follows:

Q. "Did Smith ever tell you there was money hid in a certain place which he mentioned?"

A: "Yes."...

Q: "Did you dig?"

A: "Yes"

Q: "Did he not lie to you then, and deceive you?"

A: "No! The money was there, but we did not get quite to it!"

Q: "How do you know it was there?"

A: "Smith said it was!"204

Despite the fact that neither silver nor gold were ever found on the Stowell

property, Stowell was still convinced of Smith's supernatural abilities ${ }^{205}$ in addition

to his basic credibility and integrity. ${ }^{206}$ In the face of what many would describe as

fraudulent activity at Stowell's expense, Stowell exhibited a trust if not faith ${ }^{207}$ in

\footnotetext{
203 One reference to this is in Vogel's The Making of a Prophet, 512 which cites EMD 1:117 and Joseph Smith Manuscript history, 44-45

${ }^{204}$ As in Vogel, The Making of a Prophet, 513. Bushman notes of the trial that Stowell "had the most implicit faith in the prisoner’s skill,” (emphasis added). Bushman, Beginnings of Mormonism, 74.

205 See Vogel, Making of a Prophet 513.

${ }^{206}$ As a witness for the defense, Stowell is said to have stated, regarding a horse of his that Smith had bought but not yet paid for, "I hold his note for the price of the horse, which I consider as good as the pay - for I am well acquainted with him and know him to be an honest man, and if he wishes - I am ready to let him have another horse on the same terms,” as in EMD 1:117. Stowell ultimately joined Smith's new church, although the precise date of his baptism is unclear, EMD 5:374.

${ }^{207}$ Non-Mormon contemporary Joel Tiffany, himself a spiritualist, wrote,

It requires faith to become a money-digger; and there must have been to their minds some evidence upon which such faith was based. Joseph was the seer. He had a stone, in which, when it was placed in his hat, and his face buried therein, so as to exclude the light, he could see as a clairvoyant (emphasis added)

Joel Tiffany, “Mormonism. (Continued from May No., p. 51),” Tiffany’s Monthly. Devoted to the Investigation of the Science of Mind . . 5 (June 1859), 110, as cited in Quinn, Magic World View, 55.
} 
Joseph that could not be dissuaded by evidence (or its lack) of a material nature. It was not the material finds that made Joseph a success, it was his ability to inspire other people to believe in him as one who possessed something truly exciting and special.

Smith's status as a scryer-his renown as one who could find buried treasures-came from his possession, or the assumption of his possession, of a special, non-obvious, non-empirical type of knowledge. The possession of secret knowledge, esoteric skills, or a divine calling is the scarce resource that leads to the possessor being held in high esteem and ultimately placed on top of hierarchical social relationships. Authority is created from the construction of truth, and Smith's persuasiveness regarding his supernatural abilities, his knowledge of, and adept negotiation of, the supernatural realm were convincing. Given that buried treasures were never produced, his ability to convincingly explain his way out of abject failure was perhaps his greatest asset. The ability to convince those inclined to believe in the material existence of things that do not exist materially has obvious applications in the domain of religious life where faith is lauded as the primary epistemic regime.

Stowell implicitly believed in Joseph and his ability to negotiate the supernatural world in such a manner that physical riches could be taken from the earth—just as Smith's earliest religious followers believed he could receive revelations from God and could translate obscure or dead languages through inspiration and "peep" stones. Stowell was not alone in his implicit belief in the scryer Smith. Book of Mormon witness and early member David Whitmer said of Joseph's former money-digging friends, 
I had conversations with several young men who said that Joseph Smith had certainly golden plates, and that before he attained them he had promised to share with them, but had not done so, and they were very much incensed with him. ${ }^{208}$

Stated succinctly, there is not a substantial vocational difference between persuading seekers of gold that they could be led to find buried treasure and persuading seekers of God that they could find truth and salvation through a recently unearthed golden record of God, his people and his commandments. Abram W. Benton, a non-Mormon who witnessed Smith's July 1, 1830 court appearance in Harmony, Pennsylvania, noted at the time that "it was shown that the Book of Mormon was brought to light by the same magic power by which [Smith] pretended to tell fortunes, discover hidden treasures, \&c. [sic]." 209 Whether it was access to hidden gold or access to God's restored church, to the seeker, Smith offered avenues to "find" under the skilled guidance of a persuasive and confident leader.

\section{Skill Sets and Improvisation: The Alchemist Entrepreneur}

The production of the Book of Mormon represents a subtle, entrepreneurial improvisation on treasure digging. ${ }^{210}$ Barring the discovery of buried pirates' treasure, a sealed and forgotten Spanish silver mine, ancient Indian relics or the

${ }^{208}$ Quinn, Magic World View, 169, 478 n 295, which cites a statement given by David Whitmer in Lyndon W. Cook, ed. David Whitmer Interviews: A Restoration Witness.

${ }^{209}$ Vogel, The Making of a Prophet, 514.

210 The idea of a buried record of hieroglyphics that provided the history of an important institution was not a new one in Smith's era. The Freemason's Monitor or: Illustrations of Masonry provides an account of a "triangular plate of gold" that was adorned with precious stones and inscribed with "ineffable characters.” This golden plate was then buried under the arch of Enoch's subterranean temple to preserve the important knowledge for posterity. Thomas Smith Web, The Freemason's Monitor or: Illustrations of Masonry (Salem: Cushing and Appleton, 1818), 270-71. The Freemason's Monitor was first published in 1802. 
equivalent, digging for money in the manner practiced by the Smith family is not a lucrative trade if one is to rely solely on the material value of unearthed treasures. $^{211}$ Once the pool of local or even regional treasure seekers who are willing to pay Smith to look into his stone is exhausted, the scryer will need to come up with more lucrative uses of his tools. ${ }^{212}$ An ancient record of a lost people provided such an opportunity. Surely enough gold to inscribe the equivalent of 588 English pages of text would be of tremendous value-both to the archeologist and the gold dealer. But plates of gold could only be converted to money once they were subjected to the brutal reality of material authentication such as the scale of a gold dealer or the acquisitions representative of a museum or research institution that had an interest in the histories of ancient people. In other words, tangible verification and a material exchange were required if Smith wanted to financially capitalize on his golden finds. The Book of Mormon provided such evidence. Brodie writes that the Book of Mormon "was something that he could offer to his followers as sober proof of the authenticity of his own prophetic mission."213 Smith's entrepreneurial thinking determined that a record of an ancient people-especially one that physically mimicked and was theologically compatible with the Holy Bible

\footnotetext{
${ }^{211}$ Smith remained sincerely convinced of the possibility of finding treasures hidden in the earth until at least 1836, six years after the founding of his church. Evidence for this claim is based on Smith and the First Presidency's trip to Salem in search of buried treasure, as documented by Quinn, Magic World View, 262-265. Quinn writes that

The treasure-quest failed to obtain the literal "gold and silver" Joseph Smith sought in July-August 1836, and the revelation substituted instead a spiritual "treasure" of potential converts to the LDS church. As the LDS church's official centennial history stated: "Whereas these brethren had come seeking an earthly treasure, God directs their attention to spiritual things ... ." Magic World View, 263.

${ }^{212}$ For Smith earning (or being perceived to have earned) money from his seer stone, See Quinn, Magic World View, 43, 51, 59, 63, 65, 158-9.

${ }^{213}$ Brodie, No Man Knows My History, 83.
} 
held so dear by nineteenth century America-might prove to be just such an opportunity. ${ }^{214}$ Smith knew in advance that he would face pressure to share the proceeds of the unearthed gold from many of his former treasure-seeking associates. ${ }^{215}$ To protect himself against these anticipated pressures, Smith engages in some classic prophecy ex eventu. In the Book of Mormon he puts the following prophetic words on the lips of Moroni,

I am the same which hideth up this record unto the Lord; the plates thereof are of no worth, because of the commandment of the Lord. For he [the Lord] truly saith, That no one shall have them to get gain; but the record thereof is of great worth; and whoso shall bring it to light, him will the Lord bless. For none can have power to bring it to light, save it be given him of God: for God will that it shall be done with an eye singled to his glory .... And blessed be him that shall bring this thing to light. 1830 BoM, 532-533 (emphasis added).

In the passage above, we see that Smith has justified the necessity of keeping the golden source plates out of the public domain with a commandment of God. He is explicitly told that "no one shall have them to get gain." The value of the plates is as a "record" which is "of great worth" (1830 BoM, 533). The same passage also accords praise to Smith as the one who brings "this thing to light" as one who is "blessed" by the Lord. Smith's aggrandizement of himself in his writings is a subtopic of the following chapter.

\footnotetext{
${ }^{214}$ Bushman notes that Joseph’s Palmyra neighbors boycotted the Book of Mormon, "to prevent Joseph from profiting by it.” Rough Stone Rolling, 127. Smith’s mother Lucy later wrote of her son’s “"pecuniary' motivations 'to secure some imaginary treasure' during his visit to the hill [Cumorah]." Smith's brother William "referred to Joseph's desire to use the plates 'for the purposes of making money,", Quinn, Magic World View, 146-147. These witnesses are family members, not outsiders or hostile antagonists.

${ }^{215}$ Recall the words of David Whitmer attesting to this fact in the quotation a couple of pages above. Quinn, Magic World View, 169, 478 n 295, which cites a statement given by David Whitmer in Lyndon W. Cook, ed. David Whitmer Interviews: A Restoration Witness.
} 
Introducing a profit motive to Smith's actions is not meant to suggest that Smith was indifferent to religion and salvation-clearly these notions were important to him. His life suggests a deep belief in the realm of demons, angels, spirits and gods. But Smith and his family were as impoverished as they were creative. In Smith's improvisation-the quasi alchemy that transformed buried gold into a book for sale-it is difficult not to recognize the simple self-interest that attends human beings of all stripes. Smith's entrepreneurial improvisation resulted in a book for which he obtained a copyright and offered for sale as the "Author and Proprietor." While the Book of Mormon did not immediately bring the financial rewards that would have alleviated the persistent poverty of the Smith family, it did produce other benefits both psychological and material. By 1831, Smith was no longer a day-laborer and scryer but a prophet who was living in a house built and paid for by his Ohio community. Smith's social standing continued to increase within his community. As the community grew larger, so did Smith's social status. By the time of his assassination in 1844, Smith was the Mayor of the second largest city in Illinois, Nauvoo; ${ }^{216}$ the commanding officer the largest militia in the state, the Nauvoo Legion; ${ }^{217}$ head of the city council and a candidate for President of the United States. He lived in structures built and paid for by his congregation and had a vast network of spiritual wives. ${ }^{218}$ While Smith's success might not be easily measured in crass monetary terms, his attainment of symbolic and economic capital

\footnotetext{
${ }^{216}$ Smith served as mayor beginning in 1842, Quinn, The Mormon Hierarchy, 110.

${ }^{217}$ The Nauvoo legion had 2,000 troops in 1842 and nearly 3,000 by 1844. In that year the U.S. Army numbered 8,500 soldiers. Quinn, The Mormon Hierarchy, 106, 110.

${ }^{218}$ See Todd Compton, In Sacred Loneliness: The Plural Wives of Joseph Smith (Salt Lake City, UT: Signature Books, 1994).
} 
was substantial. His rise up the ladder of social power and prestige is clearly documented on a number of fronts. Historian Quinn writes that "[b]y 1844 Nauvoo had the appearance of Smith's personal theocracy."219

Smith's production of the text of the Book of Mormon generated notoriety, symbolic capital and ultimately power. The creation of and participation in novel or alternative societies provides access to status and prestige that is simply not otherwise available in to the folks who are not part of elite, municipal or other recognized social structures.

${ }^{219}$ Quinn, Mormon Hierarchy, 110. 


\section{CHAPTER THREE}

\section{AUTHORING AUTHORITY}

\section{THE POWER OF WRITING REALITY}

... because it is written ...

$$
\text { -Monty Python }{ }^{1}
$$

what role is to be attributed to human agency and choice? Why did people choose-and a choice it most decidedly it was - to invent entirely new forms of culture?

-Sheldon Pollock ${ }^{2}$

behold, I, the Lord, utter my voice, and it shall be obeyed

一Joseph Smith, $D \& C 63.5$

This section analyzes the various textual, rhetorical and performative strategies upon which these two men built their positions of power. Paul used letters to present, and reaffirm, himself as a human recipient of divine mandates, "an apostle of Christ Jesus by the will of God" (2 Cor 1.1), charged with spreading his message. Smith used a variety of textual genres to present himself as a divine mediator-under the titles prophet, seer and revelator-selected to restore Christ's true church to humanity. In each case, the texted productions served as material evidence of its author's privileged status and positioned him as the obvious terrestrial leader of their communities. To receptive readers, the charismatic aura

\footnotetext{
${ }^{1}$ Life of Brian, Brian's mom upon being asked why women were not allowed to participate in public stonings.

${ }^{2}$ The Language of the Gods in the World of Men, 31.
} 
of the author infused the text with a special status-and vice versa. In their own life times, both authors and their texts transcended the status of the ordinary. ${ }^{3}$ Both author and production become fundamental to the shaping of the communal perception of reality.

The first section of this chapter makes a number of related arguments. The first is that the texts produced by these men articulate and signify - if not embody and reify-the charismatic's construal of reality. They provide the community's cosmology, soteriology and theology which provides hope, security and purpose. ${ }^{4}$ The second argument, a subset of the first, is that texts of this nature also express the behavioral expectations and standards required of those who embrace the group-which amounts to an implicit social contract. The ethical components within the social contract facilitate communal identity and solidarity. Yahweh's texted insistence on "covenants" between himself and his people set a cultural precedent for both cultural phenomena under consideration. ${ }^{5}$

\footnotetext{
${ }^{3}$ W. C. Smith well expresses the relational element facilitating the elevation of a text when he writes, "no text is a scripture in itself . . . . [p]eople make text into scripture." He pushes this notion further with respect to the relational component of people, text and perceptions of external reality itself. He writes that beyond the "relation between a people and a text" is the issue of "the relation between a people and the universe, in the light of their perception of a given text.” W. C. Smith, What Is Scripture? A Comparative Approach (Minneapolis, MN: Fortress Press, 2005), 18.

${ }^{4}$ Consider here anthropologist Clifford Geertz’s definition of religion. He writes, "religion is:”

(1) a system of symbols which acts to (2) establish powerful, pervasive, and long-lasting moods and motivations in men by (3) formulating conceptions of a general order of existence and (4) clothing these conceptions with such an aura of factuality that (5) the moods and motivations seem uniquely realistic. The Interpretation of Cultures: Selected Essays (USA: BasicBooks, A Division of HarperCollins, 1973), 90.

${ }^{5}$ One classic formulation is from Leviticus 26, where Yahweh is made to state:

If you follow my statutes and keep my commandments and observe them faithfully, I will give you your rains in their season, and the land shall yield its produce . . . . and I shall not abhor you. And $I$ will walk among you, and will be your God, and you shall be my people. . . But if you will not obey me .... I will bring terror on you; consumption and fever that waste the eyes and cause life to pine away. You shall sow your seed in vain .... I will let loose wild animals against you, and they shall
} 
Beyond delineating expectations required of followers, texts also attribute power to their authors and as such unambiguously indicate who is to direct the new social formation of believers. Fabricators and interpreters of "scripture" play a fundamental role in contributing to how reality itself is perceived. Part of this depiction of reality indicates who among the group should hold power.

The central component of this complex of issues is the process of an individual's attainment of power-which, by virtue of its relational nature, is meaningless without a community to head. Claiming power is an integrated effort, one that in the situations considered here makes use of existing scriptural traditions (their cultural and religious capital and the phenomenon of scripturalization), new texts, persuasive personalities and receptive hearers. It is the dialectic exchange among all of these factors that facilitates the development of a community guided by the author of certain texts. All of the claims analyzed are found in a texted format, ${ }^{6}$ although some are explicit while others lurk implicitly.

Importantly, however, the many disparate components that together construct "reality" and articulate behavioral standards are not always literally

bereave you of your children and destroy your livestock; they shall make you few in number .... I will send pestilence .... Y You shall eat the flesh of your sons, and you shall eat the flesh of your daughters ... . I am the LoRD [Yahweh]" Leviticus, 26. 3-4, 11-12, 14, 16, 22, 29, 45 (all emphasis added).

Although he does not refer specifically to Leviticus 26, Weber writes that this "contractual relationship ... is the primary root of what is most distinctive in Israelite religion: the trait of mutual promise which despite various analogues is found nowhere else in such intensity.” Max Weber, The Sociology of Religion, Introduced by Talcott Parsons (Boston: Beacon Press, 1993), 16.

\footnotetext{
${ }^{6}$ Lincoln writes that regarding the past, "I deal with texts, not the events themselves as is always true when one studies the past." He continues that his use of texts is

not for the recovery of "actual events" but for the elucidation of what authority was and how it operated within these societies. I trust that these texts said things which their audience found credible and which we may therefore take to reflect with some accuracy the sociopolitical processes and authority effects with which those people were familiar. Bruce Lincoln, Authority: Construction and Corrosion, 12.
} 
expressed in the text. The text, as guiding narrative, however, is made to support or provide the root justification or understanding of the group's ideological orientation.

\section{The Subtle Power of Texts (in context)}

We might speak of . . poetry's [prophecy's] own ideological justification and idealized self-representation, or yet again, as a myth about a myth: a story poetry [prophecy] tells about itself as a means to define, defend, reflect upon, romanticized, analyze, legitimate, exaggerate, mystify, modify, and advance its own position, not to mention that of its practitioners

$$
\text { -Bruce Lincoln } 7
$$

Texts function in culture in a way that the spoken word can not. ${ }^{8}$ Writing is a technology of the intellect, and of power. ${ }^{9}$ But although certain authoritative texts are formative and authoritative they can be found to be ambiguous and confusing. ${ }^{10}$ As the author of 2 Peter was well aware, every passage is prone to innovative interpretation and reinterpretation. Interpretations can have significant social implications as students of someone like Martin Luther can attest. Social conditions and human needs change over time, yet the written text endures. The durability inherent in written documents can present interpretive hurdles when cultural conditions change. A persuasive (re)interpretation of a hallowed text leverages the sanctity and authority of tradition and conscripts it into the service required by the

\footnotetext{
${ }^{7}$ Theorizing Myth, 21. In the epigraph, the term poetry could be replaced by any of the genres used by Paul or Smith — epistle, revelation or pseudepigraphy_and the observation would still hold.

${ }^{8}$ There are a number of ramifications of this observation, some of which are well articulated by Jack Goody, The Logic of Writing and the Organization of Society, Studies in Literacy, Family Culture and the State (Cambridge: Cambridge University Press, 1996), 1-44.

${ }^{9}$ Jack Goody, The Power of Written Tradition (Washington D.C.: Smithsonian Institution Press, 2000), 132-151, 152. See also, Sheldon Pollock, The Language of the Gods in the World of Men.

10 “Our beloved brother Paul wrote to you according to the wisdom given him, speaking of this as he does in all his letters. There are some things in them hard to understand, which the ignorant and unstable twist to their own destruction, as they do the other scriptures” 2 Peter 3.15-16.
} 
interpreter. This phenomenon is part of the human meaning-making process and can be harnessed by any numbers of competing interests. Inevitably some uses of these texts whether "hard to understand," or just simple to manipulate, will elicit criticism for the way they are "twist[ed]" by the "ignorant and unstable" (2 Peter 4.15-16).

Textuality in itself lends a particular gravity to the ideas being circulated. Both of these men arose from a world that was already formatively shaped by authoritative texts, "scriptures," of various kinds. In Paul's world, the written law codes of Solon, Hammurabi, Moses or the "twelve tables" of Rome provided the formative basis, behavioral expectations and notions of identity of the ancient Athenians, Babylonians, Hebrews, and Romans respectively. ${ }^{11}$ The great legal codes of antiquity were carved into stone, a technique that displayed material wealth and the power and ability to marshal resources. Writing in stone ensured durability rather than mobility. The prologue of one copy ${ }^{12}$ of Hammurabi's great code provides the authoritative story of Hammurabi's divine calling. It reads in part, the gods Anu and Enlil, for the enhancement of the well-being of the people, named me by my name: Hammurabi, the pious prince, who venerates the gods, to make justice prevail in the land, to abolish the wicked and the evil, to prevent the strong from oppressing the weak .... I am Hammurabi the shepherd, selected by the god Enlil ....13

\footnotetext{
${ }^{11}$ Legal codes are little more than the geographically limited or nationalistic version of religious laws. They construct reality, articulate the social contract and shore up power for the leader who claims his power is authorized by the gods.

${ }^{12}$ The so-called "Louvre stele" forms "the basis of every edition of the Laws," Martha T. Roth, Law Collections from Mesopotamia and Asia Minor, Second Edition, SBL Writings from the Ancient World Series (Atlanta, GA: Scholars Press, 1997), 73.

${ }^{13}$ Laws of Hammurabi, Prologue, as in Roth, Law Collections, 76-77.
} 
Appearing above these words on the stela is a depiction of king Hammurabi, standing before the sun-god Shamash, god of justice, who is seated on his throne. The transference of the divine code from the heavens to the earth is clearly depicted, ${ }^{14}$ even to the illiterate. ${ }^{15}$ Hammurabi, like Moses, is designated by the gods to enact their will. The thrust of the callings and authorizations of Paul and Smith share the same basic features. In all these situations the awesome knowledge possessed by the gods-knowledge of behavioral codes essential for the betterment of society and the happiness of the gods-is entrusted to a specific individual who is commissioned to enlighten humanity.

Smith's world was not only shaped by the Authorized Version of the Bible, but also by the revolutionary political events that sought sanction in a host of new documents known as the Declaration of Independence, the American Constitution and its first ten amendments known as the Bill of Rights. These political documents provided a basis for a new national identity. Beyond reiterating and revising biblical themes, Smith's writings show an appreciation of the political ideals enshrined in the charter documents of the newly formed nation in which he lived. Texts shape cultural perspectives, national identities and an individual's world.

In addition to the political situation of his day, Smith's location in postReformation America adds to the gravity accorded the written word in his era. He was heir to centuries of wrangling over the authority of the sacred text as contained in the Christian Bible; especially the relative authority of the biblical text in relation

\footnotetext{
${ }^{14}$ Note the parallels with Moses receiving the Law from Yahweh in Exodus 3.

${ }^{15}$ Roth, Law Collections, 73.
} 
to the tremendous authority of hallowed, ancient ecclesiastical institutions. Smith's North America was predominantly a Protestant country founded by religious dissenters. Anti-Catholicism was common. Protestant cries of sola scriptura ${ }^{16}$ were countered with suspicions that the sacred texts of antiquity had been adulterated by human hands and were in some cases unreliable. While one host of cultural assumption held that the Bible was absolutely authoritative, ${ }^{17}$ its interpreters were at such variance over its meanings and interpretations that reliance on the text as definitive became problematic for Smith.

Some of the most poignant evidence for the era's complicated respect of the Bible's authority is seen in Thomas Jefferson's attempt to produce his own version of "the life and morals of the teachings of Jesus of Nazareth." 18 Jefferson's method was to apply his own editorial sensibilities to the Christian gospels. He excised the components of the gospel accounts he viewed as spurious or bogus in favor of focusing on "the pure and unsophisticated doctrines" which he felt were as “distinguishable as diamonds in a dunghill." To his colleague and former political rival John Adams, he wrote,

In extracting the pure principles which he [Jesus] taught, we should have to

\footnotetext{
${ }^{16}$ New Testament scholar Richard B. Hayes writes that "The Protestant reformers of the sixteenth century proclaimed that God's word in Scripture must serve as the final judge of all human tradition and experience," The Conversion of the Imagination: Paul as Interpreter of Israel's Scripture (Grand Rapids, MI: William B. Eerdmans Publishing Company, 2005), 190.

${ }^{17}$ One historian of the era has noted of "the role of the Old Testament in historic American society: it was 'so truly omnipresent in the American culture of 1800 or 1820 that historians have as much difficulty taking cognizance of it as of the air people breathed'” The comments are those of Perry Miller, American Heritage, "The Garden of Eden and the Deacon's Meadow," 7 (1955) 55, as cited by Martin E. Marty, Religion and Republic: The American Circumstance (Boston: Beacon Press, 1989), 142.

${ }^{18}$ The book's title is here used descriptively. It was published posthumously by Jefferson's grandson as, Thomas Jefferson, The Life and Morals of Jesus of Nazareth Extracted Textually from the Gospels: The Jefferson Bible (Washington DC: Government Printing Office, 1904).
} 
strip off the artificial vestments in which they have been muffled by priests, who have travestied them into various forms, as instruments of riches and power to them ${ }^{19} \ldots$. We must reduce our volume to the simple evangelists, select, even from them, the very words only of Jesus, paring off the Amphibologisms into which they have been led by forgetting often, or not understanding, what had fallen from him, by giving their own misconceptions as his dicta, and expressing unintelligibly for others what they had not understood themselves. ${ }^{20}$

Smith shared Jefferson's basic sentiments. Through the Book of Mormon character Nephi, framed in the sixth century BCE, Smith gives voice to his frustration with the convoluted nature of what he believed should have been simpler sacred texts when he writes,

I must speak, concerning the doctrine of Christ; wherefore, I shall speak unto you plainly, according to the plainness of my prophesying. For my soul delighteth in plainness: for after this manner doth the Lord God work among the children of men ... for he speaketh unto men according to their language, unto their understanding (1830 BoM $118=2$ Nep 31.2-3).

The problematics expressed by Smith's Nephi and by Jefferson were shaped by late eighteenth-, early nineteenth-century New World ideology which rejected the "amphibologisms" 21 that had complicated what was believed to have been a simpler, less ambiguous textual rendering. Jefferson's literary endeavor provides us with a clear-cut example of both the authority and the suspicion with which the Bible was perceived in Smith's era. Jefferson's focus on the teachings of Jesus also reflects the

\footnotetext{
${ }^{19}$ Jefferson here seems well aware of how specific human interests, here those of the priestly class, harnessed the text for "riches and power." In other words, he was well aware of the "work people make scriptures do for them.”

${ }^{20}$ Thomas Jefferson in written correspondence to John Adams, dated October 12, 1813, as presented by the National Humanities Center, accessed August 25, 2011. http://nationalhumanitiescenter.org/pds/livingrev/religion/text3/adamsjeffersoncor.pdf. The emphasis added indicates another type of sola scriptura - the words of Jesus were taken by Jefferson as a canon within a canon.

${ }^{21}$ Used by Jefferson in his correspondence with Adams, an amphibologism is an ambiguous, equivocal statement, one that can have a host of meanings.
} 
notion that the authority of a text is principally related to the particular authority of the human being that gave rise to the text, in this case Jesus. In the case of Smith and Paul, both claim to be messengers, and in both situations, the messengers and the message become circularly entangled, whereby author authorizes his text, and in turn the text authorizes its author. ${ }^{22}$

Reflecting on his odyssey to prophethood, and of his perceptions of biblical authority in light of interpretive problematics and their associated denominational conflicts, Smith wrote, "for the teachers of religion of the different sects understood the same passages of scripture so differently as to destroy all confidence in settling the question by an appeal to the Bible." ${ }^{23}$ Despite this quasi-autobiographical recollection-and rhetoric within the BoM about plain and precious things being removed from scripture ${ }^{24}$ (in addition to adulterations that may have come at the "hands of men")—Smith still views the biblical text as authoritative, but not without reservation. In the passage that directly follows Smith's exasperation that myriad interpretations serve to "destroy all confidence in ... the Bible," he cites a passage from the New Testament that, as he recounts it, transformed his life as it led him to his epiphany and set him on his path to prophethood. ${ }^{25}$

\footnotetext{
${ }^{22}$ Jefferson's example also shows us that, as with many reconstructions of heroic figures, the reconstruction matches the author's idealized notions of that being. Jefferson's Jesus was one that resonated with Jefferson's personal sensibilities. Not all people find the same diamonds in a given dunghill. So too, the heroic status Paul and Smith ultimately achieved in their respective communities is idealized, which complicates retrospective assessments of their personalities, intentions, actions and motivations.

23 "Extracts from the History of Joseph Smith, The Prophet," (Salt Lake City: The Church of Jesus Christ of Latter-day Saints, 1975), 2.12. These "extracts" are found bound with the canonical LDS scriptures, the Standard Works.

${ }^{24} 1$ Nephi 13.28, 40.

${ }^{25}$ Smith, "Extracts from the History of Joseph Smith, The Prophet," 2.11-14. Smith relied on James
} 
Smith intuitively recognized, through personal experience and observation, that the widespread interpretive problems with the Bible was a result of his culture's search for meaningful answers derived from the culture's singularly authoritative text. In the language of an economic model, the phenomenon represented a "demand" for biblical solutions and provided spiritual entrepreneurs an opportunity to produce, or "supply," a text that could clarify those very problems. But it had to be the right text, one that blended tradition and innovation. ${ }^{26}$ Smith's major concerns with biblical authority are summarized in the Table 3.1.

Table 3.1 Smith: Ambiguity Regarding Textual Authority

\begin{tabular}{|l|ll|}
\hline \multicolumn{2}{|c|}{ Smith } \\
\hline \multicolumn{1}{|c|}{ Biblical Text as Authoritative } & & Problems with Bible's Authority \\
\hline $\begin{array}{l}\text { Smith uses canonical James 1.5-8 and } \\
\text { receives a major epiphany } 27\end{array}$ & $>$ & Implicit in Smith's creation of new texts. \\
The angel Moroni appears to Smith and & & Pervasive Protestant notions of ancient \\
texts corrupted by the hands of men & during the transmission/translation \\
cites scriptures from OT and NT - i.e. & & process. \\
biblical scriptures are considered & $>\begin{array}{l}\text { Widely varying interpretations made to } \\
\text { authoritative in the heavens too! } 28\end{array}$ \\
KJV style scriptural language fills the & & suit particular denominational needs. ${ }^{29}$ \\
\hline
\end{tabular}

1.5ff. There are a number of problems with using Smith's “recollections” as a source of history. As with the tid-bits of any putative auto-biography in Paul's letters, the personal reflections serve the current rhetorical needs of the author more than they present an accurate personal history. Given the rhetorical intent of Smith's historical recollections, the interpretive problems of the Bible are recalled in large part to explain and justify his production of a text that served as a parallel to biblical history of a righteous people from Jerusalem and their longing for, and reception of, Jesus.

${ }^{26}$ Such a statement should not detract from the possibility that Smith himself felt a tremendous spiritual void which was filled by his literary production of solutions to biblical problems.

${ }^{27}$ Smith, "Extracts from the History of Joseph Smith, The Prophet," 2.11. This account was written in 1838 in response to a crisis of apostasy in the Church, and most likely does not accurately represent Smith's early sentiment so much as his needs at the time of writing. See Grant Palmer, An Insiders View of Mormon Origins (Salt Lake City: Signature Books, 2002), 248-254.

${ }^{28}$ Smith, "Extracts from the History of Joseph Smith, The Prophet," 2.40-41, "He [“a personage appeared at my bedside, standing in the air, for his feet did not touch the floor" "his name was Moroni"] quoted the eleventh chapter of Isaiah, saying it was about to be fulfilled. He quoted also the third chapter of Acts, twenty-second and twenty-third verses, precisely as they stand in our New Testament ... He also quoted the second chapter of Joel ...” 2.30, 33, 40-41. Beyond stating that the correct version of scripture is maintained in heaven, Smith assures "certain elders" of his church that the "testimony which ye have borne, is recorded in heaven for the angels to look upon," BoC LXIII.3. 
pages of Smith's texts

Cultural impact of the sola scriptura refrain

$>$ The phrase, "As it is written..." is attributed to Jesus in a revelation to Smith, BoC XXIX.7
Angel Moroni cites alternative versions of scripture in his apparition to Smith, ${ }^{30}$ i.e. some of the scriptures on earth are in need of inspired correction.

\section{Paul: Ambiguity Regarding Textual Authority}

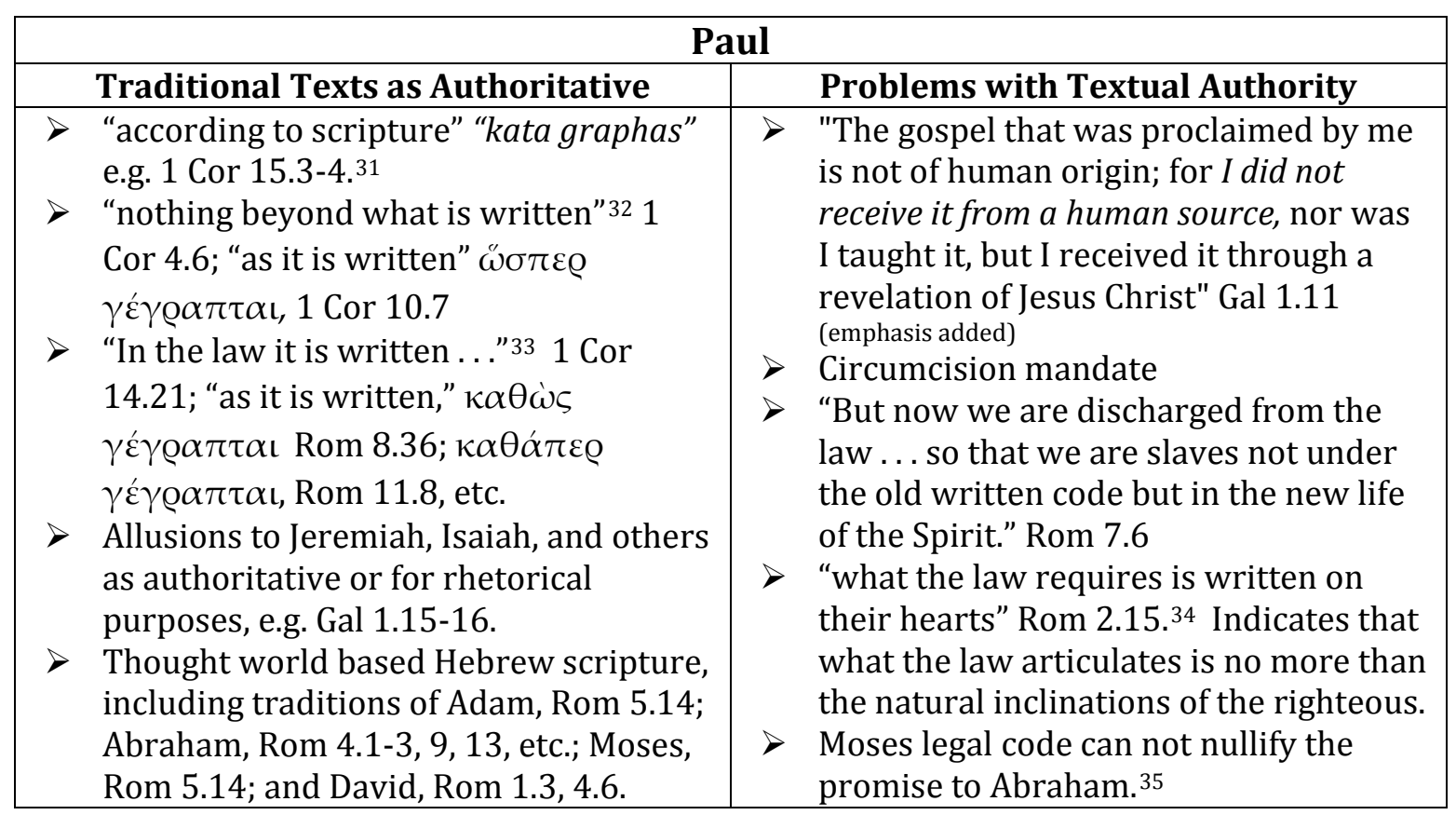

${ }^{29}$ Smith, "Extracts from the History of Joseph Smith, The Prophet," 2.12

${ }^{30}$ Smith, "Extracts from the History of Joseph Smith, The Prophet," 2.33. Smith writes, "He [Moroni] commenced quoting the prophecies of the Old Testament. He first quoted part of the third chapter of Malachi; and he quoted also the fourth or last chapter of the same prophecy, though with a little variation from the way it reads in our Bibles. Instead of quoting the first verse as it reads in our books, he quoted it thus: ..." "He also quoted the next verse differently ..." 2.36-39, emphasis added.

${ }^{31}$ The scripture to which Paul refers in 1 Cor 15.3, 4 has yet to be conclusively identified by biblical scholars - which suggests either Paul's 1) "spiritual" interpretation of canon beyond what moderns can imagine, or, 2) citation of a noncanonical text as authoritative, or 3) a manufactured allusion to graphas to strengthen his claim.

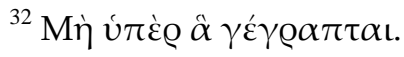

${ }^{33} \dot{\varepsilon} v \tau \tilde{\omega}$ Vó $\mu \omega \gamma \varepsilon \dot{\varepsilon} \gamma \varrho \alpha \pi \tau \alpha \iota$ ótı. Paul writes “in the law” even though the passage he cites is from the prophet Isaiah 28.11-12. The point remains that authoritative writings are essentially treated as law even if not in the Torah. Moreover, Paul's takes the Isaiah passage out of context and presses it into the service of supporting his point.

${ }^{34}$ This passage in itself provides one powerful definition of the power of "scripturalization."

${ }^{35}$ To the Galatians, Paul writes: "My point is this: the [written] law, which came four hundred thirty years later, does not annul a covenant previously ratified by God, so as to nullify the promise” Gal 3. 18 . 
Paul's environment was somewhat different. Literacy was not widespread and education was a luxury of scribal and elite classes. ${ }^{36}$ In spite of this, or perhaps because of the elite status held by the literate class and their productions, the written word was considered authoritative. ${ }^{37}$ Paul was an heir not only to the scriptures (graphas: literally, "writings") of the Hebrews, written in Greek and referenced these days as the Septuagint, but also to the collections of authoritative writings penned by ancient Mediterranean philosophers, statesmen and religious functionaries. ${ }^{38}$ The practitioners of traditions associated with Orpheus had their own sacred books (biblwn) ${ }^{39}$ which had been used in connection with religious rituals since at least the time of Plato and probably centuries earlier. Pseudepigraphical writings, sometimes apocalyptic, proliferated as is documented by the huge number of ancient texts collected by Charlesworth and others. ${ }^{40} \mathrm{By}$ Paul's time, the community at Qumran had been engaged in the study, reproduction

\footnotetext{
${ }^{36}$ Attesting to the broad illiteracy of the time and place, Goody argues that the texted nature of Christianity may have somehow implicitly attracted individuals who desired to become literate, The Logic of Writing, 5.

${ }^{37}$ Pollock, The Language of the Gods, 4.

${ }^{38}$ David L. Dugan, Constantine's Bible: Politics and the Making of the New Testament (Minneapolis, MN: Fortress Press, 2007). See in particular Dugan's chapter four for the importance of canonical philosophical works, especially those attributed to the founding personality claimed by the philosophical tradition. Abraham Malherbe writes that "There can no longer be any doubt that Paul was thoroughly familiar with the teaching, methods of operation, and style of argumentation of the philosophers of the period, all of which he adopted and adapted to his own purposes," Abraham J. Malherbe, Paul and the Popular Philosophers (Minneapolis, MN: Fortress Press, 2006), 68.

${ }^{39}$ Plato, Rep. 364e.

${ }^{40}$ See for example, James H. Charlesworth, editor, The Old Testament Pseudepigrapha, Volume I: Apocalyptic Literature and Testaments, Anchor Bible Reference Library (New York: Doubleday, 1983); The Old Testament Pseudepigrapha, Volume 2: Expansions of "Old Testament" and Legends, Wisdom and Philosophical Literature, Prayers, Psalms and Odes, Fragments of Lost Judeo-Hellenistic Works, Anchor Bible Reference Library (New York: Doubleday, 1985); and, Wilhelm Schneemelcher, editor, New Testament Apocrypha, Volume Two: Writings Relating to the Apostles; Apocalypses and Related Subjects, Revised Edition, Translated by R. McL. Wilson (Louisville, KY: Westminster John Knox Press, 2003).
} 
and preservation of scripture for a couple of centuries. ${ }^{41}$ Written letters of recommendation were presented by traveling preachers in early Pauline communities as a way to provide approval of one's bearer (e.g. 2 Cor 3.1).

One witness to the power of invoking the written word is Paul's claim of scriptures being fulfilled in the events he preaches. These prove powerful even if the source of the scripture can not be found by moderns. ${ }^{42}$ One example lies behind the central component of Paul's message. He writes to the Corinthians,

For I handed on to you as of first importance what I in turn had received: that Christ died for our sins in accordance with the scriptures (kata; taV; grafavV), and that he was buried, and that he was raised on the third day in accordance with scriptures (kata; taV; grafavV) (1 Cor 15.3-4).

Modern biblical scholars still wonder what "scripture" Paul is referencing as such notions are not found in what is today recognized as the Hebrew Bible. Perhaps, Paul was confident enough that his Corinthians were not intimately familiar with the corpus of holy Hebrew writings that he could simply assert that his message was "in accordance with scripture" (grafavV/graphas) even if it wasn't. Paul's scriptural source for 1 Cor 15.3-8 has not been conclusively identified ${ }^{43}$ and-baring a rather bold interpretive move-is probably not from the central texts

\footnotetext{
${ }^{41}$ Harry Y. Gamble, Books and Readers in the Early Church: A History of Early Christian Texts (New Haven, CT: Yale University Press, 1995) 23-24.

${ }^{42}$ Of 1 Cor 15.3-4, John Ashton writes "numerous Old Testament texts have been proposed,” John Ashton, The Religion of the Apostle Paul (New Haven, CT: Yale University Press, 2000), 9 n. 12. None have been embraced with anything approaching consensus.

${ }^{43}$ Regarding 1 Cor 15.3, Stephen Finlan writes, "Believers and Scholars have spent twenty centuries trying to identify which scriptures he [Paul] intends; many believers today point to the suffering servant figure in Isaiah 53, but this figure does not appear in any major way in the NT," The Apostle Paul and the Pauline Tradition (Collegeville, MN: Liturgical Press, 2008), 53. Richard B. Hayes writes that "it would be speculation" to assume that Paul was referencing a royal lament psalm in this passage, Conversion of the Imagination: Paul as Interpreter of Israel's Scripture (Grand Rapids, MI: William B. Eerdmans Publishing Company, 2005), 107 n. 20, 118.
} 
of the Hebrew tradition. His source might have been pseudepigraphical. The mere claim that recent events were the fulfillment of earlier (texted) prophecy was enough to lend credibility to what would otherwise be a difficult proposition to accept. Moreover, as the notion of a dead man rising from the grave to live again is not an easy notion for one from any generation to accept without some cultural (pre)conditioning. Placing the prophecy of a miraculous event in hallowed texts makes its occurrence or fulfillment not only easier to believe, but exciting as ancient texts are thus "proved" to be valid indicators of future events. New texts can facilitate, and build upon, this process as they integrate current events and contemporary philosophies with interpretations of ancient prophecies to generate meaning relevant to the contemporary situation. Referencing and harnessing the thought of existing "scripture" is one way to garner legitimacy for innovated ideas, ${ }^{44}$ pseudepigraphy is another.

\footnotetext{
${ }^{44}$ A. Lindemann concludes his Schrift als Tradition, 225, with the following, "Paulus selbst im Zuge der Heidenmission die jüdische Bibel als die authoritative Tradition des Christentums eingeführt hat," ("Paul himself, in the course of the mission to the gentiles, had introduced the Jewish Bible as authoritative tradition of the Christians," translation mine). German cited in Hayes, Conversion of the Imagination, 7.
} 


\section{Revelations Reveal Reality}

I want you to know, brothers, that the gospel that was proclaimed by me is not of human origin; for I did not receive it from a human source, nor was I taught it, but I received it through a revelation of Jesus Christ

—Paul, Gal 1.11-12

his revelations themselves reveal the most about what he meant when he said, 'I am Joseph the Prophet'

-R. L. Bushman ${ }^{45}$

We read the Gita not in order to understand the Gita. Rather, we read it, if we are Hindus, in order to understand the world, and our life within it; and if we are historians, in order to understand how the world has been seen by Hindus

-W. C. Smith 46

Given that certain groups of texts are held as sacred in both of these

traditions, it is little wonder that cultural entrepreneurs would capitalize on the archaic text to make it relevant in their own time. Use of the past implies a construction of the past, the past being a "cultural-specific invention and protectorate," 47 that serves specific social interests such as claims to power. Texts, and their interpretations, serve as a primary vehicle for this process. Paul proved adept at extracting scripture from its archaic Hebrew context and deploying it for his own needs. ${ }^{48}$ Smith's texts embody this very practice. Smith's contemporary, the restorationist preacher Alexander Campbell, noted that the Book of Mormon exuded a nineteenth century American conception of the biblical issues of the day. ${ }^{49}$

\footnotetext{
${ }^{45}$ Rough Stone Rolling, 128.

${ }^{46}$ What Is Scripture, 34.

${ }^{47}$ Wimbush, “The Work We Make Scriptures Do For Us,” 360.

${ }^{48}$ e.g "Is God the God of Jews only? Is he not the God of Gentiles also? Yes of Gentiles also,” Rom 3.29. So too, Abraham becomes the father of the gentiles, e.g. Rom 4, and Hayes, Conversion of the Imagination, 61-84.

${ }^{49}$ Less than one year after the publication of the Book of Mormon, Campbell denounced it in his Millennial Harbinger, in terms that provide a summarizing example of the analysis above. He writes:
} 
In the cases when Smith's writings do not claim inspired revelation, they claim archaic origination for themselves. In doing so they cloak nineteenth century discourse in archaic guise.

The net effect of this carefully crafted presentation is not limited to the book or its textual content. It reflects on Smith. Implicit in the production of the Book of Mormon was God's specific calling of Joseph to reveal and translate. God's selection process could not have been random. Surely such a grave responsibility of "restoring Christ's true church" is a role for someone who has found divine favor. Such carefully cultivated perceptions implicitly benefitted Smith's enterprise. ${ }^{50}$ Paul's process of reinterpreting Hebrew scripture is not something novel, but a broad practice that flourished in this time period among other Hellenized Jews like Philo and Aristobulus. These learned Jews set about harmonizing the texts of their

This prophet Smith, through his stone spectacles, wrote on the plates of Nephi, in his book of Mormon, every error and almost every truth discussed in N. York for the last ten years. He decides all the great controversies-infant baptism, ordination, the trinity, regeneration, repentance, justification, the fall of man, the atonement, transubstantiation, fasting, penance, church government, religious experience, the call to the ministry, the general resurrection, eternal punishment, who may baptize, and even the question of freemasonry, republican government, and the rights of man. All these topics are repeatedly alluded to. How much more benevolent and intelligent this American Apostle, than were the holy twelve, and Paul to assist them!!! He prophesied of all these topics, and of the apostasy, and infallibly decided, by his authority, every question. How easy to prophesy of the past or of the present time!!

Sub-titled "A Monthly Publication Devoted to Primitive Christianity" Conducted by Alexander Campbell and in production from 1830-1866.

${ }^{50}$ In some respects, this texting process parallels the institutionalized academic enterprise. Doctoral students are not anointed with a $\mathrm{PhD}$ until they generate a substantial textual product that indicates a certain expertise or skill in methods and in a given field of knowledge. Moreover, achieving tenure as a professor is often subject to the continued production of authoritative texts - that is texts that are recognized as authoritative by various publishing entities and the appropriate committees of those already vested with academic authority. Recognition of one's abilities and the crowning with a particular status comes as a result of one's ability to commit persuasive and imaginative, while academically rigorous, thinking to text. Rather than citing the authority of preceding holy men or scripture, scholars cite respected scholars in footnote form. 
Hebrew ancestry and tradition with the Greek-inflected Hellenistic culture of their contemporary environment. Both have Greek names and write in Greek. ${ }^{51}$

Just as the works of Philo, Aristobulus and Smith reflect their respective contemporary environments, so does Paul's. Paul's notion of cosmic and body/soul dualism reflects Platonic and Zoroastrian cosmology 52 more so than pre-Hellenistic Jewish thought. The tendency towards reinterpreting the past to make sense of the present was also critical to the emergence of the later rabbinic tradition that developed in the centuries after the Jewish wars, including the great (and legendary) Council of Jamnia. ${ }^{53}$ Reinterpretation of tradition keeps the thought world of many social formations alive and meaningful. In fact, reinterpretation of the past to work for the present resides at the core of the meaning-making exercise. This is part of "the work we make scriptures do for us." ${ }^{54}$ New texts, freshly reinterpreted scriptures, or even the simple conveyance of a revelation to followers provides, if not creates, a new understanding of "reality." Reality is a social construction and texts and their promoters and interpreters articulate precisely

${ }^{51}$ John J. Collins remarks that Hasmonean coins bear Greek inscriptions in addition to Hebrew and that Aristobulus "called himself philhellen, "lover of the Greeks." Collins then offers "it is not surprising, then, to find that we cannot draw a clear line between the literature of the Diaspora and that of Judea.” John J. Collins, Between Athens and Jerusalem: Jewish Identity in the Hellenistic Diaspora, Second Edition (Grand Rapids, MI: William B. Eerdmans Publishing Company, 2000), 17.

${ }^{52}$ Gregory J. Riley posits that Christianity was the first thought system to combine the Platonic notions of body/soul dualism with the Zoroastrian notions of cosmic, or good/evil dualism. River of God: A New History of Christian Origins (New York: HarperSanFrancisco, 2001), 133-169, 157.

53 "Interpretation of earlier tradition is already an essential and continuous part of biblical and intertestamental literature," Dieter Georgi, The Opponents of Paul in Second Corinthians (Philadelphia: Fortress Press, 1986) 359-60. For an analysis of the constructed nature of the "Council of Jamnia” see Boyarin's Border Lines, 151-201.

${ }^{54}$ See Vincent L. Wimbush, “The Work We Make Scriptures Do For Us: An Argument For Signifying (On) Scriptures As Intellectual Project,” in Elisabeth Schuessler Fiorenza and Kent H. Richards, editors, Transforming Graduate Biblical Studies (Atlanta, GA: Society of Biblical Literature, 2010), 355-366, 363. See Also Theorizing Scriptures,1-16 and the Institute for Signifying Scriptures web site, www.iss.cgu.edu. 
what their versions of reality look like. Of the harnessing of ancient traditions for contemporary purposes, Biblical and Hellenistic scholar John J. Collins writes that "the power of such traditions to shape the identity of people derives from the fact that they are commonly taken as objective reality, within a given society." 55

The occurrence of (seemingly perpetual) reinterpretation of earlier tradition "had always been a central part of Israelite life and remained the major structuring and organizing device in postexilic Judaism." 56 John Ashton writes that

The practice of interpreting the sacred writings of the past as if they were intended to refer to the present was well known at Qumran. What has come to be called the pesher method of interpretation is really just another form of oracular prophecy. ${ }^{57}$

The inverse implication of Ashton's observation is that "oracular prophecy" is "really just another form" of scriptural interpretation. It could be argued that in the Judean-Christian tradition, texts and their interpretations-perhaps more precisely, texts and their interpreters - have taken the place of the diviner and shaman. Authorized interpreters of the will of the gods-whether they derive their interpretations from "reading" holy writings, liver omens, flights of birds, tea leaves, or other components of nature-hold positions of power over those who seek meaning from the archaic texts or surrounding environment. These interpreters construct and possess a knowledge that when promulgated serves to reinforce the

\footnotetext{
55 John J. Collins, Between Athens and Jerusalem, 2.

${ }^{56}$ Georgi, Opponents, 359. While this reinterpretive practice is claimed to have been normative and acceptable in ancient times, it is hard to imagine that the results of the interpretations were always warmly embraced-especially by those in power if novel interpretations somehow undermined traditional means of authority. The meaning-making exercise is generally not without tension of some kind or another.

${ }^{57}$ Ashton, The Religion of the Apostle Paul, 188. One could plausibly assume a link between some of the more creative and political results of the Qumran community's interpretive practices and their decision - whether voluntary or not - to reside in an isolated, barren location less than a mile from the northwest boundary of the Dead Sea.
} 
social structure and its norms—or, alternatively, encourage and validate the innovation promoted by the interpreter. Knowledge constructed from texts is made to argue for, and ultimately support, positions of power for the interpreting class within their respective communities.

The construction of reality includes more than narrating an account of creation or depicting God's impending wrath. The construction of reality includes delineating a social contract which outlines human behavioral expectations, beliefs to hold and depictions of who should be recognized as a teacher, prophet or king. Interpretations of holy texts may themselves become "scripture" as they too are invested with the awe and sanctity attributed to the written word. The ascent of a text in human perception from mere ink and paper to the irreproachable words and expectations of the gods is the basis of the scripturalization process.

Scripturalization implies that a particular text or texts both contain, and represent, a special knowledge that is authoritative and unavailable anywhere else. Moreover, scripturalization implies that the world view implanted in scripture is perceived as ultimate reality which then imposes itself back onto readers much as Berger describes the "sacred canopy." The knowledge explains and frames the way humans should live their lives and provides its own internal logic for why this is so. W. C. Smith provides an excellent summation of some of these issues. He writes,

By reading, cherishing, reverencing it, by recognizing it as scripture, not only were Jews assured of solidarity with their fellows, and of their fellows with them, and that their life had depth and meaning and richness, both in personal and in cosmic terms. More substantially, it was-became-a matter not simply of assurance but of fact. ${ }^{58}$

\footnotetext{
${ }^{58}$ W.C. Smith, What Is Scripture, 28
} 
As societies evolve, revised interpretations of - which is to say fresh constructions of-humanity's relationship to the visible and unseen worlds must also evolve to remain relevant and meaningful. Such a process provides niche opportunities for spiritual entrepreneurs. Paul and Smith both respond to these opportunities. Sociologist and historian (respectively) Lee and Sinitiere write that,

religious suppliers thrive in a competitive spiritual marketplace because they are quick, decisive, and flexible in reacting to changing conditions, savvy at packaging and marketing their ministries, and resourceful at offering spiritual rewards that resonate with the existential needs and cultural tastes of the public. 59

Texted, prophetic responses to cultural opportunities should not be construed as simply mercenary profiteering, but as motivated by the same cultural climate that had generated widespread pockets of demand. Demand for the authoritative answers offered by these types of writings is evidenced by the growth of Paul and Smith's respective followings. Their innovative, meaningful riffs originating from traditional thought and practice, found a receptive audience. Constructing texts provided a vehicle for legitimizing and disseminating their meaning-making (perhaps meaning-refining) excursions. Both were aware of the power of texts. Moreover, as texts come to hold power in themselves, their producers can not but be perceived as men who have found special favor in the eyes of God. Such a perception generates an exceptional status in the eyes of their community.

\footnotetext{
${ }^{59}$ Shayne Lee and Phillip Luke Sinitiere, Holy Mavericks: Evangelical Innovators and the Spiritual Marketplace (New York: New York University Press, 2009), 3.
} 
An excellent example of the power implications inherent in Smith's construction of reality comes from a revelation attributed to the day the church was formally founded. ${ }^{60}$ Smith revealed that a history of the little church was to be kept by the followers. Smith also revealed specific instructions as to how he should be viewed in that history. His revelation reads,

there shall be a record kept among you, and in it thou shalt be called a seer, a translator, a prophet, an apostle of Jesus Christ, an elder of the church through the will of God the Father and the grace of our Lord Jesus Christ (BoC XXII, 1).

The revelation continues that Smith is "inspired by the Holy Ghost to lay the foundation [of the church], and to build it up unto the most holy faith." Moreover, the church ... shalt give heed unto all his words, and commandments, which he [Smith] shall give unto you, as he receiveth them, walking in all holiness before me: For his word ye shall receive, as if from mine own mouth, in all patience and faith; For by doing these things, the gates of hell shall not prevail against you (BoC XXII, 4-5, emphasis added).

The revelation constructs a world view where Smith is to be understood as the primary authoritative figure within the new reality. Smith presents himself as one that the gods mandate to be recognized under a host of esteemed titles: a "seer, a translator, a prophet, an apostle of Jesus Christ, [and] an elder of the church." In doing so, Smith presents himself as the key figure to a newly constructed understanding of the world. Smith's "words and commandments" shall be received as if they were straight from the mouth of God. Moreover, this recognition of his

${ }^{60}$ Marquardt and others contest this date. The games played with respect to manufacturing a time, date and place for the "founding" of a church is another clear example of concocting texts to serve a social (or legal, or administrative) purpose. See H. Michael Marquardt and Wesley P. Walters, Inventing Mormonism: Tradition and the Historical Record (Salt Lake City: Smith Research Associates/Signature, 1994), 153-172, Quinn, The Mormon Hierarchy, 275-276, and Bushman, Rough Stone Rolling, 109. 
superior status (be it seer, translator, a prophet, or an apostle of Jesus Christ) is to be commemorated in texted form as a written history of the organization.

The impulse to record events for posterity suggests in itself that the events to be recorded are of historical significance. They preserve and broadcast Smith's position as prophet, seer and revelator. While the historical project falls just shy of pure hagiography, it is a similar endeavor, not unlike a court-history. The early Mormon history project, while admittedly much less visual, serves the same social and political functions as the large ubiquitous images of late North Korean leader Kim Il Sung that refer to him as "eternal leader." ${ }^{1}$ Such projects, physical and textual, function to instruct the multitudes in no uncertain terms how the leader is to be perceived.

Smith's directives to recognize him with a host of lofty titles mimics overt political propaganda. The titles that Smith chose for himself are designed to shape perceptions of him and distinguish him as the obvious leader of the new community. Moreover, the community is explicitly told that Smith's dictates should be embraced as if they were the very words of the gods themselves. Doing as Smith says allows one to avoid the gates of hell (BoC XXII.5). In sum, a significant component of the new reality Smith creates for his following is the articulation of a social agreement whereby he alone is to be recognized as the one with uncontestable power.

\footnotetext{
${ }^{61}$ By one account there are over 500 statues of Kim Il Sung in North Korea. Murals, portraits and banners located in public squares, post offices, train stations and the like number in the thousands. See Jane Portal, Art under control in North Korea (British Museum Reaktion Books, 2005), 82. Jasper Becker, Rogue Regime: Kim Jong Il and the Looming Threat of North Korea. (New York: Oxford University Press, 2007) 201. This information was accessed from http://en.wikipedia.org/wiki/Kim_Il-sung, accessed September 20, 2011.
} 
To Paul's communities the equivalent sentiment is expressed by Paul's rhetorical query of: "am I not an apostle, have I not seen the Lord?" (i.e. "I am an apostle and I have seen and been commissioned by Jesus Christ our Lord," 1 Cor 9.1) which is combined with the expression that anyone who preaches a gospel (i.e. a version of reality) other than Paul's is to be accursed (Gal 1.7-9). Other examples might include Paul's claim that "our competence is from God, who has made us competent to be ministers of a new covenant" (2 Cor 3.5-6); and "So we are ambassadors for Christ, since God is making his appeal through us; we entreat you on behalf of Christ... " (2 Cor 5.20). ${ }^{62}$ Each of these statements takes as a point of departure, the assumption that Paul has earned a special designation as the mouthpiece for the ultimate unseen powers of the universe. Such assumptions and claims are not trivial. What Paul reveals as the way of Christ Jesus, God or the correct interpretation of scriptural traditions serves to depict a revised reality for his communities, a reality where he is to be understood as firmly in the authoritative position.

${ }^{62}$ And also, "the signs of a true apostle were performed among you with utmost patience, signs and wonders and mighty works." 2 Cor 12.12; and see 1 Cor 4.15, 17. 


\section{Texts Articulate the Social Contract}

Paul's interpretation of Scripture is always a pastoral, community-forming activity... they seek to shape the identity and actions of a community

—Richard B. Hayes ${ }^{63}$

[B]ehold, I give unto you a commandment, that you rely upon the things which are written

-Smith, BoC XV.3.

Of the three main bodies of Smith's writings that ultimately achieved canonical status, the writings most comparable to Paul's letters are the series of revelations compiled in the 1833 Book of Commandments which, after modest editing and augmentation, exists as today's Doctrine and Covenants. ${ }^{64}$ The primary similarity this collection of revelations has with Paul's letters is functionality (see Table 3.4). Both collections of texts were written to address specific needs within the recently formed communities. Both also functioned as a platform from which their producers could bellow their claims of special status. Importantly, both articulated the basics of the social contract between leader and led.

One of Smith's early revelations ${ }^{65}$ reinscribes words and sentiments of Matthew's Jesus: "He that is not with me is against me; and he that gathereth not with me scattereth abroad," (Matt 12.30, KJV). Such a statement concisely articulates the totalizing and high-stakes nature of the social relationship and its justification as working to fulfill the will of the gods on earth. In keeping with his

\footnotetext{
${ }^{63}$ The Conversion of the Imagination: Paul as Interpreter of Israel's Scripture (Grand Rapids, MI: William B. Eerdmans Publishing Company, 2005), xv.

${ }^{64}$ Paul's letters received plenty of grooming over the years. See Pervo, The Making of Paul, Crossan and Borg, The First Paul.

${ }^{65} \mathrm{BoC}$ IX.17, cited further below. In the $1833 \mathrm{BoC}$ this revelation is dated to May of 1829 . In the contemporary $D \& C$ the date is listed as the summer of 1828.
} 
professed role as God's appointed messenger on earth, Smith articulates God's vision for humanity as one that demands Smith act as God's proxy to fulfill. In the first-person voice of God, Smith writes,

behold, this is my doctrine: whosoever repenteth, and cometh unto me, the same is my church: whosoever declareth more or less than this, the same is not of me, but is against me: therefore, he is not of my church" (BoC IX.17, recall also Gal 1.7-9).66

This grandiose statement serves a social purpose. Aside from the obvious implication that Joseph has been chosen to speak for God, the revelations emphasize that in the high-stakes world that is approaching the End of Time, there is no wiggle room for those less than fully devoted. The individual must be committed to the prophet's vision of God as any variation from it is represented as opposition. The statements are intentionally divisive, which serves an important social purpose. The individual must choose his allegiance carefully so as not to oppose the will of the gods. Social formations that demand a high level of devotion from their members prove to be internally stronger than groups that demand less than a full and focused commitment. ${ }^{67}$ Communities that position (or find) themselves in tension with the mainstream generate solidarity within. 68 Moreover, the rhetoric is

${ }^{66}$ A similar, more detailed formulation reads,

And now this calling and commandment give I unto all men, that as many as shall come before my servant Sidney and Joseph, embracing this calling and commandment, shall be ordained and sent forth to preach the everlasting gospel among the nations, crying repentance .... And this commandment shall be given unto the elders of my church, that every man which will embrace it with singleness of heart, may be ordained and sent forth, even as I have spoken. I am Jesus Christ, the Son of God.” BoC XXXVIII, 3-5.

${ }^{67}$ Stark, Acts of Faith, 141-162. See also argument in chapter two.

${ }^{68}$ See Armand L. Mauss, The Angel and Beehive: The Mormon Struggle with Assimilation (Urbana, IL: University of Illinois Press, 1994) for a study of the twentieth century LDS church's struggle to find the right amount of "tension" with and within mainstream American society. Stark and Finke argue that "the higher a group's level of tension with its surroundings, the higher its average level of member commitment," and continues that religious organizations that demand a high commitment from its members 
clear in that no way other than that of the charismatic's is beneficial. Deviation from the charismatic's mandates is not simply neutral, it is disruptive and counter to the wishes of the gods.

Smith's revealed statements summarize one basic articulation of the charismatic relationship. One is to come to the prophet and embrace all of what he says. To fail to do so puts the individual in dangerous grounds as one that is "against me [God]." As Smith represents himself as divinity's mouthpiece, people who seek (Smith's version of) God must come to Smith to get it right. There is no mention here of baptisms, creeds, rituals, official leadership or anything else. In this passage, the language is simultaneously vague and restrictive: vague in the sense that no objective criteria is mentioned, restrictive in that unlimited devotion is expected and unstated criteria must be embraced exactly once articulated. The now-texted passage effectively claims for Smith the authority to be the sole mouthpiece of God in much the same way Paul did in Galatians 1.8. Note also that the radical subjectivity is akin to the declaration in the late first century Christian Didache that true prophets are those that embrace and repeat the teachings of the community leaders while contradicting messages espoused by those already considered false prophets. ${ }^{69}$

tend to provide more rewards for its members, Acts of Faith, 145. Internal solidarity is one such reward.

${ }^{69}$ See Didache chapters $11-13$ for the criteria that indicates who is a true and who is a false prophet. The crux of the argument is that anyone who preaches what the community already believes is considered a genuine prophet (as long as he does not stick around for too many free meals).

Now you should welcome anyone who comes your way and teaches you all we have been saying. But if the teacher proves himself a renegade and by teaching otherwise contradicts all this, pay no attention to him. But if his teaching furthers the Lord's righteousness and knowledge, welcome him as the Lord. . . . However, not everybody making ecstatic utterances is a prophet, but only if he behaves like the Lord. It is by their conduct that the false prophet and the [true] prophet can be distinguished" (Didache 11.1-2, 8). 
The idea and process of one "repenting" and "coming unto me" is a very powerful socialization tactic. These simple phrases belie a controlling and conforming psychological strategy in that those who will follow have already gone through important preliminary steps that allow them to 1) renounce the wrongheadedness of their former ways by "repenting" and 2) embrace the words and vision of reality put forth by the new prophet, "cometh unto me." The etymology behind the word repent is instructive. One is to re-penso, -pensare. One is to rethink, reconsider one's former position as inherently wrongheaded and to come to a revised conclusion, one that matches the mission and agenda of the charismatic calling for repentance. ${ }^{70}$ If one can not revise one's thinking in a way that matches the charismatic's, they will not be able to "hear the call." Perhaps so much is axiomatic. Stripped of their religious connotations, the sentiments expressed by "repenteth" and "cometh unto me" might be rendered in secular jargon as renounce your past, acquiesce to a new power structure and orientation, and embrace my vision of the world. Not having the ring of tradition and familiarity, the latter articulation resonates with potentially sinister undertones. ${ }^{71}$ The commitment to the new group is totalizing. Let the dead bury the dead (Matt 8.22, Luke 9.60). In the command to "come unto me" the ambiguity of who speaks in the first persongiven that the prophet speaks for and claims to represent God herself-is also

As in, Cyril C. Richardson, editor, Early Christian Fathers (New York: Touchstone, 1996), 176-77.

${ }^{70}$ From the Latin penso, pensare, to weigh carefully, estimate, to ponder, consider. Cassell's Latin Dictionary (New York: Wiley Publishing, 1968)

${ }^{71}$ Such "acquiescence" and "reorientation" is the baseline criteria for anyone joining an new, totalizing, community. To most outsiders, these new communities are often tagged with the derisive moniker of "cult." 
powerful. The proclaimer and the proclamations have become enmeshed.

Moreover, as these commandments are packaged and promulgated in texted form, the texts themselves wield tremendous charismatic authority as they convey the words of God, the mission of the charismatic, a new construal of reality, and the individual's role within the new community.

Smith is acutely aware of the power of revealed text and energetically preserves his sole authority to pen the words of the gods. In a revelation directed towards early convert and close collaborator Sidney Rigdon, Smith confirms his own privileged authority by limiting Rigdon's. To the former Campbellite minister, Smith writes that he is allowed to "preach my gospel" and even "inasmuch as ye do not write, ... [to] prophesy" (BoC, XXXVII. 25, 24, emphasis added). Smith encouraged Rigdon to speak from the heart, even to "prophesy," but explicitly forbids him the right to commit his sentiments to text. ${ }^{72}$ In limiting Rigdon in this fashion, Smith is able to control the message and the shaping of reality for his flock. Smith's revelation plays the role of a social contract with Rigdon. ${ }^{73}$ The revelation keeps Rigdon as a close advisor and collaborator and empowers him to prophesy and preach. At the same time, the revelation strips Rigdon of his right to write which effectively caps his ability to compete for the top leadership position and social status that Smith zealously reserves for himself. With this limitation, Smith

\footnotetext{
${ }^{72}$ Rigdon is viewed by disillusioned Mormonite Ezra Booth as one "constitutionally inclined to exaggerate.” Booth claimed that when he challenged Rigdon's written description of Zion as inaccurate, Rigdon replied, "what I write will be written with the most infallible inspiration of the holy spirit." In the same letter, Booth writes that he is "persuaded, that truth by this embellishing touch, often degenerates into fiction." The excerpts are from a letter written from Booth to the first Mormon Bishop, Edward Partridge, dated September 20, 1831, as included in Howe’s Mormonism Unvailed collection, "Letter VII," 208-09.

${ }^{73}$ This theme is expanded upon below under the heading "Claiming Authority Over Men," specifically under the sub-heading "Smith: Power and Disempowerment."
} 
disempowered Rigdon. Smith will not suffer his revelations to be "enhanced" or contradicted by one of his own followers. The revelation constructs a world in which Smith alone, and not Rigdon, is allowed to commit the words of the gods to texts. ${ }^{74}$ Smith demonstrates his understanding of the implicit power of the written word when he reveals to Cowdery and David Whitmer that they are to act (including the right and ability to baptize) only within the constraints of "the words which are written," (BoC XV.31-32).

Coming to Smith is the surest route to "come unto [God]." Given the acceptance of Smith's prophetic designation, the prophet has a fair bit of latitude to articulate "God's plan" for "his church." To those with whom Smith is displeased, he writes,

Hearken 0 ye people which profess my name, saith the Lord your God, for behold mine anger is kindled against the rebellious, and they shall know mine arm and mine indignation in the day of visitation and of wrath upon the nations. And he that will not take up his cross and follow me, and keep my commandments, the same shall not be saved. Behold I the Lord commandeth, and he that will not obey shall be cut off in mine own due time (BoC LVIII.1-3, emphasis added).

Such a revelation summarizes the two functions addressed in this section. It provides some details of Smith's constructed reality in that followers are now explicitly apprised of God's growing anger. The vagueness of what constitutes "rebellious" behavior keeps hearers attentive to further revelations and the interpretations provided by the living prophet. The revelation also reiterates the social contract with the command to "take up the cross," "follow" and abide by the

\footnotetext{
${ }^{74}$ Smith also instructs Cowdery that he "shalt have revelations but write them not by way of commandment” BoC XXX.7.
} 
community's operating parameters-i.e. Smith's dictates. The social contract is also stated in negative terms as in the first revelation of the $B o C$. It reads in part,

for the Lord is nigh, and the anger of the Lord is kindled, and his sword is bathed in heaven .... they who will not hear the voice of the Lord, neither the voice of his servants, neither give heed to the words of the prophet, and apostles, shall be cut off from among the people: For they have strayed from mine ordinances, and have broken mine everlasting covenant, they seek not the Lord (BoC I.3, emphasis added).

Those who do not heed the "words of the prophet" and who ignore the Lord's "servants," who have articulated the "ordinances and ... everlasting covenant" "shall be cut off from among the people." The social contract demands obedience and conformity. Threats of ostracism and exile indicate the high-stakes nature of the specific behavior required by the social proposition.

Paul's procedure for expressing social expectations and constructing reality are similar, even if presented somewhat differently. After claiming power for himself and criticizing his competitors, Paul's letters to the Corinthians and the Galatians proceed to inform the community of its behavioral obligations. To remain part of the community, individuals are to abide by certain practices regarding sexuality (1 Cor $5.1,9,11 ; 6.9,16$, etc); certain legal proceedings against fellow insiders (1 Cor 6.1, 4-6), treatment of food previously sacrificed to idols (1 Cor 8), and so on. Given these explicit communal guidelines, and Paul's call to imitate his own behavior (1 Cor 4.16. etc.), his letters specifically articulate the communal ideals to be embraced and the behavioral expectations demanded of his nascent social formation. Those who want to remain within the community must abide by the conditions expressed in this implicit social contract. 


\section{CLAIMING POWER: THE SELF-PROMOTER ARGUES HIS CASE}

Now even if I boast a little too much of our authority, which the Lord gave for building you up and not for tearing you down, I will not be ashamed of it

-Paul, 2 Cor $10.8^{75}$

Behold, I the Lord, will give unto my servant Joseph Smith, Jun., power that he shall be enabled to discern by the Spirit ${ }^{76}$

-Smith, $D \& C 63.41$

I give my opinion as one who by the Lord's mercy is trustworthy

-Paul, 1 Cor 7.25

Neither Paul nor Smith were born into, nor handed a position of power. It was by force of individual commitment and entrepreneurial will that they achieved what they did. The process of attaining power took time. Paul's and Smith's own writings provide evidence that the authoritative positions they eventually held in their own communities were not always so stable, clear cut or certain. As any student of history or sociology should expect, their leadership was not uncontested and their eventual dominance developed over time. Paul's and Smith's own writings document legitimate and hotly contested leadership challenges mounted against them. These challenges are then refuted by the respective authors. The writings which document the challenges to their author's leadership, are read today by those who already know the outcome of the struggles. ${ }^{77}$ Looked at retrospectively by

75 See and compare 2 Cor 10.7-12; 11.12-13, 20-23; 12.1-9 where Paul tries to differentiate his boasts from the boasts of his competitors.

${ }^{76}$ This is a subtle piece of writing. Within context it provides Smith the authority "to discern" who is to able to "go up unto the land of Zion." But that this statement of a divine gift to a human being can be uttered at all speaks to Joseph's position as one already chosen by the gods to convey their wishes to the world. In other words, this explicit grant of Joseph being “enabled by the Spirit to discern” is of a lesser status than is the already implicit authority held by one who receives and speaks the very words of the gods. Smith’s revelation explicitly confirms a status he has already implicitly claimed.

${ }^{77}$ Castelli, Imitating Paul, 21-33. 
today's devotees and even many scholars, historical power struggles are generally simplistically perceived as illegitimate attempts to usurp power by unauthorized individuals. At the time of the power contest under consideration, however, the threat to the eventual victor's authority were substantial enough to merit authoritative rebuttals, words or writings to undermine, counter or denounce the claims of the challenger. Written responses to competing claims of authority indicate that some of these challenges, even if quite subtle, were significant enough that they had to be directly and decisively refuted in a written form. Paul's authentic letters were essentially position statements dedicated to defending Paul's authoritative position as much as they were to addressing communal questions or theologizing. His letters served to secure his theological propositions and leadership status against competing notions and their promulgators. His letters not only aided in disseminating his theology, but functioned to establish precisely whose word should be taken as authoritative.

Over a century ago, the respected biblical scholar F. C. Baur wrote of Paul's letters to the Corinthians, "now a great deal of space is devoted in both of the Epistles to a vindication of his [Paul's] apostolic dignity, which his opponents refused to concede to him to its full extent." 78 For Baur and those of his orientation, ${ }^{79}$ Paul's apostolic authority is a forgone conclusion. With the blinding

\footnotetext{
${ }^{78}$ F. C. Baur, Paul: The Apostle of Jesus Christ, His Life and Work, His Epistles and His Doctrine, trans. Eduard Zeller, 2nd ed. (Edinburgh: Williams and Norgate, 1876), 1:266.

${ }^{79}$ Baur saw history as chronicling the works of God through human actors. Opponents of Paul failed to recognize Paul as an agent of God, but Paul was ultimately vindicated through the historical process where "God as Absolute Spirit" is active and the "reconciliation of the divine and human takes place in history." See William Baird, History of New Testament Research: Volume One, From Deism to Tubingen (Minneapolis, MN: Fortress Press, 1992), 258-260.
} 
influence of hindsight, Baur assumes that Paul's status was firmly grounded and should have been recognized by everyone he encountered. ${ }^{80}$ Critical analysis indicates otherwise. Reading Paul without Baur's implicit assumptions of Pauline triumph reveals a more complex scenario. Paul devotes a lot of space in his epistles to forging his apostolic status for a reason: his authority is not as recognized as he would like it to be. He is fighting to be recognized as authoritative in the midst of potent competing interests.

\section{Supernatural Sanction: Chosen Messengers and the Claims of Packaging}

Beware of false prophets, which come to you in sheep's clothing, but inwardly they are ravening wolves

-Mattew 7.15

-BoM 3 = 1 Nephi 14.15

\section{Paul: Explicit Claims of a Divine Commission}

'We know how to recount many falsehoods [yeudea] like real things, and We know how to proclaim truths when we wish.' Thus spoke the glib-tongued daughters of great Zeus And they gave me a scepter, a branch of luxuriant laurel, A wondrous thing they had plucked. And they breathed a voice into me: A divine one, so that I might tell of things that were and will be

-Hesiod, Theogony 26-3281

Not unlike some of the first lines of Hesiod's Theogony, the beginning of Galatians asserts not only Paul's divine commission but the perspective that ordinary humans are not capable of calling an individual to an exalted role in the

\footnotetext{
${ }^{80}$ At least one commentator argues that the influence of Hegelian philosophy on Baur drives him to see Paul as being opposed in his promotion of "Gentile Christianity" in the face of "Peterine Christianity." See Jerry L. Sumney, "Paul and His Opponents: The Search” in Mark D. Given, Paul Unbound: Other Perspectives on the Apostle (Grand Rapids, MI: Baker Academic, 2010), 55-70, 56.

${ }^{81}$ As translated by Bruce Lincoln in Theorizing Myth, 23.
} 
same manner that Paul has been called. ${ }^{82}$ Hesiod claims that his divine ability is a gift from the daughters of Zeus. Paul attributes his powers to his own god. Both assertions imply that the grounds of their commission reside in a private experience, that lies beyond the realm of empirical challenge or human contestation. ${ }^{83}$ Thomas Overholt summarizes the generic case of prophetic callings. He writes,

the prophet makes the claim that the deity has authorized the proclamation of a certain message. The basis of this claim is usually a religious experience that is private and therefore essentially intangible and unverifiable by the members of the audience, who nevertheless assume that genuine prophets will have had such an experience. ${ }^{84}$

Paul begins his letter to the Galatians (Gal 1.1-5) with what is nominally a greeting; yet the implications inherent in the formulation of his words reach well beyond those of an innocent, agenda-free salutation (Gal 1.3). Indeed, "salutation" may be the wrong term, as the beginning sentences constitute an emphatic, selfpromotional declaration of how Paul wants the letter's recipients to understand him. The actual "salutation" part of the introduction is little more than a

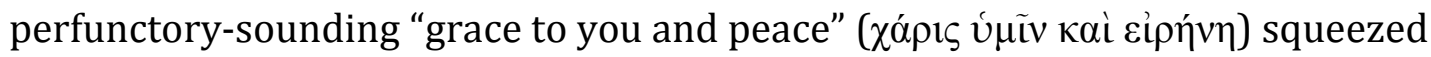
between, and integrated into, his self-promotional assertion and the proclamation of

\footnotetext{
${ }^{82}$ Regarding Paul’s “call” versus “conversion,” the more common term, see Krister Stendahl, Paul Among Jews and Gentiles (Philadelphia: Fortress Press, 1976), 7-23; and Ashton, The Religion of Paul, 28, 73-104. Hyum Maccoby argues that Paul's transformation was not a conversion as Christianity did not yet exist. The Mythmaker: Paul and the Invention of Christianity (New York: Barnes and Noble Books, 1998) 103. See also Eisenbaum, Paul Was Not a Christian and Segal, Paul the Convert.

${ }^{83}$ Lincoln, Authority, 112.

${ }^{84}$ Channels of Prophecy: The Social Dynamics of Prophetic Activity (Eugene, OR: Wipf and Stock Publishers, 1989), 70. Part of the burden of this dissertation is to explain how the prophet gets the people to assume he is genuine. Max Weber writes, "it is characteristic of the prophets that they do not receive their mission from any human agency, but seize it as it were." On Charisma and Institution Building: Selected Papers, ed. S.N. Eisenstadt (Chicago: Univ of Chicago Press, 1968), 258.
} 
his basic message of the atoning works of the Lord Jesus Christ (Gal 1.1-3). See

Table 3.3 below. Paul claims supernatural sanction in his very first sentence. His selection as an apostle was not via a "human commission" but by powerful, nonobvious, invisible beings who rule Paul's version of the supernatural realm.

There is little reason to doubt that Paul underwent a palpably real, biologically-measurable experience that he perceived as a divine visitation. ${ }^{85}$ It is difficult, however, to reconstruct, validate, or verify the type of private emotional experience that Paul underwent-which will differ each time it is recalled to fit the rhetorical, theological, and other needs at hand. ${ }^{86}$ Given that our analytical framework is limited to the natural world, it does not really matter what his private experiences were. What is relevant is the manner in which private experiences are presented and the degree of validity, seriousness and meaning attributed to them by all parties involved. People continue to have these types of experiences in the contemporary world. ${ }^{87}$ What needs to be examined is the way in which Paul puts

${ }^{85}$ Scholar of religious naturalism and science, Willem B. Drees, argues,

Sometimes events are interpreted as religiously significant, and the interpretation is based on an existing religious framework, rather than due to any unusual features of the experience. There are quasi-sensory experiences, such as visions and dreams, voices ... flashes of insight, moments of inspiration, sudden convictions, and perhaps even mystical visions may be called revelatory.... The existence of such experiences — as described by the individuals who had them-is not disputed here. Once their existence as experience is granted, [however], the question arises of how the experience should be evaluated (emphasis in original). Religion, Science and Naturalism (Cambridge: Cambridge University Press, 1998), 166.

${ }^{86}$ It is well known that the accounts of Paul's road to Damascus event in Luke's Acts differ from the accounts given by Paul in his authentic letters. Compare also the evolving accounts of Smith's first vision with respect to the meaning-making enterprise in James B. Allen, “The Significance of Joseph Smith's First Vision in Mormon Thought,” Dialogue: A Journal of Mormon Thought 1, no.3 (Autumn 1966): 29-45.

${ }^{87}$ See Lewis R. Rambo, Understanding Religious Conversion (New Haven, CT: Yale University Press, 1993); C. Daniel Batson, Patricia Schoenrade and W. Larry Ventis, eds. Religion and the Individual: A Social-Psychological Perspective (Oxford: Oxford University Press, 1993); and Andrew Buckster and Stephen D. Glazier, The Anthropology of Religious Conversion (Lanham, MD: Rowman and Littlefield Publishers, 2003). For some historical perspective on this phenomenon in the time period of the individuals addressed here, see Ann Taves, Fits, Trances, and Visions: Experiencing Religion and 
his experience to work for himself with the goal of establishing and maintaining a position of power and authority in the communities he controls or seeks to control. Claims of divine visitations are in themselves implicit strategies of power. ${ }^{88}$ Why would Paul feel the need to begin his letter with his claim of a divine commission? A basic reading of Galatians reveals that Paul was compelled to establish his own authority before anything else. In the midst of a broad variety of ancient local traditions, the Mediterranean world of this era was a seething cauldron of spiritual innovation, new cults, new associations, and new gods. ${ }^{89}$ Those inclined to seek out spiritual solutions or communal association had a number of compelling options in the marketplace of religious ideas and their ideological communities. In Galatia itself, Paul sensed erosion in the authoritative position he had established at his last visit. He had to address their leadership and theological predicaments. It is

Explaining Experience from Wesley to James (Princeton, NJ: Princeton University Press, 1999) and David E. Aune, Prophecy in Early Christianity and the Ancient Mediterranean World (Grand Rapids, MI: William B. Eerdmans Publishing Company, 1991).

${ }^{88}$ See Elizabeth Castelli's excellent work on Paul for the reasonably parallel notion that Paul's exhortation to "imitate me" is in itself an implicit strategy of power in, Imitating Paul, 15, 21-6, 31, 36, 86117.

${ }^{89}$ There is a huge body of research on the social and spiritual marketplace of the ancient Mediterranean world. Studies have been approached from a number of disciplinary perspectives. See for example: Robert Turcan, The Cults of the Roman Empire, trans. Antonia Nevill (Oxford: Blackwell, 2000); Philip Harland, Associations, Synagogues and Congregations: Claiming a Place in Ancient Mediterranean Society (Minneapolis: Fortress Press, 2003); David Ulansey, The Origins of the Mithraic Mysteries: Cosmology and Salvation in the Ancient World (New York: Oxford University Press, 1989); Hans-Josef Klauck, The Religious Context of Early Christianity: A Guide to Graeco-Roman Religions, trans. Brian McNeil (Minneapolis: Fortress Press, 2003); Richard A. Horsley, Bandits, Prophets and Messiahs: Popular Movements in the Time of Jesus, with John S. Hanson (Harrisburg, PA: Trinity Press International, 1999); Keith Hopkins, A World Full of Gods: The Strange Triumph of Christianity (New York: PLUME/Penguin, 2001); Hugh Bowden, Mystery Cults of the Ancient World (Princeton, NJ: Princeton University Press, 2010); T. W. Overholt, Channels of Prophecy: The Social Dynamics of Prophetic Activity (Eugene, OR: Wipf and Stock Publishers, 2003); and Michael Attyah Flower, The Seer in Ancient Greece (Berkeley, CA: University of California Press, 2009); Walter Burkert, Greek Religion, Translated by John Raffan (Cambridge, MA: Harvard University Press, 1985); Mary Beard, John North and Simon Price, Religions of Rome (Cambridge, MA: Cambridge University Press, 2000). 
precisely in these "select moments of crisis" 90 that asserting power and negotiating authority are most visible and most easily analyzed. ${ }^{91}$ Apparently, sources ${ }^{92}$ have told Paul about competing apostles and alternative gospels. To confront these challenges, he uses the beginning of his letter to address those who doubt his right to refer to himself as an apostle. ${ }^{93}$ To do so, he reaffirms not only his selfproclaimed title of apostle but also the superior authorizing nature of his calling and even the authoritative credentials of the powers that called him. Paul is not hawking just any old god, ${ }^{94}$ but one powerful enough to raise humanity from the dead-as supported by the claim of raising Jesus (now proclaimed as Christ) from the grave. As such, his extended "salutation" serves as part credo, in that it states

${ }^{90}$ To defend his choice to analyze the construction of authority by "investigat[ing] select moments of crisis,” Lincoln writes,

I am . . . inclined to think that the best way to study something like authority is not when it operates smoothly and efficiently, for its success in some measure depends on naturalizing itself and obscuring the very processes of which it is the product.

Authority: Construction and Corrosion, 11.

${ }^{91}$ See the work of psychiatrist Nassir Ghaemi whose thesis about mental health and leadership becomes most apparent in the leader's response to crisis, A First Rate Madness: Uncovering the Links Between Leadership and Mental Illness (New York: Penguin, 2011).

92 Paul makes no explicit mention of sources or gossip in Galatians, but he does in 1 Corinthians, e.g., "For it has been reported to me by Chloe's people that there are quarrels among you . . . “ (1 Cor 1.11). He was, though, aware that there were those in Galatia trying to confuse his flock (Gal 1.7-9; 3.1ff). It is probably safe to assume that Paul was part of some sort of informal, ad hoc network of communication that existed among missionaries and travelers of the day.

${ }^{93}$ Smith also took to writing to address the crisis of apostasy in 1838. After losing about 300 members of the Kirtland church, he took to rewriting his account of his first vision in a way that "served an immediate, institutional purpose in consolidating his authority and quashing dissent," Grant Palmer, An Insider's View of Mormon Origins, 248, 254.

${ }^{94}$ So too, Smith's church was not just any old church. His written revision of his first vision account was one that shifted its focus from the individual needs of "forgiveness of sins" to the institutional needs of claiming that all other denominations and creeds were "an abomination in his [God's] sight." In the face of massive dissent, it was important that Smith reasserted that his restored church was the only true and living church on the face of the earth. The 1832 first vision account might be more accurate historically, but the 1838 first vision account was more useful for the needs of the crisis at hand. See Palmer, Insider's View, 235-254. 
Paul's conviction to the divine powers he serves, and part paean, in that it recites the mighty works of Paul's god and the beneficent atoning death of Jesus (see Table 3.3).

To back his claim of being an apostle, Paul clearly states that this status came neither from humanity, nor through any single individual, but through the anointed

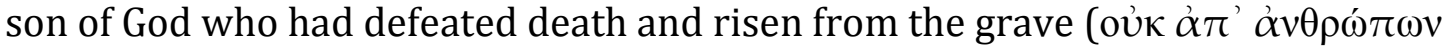

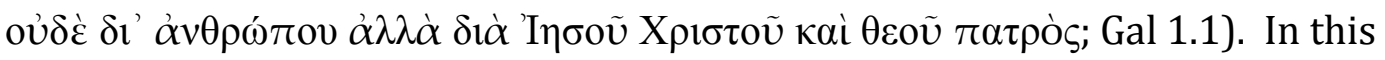
opening phrase, Paul emphatically distances himself from the authorizing capacity of humanity as a whole ( $\dot{\alpha} v \theta \rho \omega ́ \pi \omega v)$ and even that of individual men ( $\dot{\alpha} v \theta \rho \omega ́ \pi \sigma o v)$. He passionately repeats his case of sole divine authorization by asserting that "the gospel that was proclaimed by me is not of human origins; for I did not receive it from a human source ... but received it through a revelation of Jesus Christ" (Gal 1.11-12). In this, Paul again places his authorization outside the realm of human life and experience and directly into the hands of forces that can neither be known empirically nor contested. ${ }^{95}$ Noam Chomsky writes, "the standard way you cloak and protect power [is that] you make it look mysterious and secret, above the ordinary person." 96 The implicit notion here is that humanity is not qualified to authorize who is to speak for God. Only God herself is. Explicitly, Paul claims that he has been specifically selected by God and Christ for his mission. The table below breaks down the implicit power claims in Paul's initial salvo.

\footnotetext{
${ }^{95}$ Lincoln, Authority, 112. Overholt, Channels of Prophecy, 70.

96 “_-otherwise why should anybody accept it?” Noam Chomsky, Understanding Power, 11
} 
Table 3.3

Analysis of Paul's Introduction to the Galatians

\begin{tabular}{|c|c|c|}
\hline NRSV: Gal 1.1-5 & Greek: Gal 1.1-5 & Analysis \\
\hline $\begin{array}{l}\text { Paul an apostle - sent } \\
\text { neither by human } \\
\text { commission nor from } \\
\text { human authorities, but } \\
\text { through Jesus Christ and } \\
\text { God the Father, who } \\
\text { raised him from the dead } \\
\text { - and all the brothers } \\
\text { who are with me, }\end{array}$ & 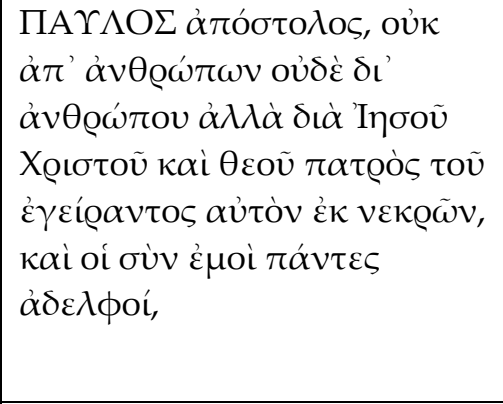 & $\begin{array}{l}\text { 1. Forceful self-promotional } \\
\text { claims of receipt of divine } \\
\text { authority - beyond what } \\
\text { humanity can authorize, i.e. } \\
\text { supernatural sanction. } \\
\text { 2. Citation of mighty deed of } \\
\text { patron deity who brought a } \\
\text { dead man back to life. }\end{array}$ \\
\hline $\begin{array}{l}\text { To those called out } 98 \text { of } \\
\text { Galatia: } \\
\text { Grace to you and peace }\end{array}$ & 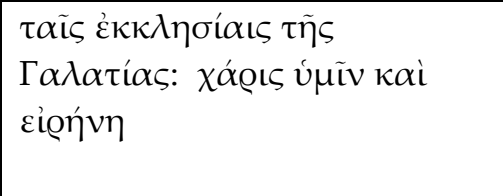 & $\begin{array}{l}\text { 1. Salutation. } \\
\text { 2. Implicit recognition of God's } \\
\text { favor of the letter's recipients } \\
\text { - "those called out" (by God). }{ }^{99}\end{array}$ \\
\hline $\begin{array}{l}\text { from God our Father and } \\
\text { the Lord Jesus Christ, } \\
\text { who gave himself for our } \\
\text { sins to set us free from } \\
\text { the present evil age, } \\
\text { according to the will of } \\
\text { our God and Father, to } \\
\text { whom be the glory } \\
\text { forever and ever. Amen. }\end{array}$ & 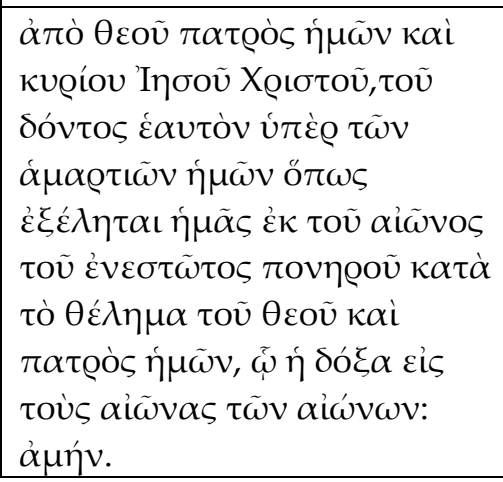 & $\begin{array}{l}\text { 1. Paean of mighty and } \\
\text { beneficent works of patron } \\
\text { deities and basic crux of Pauline } \\
\text { message: Jesus Christ sacrificed } \\
\text { as a human offering to (a) offset } \\
\text { the sins of humanity, and (b) } \\
\text { provide liberation to believers } \\
\text { from the dark supernatural } \\
\text { forces that haunt the earth }\end{array}$ \\
\hline
\end{tabular}

Paul continues in his theme that he is not to be viewed as just another itinerant teacher searching for a free meal, but that he is in fact doing what supernatural forces demand of him. In this, his rhetoric of not doing what is

\footnotetext{
${ }^{97}$ The literal translation of the Greek as "brothers" - rather than the more politically correct, gender neutral "members of God's family" as rendered in the NRSV - unmasks both the patriarchy inherent in the ancient world and the "corruption at the hands of men" that modern Biblical translations (e.g. the NRSV) are still subjected too.

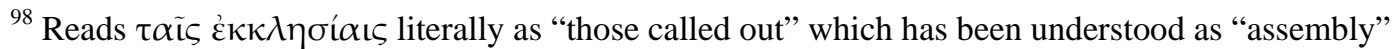
since the golden age of Hellenic democracy and as "church" by most Christians of post Pauline eras. The simple notion that Paul identified or understood himself as a "Christian" who founded an inherently Christian "church" is problematic and contested in scholarship. Moreover, the simple term church conceals the notion of special election implicit in "being called." See Boyarin, Border Lines and also Eisenbaum, Paul Was Not a Christian.

${ }^{99}$ This point only works if one accepts the word play stemming from a literal reading of $\tau \alpha \tilde{i} \varsigma$ $\dot{\varepsilon} \kappa \kappa \lambda \eta \sigma i ́ \alpha ı \varsigma$ as "to those called out."
} 
allegedly in his best interest actually serves his self-interest. Presenting himself as a devoted slave $(\delta \circ \tilde{\nu} \lambda \circ \varsigma)^{100}$ to Christ is intended to enhance the Galatian perception of Paul as doggedly and selflessly performing the work he has been called to do-even in the face of skepticism and ridicule. He challenges his community by asking if its members think he is "seeking human approval, or God's approval?" (Gal1.10) and noting that if he merely cared about what humans thought, he could not claim to be a "slave of Christ" (Gal 1.10). This portrayal-whether or not it is based in reality beyond Paul's rhetoric-serves to enhance the perception of Paul's conviction of his extramundane calling. His assertion of his own indifference to human judgment (Gal 1.10; 1 Cor 4.3 ) is a claim aimed at generating a favorable human judgment, at increasing his authoritative status in terms of human perception and discernment, specifically in the eyes of those to whom he writes. If Paul did not worry about "human judgment," he would not spill so much ink trying to justify himself in the eyes of his fellow humans. Feigned indifference is but another tactic.

Paul's letter to the Galatians is not an isolated example. He makes similar, if not more extensive claims in his opening pericope to the Romans (Rom 1.1-7). To the Corinthians he focuses on his "call" by the "will of God" (1 Cor 1.1) and to the Philippians he simply claims to be a "slave" of Christ. All convey his sense of being selected by the ultimate powers of the universe, who remain invisible to ordinary perception.

\footnotetext{
${ }^{100} \delta$ ov $\lambda$ o $\varsigma$ can refer to either a slave or a servant. In classical Greek $\delta$ oṽ $\lambda$ o $\varsigma$ was a "born bondsman or slave" which was "frequently used of Persians and other nations subject to a despot" by writers like Herodotus. Liddell and Scott, An Intermediate Greek-English Lexicon (Oxford: Clarendon Press, 2002). $B D A G$ defines $\delta$ ov $\lambda$ o as "slave” and as "one who is solely committed to another, ... . [a] subject."
} 


\section{Smith: The Implicit Claims of Packaging}

Behold thou art Joseph, and thou wast chosen to do the work of the Lord -Smith, BoC 2.4

A significant difference between Paul and Smith is how they positioned themselves as mediators, or more specifically how each presented his own role as deliverer of the message; how each conveyed his revelatory insight and human mandates. Some of the differences between the writings of Smith and Paul are highlighted by the differences between apocalyptic and pseudepigraphical literature. The genre of a text in itself makes powerful unspoken claims about its author. Paul's letters contain apocalyptic components where he recounts his visions of the supernatural. Smith's revelations (i.e. the $B o C$ ) present themselves as entirely apocalyptic, with Smith simply penning the divine commands. The Book of Mormon is pseudepigraphical as it was produced by Smith and not the ancients whose names are attached to the texts. Five of Paul's authentic letters capitalize on existing communal relationships. ${ }^{101}$ Despite the existence of established communities, ${ }^{102}$ Paul's letters still seek to reinforce his position of leadership in the respective social relationships.

Smith's texts are first meant to convince readers of his special status which is intended to engender a following. As author/translator, ${ }^{103} \mathrm{Smith}$ is recognized as a

\footnotetext{
${ }^{101}$ Paul had not yet visited the Roman community when he wrote. His letter to Philemon capitalizes on the preexisting relationship with a particular individual rather than a community.

${ }^{102}$ Paul's letter to the Romans is the exception. There seems to be an established community there, but Paul has yet to visit personally. In the final chapter, Romans, he does indicate a personal relationship with many of those in the Roman community, 16.3-16. Given that Romans 16 is not a part of some of the earliest manuscripts, however, there is some doubt of its authenticity.

103 See the front cover and title page of the 1830 BoM, where the Book of Mormon is presented as "By
} 
leader, although the formalization of his leadership takes a couple of years-and a couple of authorizing revelations-as the community develops into a more formalized organization. Subsequent revelations direct the development of this community. The table below shows some of the similarities and differences between the writings of Paul and those of Smith.

While Paul's letters and Smith's revelations share some common literary features, their most similar attributes pertain to the social functions they achieve. They serve to construct the cosmological, soteriological and theological understandings of their readers' worlds at the same time they distinguish their authors as men who should lead. A primary difference, however, is how each of our authors positions himself with respect to the production of his texts.

Joseph Smith, Junior, Author and Proprietor.” 
Table 3.4

Texts: Comparative Claims, Characteristics and Packaging

\begin{tabular}{|c|c|c|c|}
\hline Table 3.4 & Paul & \multicolumn{2}{|c|}{ Smith } \\
\hline Title & $\begin{array}{l}\text { Letters to Corinthians, } \\
\text { Galatians, Thessalonians, } \\
\text { Philippians, Romans and } \\
\text { Philemon }\end{array}$ & $\begin{array}{l}\text { Book of Commandments/ } \\
\text { Doctrine and Covenants }\end{array}$ & Book of Mormon \\
\hline Genre $^{104}$ & $\begin{array}{l}\text { Epistles, authoritative } \\
\text { correspondence }\end{array}$ & $\begin{array}{l}\text { Collected Revelations, } \\
\text { i.e. apocalyptic texts }\end{array}$ & Pseudepigraphy \\
\hline Packaging & $\begin{array}{l}\text { Authoritative epistles: the } \\
\text { words, directives and } \\
\text { commandments of God }\end{array}$ & $\begin{array}{l}\text { Collection of revealed } \\
\text { words, directives and } \\
\text { commandments of God }\end{array}$ & $\begin{array}{l}\text { Biblical-style sacred } \\
\text { history }\end{array}$ \\
\hline $\begin{array}{l}\text { Claimed } \\
\text { Source of } \\
\text { Content }\end{array}$ & $\begin{array}{l}\text { human with apocalyptic } \\
\text { references, i.e. Paul recounts } \\
\text { his visions of Christ and } \\
\text { mystical experiences }\end{array}$ & $\begin{array}{l}\text { apocalyptic with Smith } \\
\text { simply acting as a } \\
\text { conduit by penning the } \\
\text { words of God and/or } \\
\text { Christ }\end{array}$ & $\begin{array}{l}\text { An ancient record } \\
\text { unearthed by Smith by } \\
\text { means of supernatural } \\
\text { guidance. Magical } \\
\text { "interpreters" were } \\
\text { included with the plates } \\
\text { to aid the "interpretive" } \\
\text { process }\end{array}$ \\
\hline $\begin{array}{l}\text { Actual } \\
\text { source of } \\
\text { content }\end{array}$ & Paul & Smith & Smith \\
\hline $\begin{array}{l}\text { Claimed } \\
\text { mandate for } \\
\text { production }\end{array}$ & $\begin{array}{l}\text { Supernatural directives, as a } \\
\text { "slave of Christ" }\end{array}$ & $\begin{array}{l}\text { Supernatural directives, } \\
\text { compelled as "my } \\
\text { servant Joseph" }\end{array}$ & $\begin{array}{l}\text { Restore "true church" } \\
\text { to bereft humanity. } \\
\text { Provide sacred history }\end{array}$ \\
\hline
\end{tabular}

${ }^{104}$ The use of apocalyptic here is in keeping with its archaic, literal sense as it is used adjectively to describe a genre of literature which purports to communicate the otherwise unavailable will of the gods. An apocalypse is literally an "unveiling" of what was formerly hidden or concealed from humanity. Thanks to the select divine intermediary, this precious material from the unseen realm is now unveiled, or revealed to the world. In this sense, both the authentic letters of Paul and the revelations of Joseph contained in the $B o C$ are apocalyptic in that they reveal the words and will of the gods, including specific instructions regarding human behavior and expectations. The use of the more popular, less literal connotation of apocalypse - derived mainly from the title of the final book in the New Testament, the Apocalypse of John - as a time of cataclysmic destruction and judgment at the hands of supernatural forces is avoided here. John's "apocalypse" revealed the End of Times. The alternative title for the final book of the New Testament, reflecting the Latin translation of the Greek, is Revelation. The revelation (apocalypse) given to John of Patmos included details of End-Time events.

While not strictly apocalyptic in the more traditional sense of being revealed through a (or a series of) heavenly vision(s), The Book of Mormon, Book of Moses and Book of Abraham, however, can still be understood as apocalyptic in so far as they reveal the previously veiled desires of the gods. They should, however, still be recognized as pseudepigraphical at the same time they are apocalyptic. They are pseudepigraphic as their production is attributed to traditional or fictional individuals who had nothing to do with their content or production.

In comparison, the deutero Pauline corpus (Ephesians, Colossians, 2 Thessalonians, Hebrews, The Pastorals: 1 and 2 Timothy, Titus) is pseudepigraphical in that the letters were not written by Paul but by others who attributed them to Paul. The deutero Pauline corpus not only testifies to the power of Paul's epistletory legacy, but undoubtedly boosted the status of those who forged the letters. Writing under Paul's name provided a mechanism whereby the teachings of the pseudepigraphers could appear as if it were Paul's own. 


\begin{tabular}{|c|c|c|c|}
\hline Table 3.4 & Paul & \multicolumn{2}{|c|}{ Smith } \\
\hline $\begin{array}{l}\text { Implicit } \\
\text { impetus for } \\
\text { production - } \\
\text { individual } \\
\text { basis }\end{array}$ & $\begin{array}{l}\text { Assert and shore-up } \\
\text { authoritative position in } \\
\text { respective communities. } \\
\text { Fend off competitors and } \\
\text { competing claims. }\end{array}$ & $\begin{array}{l}\text { Promote and guard } \\
\text { position of power as } \\
\text { singular mouthpiece of } \\
\text { the divine will. } \\
\text { Fend off competitors by } \\
\text { denying their right to } \\
\text { receive revelation. }\end{array}$ & $\begin{array}{l}\text { Uncontrollable muse? } \\
\text { Tool to improve social } \\
\text { status and transcend } \\
\text { the misery of } \\
\text { poverty? }{ }^{105} \\
\text { Earnest conviction of a } \\
\text { mandate to invent a } \\
\text { narrative - that } \\
\text { depended on a ruse - to } \\
\text { restore true religion. }\end{array}$ \\
\hline $\begin{array}{l}\text { Implicit } \\
\text { impetus for } \\
\text { production - } \\
\text { communal } \\
\text { basis }\end{array}$ & $\begin{array}{l}\text { Contingent on human needs, } \\
\text { e.g: competition in } 1 \text { Cor, } \\
\text { monetary collections in } 2 \\
\text { Cor, self-introduction to } \\
\text { Roman community, warning } \\
\text { of End Times in Thess }\end{array}$ & $\begin{array}{l}\text { Contingent on human } \\
\text { needs, e.g: Provides } \\
\text { Smith a powerful tool } \\
\text { with which to direct the } \\
\text { new movement. } \\
\text { Provides timely, } \\
\text { authoritative directives } \\
\end{array}$ & $\begin{array}{l}\text { Eventually served as } \\
\text { the symbolic center of } \\
\text { the new community as } \\
\text { it proved the status of } \\
\text { Smith as a modern day } \\
\text { prophet }\end{array}$ \\
\hline $\begin{array}{l}\text { Inherent } \\
\text { implications, } \\
\text { i.e. power } \\
\text { function: }\end{array}$ & $\begin{array}{l}\text { Clearly depicts Paul as } \\
\text { chosen vehicle of divine } \\
\text { knowledge }\end{array}$ & $\begin{array}{l}\text { Indicates Smith is the } \\
\text { chosen vehicle of divine } \\
\text { knowledge }\end{array}$ & $\begin{array}{l}\text { Indicates divine } \\
\text { selection of Smith as } \\
\text { chosen vehicle to } \\
\text { restore "truth" to } \\
\text { planet }\end{array}$ \\
\hline $\begin{array}{l}\text { Voice: } \\
\text { "For the Spirit } \\
\text { used them just } \\
\text { as a flute player } \\
\text { blows on a } \\
\text { flute" } \\
\text { - Athenagoras, } \\
\text { Plea. } 9106 \text { ca. } \\
177 \text { CE. } \\
\end{array}$ & $\begin{array}{l}\text { Paul as authorized and } \\
\text { commissioned by Christ (Gal } \\
1.11 ; 1 \text { Cor 9.2); and "when } \\
\text { you received the word of } \\
\text { God ... you accepted it not as } \\
\text { a human word but as what it } \\
\text { really is, God's word" (1 } \\
\text { Thess 2.13) }\end{array}$ & $\begin{array}{l}\text { Alternatively Smith's, } \\
\text { God's, Christ's; but } \\
\text { always presented as the } \\
\text { will of God, "and not of } \\
\text { man." The gods respond } \\
\text { to human situations (e.g. } \\
\text { rev to Cowdery, BoC } \\
\text { VIII). } \\
\end{array}$ & $\begin{array}{l}\text { Manufactured literary } \\
\text { characters. } \\
\text { All use KJV language. }\end{array}$ \\
\hline $\begin{array}{l}\text { Surface } \\
\text { function }\end{array}$ & $\begin{array}{l}\text { God building up his church, } \\
\text { revelation of divine } \\
\text { knowledge, communal } \\
\text { behavioral directives }\end{array}$ & \begin{tabular}{|l} 
God building up his \\
church, revelation of \\
divine knowledge, \\
communal and \\
individual behavioral \\
directives \\
\end{tabular} & $\begin{array}{l}\text { Provide additional } \\
\text { testament of Christ to } \\
\text { facilitate "restoration of } \\
\text { all things." Reveal } \\
\text { history of a splinter } \\
\text { group of Israelites. }\end{array}$ \\
\hline
\end{tabular}

${ }^{105}$ Given the underlying, naturalistic assumptions guiding this analysis, it is difficult to see Smith's actions in concocting the golden plates story as anything other than a calculated attempt to improve his own plight in life. Production of revelations, the Book of Moses and the $B o C$ did not provoke the harsh critique that the $B o M$ story did. People everywhere receive inspiration, relatively few use it to start a new religion. Claiming the discovery of an ancient religious record is a different beast.

${ }^{106}$ A Plea Regarding Christians by Athenagoras, the Athenian a Philosopher and a Christian, as in Richardson, Early Christian Fathers, 308. 


\begin{tabular}{|c|c|c|c|}
\hline $\begin{array}{l}\text { Competitors } \\
\text { refuted/ } \\
\text { denounced }\end{array}$ & $\begin{array}{l}\text { - Purveyors of "wisdom" in } \\
\text { Corinth (e.g. } 1 \text { Cor 1-4), } \\
\text { - Other preachers in Galatia, } \\
\text { e.g. Gal 1.7-9. } \\
\text { - Peter and Jerusalem Pillars } \\
\text { in Gal } 2 . \\
\text { - "Bewitchers" in Gal 3.1ff. }\end{array}$ & $\begin{array}{l}\text { - "no one shall ... } \\
\text { receive ... revelations } \\
\text { [but] my servant } \\
\text { Joseph Smith, Jr." } D \& C \\
28.2 \\
\text { - Cowdery: "thou shalt } \\
\text { not command him who } \\
\text { is at they head" BoC } \\
\text { XXX.6 } \\
\text { - Page: "that stone ... } \\
\text { deceiveth" BoC XXX.11 } \\
\text { - P. Pratt, Cowdery, Z. } \\
\text { Peterson, P. Whitmer: } \\
\text { "pretend to no more } \\
\text { revelations" } D \& C 32.4\end{array}$ & $\begin{array}{l}\text { - "cunning of devil will } \\
\text { not persevere" } \\
\text { "And they began to be } \\
\text { divided into classes; } \\
\text { and they began to } \\
\text { build up churches } \\
\text { unto themselves to } \\
\text { get gain, and began to } \\
\text { deny the true church } \\
\text { of Christ" } 4 \text { Nephi } \\
1.26 \text {. }\end{array}$ \\
\hline $\begin{array}{l}\text { Financial } \\
\text { implications }\end{array}$ & $\begin{array}{l}\text { - "God loves a cheerful } \\
\text { giver," } 2 \text { Cor } 8.3-11,9.7 \\
\text { - "those who proclaim the } \\
\text { gospel should get their } \\
\text { living by the gospel," } 1 \text { Cor } \\
\text { 9.14, } 18 \\
\text { - "I do not say this as a } \\
\text { command, but I am testing } \\
\text { the genuineness of your } \\
\text { love against the } \\
\text { earnestness of others," } 2 \\
\text { Cor } 8.8 \\
\text { - Rom 15.24-28 } \\
\text { - } 1 \text { Thes } 2.5,7,9 . \\
\text { - All of Philemon where Paul } \\
\text { acquires a believer's slave } \\
\text { via rhetorical extortion. } \\
\text { See "The Work of the Lord } \\
\text { as Financial Extortion: } \\
\text { Philemon" below. } \\
\text { - "Who plants a vineyard } \\
\text { and does not eat any of its } \\
\text { fruit? Or who tends a flock } \\
\text { and does not get any of its } \\
\text { milk... If we have sown } \\
\text { spiritual good among you, } \\
\text { is it too much if we reap } \\
\text { your material benefits?" } \\
1 \text { Cor 9.7, } 11 \text { (emphasis } \\
\text { added). }\end{array}$ & $\begin{array}{l}\text { - To Harris: "I command } \\
\text { you, that thou shall not } \\
\text { covet thine own } \\
\text { property, but impart it } \\
\text { freely to the printing } \\
\text { of the [BoM]" BoC XVI. } \\
\text { 27; } 107 \text { "Impart a } \\
\text { portion of thy } \\
\text { property; Yea, even a } \\
\text { part of thy lands and } \\
\text { all save the support of } \\
\text { thy family. Pay the } \\
\text { printer's debt. Release } \\
\text { thyself from bondage" } \\
\text { BoC XVI.36-38. } \\
\text { - thou needest not fear, } \\
\text { [Emma] for thy } \\
\text { husband shall support } \\
\text { thee from the church" } \\
\text { XXVI.8. } \\
\text { - "My servant Joseph } \\
\text { should have a house } \\
\text { built, in which to live } \\
\text { and translate" BoC } \\
\text { XLIII. 9. } \\
\text { - "Let my servant } \\
\text { Newell ... impart all } \\
\text { the money which he } \\
\text { can impart," BoC LXIV } \\
44,46 . \\
\text { - "Behold this is my } \\
\text { will, obtaining moneys } \\
\text { even as I have } \\
\text { directed." BoC LXIV. } \\
50 .\end{array}$ & $\begin{array}{l}\text { - BoM as "by" Smith, } \\
\text { "Author and } \\
\text { Proprietor." } \\
\text { - Newspaper ads: BoM } \\
\text { "will be ready for sale } \\
\text { in the course of next } \\
\text { week" Mar. 13, 1828, } \\
\text { "BoM... is now for } \\
\text { sale, whole-sale and } \\
\text { retail," Mar. 26, EMD" } \\
2.219 \text {. } \\
\text { - BoM Copyright to be } \\
\text { sold in Canada. H. } \\
\text { Page, EMD V.257. } \\
\text { - Accounts of Smith's } \\
\text { early delays in getting } \\
\text { the plates due to his } \\
\text { "over anxious desire } \\
\text { for filthy lucre" H. } \\
\text { Page, EMD V.257. } \\
\text { "And again, I say unto } \\
\text { you, that if ye desire } \\
\text { the mysteries of the } \\
\text { kingdom, provide for } \\
\text { him food and } \\
\text { rainment and } \\
\text { whatsoever things he } \\
\text { needeth to } \\
\text { accomplish the work, } \\
\text { wherewith I have } \\
\text { commanded him"BoC } \\
\text { XLV.12 }\end{array}$ \\
\hline
\end{tabular}

${ }^{107}$ According to Pomeroy Tucker, "[Martin] Harris was led to believe that the book would be a profitable speculation for him,” EMD 3:484. 
Paul's letters were simply that, letters. They contain apocalyptic components but they were authored by a human being who transmitted his visionary claims and his special called status in the text (e.g. 1 Thess 2.13, 2 Cor 5.20). Paul did not attempt to conceal his active authorship. In fact, his authorship of "weighty" (2 Cor 10.10) letters was critical to his leadership claims and how he wanted to be perceived. The letters convey a sense of-indeed claim outright-authority at the same time they communicate his powerful visionary experiences.

Smith's approach is related but different. He presented his directives as revelations from God in a manner that sought to conceal his role as a social actor responsible for the apocalyptic content of the text. Presenting oneself as an active author is a distinctly different claim than is presenting oneself as a simple translator/messenger with no active input into the text. ${ }^{108}$ Both vehicles can serve the needs of power and attract and influence the lives of followers. "Revelation" has at least two components. The first is the human/divine encounter, the "epiphany and divine disclosure" that constitutes the revelation itself. A second part is the transmission of this transcendent moment, the expression, articulation and ultimate commitment to language and text what otherwise may seem ineffable. ${ }^{109}$ The difficulty is in connecting the two. In some respects the divine status of the revelation is "inversely relat[ed] to the prophet's human involvement." ${ }^{110}$ Human agents can not improve the words of the gods. Second century Christian apologist,

\footnotetext{
${ }^{108}$ Kassam explores the rhetorical features and problematics of revelation, revelator and text with respect to Muhammad and Islam in "Signifying Revelation in Islam" in Theorizing Scripture, 29-40.

${ }^{109}$ Kassam, “Signifying Revelation in Islam,” 34.

${ }^{110}$ Kassam "Signifying Revelation in Islam,” 34.
} 
Athenagoras, offers an apt image when he writes, "For the Spirit used them [prophets] just as a flute player blows on a flute" (Plea 9). Moreover, human competence would be taxed in the extreme to represent the divine disclosures accurately and correctly. Paul indicates the radical, unspeakable nature of a mystical encounter when he writes that "a person in Christ" (probably Paul himself)

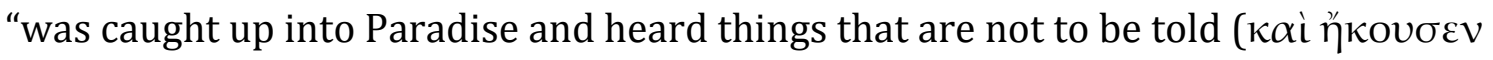

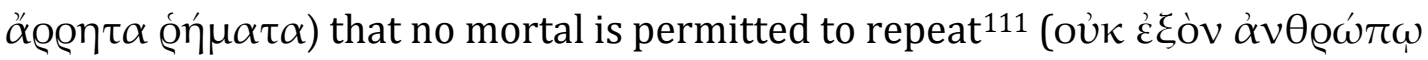
$\lambda \alpha \lambda \tilde{\eta} \sigma \alpha \iota) "(2$ Cor 12.2, 4).

Paul wrote as an inspired human being and "slave" to Christ. He believed his visionary experiences had charged him with commission to preach, and had provided him the content of his message. His letters contained directions from the heavens. As the recipient of visions, Paul wrote as an active agent who disseminated what he had had revealed to him. ${ }^{112}$ His letters allude to his mystical encounters (2 Cor 12.2-4) and claim a divinely commissioned status.

Smith took a related approach. He kept the descriptive recollections of his visionary experiences separate from what he presents as revealed or translated "scripture." His visions were recounted in other formats such as his personal history. The Book of Mormon was presented as a translation of an ancient record which Smith achieved only by supernatural means. Smith said very little about his translation process other than "the Lord had prepared spectacles for to read the

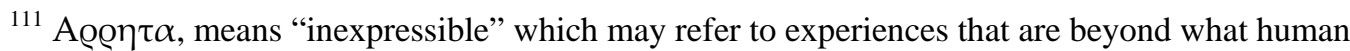
powers can convey, or alternatively, simply to holy to utter.

${ }^{112}$ At least those things he is permitted to, or able to, communicate; contra 2 Cor 12.4.
} 
Book."113 Neither "reading," nor "translating" in the literal sense of the terms are accurate descriptions of the process. ${ }^{114}$ During the creative process, the source plates were either covered by a cloth to prevent others from seeing them or not even present in the same room in which he was "translating." Bushman writes that Smith "received the words by 'revelation,' whether or not a text lay before him." 115 Smith acts as a route for the delivery of divine knowledge, feigning no input of his own. ${ }^{116}$ Smith's description of a visitation by the divine messenger Moroni is perhaps instructive as to how Smith saw himself. After communicating with Smith, the angel is depicted as retreating to heaven. Smith relates that he saw "a conduit open right up into heaven, and he [Moroni] ascended till he entirely disappeared."117

\footnotetext{
${ }^{113}$ As in Bushman, Rough Stone Rolling, 72, where Bushman presents Smith’s "translation” as "transcription." See earlier section on "seer stones" in which several citations of Smith's performances of burying his seeing stone and face in a hat are provided. Much as was the case with Muhammad's alleged illiteracy, Smith's lack of learning was promoted as proof he could not have written the book on his own. See Bushman, Rough Stone Rolling, 72. His own mother claimed he "had never read the Bible through in his life," Lucy, Biographical Sketches, 84, and yet he was recognized by non-Mormons in his adult life as a man with the "wit and intelligence" of a congressman and one who seemed to be "intellectually superior to so miserable a delusion." The observations are those of Josiah Quincy Jr. who would later become Mayor of Boston, Bushman, Rough Stone Rolling, 4, 5. See Quinn regarding Smith's learning and the proximity of available literary, intellectual and occult resources, Magic World View, 178-236 (192). Against the argument that Smith couldn't possibly have read all the resources Quinn cites, the basic fact that local libraries and booksellers were so robustly stocked with occult literature indicates a heavy demand for and a deep interest in such works in the local area.

114 "There is no evidence that he ever translated a document as we would understand that phrase" Palmer, Insider's View, 259.

${ }^{115}$ Bushman, Rough Stone Rolling, 132. Grant Palmer writes "if we accept the idea that he dug up a real, physical record, then we must account for the fact that he never used it in the translation process, Insider's View, 259.

${ }^{116}$ That no source document was needed for Smith to produce his inspired "translation" begs the question of the need for the entire golden-source-document charade. At this early point in his career, Smith apparently did not feel that his own inspired writing could stand without attribution to a physical source. Who would take the scryer's writings seriously if they were not rooted in a physical, hallowed source? His success with the Book of Mormon - in light of the ordeal that accompanied the pretense of the procurement and return golden source-perhaps taught him that he need not claim a physical source. It was too much trouble and invited as much skepticism as it provided credibility. The Book of Moses, produced in 1830, needed no physical source. Smith never claimed one. It was the product of mystical encounters and a rich imagination.

117 “Extracts From the History of Joseph Smith, The Prophet,” 2.43 (emphasis added).
} 
Smith is the human end of the conduit that gives voice to the divine word for the rest of humanity.

Such a technique is not novel. The notion that the muse inspires the poet and the gods inspire the prophets predates Paul. Plato writes that the ability to generate poetry is "not mastery ... but a divine power." He continues,

That's why the god takes their [the poet's] intellect away from them when he uses them as his servants, as he does prophets and godly diviners, so that we who hear should know that they are not the ones who speak those verses... for their intellect is not in them: the god himself is the one who speaks, and he gives voice through them to us. (Plato, Ion, 534b, c.) ${ }^{118}$

Smith's revelations contained in the Book of Commandments read as if they are directly from the mouth of God. Examples include, "Yea, even I, I am he, the beginning and the end: Yea, Alpha and Omega, Christ the Lord, the Redeemer of the world: I having accomplished and finished the will of him whose I am, even the Father ..." (BoC XVI.1), and "Behold, I speak unto you" (BoC XVII.1, BoC XVIII), "Listen to the voice of Jesus Christ..." (BoC XXVIII.1, XXIX.1), and so on. Presenting one's marching orders as a mandate of, and in the voice of, the gods is a powerful and effective packaging technique. Bushman acknowledges and yet perhaps understates the impact considerably when he writes of Smith's revelations that "one rhetorical feature may partly account for their authority: the voice in them is purely God's. Joseph as a speaker is absent from the revelations, just as he is from the Book

\footnotetext{
${ }^{118}$ It should be noted that Plato is not immune to the same social, power dynamics that motivate Smith and Paul. His description of poets and prophets - while a bit more sophisticated than dismissing them simply as "false prophets"-is intended to minimize their human role, and therefore minimize the power and respect that should be attributed to humans who act as mouthpieces of the gods. In doing so, he builds a case for philosophers like himself that comprehend the will of the gods through intellection and philosophy.
} 


\section{of Mormon." 119 Smith relied upon simple literary techniques to distance himself}

from his writings. Yet while the person of Smith may be absent rhetorically, his

interests are present and clear. Simply presenting himself as the chosen messenger

of God's message implies an elite status. Presumably the gods do not pick their

spokespeople without a solid reason. ${ }^{120}$

Paul would boast of his calling, remind his readers of their collective experiences, and present his teachings as dictates from God that were delivered with "power and in the Holy Spirit."121 Both authors presented their writings as tangible evidence of their mediating status. But Paul's letters recited and transmitted his claims to power (e.g. "when you received the word of God that you heard from us, you accepted it not as a human word but as what it really is, God's

${ }^{119}$ Bushman, Rough Stone Rolling, 128-129. See also Richard L. Bushman, "That Little Narrow Prison of Language" in Reid L. Neilson and Jed Woodworth, editors, Believing History: Latter-day Saint essays (New York: Columbia University Press, 2004), 253. Dan Vogel, Making of a Prophet, and Anderson, Inside the mind of Joseph Smith, disagree. They argue that Smith's life is writ large in the Book of Mormon and that his texts clearly document his life, struggles and developing beliefs. The perspective taken here is somewhere in between. On the one hand, Smith's location and life clearly inform and provide material and narrative structure for the Book of Mormon. On the other hand, an attempt to link every event in the $B o M$ to the life of Smith is bound to fall short. To do so reduces Smiths enormous creativity to thinly veiled autobiography. Also problematic are the inherent limitations of psychoanalytic interpretations which, after all, are interpretive, and as such bound to reflect the assumptions and interests of the analyst. The position taken here is that Smith's production of the Book of Mormon is, among other things, part of a discursive strategy by which Smith can improve his lot in life in terms of both financial and social (i.e. power) status. Such an endeavor need not be entirely conscious.

${ }^{120}$ Plato, who most likely would never allow himself to lose his wits and prophesy, puts a different spin on the implicit status of the inspired speaker. He argues that the selection of the divine mouthpiece is made to attribute greatness to the gods, not status to a human. He writes,

I think, the god is showing us, so that we should be in no doubt about it, that these beautiful poems are not human, not even from human beings, but are divine and from gods; that poets are nothing but representatives of the gods, possessed by whoever possesses them. To show that, the god deliberately sang the most beautiful lyric poem through the most worthless poet. Plato, Ion 534d.

This observation of Plato's suggests a number of (in his view) otherwise "worthless" poets and prophets were competent to sing the songs of the gods. He had to explain their ability somehow. In degrading their humanity as hollow vessels, he attempts to undermine any status their ability might have generated. In doing so he implicitly fostered an improved status for intellectuals and philosophers like himself.

121 The "power" and "holy spirit” experienced by the Thessalonians was to serve as proof that God "ha[d] chosen” the Thessalonians. 1 Thess 1.4-5. 
word" (1 Thess 2.13), while Smith's revelations, generally written in the first person of God, transmitted and embodied a claim to power (e.g. "Behold, thus saith the Lord, ... For I am able to make you holy and your sins are forgiven you" BoC LXI.1, 11).

Both, however, framed their proclamations as the very words of the gods. Readers of Smith's revelations are reminded that "for his [Smith's] word ye shall receive, as if from mine own mouth, in all patience and faith," (BoC XXII.5). Paul claims the exact same privilege for himself when he writes,

I want you to know, brothers, that the gospel that was proclaimed by me is not of human origin; for I did not receive it from a human source, nor was I taught it, but I received it through a revelation of Jesus Christ (Gal 1.11; see also 1 Thess 2.13).

As Smith's writings are attributed to sources external to himself, his claims of supernatural sanction do not appear in his texts in the same way that they appear in Paul's. As his voice is absent from the pages of the BoM itself, his clear statements of authorship and of the divine mandate that called him to the work are found only in the "non-scriptural" Preface of the 1830 version of the Book of Mormon, in addition to some of the publisher's summary fine print at the beginning of the text. The 1830 Preface (no longer printed in modern editions) addressed "To THE READER" is meant to fend off "false reports ... by evil designing persons" regarding the loss of the first 116 pages of Smith's initial BoM manuscript. In the Preface he asserts that he "translated, by the gift and power of God, and caused to be written" this early manuscript. Here clear supernatural sanction is claimed for a portion of his work that had been lost and was no longer available for publication. Joseph continues that he has been "commanded of the Lord" not to retranslate this first effort which is followed by the assertion that "the Lord said unto me" that he (Smith) should (in 
effect) spend his efforts translating the remainder of the plates, those yet untranslated. The text that follows the Preface, i.e. the BoM itself, is presented as evidence of Smith's attempt "to be obedient unto the commandments of God" (1830 $B o M$, iv). Smith writes that "through his grace and mercy" he (Smith) has "accomplished that which he [God] hath commanded me respecting this thing." Smith asserted plainly that his obedient actions were not some whim of his own choosing, nor a quixotic endeavor based on spurious interpretations of text, but as a result of the Lord speaking directly to him. Without a hint of uncertainty he writes, "behold, the Lord saide unto me .... thou shalt translate from the plates of Nephi."

The BoM Preface is not the only place Smith claims supernatural sanction, but it is the cleanest and clearest example of his making such a claim in his own voice. Other sections of the Book of Mormon are made to sanction Smith's literary endeavor as that of a divine calling. His revelations, however, clearly document his claims of supernatural sanction. They are written in the first person voice of God in such a manner that Joseph's human interests are clearly articulated even if masked. Smith's interest in personal power, leadership and unchallengeable control are presented as if they were God's interests for the benefit of the community. ${ }^{122}$ Smith feigns the role of humble servant and translator even as what he reveals and writes bestows enormous power and authority upon himself. ${ }^{123}$ He refers to himself as

\footnotetext{
${ }^{122}$ It is important to note here that the community may well benefit from having a single, powerful leader. Certainly it is equally important to note that the power of such a community's leader is strengthened when that leader is seen as selected by the gods and absolutely authoritative.

123 Specific examples are considered below.
} 
"my servant Joseph" at least forty-five times in his revelations which frame him as humbly in servitude to the supernatural. Feigned humility functions to humanize Smith and calibrate his dictums such that his more audacious claims will appear sincere, legitimate and true. ${ }^{124}$ In fairness, in the Doctrine \& Covenants many others are referred to as "my servant" by the Lord, but none nearly as many times as Smith.

Referring to oneself as a slave to Christ or as a servant of the Lord pales in comparison to speaking in the first person voice of God himself. The former claim can be made by any rank and file devotee. The latter is reserved for the prophet who acts as a conduit to make the divine will audible. As an example of Smith unambiguously speaking in the voice of the Lord, a revelation given to Oliver Cowdery and David Whitmer in June of 1829 forcefully argues for Smith's authorized prophetic status. In the $1833 B o C$, Smith writes,

And I Jesus Christ, your Lord and your God, have spoken it. These words are not of men, nor of man, but of me:125 Wherefore you shall testify they are of me, and not of man; for it is my voice which speaketh them unto you: For they are given by my Spirit unto you: And by my power you can read them one to another; and save it were by my power, you could not have them: Wherefore you can testify that you have heard my voice, and know my words... Behold I Jesus Christ, your Lord and your God, and you Redeemer, by the power of my Spirit, have spoken it: Amen (BoC XV.36-41, $50^{126}$ emphasis added).

${ }^{124}$ Recall discussion of witness believability in the chapter two where witness "calibration trumps confidence" in terms of believability.

${ }^{125}$ Note how this sentence imitates not only the sentiment, but almost the precise language of Paul's introduction to the Galatians, "not of men, neither by man, but by Jesus" Gal 1.1, KJV. Here I am not suggesting that Smith consciously used Galatians as a source, although to have done so is not beyond plausibility. Grant Palmer documents a number of passages from both Smith's revelations and the BoM that show an intimate familiarity with specific KJV passages, An Insider's View of Mormon Origins (Salt Lake City, UT: Signature Books, 2002), 46-55.

${ }^{126}$ Also H. Michael Marquardt, The Joseph Smith Revelations: Text and Commentary (Salt Lake City, UT: Signature Books, 1999), xiv, 47-48, document \# 14, and D\&C 18:33-36. The date given is June of 1929. 
Beyond implicitly claiming supernatural sanction as the voice box of the gods, what is remarkable about this revelation is its attempt to convince Cowdery and Whitmer that they too now have palpable proof that Smith has been selected by the divine realm. Stark and Finke make a couple of points related to the sociological effect of this type of mystical directive. The first is that "confidence in religious explanations will increase to the degree that miracles are credited to the religion," and further "will increase to the degree that people have mystical experiences. ${ }^{127}$ Cowdery and Whitmer are both predisposed to see Smith's revelatory performances as authentic interaction with the divine. His performances and their mystical experiences are compelling. Stark and Finke also propose that "an individual's confidence in religious explanations is strengthened to the extent that others express their confidence in them." 128 Smith's goal here is to promote confidence in his work by having others testify of their own confidence in his work. At the same time, he provided his earliest supporters with a sense of empowerment where they could "testify" to his authority and to the divine realm's sanction of his prophetic calling and role.

\section{Claiming Authority Over Men:}

And what I do I will also continue to do, in order to deny an opportunity to those who want an opportunity to be recognized as our equals in what they boast about

-Paul, 2 Cor 11.12

Since Paul's letters were occasional and sent from a distance, he would attempt to handle a large body of theological, hierarchical and communal business

\footnotetext{
127 Stark and Finke, Acts of Faith, 109-110.

${ }^{128}$ Stark and Finke, Acts of Faith, 107.
} 
in a single letter. Inevitably there were substantial lags in time between when an issue arose, when Paul could address it, and when the community would be able to hear his response. In contrast, Smith's proximity and ability to receive continuous revelations allowed him to deal with looming problems or address followers almost immediately. ${ }^{129}$ He could specifically and directly answer questions and provide direction. Despite issues of timing and frequency, however, the basic role of mediation between heaven and earth is in many ways similar between Paul and Joseph.

The overt intention of pastoral guidance in both situations illustrates that human events provided the impetus and determined the content of the letter or revelation, to whom it was addressed and what it advised. The prophetic mediators allow the gods to be responsive to human contingencies. The ease of offering divinely inspired guidance suggests that the mediator's position of power and authority is on its way to becoming entrenched if not itself naturalized. Followers turn to their shepherd for leadership and guidance, which is the obverse of the vigilant shepherd corralling or correcting those beginning to stray. They are the two sides of the common relationship. The letters and revelations document the construction of a communal hierarchy and indicate who is permitted to speak. Not surprisingly, the authors of the texts, Joseph and Paul, authorized themselves as the

\footnotetext{
${ }^{129}$ An excellent example of a near instantaneous revelation is found in the Book of Commandments where Smith is prohibited from "purchasing wine, neither strong drink of your enemies" BoC XXVIII.4. The later $D \& C 27$ version of this revelation frames it as being received as Smith was in route to buy sacrament wine for an upcoming service. He was met on the way by a heavenly messenger and instructed that "it mattereth not what ye shall eat, or what ye shall drink, when ye partake of the sacrament" $B o C$ XXVIII.2. While the revelation was later justified on the basis of the potential of using "wine of an unassured purity in the sacrament" $D \& C$ 27, introduction; at the time it saved Smith a trip, some money, and the indignity of patronizing those who opposed him.
} 
ultimate terrestrial authorities. Part of their authority-building campaign relies on identifying and undermining positions held by others. For Paul, these "others" include competing apostles and "Law Abiders" in Galatia and the and the purveyors of Wisdom in Corinth (1 Cor 1-4). For Smith, his most direct challenges come from early members of the movement: Oliver Cowdery, Martin Harris, Hiram Page, Parley Pratt and others (e.g. BoC VIII, IX, X, XV, XXII, etc.). Who is allowed to speak, who is permitted to reveal the ways of God does much to establish power relations within a community. Analyzing the writings of Smith and Paul lays bare the rhetorical efforts to subvert if not completely disempower and dominate competing voices at the same time they assure the unassailable viability of their own.

\section{Paul: Pursuing Dominance in a Competitive Market Place}

can it be ... that the sophist is really a sort of merchant or dealer in provisions on which the soul is nourished... hawking them about to any old purchaser who desires them?

$$
\text { -Plato, Protagoras, 313c-d }{ }^{130}
$$

such boasters are false apostles, deceitful workers, disguising themselves as apostles of Christ... even Satan disguises himself as an angel of light

$$
\text { -Paul, } 2 \text { Cor 11.13, } 14
$$

In his opening comments to the Galatians, Paul adamantly asserted that his calling and sanction were firmly rooted in the supernatural world. He even took pains to assert his indifference to human judgment (Gal 1.10).131 Yet within this

\footnotetext{
${ }^{130}$ See also Plato’s Sophist, especially 223e, 231d-e, 233b, 235a-b.

${ }^{131}$ As God, not man, is to be his judge, he writes, “am I now seeking human approval, or God’s approval (Gal 1.10). Examples from other letters include, "with me it is a very small thing that I should be judged by you or by any human court ... It is the Lord who judges me. Therefore do not pronounce judgment before the time, before the Lord comes . . . 1 Cor 4. 3,4; "it is the Lord [only] that judges me" 1 Cor 4.4; and "those who are spiritual discern all things, and they are themselves subject to no one else's
} 
context and rhetoric, Paul still finds (at least the perception of) human authorization important. Specifically, Paul wants to be recognized in the eyes of his Galatian community as duly sanctioned by other prominent Jesus-preaching apostles. This desire is indicated by his boast that at the end of an earlier trip to Jerusalem "the acknowledged pillars ... gave to Barnabas and me the right hand of fellowship agreeing that we should go to the Gentiles" (Gal 2.9). Boasting of a recent agreement, however, suggests that itinerant competitors, an organized body, or local voices have questioned Paul's authority and message as it related to certain established figures connected with a prominent Jesus movement in Jerusalem. Announcing his sanction by the "pillars" of that movement is meant to put those questions to rest.

In his Corinthian correspondence, Paul admitted that he had never met Jesus during the latter's earthly preaching tenure (1 Cor 15.8). Such an admission may have put him at a competitive disadvantage in the face of competing preachers of Jesus who would or could make such a claim. Paul addressed this issue by asserting that his commission—which came from the risen Christ (1 Cor 15.4-8) ${ }^{132}$-trumped those who may have claimed sanction from the earthly Jesus. ${ }^{133}$ Tension over the same power issue appears in the Galatian correspondence.

scrutiny"(!) 1 Cor 2.14-15.

${ }^{132}$ John Ashton writes that "belief in the gods in Asia Minor in this period was so strong that from time to time people could easily be induced to affirm that they had actually put in an appearance on earth. Many people today are equally convinced of the reality of visitors from outer space.” The Religion of Paul, 7-8.

${ }^{133}$ The terms "risen" versus "earthly offer another way of differentiating the human sacrifice, resurrection-based, Christ-crucified theology of Paul from the wisdom theology of the human teacher from Galilee, named Jesus. 
Immediately following Paul's energetic claim of divine sanction, Paul expressed his astonishment to the Galatians that they were "so quickly deserting the one who called you in the Grace of Christ" (Gal 1.6). Paul's competitors are diminishing his market-share. He claims that these others are "confusing" (oi

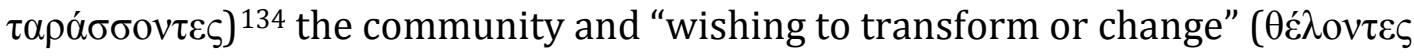
$\mu \varepsilon \tau \alpha \sigma \tau \rho \varepsilon ́ \psi \alpha 1)^{135}$ the only legitimate gospel of his patron deity (Gal 1.7-9).

The Galatian community had evidently hosted a number of traveling preachers, each of whom no doubt made his or her own claims as to the truth and authority of his or her message. The confusion is understandable. The number of cosmologies and soteriologies in the spiritual marketplace was vast and diverse, as was the number of religious entrepreneurs promoting various systems and vying for spiritual authority. ${ }^{136}$ This point highlights that in the world full of gods in which Paul lived, ${ }^{137}$ recognizing the right gods and right messengers was tricky business. Basic notions of human self-interest dictate that Paul presented himself and his system in the most compelling fashion possible. This compelling presentation includes the disparagement of others and the undermining of their claims. Discourse is never innocent. 138

${ }^{134}$ Literally "the confusers" or "the confusing ones.” See also Gal 3.1; 5.7, 10, 12 for Paul's concern about deceivers in the community.

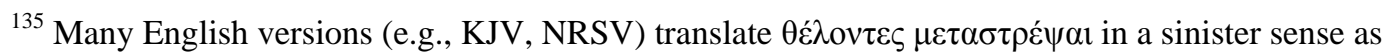
"pervert" instead of the more innocuous "alter" or "change". In doing so, translators implicitly side with Paul in his claim of only one pure gospel that cannot be altered or rendered in any other form without being "perverted."

${ }^{136}$ See Apollonius' The Prophet for an ancient lampooning of a similar type of individual responding to these types of market conditions.

${ }^{137}$ This phrase is borrowed from an insightful and entertaining book by Keith Hopkins, A World Full of Gods: The Strange Triumph of Christianity (New York: Plume, 2001).

\footnotetext{
${ }^{138}$ Castelli, Imitating Paul, 53.
} 
Competing interests, a range of truth claims and the resulting confusion are a threat to Paul's status and authority. To Paul, the competing apostolic messages are not just other ways of understanding the world, not just alternative versions of reality, and not just without God's authorization. Rather, any competing interest embodies something that Paul rhetorically claims is detrimental to heaven's plan as he-the self-proclaimed apostle and self-appointed transmitter of the divine message from the heavens to humanity-understands it. The real danger for Paul is not an adulterated "gospel" in itself, it is his loss of authority in the eyes of his community if a message other than his own is embraced. Rather than present threats to his ministry for what they are-corrosive to his leadership status-he presents them as perversions of God's truth.

In response to the threat posed by competitors, Paul twice calls for anyone proclaiming a message that is contrary to what he has preached to be accursed 139 ( $\dot{\alpha} v \alpha \dot{\theta} \varepsilon \mu \alpha ;$ Gal 1.8-9), ${ }^{140}$ even if that messenger (literally: "angel") is from heaven ( $\eta$

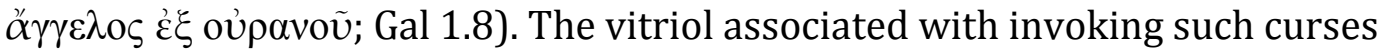
suggests that the "other gospels"—and their proclaimers—presented serious threats to Paul's leadership. Some of the competing prophetic claims perhaps sounded disconcertingly similar. Condemning other heavenly messengers and messages is especially bold as heaven is precisely the origin of Paul's claim to

139 "Accursed" is also the word Smith uses in the Book of Ether when he writes, "And he that will contend against the word of the Lord, let him be accursed; and he that shall deny these things, let him be accursed" 1830 BoM, 546. The passage from Galatians may have been a verbal model—but the sentiment it expresses needs no forerunner.

${ }^{140}$ The term $\dot{\alpha} v \alpha \dot{\alpha} \theta \varepsilon \mu \alpha$ developed its derisive connotations by reference to votive offerings dedicated to other (i.e., false) gods that were considered cursed or deserving of a curse. 
authoritative sanction (e.g. Gal 1.12, 1 Cor 15.8). Later in his letter, Paul reminds his Galatian community they had earlier welcomed him as an angel (i.e., messenger) of

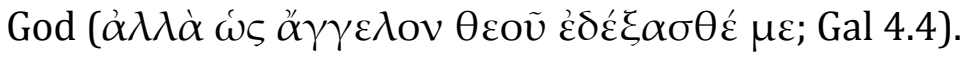

Paul steadfastly clung to his supernatural sanction with the rhetoric "that the gospel that was proclaimed by me is not of human origin" (Gal 1.11). He claimed that he "did not receive it from a human source, nor was [he] taught it" (Gal 1.12). He stuck to his claim of being divinely authorized as he declared that he "received it [the gospel] through a revelation of Jesus Christ" (Gal 1.12). So just as Paul asserted that his authority had come from sources beyond human contestation, so too did he emphasize that the content of his message had come from the divine realm.

Despite these unambiguous pronouncements, Paul still had to nuance his relationship with existing power structures, namely some apparently well-known preachers of Jesus from Jerusalem. His relationship with his competitors was complicated. While he reiterated his disregard for human authority by writing that he "did not confer with any human being" (regarding the content of his message), there remained some ambiguity in his announcement that he did not "go up to Jerusalem to those who were already apostles before me" (Gal 1.17). His statement suggests that receiving approval from existing apostles in Jerusalem would have been expected. The admission conveys the sense of existing relationships within a social movement that is bigger than just Paul and his visions. So while Paul acknowledges a geographical center of a movement and apostles who have been part of that movement longer than he has, at this point in the text he feigns complete indifference to their message, hierarchy, headquarters or authority. Indifference 
inherently undercuts claims of authority. Eventually he discloses earlier trips to Jerusalem and his fifteen-day visit with Cephas (Gal 1.18). Fourteen years after that visit he met with the "acknowledged leaders" (Gal 2.2). This meeting was supposed to be private but was crashed by "false brothers" ( $\psi \varepsilon v \delta \alpha \delta \varepsilon ́ \lambda \phi o v \varsigma)$ who were "secretly brought in" to disrupt Paul's efforts (Gal 2.4). Not one of these leaders is named explicitly.

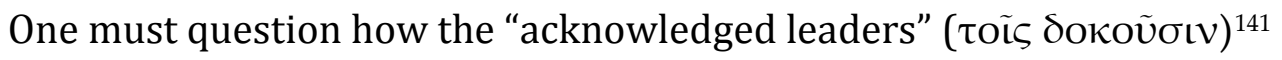
would have recollected this meeting and whether the "false brothers" were not simply sincere followers of a version of a Christ or Jesus movement that differed substantially from Paul's Christ-centered theology of the cross. These so-called "false brothers" were most likely committed partisans with their own agenda. They apparently perceived Paul's message as one that adulterated the ideological glue that bound their people, and as such, subverted their own authoritative status. They respond to Paul as if he should be "accursed." Adulteration threatens to weaken the entire social formation-in addition to individual power claims. Paul was preaching a different binding matrix, one that certain "brothers" from Jerusalem could not stomach. Moreover, Paul claimed his gospel was correct to the exclusion of others. His leadership status as an apostle was based on his vision of, and commission by, the risen Christ (Rom 1.1; Gal 1.1, 12, 15-16, 2.7-8; 1 Cor 1.1, 9.7; 2 Cor 1.1, 4.1) rather than a personal history of accompanying the living Jesus.

\footnotetext{
${ }^{141}$ Baur's lexicon suggests “the influential men” for this passage but the root of substantivized

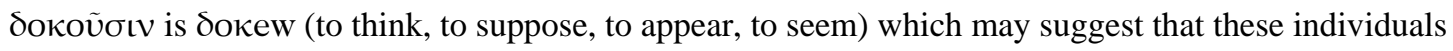
seemed to be leaders but judging by Paul's response may have only appeared that way.
} 
Competing apostles would have had good reason to have been annoyed with Paul's power claims in addition to his rejection of circumcision (e.g. Gal 2.3) and theology of the cross. Paul's leadership simply represented threats to the entrenched interests present in other Jesus-centered missionary movements. He was an outsider and his message varied from theirs.

Paul's bitterness regarding the meeting crashed by the "false brothers" is palpable. His rejection of their agenda appears to have further sullied his relationship with the (again unnamed) "acknowledged leaders." To emphasize his indifference to the authority they claimed for themselves, he wrote that "what they actually were makes no difference to me." He continues that "those leaders contributed nothing to me" (Gal 2.6). At this point, Paul seems not only resentful and bitter of his treatment in Jerusalem, but has maligned the (alleged or perceived) leadership there as unable to contribute anything of meaning to him or his mission.

Having written this mixture of criticism and indifference concerning the competing apostles and the Jerusalem leadership, Paul pulls a somewhat astounding turnaround. He mentions Peter by name and notes his authority as one who had been "entrusted with the gospel for the circumcised" (Gal 2.7). Paul goes further by claiming that even those with whom he has just disagreed did in fact recognize that his calling as a missionary to the Gentiles was of the same quality and sanctity as Peter's calling for the circumcised. Moreover, he asserts that the same divine forces that called Peter had also called him (Gal 2.8). He then mentions James, Cephas and

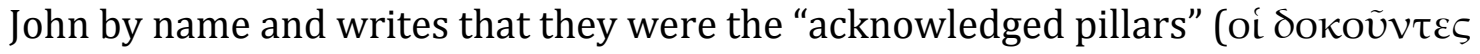




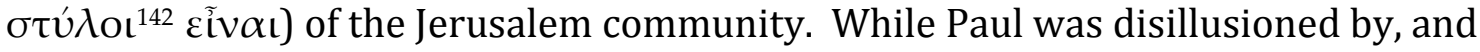
perhaps insulting to, the unnamed leaders of Galatians 2.2 and 2.6, he is now laudatory towards the named leaders James, Cephas and John (Gal 2.9). While not denying his differences with the Jerusalem crowd, Paul writes that these pillars extended to him "the right hand of fellowship, agreeing that we should go to the Gentiles and they to the circumcised" (Gal 2.9).

A number of issues are raised from this reading. The first, as one should expect, is that Paul has put a heavily favorable slant on his encounter with the Jerusalem pillars. As leaders of an exclusive community, the Jerusalem "Pillars" were more than happy to tell Paul that he could preach his version of the gospel to people who were not already a part of their exclusive community. ${ }^{143}$ Paul was encouraged to take his version of reality and his claims to power to people who were not their people. Paul spun the rejection he received by factions in Jerusalem as a positive, human, sanction even though he has just repeatedly asserted his indifference to human authority.

Recall that earlier in the same letter Paul has been emphatic that his is the only gospel not to be accursed (Gal 1.8-9). How is the reader to reconcile the notion of an exclusive message promoted by Paul with Paul's implicit revelation that his message is somehow at odds with at least some of the Jerusalem leadership? Should the gospel of the Pillars be accursed? It appears that there is one message for the

\footnotetext{
142 Here, the inclusion of “pillars” makes Paul's recognition of James, Cephas and John seem more legitimate, and less based on potentially spurious appearances.

143 The "exclusive" nature of the community should be evident by the very fact that Paul felt he needed (at least the appearance of) formal recognition in the eyes of senior members. Moreover, if the "false brothers" were seeking to regulate the "freedom" 1 Cor 2.4 enjoyed by Paul's group, there are obvious behavioral expectations that are a sign of communal inclusion.
} 
circumcised, and another for the uncircumcised. What is the status or role of these men who "contributed nothing to [Paul]" (Gal 2.6) from a theological perspective and yet have sanctioned him, at a de facto administrative level, with the commission to preach to the Gentiles? In short, how is the critical reader to understand these implicit contradictions in what Paul has written other than to see them as rhetorical manipulations to serve Paul's interest? Paul's presentation is not one a disinterested observer might give, rather it is one that promotes his individual needs. As a human being subject to human needs and human limitations, how could he write otherwise?

Whether or not this particular reconstruction of Paul's meeting with the supposed leaders in Jerusalem is precisely accurate from an historical perspective, it does highlight how Paul wanted to present and leverage his encounters with others who promoted Jesus-centered, or Christ-centered, social formation. Analyzing Paul's written presentations highlights his rhetorical skills as he maneuvered to be recognized as authoritative in a crowded and competitive market place. Despite claiming indifference to human authorization, ${ }^{144}$ Paul makes an explicit case for human support and human authorization in his mission to the Gentiles. This interaction is in some sense summarized in Paul's letter to the Corinthians that discloses his missionary philosophy as based in part on inconsistent selfrepresentation: ${ }^{145}$ "To the Jews I became as a Jew, in order to win Jews. To those under the law I became as one under the law ... To those outside the law ..." (1 Cor

\footnotetext{
${ }^{144}$ Paul claims indifference to human judgment in 1 Cor 4.3-4; 2 Cor 2.14-15 and Gal 1.10. Compare 2 Cor 8.21.

${ }^{145}$ Alternatively, consistent self-misrepresentation.
} 
9.20-21). He might continue, "to those who desired human authorization, I had human authorization, to those who desired an exclusive commission from the gods, I had an exclusive commission from the gods." Paul's rhetorical positioning concerning his indifference to human judgment—while at the same time generating the perception of being in human fellowship with rival apostles-is in line with his stated operating methods of being "all things to all people" (1 Cor 9.22). The philosophy that deception is justified in bringing glory to the gods (Rom 3.5-7) is analyzed in the next chapter.

Having just boasted of his human authorization from the hands of the pillars, he goes on to tell an unfavorable story that depicts Cephas, one of the pillars, acting hypocritically in his table behavior in Antioch. Paul's characterization of Cephas is one that undermines Cephas' credibility as a leader, and challenges his dependability as a trusted vessel of God's word. Paul's depiction shows that Cephas's instinct-manifest by his table actions—-was to behave in a manner inconsistent with Paul's current preaching. ${ }^{146}$ While Paul's account of Cephas in Antioch implies Cephas' complicity in, and sanction of, Paul's message, it also depicts him as a weak-minded ${ }^{147}$ hypocrite and as such implicitly inferior in righteousness to Paul. James and his people are also depicted as trying to restrict the liberties of the gospel that Paul preached. So at the same time Paul undermines the behavior and credibility of those considered pillars of the early movement, he relies on their

\footnotetext{
${ }^{146}$ Recall the analysis of this vignette with respect to Paul's ability to undermine and "persecute" as developed above in the "Development of Career Skills" section of chapter two.

${ }^{147}$ Assuming that Cephas and Peter are in fact the same person, Matthew's gospel gives us some insight to Peter's reputed intellectual capabilities. There, Jesus asks Peter if he is "still as dull as the rest?" Matt 15.16 (NEB). The NRSV is somewhat kinder in rendering the query as, "Are you still also without understanding?”
} 
sanction and support—as conveyed through the "right hand of fellowship" (Gal 2.9) to bolster his case and the perception of his status among the Galatians.

Paul's efforts to remain in an unassailable leadership position also played out in his first letter to the Corinthians. In contrast to the Galatian letter, one of the challenges Paul faced came from inside the community, not from other traveling apostles. The challenge was still one of authority as it related to the Corinthian community's enjoyment of "spiritual gifts" ( $\tau \tilde{\omega} \nu \pi v \varepsilon v \mu \alpha \tau \iota \kappa \tilde{\omega} \nu$, literally, "things of the spirit"). Paul's texted rhetoric achieves a number of related goals. One is the reaffirmation that all manifestations of the Spirit are from the same source, God (1 Cor $12.4,6)$ and that expressions of the Spirit are meant for the common good of the community (1 Cor 12.7). Paul's acknowledgment and acceptance of the range of emotionally laden activities common in the Corinthian community reaffirms the right and empowerment of individuals within that community to exercise spiritual gifts. Such freedoms, however, could not be allowed to challenge the leadership structure. Later in his letter, Paul established some guidelines to regulate these activities (1 Cor 14). His advice serves two purposes. The first was to keep the community actively engaged and participating in things of the spirit. The encouragement and permission was a type of personal empowerment that allowed for potent individual and communal experiences. Part of Paul's advice, however, was to control excesses which might generate unflattering perceptions in the eyes of outsiders.

These guidelines serve additional purposes. While Paul has empowered his community to enjoy "things of the spirit," he has also unambiguously stated that 
anyone enjoying "spiritual powers must acknowledge that what I am writing to you is a command of the Lord" (1 Cor 14.37). This is a serious stipulation. The possession and enjoyment of spiritual gifts can only be recognized as legitimate if those who are exercising them recognize Paul's letters as authoritative commands of the Lord. Paul's next step is to bluntly state that "anyone who does not recognize this is not to be recognized" (1 Cor 14.38). So while Paul empowers his followers to enjoy spiritual gifts, they can only do so if they acknowledge his authoritative status.

Paul wrote that all of the "called" were important components of the community, just as all parts of the body are important to the individual (1 Cor 12.1227). But within this inclusive sentiment, Paul articulated a hierarchy of important gifts and callings. The first, which should come as no surprise, was "apostle," the term Paul had unambiguously claimed for himself (1 Cor 1.1). The rest included prophets, teachers, "deeds of power," gifts of healing and tongues (1 Cor 12.28). Paul argued that he had more spiritual gifts than any of his followers. He states this rhetorically, "are all apostles? are all prophets? are all teachers? Do all work miracles? ... do all possess gifts of healing?" (1 Cor 12.29-30). Speaking in tongues is last on this list and Paul later claims that his skill in this area is superior to "all of you" (1 Cor 14.18). But following his rhetorical challenging of his community's gifts Paul writes that greater gifts are possible and it is he who has the ability to "show you a still more excellent way" (1 Cor 12.29-31). Such an offer implicitly claims possession of otherwise unobtainable knowledge concerning the ways of the gods and the mysteries of the divine realm. Possessing special knowledge is a mark of symbolic capital and of power. 
Paul sets himself above the remainder of the community by 1) asserting that apostleship is the highest of the gifts provided by God, 2) claiming that only those who recognize his status as called of God will be recognized in the community, and; 3) claiming a superior knowledge of, and an ability to instruct in the ways of, spiritual powers. Paul's argument is broad and he empowers his followers at the same time he limits their excesses and asserts his superior knowledge, calling and status. ${ }^{148}$

\section{Smith: Power and Disempowerment}

Wherefore I the Lord command and revoke, as it seemeth me good.

-Smith, BoC LVIII. 4.

Smith and Paul wrestle with different types of competitive challenges. Both do so in a way that attempts to strengthen their own positions while limiting the authority of others. Paul's primary competition comes from other traveling missionaries, some of whom appear to be connected with a larger, loosely organized Jesus movement. Smith's primary challenges come not from external threats such as circuit preachers, but from his own colleagues and converts who feel empowered to receive revelations for themselves. The challenge presented to Smith is how to corral and contain his early converts who feel empowered by the Holy Spirit to receive revelations while at the same time promoting himself as the only revelator sanctioned to receive God's words for the church as a whole. Smith's revelations in themselves provide a vehicle to effectively deal with this problem.

\footnotetext{
${ }^{148}$ See John Ashton, The Religion of Paul, 210.
} 
In addition to conveying the general will of the gods to humanity, Smith's revelations provide detailed instructions to specific individuals within his community. These revelations encourage followers to believe, preach, testify and otherwise remain intensely engaged in the new movement. At the same time, Smith's revelations protect him from significant challenges to his dominance.

Where Paul undermined the authority of Cephas and the Jerusalem apostles in his texted correspondence with the Galatians, and where Paul railed against his Wisdom-preaching competitors in his letters to the Corinthians, some of Smith's revelations were directed explicitly to his colleagues who were among the first members of his restored church. These revelations sought to empower his colleagues but with very specific limitations that protected Smith's ultimate authority. Smith's close circle of intimates longed not only for guidance and assurance, but for the ability to interact with the supernatural realm on their own. Smith was happy to oblige, but with conditions. Smith's colleagues who desired to receive revelations of their own threatened not just Smith as a revelator, but threatened to undermine his sole spiritual authority in governing a growing movement. At risk was the integrity of his message and the solidarity of the community. Historian Michael Quinn accurately observes that "a hierarchy of spiritual authority is impossible if there is unrestricted access to receive and announce God's will."149 Smith risked the evolution of his community into spiritual free-for-all like the one Paul tried to dampen in 1 Corinthians $12-14.150$

\footnotetext{
${ }^{149}$ D. Michael Quinn, The Mormon Hierarchy, 9.

${ }^{150}$ There, Paul recognized that the "things of the spirit" ( $\tau \tilde{\omega} v \tau v \varepsilon v \mu \alpha \tau \iota \kappa \tilde{\omega} v, 1$ Cor 12.1 , translated as "spiritual gifts" by both the NRSV and the KJV) enjoyed by the community worked for the "common
} 
The earliest of Smith's followers saw themselves as a community of equals where each was endowed with the spirit and the right to seek communion with the divine and receive revelations of their own. ${ }^{151}$ Book of Mormon witness David Whitmer recalls of this early time period that "Brothers Ziba Peterson, Hiram Page, Oliver Cowdery, Parley P. Pratt, Orson Pratt, Peter Whitmer, Christian Whitmer, John Whitmer, myself and many others had the gift of prophecy."152 Quinn summarizes the sentiment of the early community as "a gathering which lacked organized form and which required only professions of faith and repentance from its converts." 153 Such a loose structure is in line with the basic social contract as expressed early in the Book of Commandments, ${ }^{154}$ but it represents serious threats to unity, hierarchy, and singular authority.

By nature, a body of spiritualists each capable of communicating with the gods will soon morph in unforeseen directions. Given that different mediators will

good" (1 Cor 12.7). But he also cautioned those who speak in tongues not to speak to others, but to God. Speaking in tongues is insider discourse (1 Cor 14.22). He also urged "prophecy" over tongues (1 Cor 14.3-40) as prophecy (in Paul's usage) was a discernable discourse that could serve the purpose of building up the community (1 Cor 14.4, 17, 26). Prophecy too, however had to be regulated as "all things should be done decently and in order" (1 Cor 14.40). Paul reminded his flock that although speaking in tongues was a spiritual gift, it was the least of those gifts to be sought (1 Cor 27-30) and that greater gifts than those could be achieved if strived for in accordance with his teachings (1 Cor 12.31). Moreover, there was a developing leadership structure that put apostles and prophets at the top (1 Cor 12.28). Those who spoke in tongues were encouraged to move on towards higher orders of spiritual gifts (1 Cor 12.31), such as the ones that would "build up the community" (1 Cor 14.4, 17, 26) while supporting Paul's leadership.

${ }^{151}$ Quinn writes that "the official account of Mormon origins obscures . . . the egalitarian nature of the church before 1835” Mormon Hierarchy, 8. I would argue that the egalitarian nature began to disappear well before 1835 as many of the revelations analyzed below will demonstrate. Quinn argues that power authorized itself with the Mormon development of priesthood, 1-38. I would argue rather that this process was less complicated. Smith authorized himself and harnessed archaic notions of "priesthood" as an explanatory vehicle, a "logic" that supported his designs.

${ }^{152}$ David Whitmer, An Address to All Believers in Christ, 32, as in Quinn, Mormon Hierarchy, 8.

153 Quinn, Mormon Hierarchy, 6.

154 "Whosoever repenteth, and cometh unto me, the same is my church: whosoever declareth more or less than this, the same is not of me, but is against me: therefore, he is not of my church” BoC IX.17. 
receive different revelations, some will inevitably vary from others, different

diamonds can be found in different dung hills. Also, given that revelations from heaven are inherently authoritative and indicative of power, conflict in an egalitarian situation with open access to the divine word is unavoidable. ${ }^{155}$ In a truly egalitarian situation-where one's divine mandate can clash with another's celestial revelation-leadership by any single individual becomes impossible. Paul had to address this problem within his Corinthian community (1 Cor 12.1-11, 28-30; $14.1-33,37-40) \cdot 156$

Quinn corroborates David Whitmer's recollection of the freedom to receive revelation and prophecy in the early days of the church. He also notes a change of policy and the attempt to retroactively conceal this prophetic freedom when he writes that a number of the revelations given to Oliver Cowdery were later "printed as divine revelation to Joseph Smith." ${ }^{157}$ A simple side-by-side comparison of the

${ }^{155}$ This is essentially the argument Pagels makes for the failure of so-called Gnostics to survive in the face of the more tightly controlled, hierarchically organized, proto-Catholic Church. See Elaine Pagels, The Gnostic Gospels (New York: Vintage Books, 1989).

${ }^{156}$ Richard Pervo claims that the three versus omitted here, 34-36, exist in current bibles due to a later interpolation based on 1 Tim 2.11-13. See Pervo, Paul, 46. The interpolator's intention is to deny women the right to receive prophecy and speak in tongues-which speaks to the rising dominance of an all male clergy. The movement towards an all male clergy is indicative of an NRM's movement away from more counter-cultural or "fringe" ideals (here, allowing women as equals) towards conformity with the culture at large. It could be described as an attempt to find the "optimal level of tension" within the larger cultural setting. For twentieth century LDS parallels, see Mauss, The Angel and the Beehive. The erosion of women's leadership opportunities in the early Christian world is provided by Karen Jo Torjesen, When Women were Priests: Women's Leadership in the Early Church and the Scandal of their Subordination in the Rise of Christianity (New York: HarperOne, 1995). Encouragement to "accept the authority of every human institution (for the Lord's sake) whether of the emperor as supreme, or of governors" (1 Peter 2.13) is another clear signal of this general movement towards the mainstream.

${ }^{157}$ Quinn cites D\&C 17.8; 18.9, 22-25, 34; 20.37, 60, 73, 75-79. 
original Book of Commandments and the modern Doctrine and Covenants documents this practice. ${ }^{158}$

As time rolls forward, however, revelations become Smith's primary strategy for directing the affairs of his church and solidifying his individual power as its leader. To address competitive threats, Smith directed revelations to his closest colleagues that both reduced their spiritual authority and reinforced his own. In other words, Smith's revelations were a major tactical component of his strategy to enforce a spiritual hierarchy which placed him at the top. Such a move is hardly different from Plato's arguments in the Republic that place the philosophers, like himself, at the top of the social power hierarchy as the ruling class. ${ }^{159}$ Unlike Plato's theoretical and idealized society, Smith is actively managing a growing community. His revelations not only specifically articulated the ideal of his leadership, they codified it in written form.

Techniques such as these are well known to those who study charismatic prophets. Len Oakes writes that "the prophet's organization abounds with mechanisms that disempower the followers." ${ }^{160}$ Disempowerment has its consequences. Smith's quest to consolidate his power-among many other things ${ }^{161}$-led to the dissent of a number of significant church members in 1838 , including some of his closest associates and a number of Book of Mormon

${ }^{158} D \& C$ sections that have undergone significant changes since their first printing in the $1833 \mathrm{BoC}$ include 3, 5, 7, 8, 10, 18-20, 25, 27, 42.

${ }^{159}$ See Plato, Republic, 473c-d, 488c-489c, Laws, 713eff, etc.

${ }^{160}$ Oakes, Prophetic Charisma, 15. See also Lalich, Bounded Choice.

${ }^{161}$ This would include perceived problems with the BoM story and Smith's personal comportment, Palmer, Insider's View, 246. 
witnesses. ${ }^{162}$ On the other hand, Smith's authority and bold revelations continued to appeal to large numbers of people. His congregations grew even if a few of the earliest members grew disillusioned and left.

\section{Oliver Cowdery}

Smith's interaction with one of his earliest collaborators and followers, Oliver Cowdery, is also instructive for its subtle, effective disempowerment of a competing voice. Cowdery was a skilled divining rod worker (BoC VII.3) whose father had been an associate of Joseph Smith Senior in what a local Vermont newspaper called a "Fraternity of Rodsmen."163 Oliver became acquainted with the Smith family as a boarder in their home while a school teacher in the local area (1828-1829). He would become the primary scribe for the Book of Mormon project and perhaps the most significant person other than Smith himself in the early period of the Mormon movement. ${ }^{164}$ Along with Martin Harris and David Whitmer, Cowdery was one of the signatory Three Witnesses to the BoM. His testimony has been printed in every version of the BoM since 1830.

Cowdery was zealous for religion and for Smith's efforts to "bring . . . out of obscurity ... the only true and living church upon the face of the whole earth."165

\footnotetext{
${ }^{162}$ See, for example, Whitmer's All Believers in Christ. BoM witnesses John Whitmer and Martin Harris where excommunicated in Dec. 1837 and Mar. 1838, respectively. BoM witnesses Oliver Cowdery and David Whitmer were excommunicated in April of 1838 and two other witnesses left that same month. Four apostles either defected or were excommunicated, Luke S. Johnson, Lyman E. Johnson, John F Boynton, and William E. McLellin. "Approximately three hundred left the Church, representing about fifteen percent of the Kirtland membership,” Palmer, Insider's View, 247-48, citing Dean Jessee, Papers of Joseph Smith, 2:217 n2, 240-41.

${ }^{163}$ Which is to say that the fathers of both Joseph Jr. and Oliver were divining rod enthusiasts as were many in their area. Quinn, Magic World View, 35-36.

${ }^{164}$ Vogel, EMD 2:397.

${ }^{165}$ BoC I.5.
} 
Oliver had a passion not only for the occult, but for religious salvation and soon firmly believed in Joseph's calling as a prophet. A letter to Smith from his own hand documents his interest in being part of Smith's project. He writes to inform Smith of his "hopes and ... desires and ... longing to be freed from sin and to rest in the Kingdom of [the] Savior." ${ }^{166}$ Smith needed neither much psychological savvy nor significant "social insight" to determine that Cowdery would be a motivated and determined soldier for his cause. The two were like-minded souls in many respects—which came to present problems for Smith. ${ }^{167}$

Cowdery deeply desired to fully participate in the revelatory experiences enjoyed by Smith, but his ability to do so needed development. Smith was measured in his encouragement, seeking to nurture the well being of a follower while limiting the threat of a competitor. An early revelation reassures Oliver that whatsoever things you shall ask in faith, with an honest heart, believing that you shall receive a knowledge concerning the engravings of old records ... I [God] will tell you in your mind and in your heart ${ }^{168}$ by the Holy Ghost, which shall come upon you and which shall dwell in your heart (BoC VII.1).

\footnotetext{
${ }^{166}$ Letter from Oliver Cowdery to Joseph Smith, Nov 6, 1829, as in Vogel, EMD 2:405.

${ }^{167}$ Mormon historian Grant Underwood writes of Cowdery,
}

[F]or all Oliver's authentic religious piety, which is inspirational indeed to review, he had a serious flaw, a fatal Achilles' heel. It was his fiery independence of mind, and this was not the last time he would exercise it to challenge the Prophet Joseph Smith.... [W] see the profound paradox that was Oliver Cowdery - willing, even anxious, to expunge his own will to please God, but fearlessly demanding his independence in human affairs; pious and pliant before the Lord, but sometimes defiant before his Prophet.

Grant Underwood, “Oliver Cowdery’s Correspondence with Joseph Smith,” 2009 BYU Oliver Cowdery Symposium (Provo, UT: Religious Studies Center, Brigham Young University, 2009). https://rsc.byu.edu/archived/days-never-be-forgotten-oliver-cowdery/6-oliver-cowderys-correspondencejoseph-smith. Accessed Jan. 6, 2012. In fairness to Cowdery, it would be difficult not to be "defiant" when your former equal sought to limit your authority in the process of aggrandizing his own. See Table 3.5 below for one clear-cut example.

${ }^{168}$ Quinn argues that this type of inward or emotional confirmation was in contrast to the visible, mechanical manifestations offered by Oliver’s divining rod use, Magic World View, 37. 
Anticipating the potential ramifications of Cowdery's independence and zeal, Smith adds, "[t]rifle not with these things, Do not ask for that which you ought not" (BoC VII.4), which is no less than an explicit caution to Cowdery not to overstep the boundaries Smith was constructing for him. Smith valued Cowdery's skills as a scribe ${ }^{169}$ and wanted to keep him part of the process, but in a specific and constrained capacity. To Cowdery it is revealed that he is to "write for my servant Joseph" but that it is "not expedient that you should translate at this present time" (BoC VIII.2). Joseph wants to complete the BoM project which will be delayed if Oliver does not keep to his scribal duties. The revelation above is dated April 1829. Before the month was over, Oliver again asked to be a more significant part of the revelatory process. His query and apparent attempt to translate met with failure and disappointment which necessitated further direction from the mediator of the gods. Smith happily provided this direction at the same time he denied Cowdery the right to translate. He revealed to Oliver, that his "privilege" had been "taken away" (BoC VIII.2). The revelation continued, "[d]o not murmur my son, for it is wisdom in me that I have dealt with you after this manner.... do you not behold that I have given my servant Joseph sufficient strength ...?" (BoC VIII.2, 4). The question posed in the revelation to Cowdery implied that only one mediator was required, and essentially forced a vote of confidence in Smith's abilities.

What followed was remarkable in that Smith provided Cowdery with a method of receiving a revelation via a revelation. The revelation that Smith

\footnotetext{
${ }^{169}$ Presumably his "gift" mentioned in BoC VII.2, in addition to his "gift of working with the rod" found in the same section.
} 
produced for Cowdery was instructive as it explained why Cowdery had failed to get his own revelation in earlier attempts. The revelation was also didactic as it informed Cowdery of the correct way that a revelation should be sought. Cowdery had not properly prepared himself. As an "experienced [divining] rod worker and clairvoyant" Cowdery must have assumed that revelation would simply come from an outside source. ${ }^{170}$ Smith's revelation instructed otherwise. For Smith, revelations were a process of asking for a specific answer to a specific problem. In addition to its explanatory and didactic components, the revelation Smith delivered to Cowdery was punitive and disempowering as it highlighted the latter's errors and denied Cowdery the right to receive future revelation.

Beyond the power implications of denying Cowdery equal access to the divine realm, Smith's revelation is also instructive regarding the process that he himself apparently went through to prepare himself for a revelation. The instruction indicates the necessity of forethought and the process through which what is already internally harbored can be confirmed. The revelation to Cowdery reads,

Behold I say unto to you, my son ... the work which you are called to do, is to write for my servant Joseph ... Do not murmur my son ... Behold you have not understood, you have supposed that I would give it unto you, when you took no thought save it was to ask me; but behold I say unto you that you must study it out in your mind; then you must ask me if it be right, and if it is right, I will cause that your bosom shall burn within you: therefore, you shall feel that it is right; but if it be not right, you shall have no such feelings, but you shall have a stupor of thought, that shall cause you to forget the thing which

\footnotetext{
${ }^{170}$ Dan Vogel, "The Prophet Puzzle" Revisited, 137. Joseph acknowledges Oliver’s skill at working the divining rod when he writes "you [Oliver] have another gift, which is the gift of working with the rod," BoC VII.3.
} 
is wrong: therefore, you cannot write that which is sacred, save it be given you from me (BoC VIII). ${ }^{171}$

The above passage discloses the conscious, methodical, cerebral components required to receive a "revelation." The reproof within the revelation of "you took no thought save it was to ask me" clearly indicates that a deliberate, cognitive, human component must be deployed consciously and proactively. One must consciously engage cerebral activity and think about what it is that requires mystical, supernatural illumination or spiritual confirmation. In fact "spiritual confirmation" may be a more accurate way to describe the process than "revelation." The revelation delivered to Cowdery prescribed the method by which he could have received his own revelation had he deployed the proper technique. Given the similarities with the truth verification method Smith promotes elsewhere in his writings, ${ }^{172}$ this revelation appears to divulge Smith's own conscious and effective way of negotiating the supernatural realm. To the critic governed by the assumptions outlined in the first chapter, it is difficult to see how this methodology differs in substance from a more mundane, contemplative or meditative searching of one's heart for the solution to a vexing problem. ${ }^{173}$

${ }^{171}$ Marquardt, The Joseph Smith Revelations, 37, document \# 7 (emphasis added). Also D\&C 9:1-9 dating from April 1829. Note the methodological features shared with one's seeking a confirmation of one's own testimony, e.g. Moroni 10.4-6.

172 e.g. BoM Moroni 10.4ff.

${ }^{173}$ Sociologist Rodney Stark confirms the effective deployment of this methodology in a late twentieth century example. Stark writes of former LDS prophet and president Spencer W. Kimball's revelation that repealed the ban prohibiting men of African descent holding from the LDS priesthood. Stark wrote that,

the actual process by which he received his revelation would seem to involve nothing more (or less) than achieving a state of complete certainty about what God wanted him to do. Couldn't any sincere believer have revelations that way? Clearly, this episode demonstrated the possibility that many revelations can be understood in rational terms, and I soon realized that this assumption could be extended even to the more dramatic episodes of revelations, including those that do involve visions and voices. 
Apparently Cowdery was persistent in his requests to receive revelations as he is told over a year later, in September of 1830, that "no one shall be appointed to receive commandments and revelations in this church, excepting my servant Joseph, for he receiveth them even as Moses" (BoC XXX.2). ${ }^{174}$ In the revelation, Oliver is thrown a bone by being compared to Moses' biblical companion Aaron (BoC XXX.3) and told that he is allowed to preach, to "declare faithfully the commandments and the revelations, with power and authority unto the church" (BoC XXX.3). But he is specifically warned that he is not to challenge "him [Smith] who is at thy head, and at the head of the church." The basis of this warning is that Smith claimed that God has bestowed upon him alone the "keys of the mysteries and the revelations which are sealed" (BoC XXX.6). In insider language, Smith has informed Cowdery, and all other readers, that he alone possesses the power that attends the possession of constructed knowledge.

Cowdery has Smith's permission and trust to "be heard by the church, in all things whatsoever thou shalt teach them by the Comforter, concerning the revelations and commandments which I have given" (BoC XXX.1, emphasis added). Such a directive is both encouraging and empowering. The revelation continues, however, that Cowdery "shall go unto the Lamanites and preach my gospel unto them" (BoC XXX.7). Such a directive amounts to short term banishment from the heart of the new community.

Stark, JMH, Spring, 1999, 188. While Stark acknowledges that “any sincere believer” could operate in this manner, it takes one both bent on achieving social power and in command of a charismatic skill set to deploy this method in the construction of a new community.

${ }^{174}$ See also H. Michael Marquardt, The Joseph Smith Revelations, 83, document \# 30, and D\&C 28:2 (this is the exact time period during which Smith is producing the Book of Moses). 
While Smith has worked to keep Cowdery's interest and loyalty by relying on him as a scribe, an exhorter and a missionary, he also clearly restricts Oliver's attempts to exercise the same types of spiritual gifts that he enjoys and that are the mark of power. Smith's revelation not only denies Cowdery and anyone else the right to receive revelations for the community, but essentially temporarily exiles Cowdery to a mission in Indian territory, hundreds of miles away from Smith's location. Smith protects the right to receive and declare revelations for the entire church for himself. From a communal perspective, there are obvious benefits to having one and only one leader. At the same time, however, it is hard to not see claiming the exclusive right to speak for the nascent organization as other than selfbeneficial. Smith's revelation found a way to protect his own supremacy while keeping Oliver a committed, even if disempowered, partisan.

Smith had other local challenges to subdue. Hiram Page, one of the original "Eight Witnesses" to the Book of Mormon possessed a seer stone and was producing revelations through it. Smith may have rightly feared a cacophony of competing and contradictory revelations looming-each of which had the potential to challenge his doctrine, authority or both. The same revelation that curtailed Cowdery's right to receive revelation and exiled him to Indian territory also informed Cowdery that he was to shut down Hiram Page's revelatory enterprise. Page was on of the BoM's Eight Witnesses, but Smith had no patience for Page's competing voice and revealed to Cowdery that "those things which he [Page] hath written from that stone are not of me and that Satan deceiveth him: For behold these things have not been appointed unto him" (BoC XXX.11-12, emphasis added). 
Smith's identification of Page's revelations as being inspired by Satan is an excellent example of the rhetoric surrounding the identification of a false prophet. Recall here Paul's words to the Corinthians, "such boasters are false apostles, deceitful workers, disguising themselves as apostles of Christ ... even Satan disguises himself as an angel of light" (2 Cor 11.13, 14). In both situations the "true" prophet calls his emulator "false," and denigrates his methods ("that stone"), when in fact the emulator is working in the same manner that Smith has boasted of as authoritative. Both are accused of being pawns of Satan, the antithesis of all that is good. Given the reception to, and efficacy of, Smith's use of the a seer stone, the challenge to his authority by emulators is plain. ${ }^{175}$ The greatest threats to entrenched power are presented by those whose operational methods are similar and already accepted as legitimate and authoritative.

Most revelations concealed any overt sense of forethought and were delivered as if straight from the mouth of the relevant divine being. One example is a revelation to Cowdery and David Whitmer in June of 1829 which reinforces its divine origin throughout and concludes with, "Behold I Jesus Christ, your Lord and your God, and your Redeemer, by the power of my Spirit, have spoken it: Amen" (BoC, XV.50).176 Smith may have "studied this out in his mind" before he gave it, but

${ }^{175}$ Smith had used a seer stone since at least 1819 when he was barely a teenager. Smith's stone was critical to finding the BoM, translating it, and producing subsequent revelations and texts such as the Book of Moses. Quinn Magic World View, 33. Page’s in-laws, the Whitmer's, continued to use seer stones in mystical contexts. Photographs of early Mormon seer-stones are provided by Quinn, Magic World View, figures 11-13.

${ }^{176}$ Almost every verse contains a reference to Jesus speaking in the first person, e.g. "I," "my,” "my name,” etc, BoC XV.1-4, 6-8, 10-11, 18-20, 23, 26, 28-31, 33-42, 44, 47-50. In a reference to baptism Smith writes, that it is to be "in my name, which is Jesus Christ" 23. Three quarters of the way through the revelation is found "And I Jesus Christ, your Lord and your God, have spoken it. These words are not of men, nor of man, but of me" 36-37. 
it certainly reads as if it is a message strait from the mouth of Jesus. Barring possession or psychosis, one should assume that the delivery in the voice of the gods must have been one of the components Smith "studied out" in his mind prior to its delivery. Such a tactic oozes with authority for those with ears to hear. The message is adamant that it is of divine rather than human origin and in fact uses language reminiscent of Smith's King James version of Galatians where Paul claims that his apostleship is "not of men, neither of man" (Gal 1.1).177

The method of producing revelation is not trivial. Acting as a passive conduit diminishes the human component of the prophetic role. In contrast, revelations that are a product of conscious forethought bring the role of the prophet to center stage. The prophet who "stud[ies] it out in [his] own mind" (BoC VIII.3) relegates the role of the supernatural to that of an emotional confirmation of what the prophet has already conceived. This range of revelatory methodology problematizes Kassam's proposition concerning "divine status of revelation" as "standing in [an] inverse relation to the prophet's human involvement."178 Smith's revelations capitalize on both the human conception of the divine communication, and the performative

\footnotetext{
${ }^{177}$ An analysis of Smith's mimetic use of Pauline language is not part of the analysis here. Clearly, Paul is an important biblical and prophetic model for Smith, but the imitation of Paul's language in this study presses no further than to KJV generalities. Specific and deliberate imitation of Paul's claims to power is a related, but ultimately different, topic. Claiming authorization from the gods and not from men is not a strategy exclusive to Paul. The thrust of this dissertation is not so much on the mimetic components of Smith's use of Paul, rather it is on the types of patterns and statements that claimants to power deploy, Smith and Paul being but two specific examples of a more general phenomenon. Moses too got his directives from the gods. For a study on Smith's use of the King James Bible in his writings see Palmer, An Insider's View, 39-93, esp. 49-54.

${ }^{178}$ Are prophets necessarily to be revered any more than other passive human beings, or even more ordinary conduits such as a telephone line? If there is something truly special concerning the prophet, how does the human input make its way into the revelation, and how should the revelation be understood given the human contingency? What role do the prophet's "cognitive faculties" play during the (passive) receipt of a revelation, and the (active) pronouncement or penning of the divine mandate? See Kassam, "Signifying Revelation in Islam,” 34-36.
} 
components of its delivery as straight from the mouth of heaven. Smith's "study[ing] it out in [his] mind" (BoC VIII.3) provided him with the content and the voice (God's or Christ's) of the revelation.

The overt pedagogical nature of Smith's revelation to Oliver Cowdery $(B o C$ VIII.3) implies his conscientious thought prior to producing a revelation. Smith's forethought manifests itself in his direct command to Cowdery and Whitmer through the words of Jesus. Smith thinks about what he needs and then "reveals" his agenda as if it were from the lips of Jesus himself. Commanding others to testify of his ability to receive and transmit the words and desires of the gods clearly illustrates Smith's recognition of his own power and his desire to promote his elite status. Moreover, the revelation provides clear evidence of his interest in harnessing his followers to promote him and his calling. In effect, Smith is calling for his disciples to proclaim him. Such a tactic reinforces the (im)balance of power in the emerging group.

The ability to convince people that his revelations were not his own contrivances, but in fact direct communication from the divine realm is perhaps the most mystifying component of Smith's success. As was the case regarding the demand from money diggers to "look into the stone," religious seekers presented substantial demand for spiritual guidance and knowledge of the gods. Speaking in the voice of "Jesus Christ, your Lord and your God" proved enticing, convincing and compelling.

Like Paul before him, Smith situated the source of this authority in the supernatural world, outside the realm of human comprehension or empirical 
verification. He capitalizes on the locus of such authority, in addition to the power that is generated from the possession of special knowledge, when he writes to Cowdery and Whitmer, "And now marvel not that I [Jesus Christ your Lord and your God] have called him [Smith] unto mine own purpose, which purpose is known in me" (BoC XV.8). The direction to "marvel not" is an attempt to make Smith's mediation appear as sober and normal communication. That recipients are instructed not to be amazed is a step towards naturalizing the process in an attempt to render such skills as normative for one of Smith's chosen status.

In my reading, the repetitive and emphatic assurances of divine origin suggest a certain insecurity on the part of the prophet, who "doth protest" too much. The revelation not only seeks to convince its direct recipients, Cowdery and Whitmer, that it is directly from the mouth of Jesus, but also seeks to convince these two that they, in turn, are to convince others of its divine authenticity. Smith writes, "Wherefore you shall testify they [the words attributed to Jesus] are of me [Jesus], and not of man; for it is my voice which speaketh them unto you" (BoC XV.38). In a general sense, such an instruction is at the crux of Stark and Finke's propositions stated above where mystical experiences and the expression of confidence by others strengthens the religious explanation proffered by the prophet. ${ }^{179}$

But there is more to the functionality of having others testify than simply convincing third parties. Those who bear testimony to Smith's powers gain a

${ }^{179}$ Stark and Finke, Acts of Faith, 106-13, and:

Testimonials are especially effective when they come from a trusted source. Thus, friends are more persuasive than acquaintances, and testimonials are even more persuasive when those testifying have little to gain (and perhaps much to lose) thereby. For this reason, laity are often more persuasive than ecclesiastics, since the latter often have a vested interest in promoting religious commitment, 111. 
stronger conviction of his powers by virtue of trying to convince others. So the tactic of having others proclaim one as a true prophet and seer does more than attract additional members to the fold, it forges a more convicted cadre of followers in the process. The process of trying to convince others to believe, to take the leap of faith, functions to reaffirm belief and faith in those bearing witness to the incredible. Smith himself probably gained much from this act. His ability to convince others perhaps reassured him that his own claims were in fact the words and will of the gods, "and not of man."

A final-but far from exhaustive-example of Smith's gradual disempowerment of Cowdery via the use of texts can be documented by comparing the earliest printing of the Book of Commandments with its successor volume printed only two years later, the Doctrine and Covenants. In the early version, Joseph and Oliver share an equivalent status as "elders" in the church, indicating a type of equality that one might expect of idealistic Christian primitivists. Subsequent printings, however, show that the allure of power for Joseph was too strong to be bound by the idealism attributed to ancient models of egalitarian Christian living. Joseph sought to formalize his status as superior to Oliver's. In the 1835 version of the $D \& C$ (the revised $B o C$ ), Joseph became the first elder and Oliver the second. The relevant passages are provided for comparison in Table 3.5, below. Certainly the evolution of leadership roles in new communities is not something sinister. The critique above simply highlights the human dimension of social formation where the process of achieving power (asserting dominance) is packaged as a series of mandates from the gods. The point to understand is that the 
construction of reality is continually being reconstructed. Power finds ways to maintain, protect and augment itself. The process is driven by human agendas which this analysis seeks to render explicit. The process of literary excavation facilitates the unpacking and unmasking of power claims to lay bare the inherent and concealed human interest. The penning of sacred texts that promote the interests of their authors is a powerful tactical component in fulfilling these human agendas.

Table 3.5

Smith's Downgrading of Cowdery

\begin{tabular}{|l|l|}
\hline \multicolumn{1}{|c|}{$\begin{array}{c}\text { Book of Commandments, 1833 } \\
\text { Chapter XXIV. 3-4 }\end{array}$} & \multicolumn{1}{c|}{$\begin{array}{c}\text { Doctrine and Covenants, 1835 } \\
\text { Section II.1 }\end{array}$} \\
\hline $\begin{array}{l}\text {. J Joseph who was called of God and } \\
\text { ordained an apostle of Jesus Christ, an elder } \\
\text { of this church; And also to Oliver, who was } \\
\text { also called of God an apostle of Jesus Christ, } \\
\text { an elder of this church ... } \\
\text { (emphasis added to both passages) }\end{array}$ & $\begin{array}{l}\text {. . Joseph Smith jr. who was called of God } \\
\text { the first elder of this church; and to Oliver } \\
\text { Cowdery, who was also called of God an } \\
\text { apostle of Jesus Christ, to be the second elder } \\
\text { of this church ... 180 }\end{array}$ \\
\hline
\end{tabular}

\title{
The Work of the Lord as Financial Extortion: Martin Harris and Philemon
}

\author{
Martin Harris
}

Even before the formal founding of the Church in April of 1830, Smith was using revelations and seer stones to advance his interests. Some of the best examples derive from his interaction with an early follower by the name of Martin Harris. Harris was a well-to-do farmer who had participated in a number of religious communities, including the Quakers, the Universalists, the Restorationers,

\footnotetext{
${ }^{180}$ Smith was probably "wrought upon by the Spirit to erase the word[s] . . and substitute the word . . ..” This is an explanation that then Church historian Orson Pratt made to explain another change to the title of an office in the early days of the Church, Quinn, Origins of Power, 49, citing History of the Church, 3.381. Later Church president John Tayler made reference to Smith's right "to give a portion of a revelation and add to it afterwards,” cited in Quinn, The Mormon Hierarchy, 5 and 272-275.
} 
Baptists, and Presbyterians before becoming a Mormon. ${ }^{181}$ Later in his life, Harris would recall that in the summer of 1826, he had experienced a "revelation" of his own that informed him he had a special work to do. ${ }^{182}$

One account of Smith's first interaction with Harris depicts Smith more as a confidence man ${ }^{183}$ than a prophet. Smith was in need of money to help move his wife, Emma, from Harmony, Pennsylvania to the Manchester, New York, area. As told by a Smith family neighbor of many years, Peter Ingersoll, Smith related to him the following encounter with Harris. In Palmyra

said he [Smith], ["]I there met that dam fool, Martin Harris, and told him that I had a command to ask the first honest man I met with, for fifty dollars in money, and he would let me have it. I saw at once,["] said Jo, ["] that it took his notion, for he promptly gave me the fifty.["] ${ }^{184}$ (emphasis in original).

The time of the event described above was the Fall of 1827 in which case it appears that Smith is already accustomed to use the pretense that he "had a command [sic]" 185 for the purpose of influencing others to serve his needs. If

\footnotetext{
${ }^{181}$ G. W. Stoddar's testimony, Howe, Mormonism Unvailed, 261.

${ }^{182}$ See Harris' interview with Joel Tiffany in EMD 2:302. See also “Introduction to Martin Harris Collection” in EMD 2:252-259 for elaboration of Harris’ mystical mindset.

${ }^{183}$ The term "confidence man" is only barely anachronistic. It was presumably "coined by the New York press in 1849 during coverage of the arrest of a swindler named William Thompson." See Karen Halttunen, Confidence Men and Painted Women: A Study of Middle-class Culture in America, 1830-1870 (New Haven: Yale University Press, 1982), 6. The term is descriptive in that "con-men” first earned the confidence of their prey before defrauding them.

${ }^{184}$ Testimony of Peter Ingersoll as in Howe, 237. Harris relates what is probably the same event in a different manner. His account, as printed by Joel Tiffany, reads: “[an angel] told him [Smith] to go and look in the spectacles, and he would show him the man that would assist him. That he did so, and he saw myself, Martin Harris, standing before him. That struck me with surprise” EMD 2:309. Harris continued that "I advised Joseph that he must pay all his debts before starting. I paid for him, and furnished him money for his journey" EMD 2:310. Undoubtedly the "surprise" that struck Harris was accompanied with a healthy, yet calibrated, serving of flattery. Harris was presumably, depending on the account, "flattered" to be divinely recognized as an honest man, or, honored to be divinely selected as one to facilitate the work of the gods on earth.

${ }^{185}$ If analyzed by the details provided by Harris, claiming the appearance of Harris in Smith's seer stone would replace the claim of "the command" recalled by Ingersoll. Both accounts convey the supernatural component that appealed to Harris' sensibilities as a religious seeker.
} 
Ingersoll's testimony is accurate, it also provides insight into Smith's advanced social and emotional skills as he was quickly able discern that Harris was a suitable target for such a tactical proposition. Over time Harris would become important to Smith and his project in a number of ways. He was one of the "Three Witnesses" to the Golden Plates and paid for the printing of the Book of Mormon. Harris' actions, however, were often motivated by guidance provided by Smith's revelations. Harris implicitly trusted Smith, yet in a remarkable, somewhat inconsistent way. Less than two years into their relationship, March 1829, Harris became frustrated with not being able to physically see the golden plates. He asked Smith "for a witness from my [God's] hand, that my [God's] servant Joseph has got the things of which he has testified" (BoC IV.1). It should be noted that the very act of asking for a divine witness indicates a certain distrust of Smith, the twenty-two year old with a penchant and reputation for money-digging. At the same time, Harris' query suggests a confidence in both Smith and in the epistemic regime under which he operated. It is as if Harris was thoroughly convinced of the realities of the supernatural, and of the possibility of communicating with the supernatural, but was somewhat hesitant about the human vehicle that transmitted the revelation. Harris trusted the phenomenon and process even if he initially harbored doubts about the messenger, Smith. Smith was easily able to tell Harris precisely what he wanted to hear. He was a capable and convincing performer.

Harris was a "religious visionary and seeker" 186 himself and as such prone to find Smith's revelations not only plausible, but cogent. Given Smith's ability to read

\footnotetext{
${ }^{186}$ Dan Vogel, “Introduction to Martin Harris Collection,” EMD 2:253.
} 
and determine the emotions of others, ${ }^{187}$ he is well aware of Harris' susceptibility to certain types of persuasive methods; especially those packaged as direct, personalized, divine instruction. Capitalizing on this, Smith receives a revelation in which Harris is assured that,

I the Lord am God, and I have given these things unto my servant Joseph, and I have commanded him that he should stand as a witness of these things, nevertheless I have caused him that he should enter into a covenant with me, that he should not show them except I command him, and he has no power over them except I grant it unto him (BoC IV.2).

Smith feigns the inability to act other than as he has been commanded to by extramundane forces. The implication is that no matter how much Smith personally may want to show Harris the plates, if it does not fit the will of the gods, Smith is powerless to accommodate him. As Smith continues to reveal God's sentiment, Harris learns that "wo shall come unto the inhabitants of the earth ... if they would not believe my servant Joseph" and that "mine anger is kindled against you! ["ye unbelieving, ye stiffnecked generation"]" (BoC IV.3, emphasis added). Having informed Harris that he is powerless to show him the plates, Smith has also revealed that the wrath of God is presently kindling against those who do not believe his claims. Speaking for God, Smith reassures Harris that "this is a wise purpose in me [God]." He then begins the process of setting up Harris's future vision of the plates as one of the Three Witnesses when he reveals:

the testimony of three of my servants shall go forth with my words unto this generation; yea, three shall know of a surety that these things are true, for I will give them power, that they may behold and view these things as they are (BoC IV.4).

${ }^{187}$ See analysis in chapter two and the revelation to Cowdery, BoC V.7. 
Smith then reveals the process God expects of Harris if he is to behold the

plates. The revelation reads,

behold I say unto him [Harris], he exalteth himself and doth not humble himself sufficiently before me, but if he will go out and bow down before me, and humble himself in mighty prayer and faith, in the sincerity of his heart, then will I grant unto him a view of the things which he desireth to know (BoC IV.8, emphasis added).

Having provided the conditional method by which Harris is to prepare himself to mystically behold the plates, another stipulation is added. Harris is expected to publicly testify of his experience and his certainty of the existence of the plates. Smith reveals that,

he [Harris] shall say unto the people of this generation, ["]behold I have seen the things and I know of a surety that they are true, for I have seen them, and they have been shown unto me by the power of God and not of $\operatorname{man}["]$ (BoC IV.8).

Having provided the language for Harris' anticipated testimony, yet another condition is added. This condition is negative as it threatens Harris' future access to divine revelations. Smith reveals to Harris that if he does not

humble himself and acknowledge unto me the things that he has done, which are wrong, and covenant with me that he will keep my commandments, and exercise faith in me, behold I say unto him, he shall have no such views, for I will grant unto him no views of the things of which I have spoken (BoC IV.9).

Beyond not being allowed a view of the plates, Harris would not be allowed to "trouble me any more concerning this matter" and would have "no more gift." The entire translation process would cease. Knowing Harris' zeal to be involved in this divine and holy work, this is a powerful threat that strikes directly at Harris' deep-seated longings and vulnerabilities. 
In sum, Smith's revelation to Harris 1) provides Harris a method by which he can have a vision of the plates, 2) conditionally promises him that he will behold the plates, 3) stipulates that he is to testify of what he has seen, 4) provides a virtual script for this testimony, and 5) threatens him with being cut of from the marvels of the supernatural realm and the translation process if he does not comply. The latter threat is delivered with 6) a method by which Harris could prepare himself to be further persuaded by Smith. He is told to "humble himself" and "exercise faith in me." Intimately connected with Smith's assertion of power over Harris is his providing Harris with a powerful procedure by which Harris could find mystical verification of what Smith had been telling him. Harris must convince himself. He must "bow down ... and humble himself in mighty prayer and faith, in the sincerity of his heart" (BoC IV.8). Harris ultimately acts in accordance with these directives and becomes one of the Three Witnesses of the Book of Mormon plates-although not without lingering uncertainties. ${ }^{188}$

Once the translation was finished and the manuscript prepared, $\$ 3,000$ was needed to print the Book of Mormon. Neither Smith nor his family had the financial means to pay for the endeavor, but Martin Harris did. In March of 1830, one year after Harris received the revelation analyzed above, he received another one, the latter part of which reads, "listen to my words; walk in the meekness of my Spirit and you shall have peace in me, Jesus Christ by the will of the father," (BoC, XVI.24).

\footnotetext{
${ }^{188}$ Harris beheld the plates with his "spiritual eye," a point that subjected him to some eventual ribbing. One account goes, “'Martin, did you see the plates with you naked eyes?' Martin looked down for an instant, raised his eyes up, and said, 'No, I saw them with a spir[i]tual eye.’” John H. Gilbert Memorandum, 8 September 1892, in Vogel, EMD 2:548. See also EMD 2:270, 291, 385.
} 
Harris is then provided some standard moralizing ${ }^{189}$ before Smith gets to the crux of what he really needs. Smith reveals to Harris, "I [Jesus Christ], command you, that thou shalt not covet thine own property, but impart it freely to the printing of the book of Mormon" (BoC XVI.27). ${ }^{190}$ Harris dutifully mortgages his farm for the $\$ 3,000$ required to pay the printing costs of the Book of Mormon. ${ }^{191}$ According to one account, Harris was the only one of the "primitive Mormonites" to contribute any actual money to the fledgling enterprise. ${ }^{192}$

Paul can play this game too. To the Corinthians he writes, "each of you must give as you have made up your mind, not reluctantly or under compulsion, for God loves a cheerful giver" (2 Cor 9.7). Paul writes ahead of his arrival so that the "bountiful gift" that he is expecting "may be ready as a voluntary gift and not as an extortion" (2 Cor 9.5). He reminds the Corinthians that "[t]he one who sows sparingly will also reap sparingly, and he one who sows bountifully will also reap bountifully" (2 Cor 9.6). Such rhetoric can be used to exploit followers in the name of a higher cause.

\section{Philemon}

The best example of Paul's willingness to influence others in the same way Smith interacted with Harris is found in his letter to Philemon. The introduction to Philemon in the Oxford University Press edition of the NRSV flatly refers to Paul's

\footnotetext{
${ }^{189}$ Harris is told that he should neither "covet thy neighbor's wife. Nor seek thy neighbor's life" (BoC XVI.25-6).

190 The revelation even reiterates that Harris is to "[i]mpart a portion of thy property; Yea, even a part of thy lands ... . Pay the printer's debt. Release thyself from bondage” (BoC XVI.36-38).

${ }^{191}$ See EMD 4:473-77 for Harris’ actual mortgage document.

${ }^{192}$ See “Stephen S. Harding to Thomas Gregg” in EMD 3:154.
} 
letter to Philemon as "business correspondence."193 Such a taxonomical characterization would apply to a number of Smith's revelations that deal with temporal and monetary issues germane to the business of financing and running a church (e.g. BoC XXV 5, 6, 14; XLIII.11; LXIV.43, 46, 50, etc.). Harris' command to pay the printer is but one example. "Business correspondence," however, drastically understates the inherent exploitation involved in a transaction between one who holds power over another. On the surface, the "transaction" seems to go only one way. Paul gets a slave and Philemon gets nothing but a reminder of how much he owes Paul.

In the epistle to Philemon, Paul seeks to take the slave Onesimus as his own. Onesimus' current owner is the letter's recipient, Philemon. Paul and Philemon share some important history during which Paul had already asserted his spiritual superiority to the letter's recipient. He writes to Philemon, "I am bold enough in Christ to command you to do your duty, yet I would rather appeal to you on the basis of love" (Philemon 9). ${ }^{194}$ Paul reminds Philemon that he has the authority and chutzpa to take his slave, Onesimus, by simply commanding him [Philemon] to do what heaven requires. He couches his demand, however, as an opportunity for Philemon to express his love. Having just stated his authority and right, Paul reiterates the "voluntary" nature of his request. He assures Philemon that he would prefer to act only with his "consent" and "not as something forced" (Philemon 14) ${ }^{195}$

${ }^{193}$ The New Oxford Annotated Bible: New Revised Standard Version with the Apocrypha, Third Edition, Michael D. Coogan, editor (Oxford: Oxford University Press, 2001), NT 366-367.

${ }^{194}$ Emphasis added. Recall 2 Cor 9. 5-7 cited above. Doing the will of the gods takes financial resources!

${ }^{195}$ Note the rhetorical similarity to "so that it may be ready as a voluntary gift and not as an extortion," 
which in itself acknowledges that Paul is aware of the asymmetrical nature of his relationship with Philemon. Paul then writes, "I will say nothing about your owing me even your own self," which, contrary to the literal statement, is precisely a reminder that Philemon owes Paul for his salvation in Christ. Paul also expresses "confiden[ce] of your [Philemon's] obedience," (rhetoric which speaks for itself) and recognizes that he, Philemon "will do even more than I say" (Philemon 21). The latter statement is rather common diplomatic idiom of the time that recognizes the underling's expected, automatic complicity in the request made by a superior. Paul's rhetorical confidence that assumes Philemon will surpass his specific duty suggests that both are acutely aware of the imbalanced nature of the relationship. Philemon is plainly expected to do as Paul "asks" (lest Paul "command" it, Philemon 9), which includes bestowing Paul with material wealth, in this case human chattel.

Given the textual content of the letter, Philemon's achievement of canonical status can not possibly rest on its subject matter. Rather its authority is based solely on the reputation and importance of its author. Due to the constraints imposed by our limited ancient sources, examples of manipulation of this kind are more easily found with Smith than Paul. The point here is that documents from the hands of both men under consideration provide evidence of similar behavior between the holder of power and the holder of financial resources. The former avails himself of the resources of the latter boldly as if it were his God-given right. It is entirely plausible, however, that both Harris and Philemon found giving their spiritual leader all that he asked for a wholly satisfying experience.

2 Cor 9.5 . 
Smith's social sensitivity and insight allows him to simultaneously "satisfy the wants and exploit the vulnerabilities of the followers."196 At the same time Harris is being financially exploited ${ }^{197}$ he is encouraged to participate in spreading the word and growing the movement. Joseph reveals that Martin is to "preach, exhort, declare the truth, even with a loud voice" (BoC, XVI.40). Smith's financial exploitation of Harris is accompanied by a degree of spiritual empowerment. He specifically asks Harris if his wants are not satisfied by rhetorically querying, "canst thou read this [revelation] without rejoicing and lifting up thy heart for gladness[?]" (BoC XVI 43). In this case, Harris is exploited to pay for the printing of the Book of Mormon at the same time he is encouraged and empowered to preach the message of the newly revealed gospel. Given what Harris understands of Smith's enterprise, and given Stark's open and fluid market of spiritual systems, Harris apparently found his participation in bringing about the restored gospel of Christ, and his personal association with a living prophet, a fair exchange for the proceeds of his mortgaged farm, $\$ 3,000 .{ }^{198}$ In Stark's system of a religious economy, such trade-offs are entirely rational.

\footnotetext{
${ }^{196}$ Oakes, 15.

197 The term "exploited” is far from generous_-but then, so too is the written agreement between Smith and Harris regarding the terms under which he will be repaid for the BoM printing costs. Harris is to receive an "equal privilege" with Joseph and unnamed "friends" in the sales of the BoM until the printing costs are paid for. There is no compensation for the risk Harris incurred in making the loan, no interest paid on the loan, and no specified agreement to share in the profits once the printing costs are paid. In short, Harris is not compensated as a lender and has no equity stake in the upside. His compensation is purely psychic. See a photo of the original loan compensation agreement (and a transcription) in the plates after page 198 in Marquardt and Walters, Inventing Mormonism.

198 Paul provides other examples of his rhetoric to extract financial resources from his community. 2 Corinthians provides some of the best examples, such as: "we want you to excel also in this generous gift (cariV). I do not say this as a command, but I am testing the genuineness of your love against the earnestness of others, 2 Cor 8.7b-8. Later in the same chapter, Paul writes, "therefore openly before the churches, show them the proof of your love and of our reason for boasting about you,” 24.
} 


\section{Indwelling of the Spirit}

In some circles of discourse, the notion that a deity — or an evil spirit ${ }^{199}$ actually resides within someone is referred to as possession. ${ }^{200}$ Some of the most vivid evidence of belief in this phenomenon from Paul's era comes from the New Testament itself, where Jesus is frequently portrayed casting out demons. ${ }^{201}$ Paul claims possession for himself when he writes that "God ... was pleased to reveal his

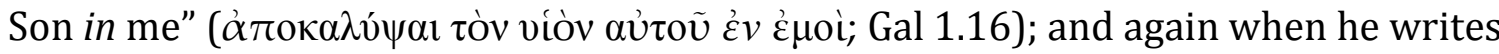

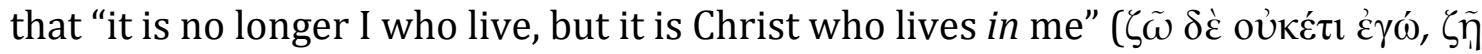

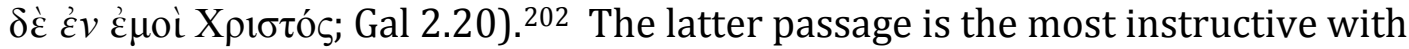
regard to what might be termed possession. In it Paul specifically states that Christ has replaced him as operator of the flesh Paul walks around in. Paul writes, "the life I now live in the flesh I live by the faith of the Son of God" (Gal 2.20). ${ }^{203}$

The other side of this polarity is exhibited by those in Galatia who are "enslaved to beings that by nature are not gods" (Gal 4.8). Paul seems to believe

199 “Even Satan disguises himself as an angel of light” (2 Cor. 11.14).

${ }^{200}$ Aune, Prophecy in Early Christianity, 19-21; Lewis, Ecstatic Religion, especially 15-31. John Ashton notes that "the conceptual tools of theology are too finely-honed to deal satisfactorily with Paul's halting attempts to put his experience of spirit-possession into words.” The Religion of Paul, 45.

${ }^{201}$ A partial list that excludes the numerous synoptic parallels: Mark 1.23-26; 5.1-20; Matt 4.23-25; 7.21-23; 8.14-17; 9.32-34; 17.14-21; John 7.20; 8.48-52; 10.20-21; Acts 5.16; 8.6-8; 10.38; and many others. Another term for this process is exorcism.

${ }^{202}$ Emphasis added. Of this passage, Ashton states plainly that "this is the language of possession. ... The ego here is totally dominated, possessed, and occupied by an alien power.” The Religion of Paul, 47. The NRSV translates the passage in Gal 1.16 as "reveal his Son to me,” but a textual note informs the reader of the more accurate Greek translation "in me” ( $\dot{v} v \dot{\varepsilon} \mu \mathrm{oi})$. See also Rom 8.9-15; 2 Cor 13.3, 5. Of the translation "to me," Ashton writes that it "demands a lot of strenuous philological wriggling if it is to be made to look respectable," $83 \mathrm{n} 16$. The translation of "to me” seems to yield to modern sensibilities and theologies by avoiding the implications otherwise of such a bold, provocative statement. Indeed, "to me" seems intended to skirt the very point that Paul is trying to emphasizeby Christ.

203 The quotation reflects the NRSV's alternative (less theologically driven) rendering of the passage, found in the NRSV's textual notes. 
that human beings are the pawn of whatever supernatural force possesses them at a given time. To the Galatians, Paul claims that it is Christ who dwells in him, but in Romans 7 Paul writes, "I do not understand my own actions" (v. 15), because it is "no longer I that do it, but [S]in that dwells within me" (v. 17); and again, "Now if I do what I do not want, it is no longer I that do it, but [S] in that dwells within me" (v. 20). "Sin" ( $\alpha \mu \alpha \varrho \tau i ́ \alpha)$ should perhaps be capitalized here, as it is used in the sense of "a destructive evil power" that "came into this world" (Rom 5.12), "exercise[d] dominion in ... mortal bodies" (Rom 6.12), and subjected all things to its powers (Gal 3.22). In Paul's world, possession by Christ serves as liberation from and a counterattack against the forces of evil, the rulers of "this world" that possess the flesh of so many. ${ }^{204}$ This understanding and claim of possession is not something unique to Paul but broadly attested throughout the ancient Mediterranean world. Various expressions of possession are culturally learned behavior that were common to "all ancient oracular speech, whether Greco-Roman, Jewish, or early Christian." 205

Some form of this phenomenon, whether referred to as possession or the indwelling of the spirit, is also evident in Smith's era. Book of Mormon character Lehi says at one point, "I, Lehi, prophesy according to the workings of the Spirit which is in me ... (2 Nephi 1.6). So too, a revelation to Oliver included the notion

\footnotetext{
${ }^{204}$ BDAG, 51. See also Phil 4.13. See also Ashton’s discussion, 131-132.

${ }^{205}$ David E. Aune, Prophecy in Early Christianity, 20-21. Anthropologist I. M. Lewis writes, "religious enthusiasm can be treated as a social phenomenon," and "the altered state of consciousness (which may vary very considerably in degree) and which for convenience we call trance is, in the circumstances in which it occurs, open to different cultural controls and to various cultural interpretations.” Ecstatic Religion: A Study of Shamanism and Spirit Possession, 3rd edition (London: Routledge, 2003), 25, 38-39.
} 
that supernatural confirmation makes itself known within one's body in the form of a tangible sensation described by Smith as "your bosom shall burn within you: therefore, you shall feel that it is right" (BoC VIII.3).

Another example from the broader traditions of Israel that stem from Hebrew scripture serves as a powerful antecedent to Paul's type of claim. As captured in the Enoch tradition, the angel Michael encounters the Lord and is told to

Take Enoch, and extract (him) from the earthly clothing. And anoint him with the delightful oil, and put (him) into the clothes of glory." And Michael extracted me from my clothes. He anointed me.... And I gazed at all of myself, and I had become like one of the glorious ones, and there was no observable difference (2 En. 22.8-10). ${ }^{206}$

While Enoch appears to be in the body of an angel in the passage above, he is in the body of a man in another celestial journey passage (1 En. 71). Alan Segal argues that 1 En. 71, "underlies the mystic transformation between the adept and the angelic vice-regent of God" 207 and that, when combined with the above passage from 2 Enoch, "could explain Paul's use of the peculiar terminology in Christ." 208 If Segal is correct, we see Paul's assertion of "Christ [being] in him" as an implicit claim to his own elevated status in some implicitly posited great chain of being.

In contrast, Smith will not need to verbally claim possession to bolster his case as divine mediator. For Smith, the persuasive evidence of God working through him is manifest in every revelation that he delivered in the voice of deity. In

\footnotetext{
206 James Charlesworth, Old Testament Pseuedepigrapha, vol. 1, 139. Insertions of “(him)” as in Charlesworth. The imagery of "clothes” is symbolic of the flesh that cloaks the soul.

207 See Daniel Boyarin's Border Lines, for research concerning the turn of the era notion of "two powers in heaven,” 38-39, 120-127, 130-147

${ }^{208}$ Alan F. Segal, Paul the Convert: The Apostolate and Apostasy of Saul the Pharisee (New Haven, CT: Yale University Press, 1990), 46-49. Maccoby argues that the "in me" terminology comes from the “mystery religions,” specifically the discourse associated with Attis, The Mythmaker, 63, 107-108.
} 
addition, the production of the Book of Mormon highlights Smith's ability (not as spiritual possession but) as a gift of "power" from God (BoC XXIV.7). Quinn offers that "the publication of the Book of Mormon signaled to the world that Joseph Smith was not simply a village mystic."209 His revelations, however, routinely state explicitly that it is not Smith but the gods who are speaking. ${ }^{210} \mathrm{He}$ is able to receive revelations frequently and apparently easily. Smith's position as chosen mediator provides for him an equivalent function to Paul's claim of divine possession. The claims work similarly within their respective cultures.

What is noteworthy here for Paul is that just as with the claim of having been called by the gods and the implicit claim of being from prophetic stock, the claim of possession (combined with allusions to spiritual journeys) can function to boost social status. ${ }^{211}$ Paul's claims in themselves argue for his communal leadership. They bolster his credentials as an authoritative mouthpiece for the will of God. For those in Galatia sympathetic to these types of claims, Paul must have looked like something pretty special. ${ }^{212}$

Paul continues presenting his case for why he should be heeded by saying that once he knew Christ was in him, he "did not confer with any human being"

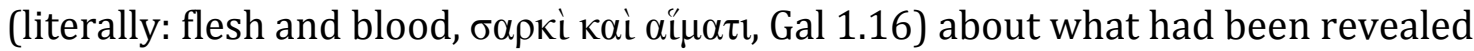
to him. Neither did he go to Jerusalem or converse with any others who had been

\footnotetext{
${ }^{209}$ Quinn, The Mormon Hierarchy: Origins of Power, 4.

${ }^{210}$ Smith at times referred to himself under the code name Enoch, e.g. D\&C 104 introduction. The person and lore of Enoch was the subject of much religious and occult speculation in Smith's era. See Quinn, Magic World View, 202-225.

211 Aune, Prophecy in Early Christianity, 20.

${ }^{212}$ Recall here the powerful notion Bruce Lincoln describes as “sentiment evocation,” Authority, 8-12.
} 
called, or had been disciples of Jesus (Gal 1.17), or had simply represented

themselves as such. Rather, his firsthand experience of Jesus—and what appears to be a statement claiming the perpetual mystical, immaterial residence of Jesus within him-is intended to appear more authoritative in the eyes of those receptive than could the claims of any other flesh-and-blood agent. It also helps Paul explain why his message contains differences from those of his opponents or of any others who represented themselves as apostles of the Jesus movement. Paul claims that unlike the other vendors of spiritual systems against whom he competes, his message is straight from the ultimate source. And yet, given the flesh and blood nature of humanity, and the constraints of the natural world, his proclamation can no more have originated in the heavens than in hades or a vacuum. As is the case with all of his competitors, Paul's message is rooted in his own idiosyncratic synthesis of culture and location. His rhetoric seeks to conceal the fact of mundane origins and place the source in the supernatural realm.

\section{Authority and Lineage}

Regarding Paul's claim of Hebrew lineage within a larger context, Michael Flower argues-in reference to the seer (mantis) of Greek antiquity-that it was not uncommon for a character of this general type to promote his authority by touting his lineage. He writes:

One important and traditional means of advertisement was to claim membership in a famous family of seers, especially a family that claimed descent from an eponymous ancestor who had acquired prophetic power either as a gift of a god or by some other supernatural means. This was important because mantic skill was seen as something that could be 
inherited; ${ }^{213}$ the original divine gift was still potent in a seer's descendants. The construction of a persona was not only important as a means of selfadvertisement and of the projection of an image. It was also a means whereby the seer simultaneously constructed an identity for himself, an identity that he internalized even as he projected it to others. ${ }^{214}$

One function of Paul's boasting of his Hebrew lineage and training was to project an image that would benefit him. The point to take from Flower's passage here is the suggestion that the "original divine gift" was "still potent in a seer's descendants," i.e. Paul as Abraham's seed inherently gave Paul a privileged position in accessing the divine. Paul promotes his privileged ancestral position and yet opens up its benefits to all who will believe his message of Christ crucified and in God's ancient promise to Abraham. So not only does Paul promote his own authority by reference to Abraham's lineage, he also renders his social formations more appealing by offering potent divine gifts to all of the archaic patriarch's metaphorical descendants. Those who hear the call are heirs of the promise (Gal 3.29). To traditionalist Jews in Asia Minor who did not hear the same call Paul heard, surely this revision of sacred tradition was enough to merit alienation if not antagonism. Joseph Smith hailed from a deep heritage of those who interacted with the supernatural-although this was not something of which he was known to boast. None of his progenitors received the renown that Smith did, but such a lineage helps to explain Smith's interests, orientation, training and proficiency at an early age..$^{215}$

\footnotetext{
${ }^{213}$ Note how the notion of inheriting gifts from one's ancestral lineage has as its parallel the notion of inheriting "sin" from one's forebears. Such was the case with Adam's "sin." See also evidence of the same concept attributed to Orphics in Plato's Republic, 3643-365a.

${ }^{214}$ Michael Attyah Flower, The Seer in Ancient Greece (Berkeley, CA: University of California Press, 2009), 242 (emphasis added).

${ }^{215}$ A recollection of an interview with Joseph Smith Sr. stated that "This Joseph Smith, Senior, we soon learned, from his own lips, was a firm believer in witchcraft and other supernatural things; and had
} 
While Smith did not boast of his lineage in the way that Paul did, he did claim that he was connected to, and prophesied of, by another Joseph, one from archaic tradition. An early BoM passage designates biblical Joseph "[who] was carried out of Egypt" as a progenitor of Lehi, the BoM patriarch. Lehi has a son who is also named Joseph and who is recognized as a "choice seer." BoM Joseph, the son of Lehi, prophecies of a future Joseph who will "write" for the purpose of "confounding false doctrines" and bringing a "knowledge of their fathers in the latter days." In the event the reader is unable to see Smith prophesying himself and the BoM in this passage, he drives the point home by writing that the latter day prophet is to be named Joseph after both the biblical prophet and his latter day earthly father, i.e. Joseph Smith Sr. (1830 BoM 66-7). Whereas Paul could capitalize on the notion that the Jews were a nation of prophets, Smith had to seek more imaginative solutions, such as an $e x$ eventu pseudepigraphical prophecy to promote his prophetic lineage and abilities.

\section{Called Before They Were Born, kata ta V grafa V}

I have been ordered to do this by God-in oracles, in dreams, in every way in which other divine apportionment orders a man to do anything.

$$
\text { -Socrates }{ }^{216}
$$

The mandates to preach, as proclaimed by both Paul and Smith, were based on models provided by archaic tradition. In Galatians 1.15 Paul frames himself

brought up his family in the same belief," Joseph Smith, Sr., "Interview with Fayette Lapham, 1830," as in EMD 1:457.

${ }^{216}$ Plato, Apology 33c. Divine callings and possession by gods or daemons were not features exclusive to the Israelite tradition - but broadly attested throughout the Mediterranean world in a bewildering variety of ways. Paul spoke and wrote in Greek. Greco Roman ideas influenced his thinking, forms of expression and even theology much more so than many traditionalists are willing to recognize. The citation from Plato above is simply to point out that a type of calling such as the one Paul claimed for himself was not out of the ordinary for revered figures in the cultural heritage that preceded and nourished the first century Greco Roman world of the Mediterranean region. 
within the call tradition of Jeremiah and Isaiah—which is to say Paul presents himself as a contemporary manifestation of his culture's archetypal prophets. ${ }^{217} \mathrm{He}$ has mined existing scripture to do so. Smith also presents himself as an archetypal prophet, 218 although beyond Old Testament generalities of prophethood, his text based justification resides in scriptures he has penned himself. Rather than looking to biblical models and framing himself as a parallel equivalent to the prophets of old as Paul did, he simply writes himself into his sacred history in such a way that he fulfills his own prophecy. ${ }^{219}$

Paul's rhetoric concerning his indifference to human judgment and the implicit directive to do as his private religious experience has mandated is yet another attempt to separate himself from his supply-side, entrepreneurial competitors in the spiritual marketplace. His rhetoric is intended to justify his mission in the eyes of those he seeks to persuade. Yet another tactic he employs in his arguments seeking legitimacy is the emulation of the call narratives associated with two of the most renowned of Hebrew prophets, Isaiah and Jeremiah. In imitating Hebrew scripture, Paul asserts that his calling did not simply arise in

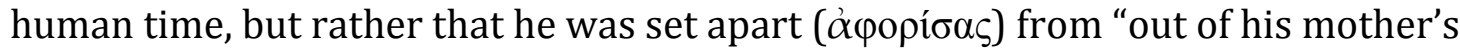

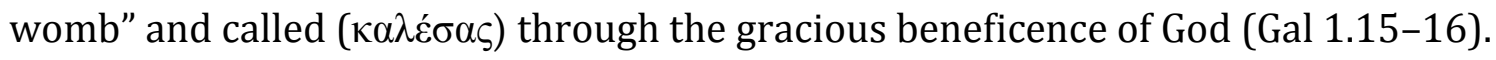

\footnotetext{
${ }^{217}$ Compare Isa 49.1 and Jer 1.5 and discussion below.

218 "Joseph disguised his identity to elude his enemies, he took the name of Enoch as pseudonym," Bushman, Rough Stone Rolling, 139. Smith reveals, "I say unto you, no one shall be appointed to receive commandments and revelations in this church, excepting my servant Joseph, for he receiveth them even as Moses" BoC XXX.2. As in the tradition of biblical Joseph, see 1830 BoM, 66-67. "Enoch and Moses are the most important non-Xn figures of divinization or angelic transformation" Segal, Paul the Convert, 43 for references to apocryphal lit. Bushman, Rough Stone Rolling, 133-142, esp. 139. See also intro to D\&C 78.

${ }^{219}$ e.g. 1830 BoM 66-68 discussed in the previous section.
} 
Those familiar with Hebrew scripture would have seen in the language of these claims close parallels to the divine commissions claimed by both Isaiah and Jeremiah. In the book of Isaiah, we find,

The LORD called me before I was born, while I was in my mother's womb he named me.... he [the LORD] says, "It is too light a thing that you should be my servant to raise up the tribes of Jacob and restore the survivors of Israel; I will give you as a light to the nations [Gentiles], that my salvation may reach to the end of the earth (Is 49.1, 6 emphasis added).

We find similar words and a similar sentiment attributed to God in Jeremiah.

Jeremiah's god says, “Before I formed you in the womb I knew you, and before you were born I consecrated you; I appointed you a prophet to the nations (goyim/Gentiles)" (Jer 1.5 emphasis added). ${ }^{220}$ Paul claims that God revealed his Son in him specifically so that he, just as did Isaiah and Jeremiah, could "proclaim" the message he has been proclaiming "among the Gentiles" (Gal 1.16), the very people of Paul's Galatian community. 221

In Israelite tradition, the prophets Isaiah and Jeremiah are hardly lightweights for emulation. ${ }^{222}$ In using the call narratives of these earlier prophets, Paul indicates not only the shaping influence that earlier generations of sacred texts have had on his own self understanding and orientation, but also that the shaping influence of these texts has reached broader circles. For Paul's claims to carry their

220 Stendahl, Paul Among Jews and Gentiles, illuminates these parallels between prophets within the context of Paul's “call” as opposed to the prevailing notion of his “conversion” 7-9.

${ }^{221}$ Jerome Murphy-O’Connor argues that the Galatian community must have been originally "pagan” as Paul could not have written "formerly you did not know God” (Gal 4.8) to Jews. Paul, 192. But see Gal 2.15, which may make use of "Jews" in the symbolic, called or chosen sense.

${ }^{222}$ So too, in the saga of Christianity, Paul is no lightweight for emulation. In a revelation to Smith, Cowdery and D. Whitmer, Smith writes, "For behold, . . . I speak unto you [Cowdery and D. Whitmer], even as unto Paul mine apostle, for you are called even with that same calling with which he was called," BoC XV.11. 
full weight here, he anticipates that his readers will be familiar with the sacred texts, traditions and prophets to which he refers. In other words Paul plays to the religious capital he assumes his hearers (readers) possess. A calling (from his mother's womb) and mission (a light to the gentiles) that imitated the respective commissions of two of Israel's greatest prophets places Paul squarely in an ancient and revered tradition.

Even though Paul refers to himself as an apostle, the language of his commission-modeled as it is on the commission of the great prophets of oldclaims that he too is a mediator of the divine word and will. Ashton writes that "in the very act of becoming an apostle, Paul undertook the responsibility for putting into effect God's plan for the world." 223 He is worthy of the prophetic mantle even if he does not claim the title of prophet explicitly. ${ }^{224}$ By any name, Paul presents himself as the chosen interpreter of God's word to humans on earth. Biblical tradition holds that the majority of Israel, to its own detriment, ignored the words of Jeremiah and Isaiah, a sentiment that helps Paul's case. In short, Paul presents himself in the prophetic mold and of divine sanction. He appropriates the mantle of Israel's greatest prophets, even if he limits his title to that of an apostle. Ashton concludes his chapter on "Paul the Prophet" by writing, "if we are to do justice to the riches of Paul's religious heritage we must be prepared to bestow on him the grand title of prophet that he was too modest to claim for himself."225

\footnotetext{
${ }^{223}$ Ashton, The Religion of Paul, 197.

${ }^{224}$ In the time period of Paul, prophecy had taken on additional meanings, one of which was the practice and phenomenon of glossalalia, as in 1 Cor 12-14. See Robert Wilson, Prophecy and Society in Ancient Israel (Philadelphia, PA: Fortress Press, 1980).

${ }^{225}$ Ashton, The Religion of Paul, 197.
} 


\section{IN SUM}

In his letters, Paul recites a litany of arguments aimed at boosting his authoritative status. These include: 1) claims of his divine calling; 2) authorization by a god powerful enough to raise the dead; 3) more zeal for the ways of his ancestors than the colleagues of his youth; 4) duty as a slave of Christ; 5) possession by Christ; and 6) a calling, "according to scripture," in the manner of those enjoyed by the prophets of Israelite tradition, specifically Jeremiah and Isaiah. Paul also asserts his indifference to human judgment at the same time he claims that he has human authorization from the pillars in Jerusalem. Paul argues for the credibility of his person, his proclamation, and his methods-which is to say that he makes a case for himself as the authoritative mouthpiece for an authoritative mode of discourse. Defending his status and reasserting his authority consumes the vast bulk of the first half of his letter to Galatia. Smith's promotion of his status, like Paul's, takes up significant space in his writings and, as in Paul's case, comes at the cost of others intimately involved with the movement.

As was the case with Paul, the analysis of Smith began with his claims of divine calling and sanction. Where Paul claimed his status outright, the Book of Mormon implicitly made a claim for Smith's status as a prophet by its very existence-which was bolstered explicitly through the prophecy of the appearance of a latter-day prophet named Joseph (1830 BoM Preface, and 66-7).

Paul writes of both his indifference to human authority and his possession of it. Smith doesn't directly acknowledge that humans doubt his authority, but his emphatic and repetitive assurances, within his revelations, of being straight from 
the mouths of the gods, serves to reinforce the divine source. Smith writes revelations in the voice of God that encourage his associates to stay involved in his church while at the same time limiting their access to the type of spiritual encounters and pronouncements that are the signs of his exclusive leadership authority. Followers such as Cowdery, Rigdon and Harris are even sent forth to promote Smith's authority. They make his claims for him.

For Joseph, the Book of Mormon functioned in a way that was critical to his ascent to power. In the process of his ascent, however, the discursive circles in which he operated shifted. Interest in the discovery of an ancient golden record was not limited to the treasure-digging crowd. The story of the golden plates allowed Smith to export his quick-thinking, entrepreneurial, performative skills from the world of folk magic and money digging to the related domain of religious faith and prophecy. In these related discursive circles, the ability to convince others that he was able to successfully navigate the supernatural order was essential. With the story of the golden plates, Smith shifted his interest from the value of finding gold (and the entertainment value of leading digs) to the value of unlocking hidden knowledge inscribed on gold (and the accompanying increase in status attached to revealing the divine word).

The shift is a subtle bit of alchemy. Smith did not transform base metal into gold, rather he produced knowledge from a rich imagination, born of a culture steeped in religious controversy, biblicized folk history and occult lore. The "alchemy" that gave rise to the BoM allowed Smith to compose a material book from a non-material source. While the precious metals claimed as the source of the book 
could not be viewed for verification, a printed BoM could be viewed as proof of his work.

In addition to bringing broad attention to Smith's claims and activities-the production of the Book of Mormon that signified his subtle shift in discursive fields also brought derision and viscerally charged antagonism. Smith had to compete in the domain of traditional Protestantism with traditionally minded religious folks. Smith's claims challenged the dear and deeply held convictions of many of his neighbors. Smith also threatened the power and status of traditional clergy enmeshed in their own traditions. These challenges and claims were made in a context where many early nineteenth century Americans were wrestling with the opportunities and challenges presented by the new economic and political landscape.

American cultural Historian Karen Halttunen writes that "[i]n sweeping away the privileges of the few, American democracy had opened the way to a universal scramble for distinction." 226 This scramble gave rise to a host of characters, both upstanding and unsavory, that capitalized on opportunities presented in an "anonymous world of strangers." 227 The biggest fear registered by those who confronted this new landscape was that of hypocrisy, was of one representing oneself as other than one was. This "sentimental demand for sincerity was a defensive strategy against the perceived dangers of placelessness in the open society and of anonymity." The other side of these threats were the enticing

\footnotetext{
${ }^{226}$ Karen Halttunen, Confidence Men and Painted Women: A Study of Middle-Class Culture in America, 1830-1870 (New Haven: Yale University Press, 1982), 191.

${ }^{227}$ Halttunen, Confidence Men, xvi.
} 
opportunities Smith offered to people from all walks of life who wanted to believe that God still spoke to humanity through his select messengers. Whereas the young Smith could be dismissed as a delusional, youthful, treasure seeker, the more mature Smith—acting as a prophet, seer and revelator in the pattern of prophets from biblical tradition-represented a real threat to the cherished and established practices of many Christians.

More than threatening any one individual or any single office of power, Smith was perceived as representing a threat to the social fabric of American society. To some, the process of "self-aggrandizement" 228 made possible by his prophetic claims seemed to be devoid of acceptable tethering to the customs and practices of his day. His behavior-although shaped by—was not limited by social convention of his times. $^{229}$

The threat perceived by Smith's antagonists was directly proportional to the ability of Smith to convince people of his claims. As exemplified by his ability to gain the faith and trust of Josiah Stowell (see chapter two), Smith could be convincing. With Smith's venture into the realm of religion however, the nature of the perceived threat he represented to society changed too. No longer was the danger limited to credulous treasure seekers of means, or neighborhood kids seeking entertainment and occult adventure. Just as is the case with many New Religious Movements in today's world, the threat to the traditionally minded Christian of this era went well beyond losing one's riches. The threat perceived in theological terms was that of an

\footnotetext{
${ }^{228}$ The quest for "social distinction" is a fundamental motivator of human action in the social theory of Pierre Bourdieu. See David Swartz, Culture and Power, 6, 66-67, 75.

${ }^{229}$ Halttunen, Confidence Men, 25.
} 
imposter offering enticing although false religion, another soul to be lost to evil, another rout for the devil to enter the world.

Socially, the threat was the potential loss of a friend or loved one to a new and exclusive community. To outsiders, the threat posed by people like Smith was an erosion in the confidence one human member of society had for another, the confidence that one was who she said she was. The discourse surrounding the 2012 Republican presidential nomination clearly indicates that many Americans still hold strong emotional reservations when it comes to members of the church Smith founded.

One intention of this analysis is to reframe anti-Mormon sentiment as an example of powerful groups demonizing new-comers that pose a threat to the status quo. Paul is fond of recounting all of the sufferings he endured as a slave to Christ. His abuse came as he was perceived as a threat to the social order. The same might be said of some of today's Mormons. As Paul and Smith both battled against their rivals in founding their movements, Christianity and Mormonism still battle against competitive interests-whether schismatic, satanic, or atheistic. Mormonism exhibits too many of the features of successful social formation, and is growing too rapidly, to escape commentary. As religious traditions have often boasted of their own growth as "proof" of their "truth," the growth of a competitor is deeply troubling. 


\section{Determined ${ }^{230}$ Social Actors}

In terms of generating power and status for himself, the Book of Mormon provided the perfect segue from scryer to prophet. While the most obvious motive behind the production of the Book of Mormon is financial relief from the uncertainty and impoverished conditions of Smith's life, other opportunities opened up that Smith could not have imagined in advance. I do not want to advance the idea that Smith saw starting a new religion as a money-making venture from the very first, rather that one opportunity led to another. ${ }^{231}$ Under the assumption that human agency lies somewhere between the antipodes of complete and non-contingent freedom and complete determinism (structural or supernatural), individuals have some role in determining where they end up in the human pecking order. According to Bourdieu, who is "willing to recognize degrees of awareness of the interested character" their "interest-oriented action does not assume conscious, rational calculation" as often "strategies are tacit and prereflective rather than conscious plans." 232

230 "Determined" is to simultaneously reflect both the cultural shaping these two could not escape, the opportunities their location provisioned, and the human drive and determination required to excel given the location in which they found themselves. Passive verb or adjective? Ambiguity not unintentional.

${ }^{231}$ Production of the Book of Mormon as a for profit venture is an easier case to make, albeit outside of the scope of this project. See, however, "Financial Implications," the last point of Table 3.4 above.

${ }^{232}$ Swartz, Culture and Power, 70. Swartz qualifies this by discussing the ambiguity in Bourdieu's work on this particular point. He writes,

Bourdieu makes no consistent distinction between conscious and unconscious forms of interest calculation. He clearly rejects a rational actor model of action and goes to great efforts to explain that the type of action he focuses on escapes the realm of conscious manipulation. He generally stresses the unwitting complicity of actors in pursuing their own vested interests. Culture and Power, 70.

Bourdieu's analysis regarding action outside of the realm of conscious manipulation, is given power and support through analogies to non-human life forms in the next chapter. 
Smith and Paul sought to lead rather than be led. Unless both are conceived of as entirely devoid of human autonomy, these men had some ability to determine how their lives would unfold. Their individual wills propelled them to make certain claims, engage in certain acts, and ultimately to achieve a power-laden social status within their own micro-cultures.

Smith's ability to convincingly interact with the supernatural realm facilitated his transition from seeing treasures buried in the ground to seeing God's plan for the salvation of humanity. ${ }^{233}$ In both cases, Smith was to lead the expeditions. In his pre Book of Mormon days, Smith's authority, to the extent he had any, would have been based on his personal comportment and mastery of scrying. ${ }^{234}$ This is to say that his authority rested on the intersection of his ability to convince people of his credibility and the pool of potential followers looking for such a leader. His mastery of various props such as the seer stone facilitated his ability to be convincing to those who found that type of stone consultation a legitimate means of obtaining esoteric information. While scryers where hardly reckoned as part of mainstream society, they could certainly achieve status and recognition within their own subculture. Producing a book like Smith's would augment that status and spill into the mainstream. Expanding from the quasi-fringe realm of the occult into more mainstream Christian culture provided Smith with a much larger pool of potential followers.

233 "Magic had served its purpose in his life. In a sense, it was a preparatory gospel," Bushman, Rough Stone Rolling, 54, see also 72-73, 131.

${ }^{234}$ Bushman writes that when compared to the early days of his vocation as a prophet, "Joseph was more popular as a money-digger” Rough Stone Rolling, 127. 
So too, Paul's move to open his religion to the gentiles represented a much larger market in which to build status and enjoy prestige. Although occluded by the expected rhetoric, Paul confesses his motivations when he writes to the Corinthians, "I do it all for the gospel, so that I may share in its blessings" (1 Cor 9.23). ${ }^{235}$

Understanding "gospel" as a euphemism for the social formation based upon an individual's divine message, Smith might concede the same thing.

${ }^{235}$ Also "I have often intended to come to you . . . in order that I may reap some harvest among you as I have among the rest of the Gentiles,” Rom 1.13, emphasis added. 


\section{CHAPTER FOUR}

\section{THE FUNCTION OF TRUE DECEPTION}

Art is the lie that makes us realize the truth

- Picasso $^{1}$

\section{SUMMARY, CONCLUSION, INTEGRATION}

But if through my falsehood ( $\psi \varepsilon v \dot{\sigma} \mu \alpha \tau \mathrm{L})$ God's truthfulness abounds to his glory, why am I still being condemned as a sinner??

-Paul, Romans 3.7

This study's focus on demonstrating the work texts are made to perform in advancing human power agendas is one critical component of a much larger puzzle of social dynamics. Building off of the assumption that human communities desire, generate and acquire meaning in their lives, the role of exceptionally gifted people: "charismatics" - those adept at reading and responding to the needs of othersgenerate the master narratives that provide relevance and purpose in the communal and personal lives of those persuaded by their presentations of reality. But what of these presentations?

The fabrication of texts that thoroughly integrated and leveraged preexisting texts and traditions served to construct reality and provide meaning for those receptive to the narrator's presentations. The process also generated

\footnotetext{
1 "Art as Individual Idea," in Richard Ellman and Charles Feidelson, Jr. eds. The Modern Tradition (New York: Oxford University Press, 1965), 25, as cited in Campbell, 13.

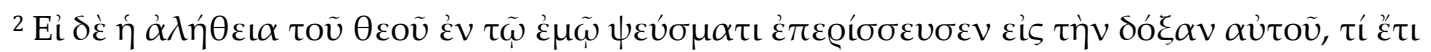

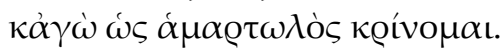


discursive authority for their authors. The attributed source of these texts as "outside of the human" worked to conceal their mundane origins. They were presented as if they were utterly unconnected to, and therefore immune from the influences of, contemporary history, culture and politics—as if they were "beyond the terrain in which interested and situated actors struggle over scarce resources" such as discursive authority and social power. ${ }^{3}$ When limited to the scope of natural phenomenon, such claims-no matter how powerful and how fervently believed by their promoters-misstate the actual source of the text. They present a contingent construal of reality as ultimate reality. These texts display their cultural origins and serve the power needs of their authors. They also raise serious questions about the role of deception in social formation and human life.

Reading these texts critically demonstrates that deception was an important part of the operating procedures of both Smith and Paul. Charismatic personalities are adept at deceiving. "Success at deception" is directly related to possession of the same social and emotional skill sets that make one a successful charismatic. ${ }^{4}$ Paul's letters respond to persistent accusations of deceitful tactics. Paul accepts "false motives" in the preachings of others so long as "Christ is proclaimed" (Phil 1.18), and even (rhetorically) challenges critics to argue why the use of "false things" is inappropriate so long as God's glory is promoted $!^{5}$

\footnotetext{
${ }^{3}$ Lincoln, Authority: Construction and Corrosion, 112.

${ }^{4}$ Riggio, Charisma Quotient, 43. "Skills in social expressivity and social control are critical to telling plausible lies .... Charismatic persons ... should be more successful than nonsocially skilled persons at deceiving," 51.

${ }^{5}$ See Rom 3.5-7, Table 4.3 below, and related discussion.
} 
Smith also had to refute perceptions of deception, sometimes in a preemptive manner that indicates deliberate forethought. Examples are considered in detail below. Smith's claims of finding, possessing and returning ancient golden plates - and the performances that induced a total of eleven "official" witnesses to "see" them—can only be described as deception ${ }^{6}$ from a naturalistic orientation. As accusations of deception are serious allegations in today's world, some contextualizing and framing are needed. Entrenched dispositions against any type of deception renders even-handed analysis challenging. The analysis that follows addresses deception as a natural means of promoting personal and communal survival.

\section{The Grace of Guile}

Scholar of religion and philosophy, Loyal D. Rue, grapples with the role of deception in human existence on a number of fronts highly relevant to the arguments advanced here. He argues that the "monstrous truth" of the "logically and empirically secure" reality of an unenchanted, aimless universe, "dead and void of meaning," has been countered historically in human society by various constructions of reality—all of which, to some degree or another, are based on some form of deception. For Rue, this is a good thing. Socially constructed notions of

\footnotetext{
${ }^{6}$ As examples of Smith's capacity to deceive, Vogel cites "his repeated public denial during the early 1840s of his own and other's plural marriages," and his attempts to minimize his involvement with treasure-seeking in his 1838 official history. Vogel continues,

For me, the most compelling evidence against unconscious fraud is the existence of the Book of Mormon plates themselves as an objective artifact which Joseph allowed his family and friends and even critics to handle while it was covered with a cloth or concealed in a box. The plates were either ancient or modern, xi.
}

See Vogel's Introduction in Joseph Smith, The Making of a Prophet, vii-xiii. 
reality are justifiable due to their ability to facilitate survival and bring meaning to human life. "Noble lies" are a staple of human existence, they mask the monstrous truth of the universe's cold, blind indifference. Rue argues that "without such lies, humanity cannot survive." 7

Rue's work sets about to illuminate the paradox of deception in a culture where deception is both necessary for survival and despised. ${ }^{8}$ As a preface to his examination of the contemporary existence, use and function of deception in nature and human affairs, Rue surveys three thousand years of deception in human history to highlight the ubiquity and depth of the phenomenon. His reasoning is to first differentiate the acts of deception themselves from the "more fundamental belief that one is harmed by being deceived." ${ }^{\prime 9}$ He then acknowledges the deep cultural prejudice against deception and duplicity in order to set these perspectives aside, and engage in a judgment-free examination of deception's role in the natural world and contemporary life. ${ }^{10}$

\footnotetext{
${ }^{7}$ Rue, Grace of Guile, 3-5.

8 Despite the disposition against it, Rue writes that "every human practices deception in a multitude of ways." Rue, Grace of Guile, 4. As an examples, the innocuous pleasantry "that new haircut really suits you," might be an outright lie. The statement can find justification in the benefits of a positive interaction between two people that results in improved spirits and higher self esteem. A brutally accurate aesthetic assessment that serves no other purpose than to "tell the truth" serves no positive social or individual function. Lucy Fontaine Werth and Jenny Flaherty write that some deceitful interactions occur via "commission, others by omission, and still others by both," "A Phenomenological Approach to Human Deception" in Robert W. Mitchell and Nicholas S. Thompson, editors, Deception: Perspectives on Human and Nonhuman Deceit (Albany, NY: State University of New York Press, 1986), 293-311,

${ }^{9}$ Rue, Grace of Guile, 6. "It is our profound fear of being deceived that gives moral substance to prohibitions against deceiving" 6 .

${ }^{10}$ To summarize his point, he writes, "only when we perceive the depth of the bias against deception in our cultural traditions will we be in a position to appreciate how forcefully recent studies of deception challenge our most deeply held beliefs," Rue, Grace of Guile, 81.
} 
Having established the entrenched cultural disposition against being deceived, Rue examines the role of deception from an evolutionary perspective where he argues for a "biological bias" at all levels of life that favors both traits for deceiving and traits for detecting deceit. ${ }^{11}$ In the non-human world, deceit is so fundamental to some creatures that it expresses itself in them morphologically. Natural selection provides shape, structure and coloration that capitalizes on deception as a survival strategy. Plants, insects and animals camouflage themselves to aid in luring prey, or as a self defense against predation. Deception also expresses itself in behavior. Apes, in the wild and in captivity, have been documented to both withhold and misrepresent information. ${ }^{12}$ One remarkable ant-eating bug, the acanthaspis petax, actually attaches the corpses of his initial victims to his body so that he can invade an ant colony undetected to feast at will. ${ }^{13}$ The ruse resembles the story of the Trojan Horse and raises the question of intentionality in the behaviors of a bug, a critter to which science does not attribute the ability of acting with conscious intentionality. ${ }^{14}$ Differentiating intentionality and nonintentionality is a "moral distinction" that has nothing to do with whether or not the underlying tactic is deceptive. ${ }^{15}$

\footnotetext{
${ }^{11}$ Rue, Grace of Guile, 4, 82-83.

12 H. Lyn Miles, "How Can I Tell a Lie? Apes, Language, and the Problem of Deception" in Mitchell and Thompson, Perspectives on Human and Nonhuman Deceit, 245-266, 245. In mammals, "relatively more instances of deception are behavioral" than morphological, although morphology and coloration still play a role. The polar bear is white to avoid detection by his prey while the snowshoe hare changes from white in the snowy winter to brown for the rest of the year to avoid the detection of predators, Rue, Grace of Guile, 121.

${ }^{13}$ Rue, Grace of Guile, 112, emphasis added.

${ }^{14}$ Rue asks, "Can one honestly dismiss the similarity of behavior on the grounds that to attribute deceit to a mere bug is to commit the fallacy of anthropomorphism?" Grace of Guile, 82.

15 Rue, Grace of Guile, 90.
} 
Human justification of deceit is contingent upon context. In the realm of sports, for example, intentional deceit is conducted by kids, amateurs and professionals. Cultural icons specifically engage in deceptive tactics for the purpose of defeating their opponents. Imagine a game of American football without a "playaction pass," a "screen" or a "draw" play. It is difficult to fathom a game where a receiver did not try to conceal the route he ran, and where a running back never tried to give the defender "the hip," a head-fake or a juke. ${ }^{16}$

Rue extends his argument beyond examples found in evolutionary biology to focus on behavioral and cultural implications of human existence on an individual and species level. Rue argues that if "the ultimate goal of humanity is to survive," it follows that "the penultimate goals of personal wholeness and social coherence are the conditions by which humans secure the promise of survival." ${ }^{17}$ He then illuminates the important role of deception in achieving personal well being and social cohesion.

The role of self-deception can not adequately be covered here. ${ }^{18}$ Maintaining self-esteem is critical to personal well being. To maintain self esteem it is not

${ }^{16}$ Baseball pitchers do not throw curveballs by accident. Former heavyweight boxing champion Floyd Patterson wrote of fellow boxer,

Jose Torres, my former stable mate and light heavyweight champion of the world ... gives the best definition of a feint I've ever heard: 'A feint is an outright lie. You make believe you're going to hit your opponent in one place, he covers the spot and you punch lands on the other side. A left hook off the jab is a classy lie.'

Ronald Mawby and Robert W. Mitchell, "Feints and Ruses: An Analysis of Deception in Sports" in Mitchell and Thompson, Perspectives on Human and Nonhuman Deceit, 313-322. It might be worth noting that all of these examples of deception in sports are non-verbal and intentional. With practice they become naturalized and even more effective.

${ }^{17}$ Rue, Grace of Guile, 181.

${ }^{18}$ Rue posits three distinct "motivational processes that are integrated into a functional unity" Grace of Guile, 129. These represent the basic human drives that compose a human being. One is the 
uncommon to engage in fantasy or to distort the recollection of past events to the

point that fiction is recalled as fact. ${ }^{19}$ Moreover, the "constructive benefits of fantasy

... can on occasion mitigate the disunifying effects of instrapsychic conflict." In

children, such fantasies can take the form of imaginary playmates that address

feelings of loneliness or take the blame for poor behavior. ${ }^{20}$

Self deception functions throughout one's life and includes the active belief in

the supernatural that serves as a "coping" strategy to address "threats to the self." 21

Rue argues that religious narratives function to mitigate threats to the self. He writes,

[I]t may be said that on the surface of things traditional beliefs about God are so obviously egocentric as to have all the transparency of infantile beliefs about an imaginary playmate. The only thing that speaks against the palpable falsehood of these beliefs is that they carry with them the awesome authority of socially defined reality. ${ }^{22}$

drive to satisfy curiosity (a cognitive system), another is the mechanisms that seek pleasure while avoiding pain (hedonic or affective system, 132) and the final seeks to preserve well being in the self, termed self-maintenance by Rue (the self-esteem motive, 136). It is the latter of these that is social in nature as it is based upon one's socialization and how well one fits the standards constructed and deemed acceptable by his or her surrounding social environment. Rue argues that the "self-esteem motivator" is the process which allows the individual to be able to affiliate with a social group 137. Given the disparate yet robust nature of these three motivational systems, they will rarely be in harmony. Personal wholeness suffers when these integrated systems are in conflict. Self-deception is a process engaged in by the individual "for the purpose of achieving intrapsychic harmony," 146. Rue distills his argument of achieving personal wholeness to the ability to maintain "a positive state of self-esteem," 147. The pressures and necessities of social life often result in humans presenting themselves as "other than they really are" which to Rue is, "in most cases[,] consistent with living up to socially instigated standards of performance," 153.

\footnotetext{
${ }^{19}$ Rue, Grace of Guile, 175.

${ }^{20}$ Rue, Grace of Guile, 174.

${ }^{21}$ Rue, Grace of Guile, 175.

22 Rue, Grace of Guile, 175-176. Rue continues,
}

this observation raises the very interesting dilemma of deciding who is furthest removed from reality: the atheist who rejects the socially defined realities of mainstream culture or the traditional religionist who fantasizes conversations with God and expects some form of subjective immortality. It is surely a grave mark against the promise of a culture whose most common options are as unattractive as these," 176. 
Self deception can be valuable strategy that helps humans to cope with the world in which they live. "Fantasy making deconstructs threats to the self by fabricating alternative realities."23 Author Jeremy Campbell makes a similar observation when he offers "people protect their well-being by keeping unwelcome facts a secret from themselves." 24 But self-deception has its limits and quickly runs into diminishing returns.

The last sentence in Rue's passage cited above ties in with the general theme of this dissertation. The "awesome authority" of these culturally accepted texts and their sacrosanct status as "scripture" facilitates belief in them and the continued immunity they enjoy from destabilizing insider critique. ${ }^{25}$ This immunity is by design. Power structures always protects their own interests. The ideology they espouse therefore will be one that legitimates their own privileged positions. ${ }^{26}$ To challenge central texts is to challenge the foundations of the ideologies made to stand on these texts, and as such challenges the status of incumbent power structures. Power interests protect themselves most efficiently when their privilege is “'seen as natural,' or not seen at all." 27 Such "naturalness" may be seen as a

\footnotetext{
${ }^{23}$ Rue, Grace of Guile, 176.

${ }^{24}$ Jeremy Campbell, The Liar's Tale: A History of Falsehood (New York: W. W. Norton \& Company, 2002), 189.

${ }^{25}$ Kassam, 34-38.

${ }^{26}$ An obvious example is the "guardians" of Plato's ideal state, position themselves at the top of society.

27 Terry Eagleton, Marxism and Literary Criticism (Berkeley: University of California Press, 1976), 4-5. One need not take the "Marxist" moniker attributed to the source of this critical perspective too narrowly. The modes of production so central to Marxist thought are not the only structures that facilitate power. Many other factors are at play, as this dissertation has endeavored to show. The point remains that "the function of power is to legitimate the power" of either the ruling class, or the cultural entrepreneur, 6 .
} 
sophisticated form of camouflage, one that conceals, and thus protects, some of the most important questions from being asked. 


\section{CUNNING INTELLIGENCE IN THE WORLDS OF PAUL AND SMITH}

There is, perhaps, no social ability that is more complex or more human, than the ability to deceive

- Ronald Riggio ${ }^{28}$

\section{Sanctioned Deception in the Ancient World}

Then, if it is appropriate for anyone to use falsehoods $(\psi \varepsilon v \text { } \delta \varepsilon \sigma \theta \alpha \mathrm{L})^{29}$ for the good of the city, because of the actions of either enemies or citizens, it is the rulers

-Plato, Republic 389b

Despite Rue's apology for the natural occurrence of deception-which is compelling and worthy of more consideration than space here allows-it is difficult for most of us acculturated in the modern era to accept deceptive tactics as something to be embraced or as a legitimate means of spreading good or fighting evil. ${ }^{30}$ At the same time we routinely engage in deceptive practices of our own, whether little white lies to make someone feel good, omissions of important behavior, or other conscious behaviors. "Considerate" lies are part of one's repertoire of good mannered behaviors. ${ }^{31}$

\footnotetext{
${ }^{28}$ Riggio, The Charisma Quotient, 42. In the epigraph, I take "more human" to mean a natural proclivity of humans rather than an attempt to isolate the domain of deception as an exclusively human endeavor.

${ }^{29}$ The Liddell Scott Greek-English Lexicon translates this term as "to cheat by lies, beguile, deceive, falsify."

30 There are of course exceptions to this. The military engages in deceptive tactics for a host of reasons. Misinformation provided by the Army or government during war time is a recognized tactic. The CIA's espionage ("intelligence gathering") is inherently deceptive. The demonization of recreational drug use and the exaggerations of its dangers are considered by many Americans a justifiable component in the country's "War on Drugs." See Rue, Grace of Guile, for a virtual catalogue of deception that ranges from the Presocratics to the evils of the mid-twentieth century, 6-81.

${ }^{31}$ Campbell, A History of Falsehood, 190.
} 
The attitude in antiquity differed from our own. There, cunning and deceptive intelligence were frequently practiced in the ancient Mediterranean and Near Eastern worlds. Examples of sanctioned if not celebrated deception abound in both the Greco Roman and Hebraic tradition. The epigraph from Plato at the top of this section explicitly sanctions a ruler's use of lying as a tool for "the good of the city" - which by this point in my argument should be recognized as code for "the good of the ruler" or the ruling class. ${ }^{32}$

While certainly not always recognized as a virtuous trait in all situations, neither cunning nor duplicity were unequivocally vile in Paul's era. ${ }^{33}$ Neither are they uniquely human. Cunning or wily intelligence, an "informed prudence" with an emphasis on "practical effectiveness," are traits encompassed by the term metis in the Greek world. ${ }^{34}$ "Wiley" and "practical" forms of intelligence are character traits that carry mostly laudable but also unsavory connotations. Cunning intelligence allows the weaker to defeat the stronger. Depending on location and context, some resourceful tactics are recognized as deception, fraud or even treachery. The victor and the defeated will differ in their characterizations of the cunning methods. Once again, taxonomy is not a neutral enterprise.

\footnotetext{
32 The interests of ruler and ruled need not be antagonistic. A healthy robust society generates that generates a surplus supplies ample taxes to the dominant class. Repressive, greedy regimes foster discontent and uprisings. No one gladly pays taxes to unjust leaders. Rulers who desire prosperous longevity need to insure their subjects are well taken care of. The relationship should be symbiotic, although the asymmetrical nature of any power relationship is prone to exploitation and abuse.

${ }^{33}$ See Marcel Detienne and Jean-Pierre Vernant, Cunning Intelligence in Greek Culture and Society, (Atlantic Highlands, New Jersey: Humanities Press Inc, 1978).

${ }^{34}$ Detienne and Vernant, 11-12.
} 
Examples of sanctioned if not heroic duplicity are common in antiquity. One well known example of the acanthaspis petax's technique is the story of the Trojan Horse from classical Greece. What Odysseus and his men offer as a ostensible gift to their opponents is little less than a treacherous ruse that leads to the sack of Troy and the slaughter of its citizens. For outright treachery, the story of the Trojan Horse is exceeded by the Rape of Dinah found in Genesis 34 where, to understate it considerably, "the sons of Jacob" answered overtures of peace and unity "deceitfully" (Gen 34.13). ${ }^{35}$

Another example of deception from Israelite tradition is biblical Jacob's theft of a blessing from his father Isaac. The blessing properly belonged to his older brother Esau. Jacob accomplished this theft by lying to—and thus deceiving—his geriatric father. Genesis 27 contains the salient passages: "Jacob said to his father 'I am Esau your first born.' ... He [Isaac] said 'Are you really my son Esau?' He [Jacob] answered, 'I am'." (Gen 27.19, 24). Can there be any doubt that this is intentional bald-faced deception? Jacob even took the additional deceptive measures of covering his arms with goat skins as his brother was a hairier man than he (Gen

\footnotetext{
35 Dinah's rapist and his family sought reconciliation with Dinah's family in accordance with the laws and practices of the times, see Ex 22.16-17; Deut 22.28-29. Reasonably contemporary Assyrian laws stipulate an equivalent procedure: "If a man forcibly seizes and rapes a maiden .... if he (the fornicator) has no wife, the fornicator shall give "triple" the silver as the value of the maiden to her father; her fornicator shall marry her; he shall not reject(?) her," Middle Assyrian Laws, 55, as in Roth, Law Collections from Mesopotamia and Asia Minor, 175. After Dinah's rape, the fornicator, Shechem the Hivite, (apparently intoxicated by his victim and in compliance with ancient law and custom) and his father offered their land up to Jacob and his sons. The parties agreed to unite their flocks, live among each other and "become one people" Gen 34.16. The Hivites even agreed to circumcision at the request of the sons of Jacob, Gen 34.15, 22. On the third day following the Hivites' circumcisions, "when they were still in pain," Gen 34.25, Dinah's brothers set upon the Hivites "unawares, and killed all the males. They killed Hamor and his son Shechem (the rapist) with the sword." Then "they plundered the city" and "took their flocks, ... herds, ... donkeys and whatever was in their field. All their wealth, all their little ones and their wives, all that was in the houses, they captured and made their prey" Gen. 35.25-29. The proposal to live in unity, which required circumcision, was nothing short of a ruse to facilitate the slaughter and plunder of a neighboring people.
} 
27.16). ${ }^{36}$ The scribal transmission that has preserved these ancient tales saw no need to scrub or re-present the brazenly deceptive components.

Deception allowed individuals to achieve their ultimate goals—even to the point of becoming cultural icons. Jacob's deception of his father earned him a prized blessing rightfully belonging to his own brother. The Genesis narrative depicts God rewarding Jacob's deception with fame and posterity. Jacob's barefaced lie facilitated no lesser honor than to become the eponymous patriarch of Israel. That the biblical writers and compilers allowed this tale of deception, and so many others, to remain in the hallowed text says something substantial about the era's attitude towards lying. The gods allow deception to accomplish their agendas.

Without delving further into the Classical tradition, suffice it to say that the use of treachery, lies, deceit—or rather wily intelligence, cunning propositions and the like-were often considered acceptable. In both examples given above deception proved effective and their perpetrators remain heroes. ${ }^{37}$ Numerous examples of duplicity and guile in both the ancient and modern world are documented in the works of Loyal Rue, Detienne and Vernant, Stephen Grenspan, ${ }^{38}$ Jeremy Campbell and others. The deceptive practices just noted are but two better

${ }^{36}$ When Isaac recognized he had been duped, he explains to Esau "Your brother came deceitfully, and he has taken away your blessing," Gen 27.35. Even if this account is not "history" in the strict sense, the biblical compilers and scribes found it a useful component of the greater tradition. The deception was not something to conceal out of embarrassment, rather it was an effective tactic for a vengeful people.

${ }^{37}$ The heroic status of Odysseus changes somewhat over the ages. The gilded tongue that allowed Odysseus to escape the Cyclops and ultimately defeat the Trojans earned him a special place as a deceiver in Dante's Inferno, see Canto 26.

${ }^{38}$ Stephen Greenspan, Annals of Gullibility: Why We Get Duped and How to Avoid It, (Westport, CT: Praeger Publishers, 2009). 
known examples of a wide-spread, simultaneously "feared and practiced"

phenomenon. ${ }^{39}$

Machiavelli wrote, "I hold it as most certain that men seldom if ever rise to great place from small beginnings without using fraud or force." 40 As a corollary to Bruce Lincoln's notion that force is but a "fig leaf" for legitimacy, ${ }^{41}$ I will offer that fraud is a complete cloak-such as the sheep's clothing that conceals the wolf (Matt 7.15). Bald-faced fraud serves to mystify one's motives and acts as the primary building blocks upon which an idiosyncratic reality can be constructed. In Machiavelli's and Plato's worlds deception is a mandatory instrument of leadership, an essential tool in the hegemon's kit.

\footnotetext{
${ }^{39}$ Loyal Rue, By the Grace of Guile, 4, 6-81.

${ }^{40}$ Niccolo Machiavelli, Discourses on the First Decade of Titus Livius, trans. Ninian Hill Thomas (Penn State Electronic Classics Series), 207. http://www2.hn.psu.edu/faculty/jmanis/machiavelli/Machiavelli-Discourses-Titus-Livius.pdf, (accessed 10 February, 2011). Like our religious subjects, Machiavelli justifies the principle and practice of deception by citing its use in ancient history. He writes that Xenophon's history of Cyrus teaches that "the Prince who would accomplish great things must have learned how to deceive." Machiavelli, 207-8. I was alerted to the passage via Rue's Grace of Guile, 245.

Corroborating this notion of Persians as prudent and skilled liars, Herodotus quotes Cyrus in saying, "an untruth must be spoken where need requires," Hdt. 3.72. This sentiment is not bound by time as Smith family neighbor Roswell Nichols recalled that Smith Sr. once "confessed that it was sometimes necessary for him to tell an honest lie, in order to live," Howe, Mormonism Unvailed, 257.

${ }^{41}$ Lincoln, Authority, 4, 6, 10.
} 


\section{Refuting Perceptions of Deception}

Deception occurs when a discrepancy between appearance and reality can be attributed in part to the causal influence of another organism. That is, an organism (A) whose agency contributes by design to the ignorance or delusion of another organism (B). Self-deception may be said to occur when A and B are the same organism.

Loyal Rue ${ }^{42}$

\section{Paul}

Was Paul any less of a hero than Odysseus? Was he any less important to the will of the gods than Jacob and his sons? Should he be considered exempt from deploying metis, as so many of his contemporaries did, because it does not sit well with modern sensibilities? Paul felt compelled to respond to accusations of underhanded dealings in over half of his known communities. To the Galatians, Paul wrote, "In what I am writing to you, before God, I do not lie!" (Gal 1.20).43 Such a statement would be superfluous if Paul had been beyond challenge or reproof,

42 Grace of Guile, 88. Stark and Bainbridge define deception as "any interaction strategy that intentionally leads other people to accept explanations which one privately rejects," Theory of Religion, 173, 329. Despite his compelling defense and framing of deception, some of Rue's terms are problematic. I have placed neutral alternatives in his citation in brackets. He writes,

In any identification of a deceptive interaction, at least three perceivers are involved. First, there is the [subscriber], whose vulnerability to deception [a compelling presentation of a posited reality] is exploited. Second, there is the deceiver [narrator], exploiting the vulnerability by designs that contribute to the ignorance or the delusion of the [subscriber]. And finally there is the observer [scholar/analyst] who presumes to attribute inadequacy [or perhaps trust in the narrator combined with a willingness to subscribe] to the [subscriber] and causal agency to the [narrator], Grace of Guile, 90.

The third party, the observer, is tasked with rendering evaluative judgment on the other two parties, yet the terms "deceiver" and "dupe" are not neutral and do no justice to the nuance of the interaction. I believe the term "narrator" is a fair one for the prophet or social leader as is "subscriber" suitable for the follower. They could be replaced by the terms "illuminator" and the "illuminated" depending on the observer's location, analytical assumptions and framework. It is not difficult to see an accomplished narrator subscribing to his own version of events, his own reality. Presumably this is the case with most prophets. To recognize the narrator as also a subscriber (Rue's self-deception) does not render his actions free from deception, but it does effect the judgment made upon the actions.

43 "I am speaking the truth in Christ, I am not lying; my conscience bears me witness in the Holy Spirit" (Rom 9.1); and "We refuse to practice cunning or to falsify God's word" (2 Cor 4.2). 
secure in his status of authority in the eyes of the Galatian community, comfortable with the plausibility of his message, and confident that his persuasive techniques would not be doubted. His claim to "not lie" would indeed be unneeded if itinerant preachers could be consistently counted on to speak with veracity or if Paul's reputation, based on his prior visitation, was that of an unsullied, compulsive truthteller.

Paul's repeated defense against accusations of dishonesty suggests that his communities find his tactics problematic. Mark Given writes that "Paul was accused by enemies both inside and outside his congregations of speaking and acting in a veiled, opportunistic, and not completely trustworthy manner." 44 Paul's repeated defense of himself and his tactics, as addressed below, presumes an accusation of unsavory behavior significant enough that it must be refuted or justified.

${ }^{44}$ Mark D. Given, Paul's True Rhetoric: Ambiguity, Cunning and Deception in Greece and Rome, Emory Studies in Early Christianity (Harrisburg, PA: Trinity Press International, 2001), 3. 


\section{Table $4.1^{45}$}

\section{Perceptions of Deception: Paul's Defense}

\section{Passage Analysis}

\section{Corinthians}

We are treated as impostors and yet are true ${ }^{46}$ (2 Cor 6.8)

We have wronged no one, we have corrupted no one, we have taken advantage of no one (2 Cor 7.2)

(God knows that)

I do not lie

(2 Cor 11:31)

I have been a fool, you forced me to it

(2 Cor 12.11)

Nevertheless since I was

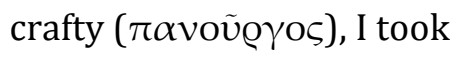
you in by deceit $(\delta o ́ \lambda \omega)^{47}(2$ Cor 12.16) 48 o Paul and his coworkers have not been accepted by everyone as credible proclaimers of God. Paul laments that he and his coworkers had been treated as "imposters," as false prophets, as wolves with transparent clothing.

o The passage acknowledges a spiritual marketplace and competing teachers-many of whom one must be wary of.

o The passage either responds to accusations that they have wronged, corrupted and taken advantage of members of the community - or, attempts to differentiate themselves from competitors, similar in appearance, who have "wronged and corrupted" their hearers.

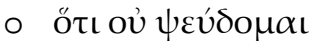

o While Paul projects confidence that the gods know he is telling the truth, clearly some of his hearers are not so sure.

o Paul here seems to acknowledge some sort of wrong doing on his own behalf-which he claims was his only option. As such, he explicitly blames his misdeed on the lack of options presented to him by his community.

o As Paul boasts of his craftiness and his deceit. One must assume that both he and his audience consider these tacticswithin certain boundaries-permissible.

o Paul reaffirms that craftiness is not only permissible, but an effective and persuasive tactic.

45 Not a comprehensive list.

46 The NEB reads, "we are the imposters who speak the truth, the unknown men who all men know," 2 Cor 6.8-9. The KJV reads: "By honour and dishonour, by evil report and good report: as deceivers, and yet true."

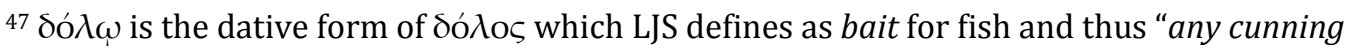
contrivance for deceiving or catching." It is through guile, the cunning contrivance of the wooden ruse

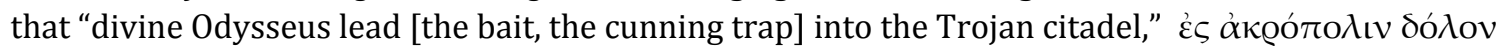

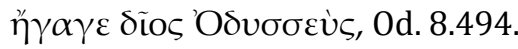

${ }^{48}$ In an attempt to polish Paul's image, editors of the NRSV have added some language to "clarify" (manufacture) what Paul must have said as opposed to what the textual record bears. 2 Corinthians 12.16 reveals that Paul believes he has been accused of being crafty. As opposed to allowing Paul to frankly admit that he has been crafty, the editors of the NRSV, insert the phrase "you say" here to alter the content to that of a false claim rather than a frank admission. The adjusted passage reads, "Nevertheless (you say) since I was crafty, I took you in by deceit." The King James Version takes no such liberties. It reads: "But be it so, I did not burden you: nevertheless, being crafty, I caught you with guile." 
If I come again, I will not be lenient-since you desire proof that Christ is speaking in me"

(2 Cor 13.2-3) o It appears here that not all of Paul's flock are convinced by his methods - in essence Paul's response is to a flock that has said to him: "prove it."

\section{Thessalonians}

Our appeal does not spring

from deceit or impure motives or trickery..."

(1 Thess 2.3)

You are witnesses, and God also, how pure, upright, and blameless our conduct was toward you believers." (1 Thes 2.10)

\section{Galatians}

In what I am writing to you, before God, I do not lie" (Gal 1.20)

But if, in our effort to be justified in Christ, we ourselves have been found to be sinners, is Christ then a servant of sin? Certainly not!" (Gal 2.17) o This passage indicates that Paul has either been accused of "impure motives and trickery" or that the community has confused him with competing preachers who frequently did exhibit "impure motives and trickery."

o Paul's reaffirms that message is based on some form of intrinsic truth which is not reliant upon, but is most convincingly presented with the tools of, "deceit" and "trickery," and driven by "impure motives"

o This passage seeks to set strait what Paul seems to apprehend as a misperception of he and his coworkers conduct. o It is hard to know whether Paul is simply doubted by his constituency, or has in fact been accused of lying to them. In other places (e.g. Gal 1.10; 1 Cor 4.3-4) he touts his indifference to human judgment as it is God who will judge him.

o Paul acknowledges that even if his human efforts have been construed as sinful, they are human tactics that should not taint his patron gods. Paul also brushes off any condemnation of his conversion techniques under the notion that the "ends" justify the persuasive "means" of conversion-even if these means appear "sinful."

The passages suggest that even in an era when many forms of deception are considered acceptable, Paul's techniques seem to be pushing the boundaries of tolerable behavior. ${ }^{49}$ Defending oneself against claims of deceit are standard fare for those who traffic in cosmologies and systems of salvation and are part of the

${ }^{49}$ Pushing the boundaries of acceptable behavior is one way of generating the right about of "tension" (as discussed in Chapter 3) for one's community in the face of larger society. 
process of ascending to authoritative status. Smith's own words exemplify this type

of defense quite well. He writes,

Owing to the many reports which have been put in circulation by evildisposed and designing persons, in relation to the rise and progress of the Church of Jesus Christ of Latter-day Saints, all of which have been designed by the authors thereof to militate against its character as a Church and its progress in the world-I have been induced to write this history, to disabuse the public mind, and put all inquirers after truth in possession of the facts, as they have transpired, in relation both to myself and the Church, so far as I have such facts in my possession. ${ }^{50}$

The construction of reality is not policed by authorities like the IRS or building inspectors in the way that tax returns and the construction of new homes are in the modern era. ${ }^{51}$ It is not just matters of politics and religion that lack policing, but even in the telling of history. ${ }^{52}$ As not everyone lives under a singular sacred-canopy, or in constructed world that is universally embraced. Justification of actions - such as recounting the past or setting the record "straight" - is an attempt

50 "Extracts from the History of Joseph Smith, The Prophet," 2.1.

51 This metaphor runs into some problems with respect to the source of the "policing." In society at large, enforcement is not solely the function of a dedicated cadre of enforcers, but is done at the social or communal level and even frequently internally. A sharp glance, critical words, dismissal of one's ideas all can have the force of reinforcing-if not policing-communal notions. See brief section on "Discourse Internalized" above in Chapter One.

52 Paul's near contemporary Josephus assures his readers with the concluding words of his history of the Jewish Wars that, "as to its truth, I should not hesitate to declare without fear of contradiction that from the first word to the last I have aimed at nothing else" (JW 7.11.5). Josephus has a location and an agenda to defend and no doubt received criticism for his actions and perspectives before his histories were even published. Indeed, the version of history he constructs serves to justify his own treacherous actions and endear himself and his Jewish heritage to his Roman patrons. Josephus may indeed believe that his history is an accurate representation of the facts-one would expect that it depicts reality as he understands it, or rather how he wants it to be understood-but his closing assertion of "truth" suggests that he is aware that not everyone will agree with his version of events. Ashton writes of Josephus, "the human capacity for self-delusion is virtually limitless; [and as such] there is no reason to doubt that by the time he came to write the story of the war he had managed to persuade himself that he was telling the truth," Religion of Paul, 188. 
to shore-up and promote a construction of reality as best fits the needs of one's agenda. ${ }^{53}$

\section{Smith}

Smith also had to defend himself against accusations of deception, even well before the publication of the Book of Mormon. ${ }^{54}$ Anticipating criticisms, the literary character Nephi, the protagonist of the early chapters of the Book of Mormon, defends his sacred history from the very first page. He writes, "I know that the record which I make, to be true; and I make it with mine own hand; and I make it according to my knowledge" (1830 BoM 5). As such, Smith's literary creation soberly attests to the truth of the fiction of which he is a part. This is a savvy discursive technique 55 typical of pseudepigraphy. Smith, like Paul, feels the need to assure his potentially skeptical readers that what he tells them is beyond reproach. Sensing (correctly) that his own story and conviction would be insufficient, Smith enlisted his earliest followers to attest to the veracity of the plates. The Eight

\footnotetext{
${ }^{53}$ Greek "Father of History," Thucydides clearly shows the process of constructing reality when he writes,

In this history I have made use of set speeches some of which were delivered just before and others during the war. I have found it difficult to remember the precise words used in the speeches which I listened to myself and my various informants have experienced the same difficulty; so my method has been, while keeping as closely as possible to the general sense of the words that were actually used, to make speakers say what, in my opinion, was called for by each situation, (emphasis added) Thuc. 1.22.

54 The most obvious example would center on the accusations of his employer Stowell's nephew that resulted in his 1826 trial as a "glass looker" and a "disorderly person." Philastus Hurlbut, while an unfriendly compiler of witnesses, collected an impressive array of testimonies regarding the behavior of Smith and his family, Mormonism Unvailed: or, a Faithful Account of that Singular Imposition and Delusion, from its Rise to the Present Time. With Sketches of the Characters of its Propagators, and a Full Detail of the Manner in which the Famous Golden Bible was Brought before the World, (Painesville, OH: E. D. Howe, 1834).

55 Perhaps "art form" is a better term. Art can misstate the literal truth at the same time it provokes and reveals deeper and more profound truths. See Campbell, A History of Falsehood, 14-15.
} 
Witnesses to the Book of Mormon state at the conclusion of their testimony "we give our names unto the world, to witness unto the world that which we have seen: and we lie not, God bearing witness of it."56 What is omitted is that the evidence "seen" was with the "spiritual eye." 57 In other words the golden source text was not "seen" in the most basic, visual, sense of the word. ${ }^{58}$ Since the purpose of the testimony of the Three Witnesses was to attest to the material nature of the plates, failing to disclose and qualify the immaterial ("spiritual") nature of their perceptions is inherently deceptive..$^{59}$

${ }^{56}$ Emphasis added. See the final page of the 1830 Book of Mormon, or the beginning pages of any modern version.

57 This "sight" was with the "spiritual eye," not the natural eye. See Palmer, Insider's View, 175213. Smith referred to the powerful insight delivered through the "spiritual eye" frequently. In writing of theophanies experienced by Moses, Smith has Moses qualify "But now mine own eyes have beheld God; but not my natural, but my spiritual eyes, for my natural eyes could not have beheld," and; "And it came to pass, as the voice was still speaking, Moses cast his eyes and beheld the earth ... discerning it by the spirit of God" (i.e. not visually), Book of Moses, 1.11, 27. David Whitmer referred to his witness experience as one where he "beh[e]ld the vision of the Angel" (emphasis added), An Address to All Believers, 32. Many of the eleven witnesses of Smith's plates (Whitmer's David, John and Jacob, Hiram Page, and Martin Harris), in addition to Lucy and William Smith, were prone to accept such stories and see such visions as they later became followers of James J. Strang, who produced his own book that claimed ancient plates as a source, Palmer, Insider's View, 208-212.

58 John H. Gilbert Memorandum, 8 September 1892, in Vogel, EMD 2.548. See also EMD, 2.270, 385, 291 (speech of recently excommunicated Martin Harris "never saw the plates"). Palmer, 175-76, 79, and EMD 3.22 Disillusioned Mormonite Ezra Booth wrote that "Smith does not pretend that he sees them with his natural, but with his spiritual eyes; and he says he can see them as well with his eyes shut as with them open," as in Howe, Mormonism Unvailed, 186.

${ }^{59}$ Part of the testimony reads:

And we also testify that we have seeen [sic] the engravings which are upon the plates; and they have been shewn unto us by the power of God, and not of man. And we declare with words of soberness, that an angel of God came down from heaven, and he brought and laid before our eyes, that we beheld and saw the plates, and the engravings thereon; and we know that it is by the grace of God the Father, and our Lord Jesus Christ, that we beheld and bear record that these things are true (emphasis added).

A declaration with "words of soberness" implies not just the gravity of the situation, but an attempt to distance the perceptions of the event from the realm of fantasy. "Soberness" implies natural, not supernatural perception. While the testimony insists that the plates where beheld "by the grace of God the Father," it fails to clarify that such grace appeared in a visionary, as opposed to a material, form. In my view, such intentional declarations and omissions qualify as deceptive. 
Table 4.2

Smith: Extrapolated Attitude Toward Deception

Passage

Analysis

\section{Book of Commandments}

"It is not written, that there shall be no end to this torment; but it is written endless torment. Again, it is written eternal damnation: wherefore it is more express than other scriptures, that it might work upon the hearts of the children of men, altogether for my name's glory ... I am endless, and the punishment which is given from my hand, is endless punishment, for endless is my name," BoC 8, 11,12.

[W]o be unto him that lieth to deceive, because he supposeth that another lieth to deceive, for such are not exempt from the justice of God. Now, behold they have altered those words, because [S]atan saith unto them, ["H]e hath deceived you, ["] ... you shall not translate again those words which have gone forth out of your hands; . . . for behold, if you should bring forth the same words, they would say that you have lied; that you have pretended to translate. .. BoC IX.5 = D\&C 10.28 . o In this passage, Smith seeks to reassure Universalistminded Harris that damnation is not endless. Rather "endless" is one of the names of God such that "endless" refers to the name of the punishment rather than the duration of the punishment. Endless punishment" is the same as "God's punishment"

o In an implicit nod to the efficacy of deception, Smith attributes the cunning play on words to the gods for the purpose of "work[ing] upon the hearts of the children of men." Such a sentiment reflects the attitude of Romans 3.7.

0 The play on words attributed to the deity resembles Smith's play on words that helped him evade the toll at the gate near Ithaca, Ingersol in Howe, 235.

o This revelation helps transition Smith's focus to a new, but related, writing project. He is aware that he cannot precisely replicate the first 116 pages that he has written, and that by attempting to do he faces the potential of being exposed by those who stole and possess his initial manuscript.

o Smith reframes the situation and avoids the burden of proof that retranslating represents.

o In condemning others as liars, motivated by Satan to "deceive because [they] supposeth that" he [Smith] has lied to deceive, Smith tips his hand to his own fears and paranoia concerning the exposure of his writing project.

\section{Book of Mormon}

"The spirit said unto me again, ["]slay him,["] for the Lord hath delivered him into thy hands. Behold the Lord slayeth the wicked to bring forth his righteous purposes: It is better that one man should perish, than that a nation should dwindle and perish in unbelief, 1830 BoM $12=1$ Nephi 4.13. o A clear example of means of a questionable nature being exonerated by the ends they facilitate.

o While the "spirit" did not say "deceive him," he did adamantly recommend another anti-social act under the justification that the gods are not bound by the same schemas of justice as are humans.

Those who construct and promote new thought systems-and even those

who hold fast to mainstream ideologies-will find situations where they must defend their tribal beliefs against those who operate based on a different host of assumptions and under a different construction of reality. When one claims that she 
tells the "truth," the surface expression of conviction should not always signal an implicit acknowledgement of, or attempt to mask, deceit. Rather it simply indicates that the proclaimer is aware that the construal of truth she promotes may not sound persuasive to all of those who hear it. Paul's assertion that he "does not lie" is made in hopes that those who hear him will eventually realize that in fact he is telling the truth—albeit perhaps not in a form that is immediately recognizable. ${ }^{60}$

\section{Epistemology and Evidence}

Men think epilepsy divine, merely because they do not understand it. But if they called everything divine which they do not understand, why, there would be no end of divine things

-Hippocrates 61

For the wisdom of this world is foolishness with God

-Paul, 1 Cor 3.19

I work not among the children of men, save it be according to their faith

-Smith, BoM $111^{62}$

One's epistemological orientation determines what constitutes acceptable evidence, including the type of data to be embraced as plausible or rejected as specious. While supernaturalists and spiritualists allow private, emotionally laden experiences to qualify as acceptable and compelling verification of supernatural

${ }^{60}$ E.g. "For the message about the cross is foolishness to those who are perishing, but to us who are being saved it is the power of God," 1 Cor 1.18. "And even if our gospel is veiled, it is veiled to those who are perishing," 2 Cor 4.3.

${ }^{61}$ Citation found in Carl Sagan, The Demon-Haunted World: Science as a Candle in the Dark (New York: Ballantine Books, 1996), 8.

62 Nephi 27.23. 
phenomenon, no such latitude is acceptable in the minds of naturalists. ${ }^{63}$ Paul is well aware of the implications of one embracing the right epistemic regime. He challenges the epistemological orientation of his Galatian community when he writes,

Who has bewitched you? It was before your eyes that Jesus Christ was publically exhibited as crucified! The only thing I want to learn from you is this: Did you grasp the Spirit by works of the law or by believing what you have heard (Gal 3.1-2). ${ }^{64}$

This passage reminds its readers that reception of the spirit is not a passive endeavor. It requires the some form of action on the part of the spiritual aspirant. Paul argues for the efficacy of actively "believing what you have heard" as opposed to the-presumably perfunctory and mechanical-performance of "works of the law" as the proper way to apprehend the spirit.

In a similar fashion, although in opposition to a different, and competing, epistemic framework ("Wisdom" discourse instead of adherence to ancestral Law), Paul challenges his followers in Corinth, "has not God made foolish the wisdom of the world?" (1 Cor 1.20). Paul continues to promote the requisite epistemic regime when he writes:

${ }^{63}$ Again, this is not to suggest that "spiritual experiences" do not take place, rather it is to reassert the perspective that these powerful events are explainable in naturalistic terms. The experience itself is not disputed, only the interpretation of the impetus of the experience and the weight it

${ }^{64}$ The translation is from the NRSV with two alterations. I take $\dot{\varepsilon} \lambda \dot{\alpha} \beta \varepsilon \tau \varepsilon(\lambda \alpha \mu \beta \alpha \dot{\alpha} \nu \omega)$ to mean "grasp" or "seize" which can represent either a physical taking, or to "apprehend with the mind, understand." My point in pushing this literal translation is that "reception" of the spirit is not as passive of an endeavor as the NRSV's translators might want to think. "Apprehension" of the spirit conveys the active human component. The Greek $\dot{\lambda} \lambda \dot{\alpha} \beta \varepsilon \tau \varepsilon$ reflects the more active sense of human apprehension versus the NRSV's passive "receive." The NRSV added "by doing" between "Spirit" and "by works" which does not appear in the Greek. 
My speech and my proclamation were not with plausible words of wisdom, but with a demonstration of the Spirit and of power, ${ }^{65}$ so that your faith might rest not on human wisdom but on the power of God (1 Cor 2.4-5, emphasis added).

Paul is adamant that grasping his message requires eschewing competing methods of knowing. "Human" or "plausible words of wisdom" fall short of the emotional confirmation provided by the Spirit. Confirming the importance of embracing the right epistemic regime, Paul continues,

Those who are unspiritual do not receive the gifts of God's Spirit, for they are foolishness to them, and they are unable to understand them because they are spiritually discerned. Those who are spiritual discern all things, and they are themselves subject to no one else's scrutiny (1 Cor 2.14-15).

Obtaining "true knowledge" and being able to decipher the "Wisdom of God" from the "wisdom of the world" require that one embrace an emotionally driven, "spiritual," epistemic regime. One can "feel" what is right and true rather than burden their cognitive capacity with word games that while "plausible" to the world of men are pure foolishness to God (1 Cor 3.19). In the epistemic regime that Paul promotes, conviction relies upon "believing what you have heard" followed by acquiescing to, experiencing and trusting the powerful emotional events conjured by holy men. These potent experiences are construed as evidence that the "power of God" is not perceived through "human wisdom" (1 Cor 2.5).66 Within the discursive circles of religious belief and witnessing, any attempt to understand the

\footnotetext{
${ }^{65}$ Compare: "our message of the gospel came to you not in word only, but also in power and in the Holy Spirit and with full conviction," 1 Thess 1.5 .

${ }^{66}$ John Ashton writes,

[T] he one who supplies the spirit (an odd expression, we might think) is either God, or Christ or, as I am inclined to think, Paul himself. In any case Paul is perfectly prepared to admit that the most obvious indication of the presence of spirit is the working of miracles: there could be no more striking proof of power, The Religion of Paul, 202.
} 
sociological or social-psychological underpinnings of these experiences is corrosive to their efficacy. Naturalistic, "plausible" explanations are not the favored epistemic regime of the supernatural. They are, quite simply, "foolishness to God."

The generation of emotional experiences that act as powerful evidence for certain theological propositions is not inherently deceptive. The causes of this type of experience are ordinary and natural in human life. That these events are construed as "proof" of the divine makes sense within the relevant discursive circle and serves a functional, epistemological purpose.

Willfully ignoring the naturalistic causes known to engender such potent emotional events, in today's world, may qualify as a form of self-deception. Within the religious marketplace, enjoying this innocuous type of self-deception allows the individual to fully participate in his or her community, and can bring rich personal and social rewards. ${ }^{67}$

As in the epigraph to this section, deception relies on more than one individual. Deception is at play when the deceived individual refuses to believe that they are being deceived, even if it is quite apparent. Ignoring deceit is one way of coping with being deceived. "Reality" is otherwise too difficult to bear. The human

${ }^{67}$ These rewards are not delusional. Rather, they function as a survival strategy. "Skeptic" Michael Shermer writes,

There is psychological evidence that magical thinking reduces anxiety in uncertain environments, medical evidence that prayer, meditation, and worship may lead to greater physical and mental health, and anthropological evidence that magicians, shamans, and the kings who use them have more power and win more copulations, thus spreading their genes for magical thinking. Why People Believe Weird Things, Revised and Expanded (New York: Holt Paperbacks, 2002), xxiv.

Baginni writes, "personal convictions cannot make for good evidence. People have many deep emotional needs that can contribute to a willingness to believe which in normal circumstances might be considered gullibility, but ... really deserves a more sympathetic name." Atheism, 19. 
interaction that leads to the formation of the charismatic bond often includes deception on both sides of the relationship. Paul confessed that deception that brings glory to the gods is perfectly acceptable. On the other side of the relationship, many who are deceived participate in their own self deception. Psychologists Werth and Flaherty write "the recipient's self-deception naturally aided her donor ${ }^{68}$ to deceive." ${ }^{69}$ Partisans who follow holy men, prophets, cult leaders or even abusive spouses frequently find that deceiving themselves of reality is more comfortable that grasping the reality of their being deceived.

The above contextualization of the use, efficacy, and justification of deception and guile is my attempt to appropriately frame what might otherwise sound like judgment-ridden moralizing against the tactics of Paul and Smith. Not only has Rue's arguments illuminated the essential role of deception in individual and communal life, but Paul operated in a world where cunning deceit was defensible and appropriate in many circumstances. Paul even acknowledges that irrespective of the methods or motivations behind his competitors' proclamations of Christ, they are acceptable to him as long as Christ is proclaimed..$^{70}$ In short, the ends serve to

\footnotetext{
${ }^{68}$ I.e. her deceiver.

${ }^{69}$ Werth and Flaherty, "A Phenomenological Approach to Human Deception," 297. The context of this research is within personal relationships where one partner is deceiving the other. The deceived participate in their own deception as the reality of confronting their partners as deceivers is more difficult that living with suppressed suspicions of dishonesty. I believe the same argument is highly plausible in high-stakes social affiliations. To acknowledge that the world view perpetuated by the community of believers may crumble if analyzed without a "suspension of disbelief" (i.e. from a naturalistic perspective), is the first step towards the potential of painful collapse of one's sacred canopy and a destabilization of all of the personal relationships under it. Pain is avoided if destabilizing naturalistic suspicions are ignored. There are social benefits, and dangers, to this type of self-deception.

70 Paul writes to his flock in Philippi that he "rejoice[s]" when "Christ is proclaimed ... whether

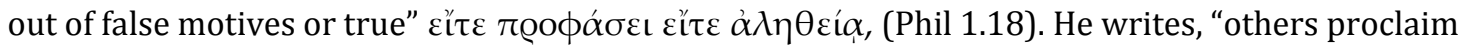
Christ out of selfish ambition, not sincerely ... and in that I rejoice" Phil 1.17-18.
} 
justify the means even if the motivations are self-serving. Deception is an essential arrow in a prophet's tactical quiver.

The case to be made for Paul's duplicity has deeper roots and implications than those that may arise from simple linguistic misunderstandings. ${ }^{71}$ Moreover Paul explicitly challenges his contemporary readers-and all of us in today's world(!)— to argue why deception that serves the purpose of bringing glory to God should be considered sinful. To the Romans, Paul wrote,

But if our injustice serves to confirm the justice of God, what should we say? That God is unjust to inflict wrath on us? (I speak in a human way.) By no means! For then how could God judge the world? But if through my falsehood $(\psi \varepsilon \dot{\sigma} \sigma \mu \alpha \tau \iota)^{72}$ God's truthfulness abounds to his glory, why am I still being condemned as a sinner?" (Rom 3.5-7, emphasis added).

This passage highlights a couple of important points and raises an important central question that will be addressed below. First, Paul freely admits that he engages in "falsehood" (KJV: "lies," $\psi \varepsilon v ́ \sigma \mu \alpha \tau \iota / p s e u s m a t i$, lit: "false things") in order to bring people to God. Acknowledging the use of falsehoods is an important disclosure that underscores Paul's strategic duplicity. ${ }^{73}$ Paul argues that $\psi \varepsilon v ́ \sigma \mu \alpha \tau$ เ should not be seen as grounds for condemnation, rather "false things" are

${ }^{71}$ The likelihood of misunderstanding is exacerbated by the use of spiritual interpretations such as the definition of circumcision and the criteria for determining "who is a Jew" in Roman's 2.28-29. "A person is not a Jew who is one outwardly, nor is circumcision something external, rather a person is a Jew who is one inwardly, and real circumcision is a matter of the heart-it is spiritual and not literal, Rom 2.28-29.

72 Note that the Greek "pseu" is the root of the modern English prefix pseudo. The Greek is literally "false things." Pseudei, $\psi \varepsilon v \delta \delta \varepsilon \iota$, is Paul's term for "lie" used in Romans 1.25 and analyzed briefly below.

${ }^{73}$ In his correspondence with the Corinthians Paul has denounced the use of $\psi \varepsilon v$ $\sigma \mu \alpha \tau \iota$ by

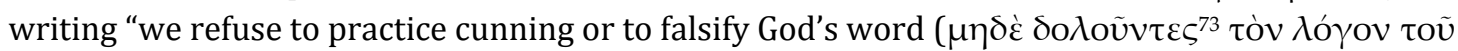
$\theta \varepsilon \delta \tilde{v}) ;$ but by the open statement of the truth we commend ourselves to the conscience of everyone in the sight of God" (2 Cor 4.2). Such a statement itself is deceptive as it clearly contradicts his challenge to the Romans (Rom 3.5-7). 
praiseworthy - which is to say that the deception in which Paul engages is a just and viable means of bringing glory, in the form of converts, to God. Paul's false things indicate God's truthfulness (note the irony here) and should be celebrated just as he has acknowledged the laudable ends that come from his competitors' dubious means in Phillipi (Phil 1.18). The ends apparently fully justify the means. Paul provides a general rationalization for his actions by arguing that God "will repay according to each one's deeds: to those who by patiently doing good seek for glory and honor and immortality, he will give eternal life" (Rom 2.6-7). In the cosmic battle of good versus evil, Paul justifies his own deceit as a tactic that God will reward.

\section{Deceiving Demons Must Be Deceived}

New Testament and religious studies scholar Mark Given argues that Paul's world is one where the majority of humanity is deceived by evil forces. ${ }^{74}$ When Paul writes to the Corinthians "the god of this world has blinded the minds of the unbelievers, to keep them from seeing the light of the gospel of the glory of Christ" (2 Cor 4.4), he acknowledges that sinister supernatural forces are actively engaged in their own deceptive practices. Paul argues that the minds of many are veiled (2 Cor $3.15,18 ; 4.3$ ) and it is his mission to remove that veil even if what he preaches initially seems equally veiled. ${ }^{75}$ To the Galatians he challenges those who have been bewitched (Gal 3.1); he writes of the reality of being "enslaved to the elemental

\footnotetext{
${ }^{74}$ Paul's True Rhetoric, 23, 31-34.

75 "And even if our gospel is veiled, it is veiled to those who are perishing" 2 Cor 4.3. Note here that the Greek word for "to veil" $\kappa \alpha \lambda u ́ \pi \tau \omega /$ kalupto is the root word of "reveal," literally "unveiling," apo- kalupto - or - apocalypse.
} 
spirits of the world," and, that "[f]ormerly, when you did not know God, you were enslaved to beings that by nature are not gods (Gal 4.3, 8, 9). From Paul's perspective, the life of flesh and blood is a life of deception. Various supernatural forces compete for allegiance via tactics of deception, which is to say various representatives of the gods compete for followers via a number of tactics, including deception. The god of this age has blinded the minds of unbelievers and confused the minds of many ( $c f 2$ Cor 4.2). The "rulers of the world" (arcwn, arxonteV, pl.) have constructed a competing and false master narrative to consciously deceive for their own malignant purposes. This sinister master narrative will include all arguments and realitites that are not Paul's (e.g. Gal 1.7-9). The language Paul uses in his letters reveals that he and his competitors, both human and supernatural, are engaged in a similar mission, as his word choices suggest in the table below. Only perspective and partisanship determines the difference between good and evil designs.

Paul believes he must shake people out of the grasp of error and bring them into a new reality. To counter the intentional deception of Satan and his minions, Paul believes that it is perfectly acceptable to deceive the deceived in order to bring them to God. This is a cosmic struggle of good versus evil and the stakes could not be higher. This contextualized explanation of Paul's behavior-in light of the tactics of spiritual warfare he is up against—fully allows deception to further the conversion process. ${ }^{76}$ Given also argues that because of Paul's rhetorical skills, his

\footnotetext{
${ }^{76}$ Given, Paul's True Rhetoric, 33-4; 83-137.
} 
letters are "designed to be heard differently by different actors in the audience, some more and some less deceived."77

Table 4.3

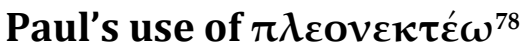

\section{$\pi \lambda \varepsilon \operatorname{cov} \varepsilon \tau \varepsilon \dot{\varepsilon} \omega$ as describing Satan's actions}

\section{Cor 2.11:}

And we do this so that we may not be outwitted [exploited] by Satan; for we are not ignorant of his designs.

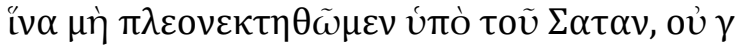

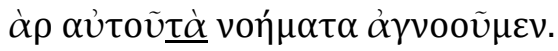

In the event that the actions of Paul's competitors look like Paul's, he insures his readers they are different.

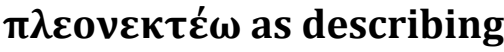
Paul's actions

\section{Cor 7.2}

we have corrupted no one, we have taken advantage [exploited] of no one

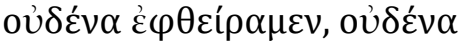
$\varepsilon \dot{\pi} \lambda \varepsilon \sigma \nu \varepsilon \kappa \tau \eta \dot{\sigma} \sigma \alpha \mu \varepsilon$

\section{Cor 9.5}

so that it may be ready as a voluntary gift and not as an extortion

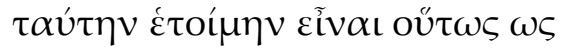

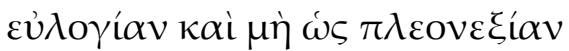
1 Thess 4.6 that no one wrong or exploit a brother

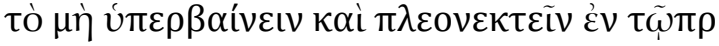

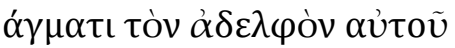

One of the conclusions Given draws from his analysis of Paul's letters to Corinth is "that Paul was indeed cunning, more so than many interpreters care to admit."79 Stripped of his apostolic exceptionalism, the Paul uncovered in this type of analysis is one of many traveling teachers that presented themselves as purveyors of truth, devoted preachers, and potential community leaders. Some of these itinerants would no doubt have done almost anything if hungry enough. ${ }^{80}$ Many of these teachers endure the same types of distrust and abuse suffered by Paul. Paul himself engages in abusive tirades against "false apostles" and "deceitful workers"

77 Given, Paul's True Rhetoric, 84.

${ }^{78}$ BDAG defines $\pi \lambda \varepsilon$ ov $\varepsilon \kappa \tau \varepsilon \dot{\omega} \omega$ as "to take advantage of, exploit, outwit, defraud, cheat."

${ }^{79}$ Given, 136.

${ }^{80}$ Didache, 11-13. Recall alleged statement from Smith Sr. "that it was sometimes necessary for him to tell an honest lie, in order to live," Howe, Mormonism Unvailed, 257, as noted above. 
(2 Cor 11.13). ${ }^{81}$ Some are abused by Paul himself. None ultimately achieved the status that Paul did.

Smith too recognizes that the differences between true and false prophets is one of perspective. For Paul, the gospel, and perhaps "truth" in general, was "veiled to those who are perishing" (2 Cor 4.3). But when an individual "turns to the Lord, the veil is removed (2 Cor 3.16). While Paul's writings are responses to criticism, Smith's writing show he anticipated criticism and sought to minimize it in advance, if not pre-empt it entirely.

As Paul used the image of the spiritually-dead's inability of to see through the veil, Smith deployed the theme of the spiritually blind's inability to recognize a true prophet. In a BoM passage that anticipated the accusations and hostility he would receive for his prophetic claims, he depicted himself in the guise of an ancient counter part, the righteous and dutiful Nephi. Despite the fact that up until this point, the $B o M$ narrative has depicted Nephi operating in an upstanding manner (providing food for the family, supporting his father, following the directions of the God-given magical "ball" that provided direction, ${ }^{82}$ etc.), Smith portrays Nephi as being viewed suspiciously by his own brothers, Laman and Lemuel. What is interesting about Smith's depiction of Nephi is that the suspicions his brothers harbored of him are the type one would hold of a nineteenth-century magician, a

\footnotetext{
81 "Such boasters are false apostles, deceitful workers, disguising themselves as apostles of Christ ... even Satan disguises himself as an angel of light" 2 Cor 11.13; "Beware of the dogs, beware of the evil workers, beware of those who mutilate the flesh!" Phil 3.2. "many false prophets shall arise and deceive many" Matt 7.15, 24.11. Second century heresiarch Irenaeus says of the variety of religious teachers and thought of his day, "there are as many schemes of 'redemption' as there are teachers of these mystical opinions, Against Heresies, 1.21.

${ }^{82}$ It worked "according to the faith, and diligence, and heed, which we did give unto [it]" BoM 40.
} 
cunning deceiver bent on dominating and exploiting others. The preceding narrative has given no grounds for the particular suspicions held. One can not fail to see Smith's attempt to inoculate himself against certain criticism by producing this exculpatory vignette. Smith wrote,

And Laman saith ... [that] Nephi ... saith that the Lord hath talked with him, and also, that angels hath ministered unto him! But behold, we know that he lieth unto us; and he telleth us these things, and he worketh many things by his cunning arts, that he may deceive our eyes, thinking, perhaps, that he may lead us away ... and after that ... he hath thought to make himself a King and a ruler over us" 1830 BoM 41 = 1 Nephi 16.37-38 (emphasis added).

Instructively, it is precisely Smith's use of "cunning arts" and the deception of people's eyes ${ }^{83}$ that had brought him success—and antagonism ${ }^{84}$-as a moneydigger and scryer. Smith deflects anticipated criticism by creating an archaic scene where it is the unrighteous that challenge techniques like his. He presents Nephi as a righteous hero who some wrongly accuse of using "cunning arts" and trumpe d'oeil.

83 "Deception of peoples eyes" anticipates his engagement of the Three Witnesses, Martin Harris, Oliver Cowdery, and David Whitmer, who beheld the plates with their "spiritual eye."

${ }^{84}$ Joseph Knight, Smith's sometime employer and benefactor, and an early Mormon convert, recalled that Smith was frequently "persecuted and abused" for not showing people the plates. He offsets the rhetoric of "persecution" with perhaps a more realistic term when he writes that "People Began to tease him to see the Book" (emphasis added). It is understandable that Smith, as the brunt of the teasing, would perceive and relate and frame the interactions as "persecution." See Deen Jesse, "Joseph Knight's Recollection of Early Mormon History" BYU Studies vol 17, no 1 (1977), 29-39; 29, $33,34,37$. 


\section{The Age of Barnum}

The irony... is that lying cannot hope to succeed in its aim unless truth is the normal practice of a society... in a system which draws much of its strength from candor, lies are all the more effective, all the more insidious.

$$
\text { Jeremy Campbell } 85
$$

I have argued that Paul made use of deception in an environment where such techniques could find justification in various circles of discourse and behavior. Explicit justifications of deception are more difficult to find in the history of American culture-which is more a function of social tastes and attitudes then any decrease in the pervasive existence of the tendency to deceive. ${ }^{86}$ The framing and analyzing of Smith's behaviors must incorporate his cultural location and the practices and behaviors of his contemporary world. One such domain to excavate is Smith's scrying and money digging activities. These took place within a larger field of activity, sometimes referred to as the "arts of deception." These "arts" were for the purpose of entertainment within a culture saturated with ruses of countless varieties. $^{87}$

Peter Ingersoll's testimony provides evidence of the market demand for these arts, specifically Smith's glass-looking performances. According to Ingersoll, after he and Smith left Harmony, Pennsylvania in August of 1827, Smith confided that he intended to keep his promise to his new father-in-law Isaac Hale regarding

\footnotetext{
85 The Liar's Tale: A History of Falsehood, 16.

${ }^{86}$ Rue's proposition that humanity benefits from deception is an important exception. See Grace of Guile.

87 James W. Cook has produced a monograph titled, The Arts of Deception: Playing with Fraud in the Age of Barnum (Cambridge, MA: Harvard University Press, 2001) which raises a number of aesthetic and moral issues surrounding "calculated act[s] of misdirection" and the limits of what constitutes "artful deception" versus "criminal fraud," 12, 14, 23.
} 
giving "up his old habits of digging for money and looking into stones." 88 Joseph reportedly told Ingersoll that "he intended to keep the promise which he had made to his father-in-law [but that] [']it will be hard for me, for they will all oppose, as they want me to look in the stone for them to dig money.[']"89 Imagine the performances in which Smith must have engaged, both impromptu and premeditated, to generate his popularity. Precious finds were never uncovered and yet the very act of participating in the scrying and digging event—which included Smith navigating the supernatural realm through a magical stone, digging within supernaturally prescribed areas, digging on fortuitous dates, pre-dig rituals, and the negotiation of "enchantments" that protected the treasure hoard from discovery. All of these components provided supernatural fodder for the scryer to negotiate, and proved part of the entertainment. Cook argues, based on P.T. Barnum's model of success, that the gestures and performances of entertainers such as a scryer in themselves begged to be exposed even as they entertained the seekers. In this we

\footnotetext{
${ }^{88}$ Peter Ingersoll's testimony in Howe's Mormonism Unvailed, 235. Hale's testimony reads: "Smith stated to me, that he had given up what he called 'glass-looking,' and that he expected to work hard for a living, and was willing to do so," Isaac Hale's testimony as in Howe's Mormonism Unvailed, 264. Compare that statement against a later revelations Smith received once he had founded his church: "and [for] temporal labors thou shalt not have strength, for this is not thy calling," BoC XXV.14; and in his Ohio years when he was being taken care of by his congregation, "I say unto you, that if ye desire the mysteries of the kingdom, provide for him [Smith] food and raiment and whatsoever thing he needeth to accomplish the work, wherewith I have commanded him," BoC XLV.12.

${ }^{89}$ Peter Ingersoll's testimony in Howe's Mormonism Unvailed, 235. I think it is worth noting that in light of Smith's conviction of the powers of the "magic" world, his move to the "religious" world may be (among other things) one of the strongest indication of his sincere commitment to religion and the god framed by the religious discourse of his era.
} 
have a "perceptual contest played out between showman and viewer," 90 where the specter of uncovering a fraud may have added to the draw of the event. ${ }^{91}$

On the other hand, the prospect of exposing the deception may not have been important to the participants. Today's World Wrestling Federation (WWF) draws thousands of fans to events that are pure theater. Crowds come to suspend disbelief and participate in the staged proceedings. ${ }^{92}$ The awareness of the theatrical charade does nothing to dampen the enthusiasm of the crowd, nor does the rigged affair rise to the level of fraud as fans are willing to pay to watch the contrived spectacle. In this, the WWF might be said to profit from the "self-conscious exploitation of illusion as a cultural practice." 93 Barnum himself was aware of this tendency. In his autobiography he wrote, "the public ... appears disposed to be amused even when they are conscious of being deceived." 94 That one of the most successful showmen of the century referred to himself as "the Prince of Humbug" suggests that there was tremendous "consumer demand for such entertainment." 95 While Smith's glass-looking may well qualify as "honest amusement"96 in some

\footnotetext{
${ }^{90}$ Cook, Arts of Deception, 14.

${ }^{91}$ Cook demonstrates how Barnum would subtly raise the possibility in the public minds that his exhibitions were vulnerable to exposure as he "cultivated some tantalizing doubts of his own" in his promotional material, Arts of Deception, 8-11.

${ }^{2}$ Cook, Arts of Deception, 258-259.

${ }^{93}$ Cook, Arts of Deception, 17

${ }^{94}$ Phineas Taylor Barnum, The Life of Barnum, 117, as cited in Cook, Arts of Deception, 16, 19.

${ }^{95}$ Cook, Arts of Deception, 22.

${ }^{96}$ Cook, Arts of Deception, 29.
} 
circles, evaluating the aesthetic merits against the social judgment becomes

“hopelessly entangled."97 Cook writes,

any effort to construct an aesthetic taxonomy of artful deception leads quickly and inescapably to a social taxonomy of the value system in which it was produced. It is simply impossible to discuss one without the other. ${ }^{98}$

Discussing and evaluating Smith's operating procedures provokes the same problematics and issues that Cook raises.

Not unlike Las Vegas style gamblers, Smith's posse of money-diggers probably deceived themselves into thinking they could beat odds that were impossibly stacked against them. It might be fair to say that the treasure seekers and money diggers who engaged with Smith in such practices were compensated by some form of thrill or "honest amusement" for their efforts.

Smith's movement from one arena of social action to another generates a similar analysis. Once the object of the quest moves out of the world of occult treasure seeking and into the world of religious world building, (from playful entertainment to a totalizing world view) the framework and implications of the costs and rewards change-as do value judgments based on these practices. ${ }^{99} \mathrm{~A}$ similar market mechanism facilitates the interaction between performer and audience in either domain of activity in a way that our modified view of Stark's

\footnotetext{
97 Cook, Arts of Deception, 23.

98 Cook, Arts of Deception, 23.

99 Vogel argues that as Smith was seeking treasure during the same time period that he was receiving heavenly messengers - and as he used the "same seer stone" to search for treasure as he did in translating the Book of Mormon-separating his scrying from his prophetic activities is a fundamentally false dichotomy, Making of a Prophet, x. Quinn writes that Smith liked to reminisce about his treasure seeking days into at least the mid 1830's, Magic World View, 266.
} 
model would suggest. Participants on both sides of the charismatic relationship are compensated (or anticipating compensation) on some level. The costs and rewards, however, must be evaluated differently. Participation in totalizing systems of salvation is quite different from an afternoon or weekend of occult entertainment, the stakes being much higher and more encompassing in the former.

For one who admits to living in the glass house of a constructed reality, throwing stones at other constructions might not be entirely fair. Morality, ethics and systems of evaluation are social constructions too. While Plato makes a case for some form of the "noble lie" and Loyal Rue may argue for the necessity of the "grace of guile," there is little objective criteria from which to govern the boundaries of deceptive actions when the construction of society is at stake. The whole topic is rife with paradox and moral ambiguity. Understanding the process by which deception is perpetuated is a different matter, one that can be described, even if imperfectly.

Vogel argues that Smith's production or procurement of some facsimile that emulated the golden plates, some material object that allowed early followers to physically heft what was presented as a golden book from antiquity (still concealed by cloth), can not be seen as other than conscious deception. ${ }^{100}$ Moreover, we have in Smith's writings the notion that God is willing to deceive if deceit (or simply exaggeration) proves effective in "work[ing] upon the hearts of the children of men,"

100 Vogel emphasizes that such a manufactured hoax can not be seen as "unconscious fraud." The Making of a Prophet, xi. Regarding Joseph's "capacity to deceive" Vogel cites as clear evidence his "repeated public denials during the early 1840's of his and others' plural marriages. The passage in his own history ("Extracts from the History of Joseph Smith, The Prophet, 2.56) that seeks to paint his involvement with Stowell is deceptive both in terms of time dedicated to the project and the role he played in the venture. 
(see Table 4.2 above). ${ }^{101}$ Given the numerical success Smith's institution achieved even in his lifetime, and the joy it still brings to many lives, moral evaluation of his techniques and practices proves difficult. ${ }^{102}$ Moreover, such moralizing is beyond the scope of this dissertation. The process by which Smith goes about constructing an utopia-to-be-realized, however, should not escape analytical critique. Smith and Paul constructed authority, disempowered competitors and laid out the basic social contract that stood at the center of the reality they manufactured. At the same time, in spite of-or perhaps because of - the deception in the claims, promotion and presentation of these texts, these men forged strong, enduring communities. Within a system where ends are allowed to justify the means, the functionality of the community can itself serve as justification for creation of the texts and construal of reality that led to its formation.

After spinning his own story of the soul and its options in the afterlife, Plato puts the following words in the mouth of Socrates:

101 The context for this statement is a revelation given to Smith for the sake of Martin Harris. Having some universalist sentiments, Harris is concerned with "eternal damnation" and "endless punishment." Smith informs him that as God's name is Eternal, that "Eternal punishment is God's punishment," and that as God's name is Endless, "Endless punishment is God's punishment," (BoC XVI. 12). Reading "Eternal punishment" is simply to understand that the endless and eternal god will punish the individual, but not necessarily endlessly or for eternity. The confusion surrounding the name, however, makes the threat of eternal punishment seem real, and as such is "might [better] work upon the hearts of ... men," BoC XVI.8.

102 Of course the other side of the "joy" is the disillusionment of those who opt out of his constructed version of reality. The denial of priesthood to women in most Christian congregations renders women second class citizens-even though most women embrace the status they are told to have by their communities. See Margret Merrill Toscano, "Are Boys More Important than Girls" in Sunstone: Mormon Experience, Scholarship, Issues and Art, Issue 146, June 2007, 19-29. Homosexuals face an exceptionally difficult plight. Their biological orientation is antithetical to church teachings. Moreover, they are told from the pulpit that their biological "wiring" is in fact a human choice that can be overcome. Many gay Christians cannot help but hate themselves. Today the web is full of help for recovering Catholics, ex-Mormons and bitter, disillusioned Christians. See Lalich, Bounded Choice, for tables that characterize the positives and negatives of high-stakes community affiliation, 234, 265-267. 
Now to affirm confidently that these things are as I have told them would not befit a man of good sense; yet seeing that the soul is found to be immortal, I think it is befitting to affirm that this or something like it is the truth about our souls and their habitations. I think too that we should do well in venturing - and a glorious venture it is - to believe it to be so. And we should treat such tales as spells to pronounce over ourselves, as in fact has been my own purpose all this while in telling my long story (Phaedo, 114d; emphasis added). ${ }^{103}$

103 Plato rationalized censorship and the promotion of untruths based on the presumed functional outcome of his idealized community. The means of social control were embedded in the grand narrative that explained humanity, its capabilities, and the potential afterlife scenarios for the soul.

See the conclusion of Plato's ResPub X, where it is claimed that Er's tale "will save us if we believe it" 621b. See also Plato's Gorgias 527b. Plato is obviously less interested in the factual veracity of his story than in its ability to form cohesive societies and influence social behavior. In fact spinning narratives that support social formation is the goal, irrespective of "facts." Cosmological and soteriological speculation will never reach definitive conclusions. But when speculative notions are taught as doctrine and become reified, they serve to play the formative role in shaping the perspectives and behaviors of individuals within a community or society. That everybody within the community shares the same values and the same general notions of life, community, and death is more important for group cohesion than whether or not the ostensibly true components of its guiding or organizing narrative are actually factual. 


\section{A TREE BUY ITS FRUITS?}

Ye shall know them by their fruits. Do men gather grapes of thorns, or figs of thistles? A good tree cannot bring forth evil fruit, neither a corrupt tree bring forth good fruit. Every tree that bringeth not forth good fruit is hewn down, and cast into the fire. Wherefore, by their fruits ye shall know them

-Matthew 7.15, KJV

Should not a tree be judged by its fruits? ${ }^{104}$ Certainly the duration of social

formations based on these prophets and their texts attests to a certain sociological efficacy gained from the use of deception. ${ }^{105}$ On our cosmically insignificant speck of a planet, nobody escapes a constructed reality. ${ }^{106}$

104 Smith's BoM (3 Nephi 14.16-19) reports a sermon given by Jesus in the New World where Jesus reads off the same crib sheet he used to deliver his Sermon on the Mount as found in Matthew 7.15.

105 South Park's Trey Parker and Matt Stone provide an excellent, simple example of this efficacy in this simple dialogue between a non-Mormon and a Mormon (all emphasis added):

Stan (South Park character, non-Mormon, speaking to the new Mormon kid in town, Gary, freshly arrived from Utah):

"Why do you have to be so fricking nice all the time? It isn't normal, you just weasel people into your way of thinking by acting like the happiest family in the world and being so nice all the time you just blindside dumb people like my Dad."

Gary, (Mormon new kid)

"look, maybe us Mormons do believe in crazy stories that make absolutely no sense and maybe Joseph Smith did make it all up. But I have a great life and a great family, I have the Book of Mormon to thank for that. The truth is, I don't care if Joseph Smith made it all up because what the church teaches now is loving your family, being nice, and helping people. And even though people in this town might think that is stupid, I choose to believe in it."

Gary continues,

"All ever did was try to be your friend Stan, but you are so high and mighty that you couldn't look past my religion and just be my friend back. You've got a lot of growing up to do [Stan]."

While South Park's Mormon kid thanks the Book of Mormon for his life and family, the pages within the Book of Mormon are silent with respect to a prescriptive method of living. Rather it is the culture that has formed around the Book of Mormon that provides the parameters, and does so under the authority that spills over from the Book of Mormon. What the text signifies far over-reaches its actual contents.

${ }^{106}$ Michael Freeden, Ideology, A Very Short Introduction (Oxford: Oxford University Press, ), 1-4. 
A brief passage from Paul's letter to the Romans (3.7) provides an opportunity to grapple directly with the problems and outcomes of deceptive methods deployed by these men and promulgated by their texts. Paul's bold admission of his use of false things, $\psi \varepsilon v ́ \sigma \mu \alpha \tau$ (deception, lies) in the assemblage of his community, challenges readers to provide reasons why deception is considered socially unacceptable given its ability to engender solid, functional and durable communities. The same passage that serves to justify his use of deception highlights the problem of taxonomy which has also featured prominently in my analysis.

When Paul defiantly asserts his right to perpetuate deception, falsehoods or lies ${ }^{107}(\psi \varepsilon v \dot{\sigma} \sigma \mu \alpha \tau)$ as a legitimate means of promoting "God's truthfulness" (Rom 3.7), it should be recognized that what Paul calls "God's truthfulness" is a euphemism for his—and only his-message (Gal 1.8-9). ${ }^{108}$ Given this interpretive move, the statement helps one understand that whatever "falsehoods" might be perpetrated, they are justified by the testimony they provide and the glory they shower upon one's particular god(s). The unspoken corollary is the glory that bathes the messenger. For Paul, one witness of God's approval is the number of people he has persuaded to join him in his movement. Not only do they indicate the abundance of God's glory, but they also serve as "the seal of [Paul's] apostleship in the Lord," (1 Cor 9.2; 2 Cor 1.21). All of this rhetoric is brought home powerfully by the reception of spiritual gifts and the powerful confirmation process that results

\footnotetext{
107 The KJV uses "my lie."

108 Under the entry $\dot{\varepsilon} \pi \varepsilon$ í $\sigma \sigma \varepsilon v \sigma \varepsilon v_{\llcorner}$the $B D A G$ translates this Romans passage as ". . by my falsehood the truthfulness of God has shown itself to be supremely great, to his glory."
} 
from the prescribed truth verification methods embodied in the texts. This method might be summarized as: "Believe what you have heard!" ( $c f$ Gal 3.2) or "rethink your old thinking, put faith and trust in the messenger, believe, really, really try hard to believe, and you will believe," ( $c f$ Moroni 10.4-6, BoC XV.20). The epistemological process, both motivation and method, is much like Plato's prescription of saying incantations over oneself ${ }^{109}$ in an effort to entrench believability. The table (Table 4.4) below provokes an important question.

109 Phaedo 114d, Rep. 376d ff cited above. 


\section{Table 4.4 \\ Paul's Challenge to Social Theorists}

\section{Paul's Ancient Challenge Roman's 3.7}

But if through my falsehood (yeu, smati)

God's truthfulness

abounds to his glory,
Paul does not spell out what his falsehoods are, but they might include 1) his proclivity to be preach a different message to different people, 2) his unorthodox "flexibility" with the term and practice of circumcision and other Torah requirements, or even 3 ) his promotion of "believing what you have heard" as no different in practices from the "bewitching" practices he condemned in others.

A euphemism for the knowledge and the message that only Paul possesses. Phrasing the discourse as "God's" serves to present the human, terrestrial agenda as one of cosmic significance.

"God's 'truthfulness"' might be evidenced by 1) the reception of "spiritual gifts" in the community, 2) Paul's teaching with "spiritual power" that is palpable to those with ears to hear, and, most importantly 3) the fact Paul has developed a following that elsewhere he describes as the "seal of my apostleship." The point is, whatever Paul is doing, it has had an effect on people that Paul wishes to rhetorically project as evidence of "God's truthfulness."

why am I still

being condemned as a sinner?
Paul had no shortage of enemies and competitors in his own day, including the pillars in Jerusalem, antagonists in every community, and the legal authorities that found reason to incarcerate him. The "condemn[ation]" of Paul's techniques indicates a certain amount of "tension" between competing interests.

\section{Restatement as a Contemporary Challenge}

But if through my narrative, the stories I tell and the reality I create,

the constructed ideal, the sacred canopy, the social experiment or novel public policy

forms the basis of a coherent, meaningrich and functional community

why am I still being labeled with taxonomically derisive terms?

In sum, Paul presents a challenge not only to readers of Romans, but to contemporary social theorists, ethicists and religionists when he essentially proposes:

If through my narrative, the stories I tell and the reality I create, the constructed ideal, the sacred canopy, the social experiment or novel public 
policy forms the basis of a coherent, meaning-rich and functional community, why am I still being labeled with taxonomically derisive terms?110

If "hav[ing] desires to serve God" (BoC III.1)—Smith's euphemism for joining a human movement that represents itself as God's-is of supreme importance, what sort of means would render this goal unacceptable? Certainly Plato is comfortable with a methodology that permits rulers to select and censor the information that is fed to the community. ${ }^{111}$ The goal of social cohesion was used by Plato to justify his telling of stories that people of intelligence would not regard as true in a literal sense (Phaedo 114d, Rep. 376d ff cited above). People were to repeat these conjectured realities to themselves as incantations that could reify what was previously only posited. Plato was writing of political entities, but the principles of social cohesion need not be limited by contemporary categories and a taxonomy that attempts to differentiate otherwise similar social alliances. Plato rendered explicit his social hierarchy and the means by which those on the top could stay on top. Plato's facile methodology needs to be appropriately masked if it is to be most effective. Paul and Smith's rhetoric of being servants to the gods is one such mask, one that serves to conceal their human interests. Moreover, each operated in a

\footnotetext{
110 Krister Stendal, in a presentation that compared BoM 3 Nephi with Matthew's Sermon on the Mount, observed a similar tendency in the Book of Mormon when he wrote of 3 Nephi, "the theological principle at work to the greater glory of God" seems to be that "When God is at work you can never understate the case."' "The Sermon on the Mount and Third Nephi," in Reflections on Mormonism: Judaeo-Christian Parallels, ed. Truman G. Madsen (Provo, UT: Religious Studies Center, Brigham Young University, 1978), 139-54.

111 Creating and regulating information is central to forming the ideal society he presents in his dialogues. The ruler was to censor those such as the poets (i.e. the equivalent of bewitchers, e.g. Gal 3.1, and false prophets) who created alternative realities that were unhelpful to his notion of the ideal state (Rep. 377ff'). Deception was critical to his social theory and his notion of the soul's immortality. Recall that Plato maintained the ruler's right to deceive just as it was the physicians' domain to administer a drug (Rep. 389b).
} 
culture where the existence of the gods was taken for granted, normative and

natural, based upon the "awesome authority of socially defined reality." 112

In his turn, Loyal Rue summarizes Plato's theory and Paul's, and Smith's ${ }^{113}$

practice when he writes of religious entities,

The primary objective of religious authorities 114 is to unify the group by eliciting conformity with an integrated myth; that is, by bringing individuals to the point where their consciousness is organized by the meanings of the myth. ${ }^{115}$

Paul's putatively cosmic goals were to be accomplish by terrestrial means. Social cohesion was fostered in the meantime. Functional sociality served as the rhetorical "truth" of the veracity of the system preached. ${ }^{116}$ In other words, the powerful sense of community and the possession of hidden knowledge and spiritual gifts in addition to powerful emotional experiences serve to verify or confirm whatever is preached as "true" to the willing congregation.

But even the occurrence of miracles and other emotional confirmations miss the mark. Sociologists have documented the essential role of human sociality in joining new movements. While the rhetoric of converts typically repeats the socially

\footnotetext{
112 Rue, Grace of Guile, 176. There was little question that the gods needed to be served, but determining the authentic spokesperson of the gods was a challenge in the eras of both Smith and Paul.

113 Paul and Smith might not have been aware of the social-theoretical implications of their strategy on an abstract basis, but certainly they capitalized on the practical implementation of such a strategy.

114 Plato would have used guardians or political rulers here as opposed to religious functionaries.

115 By the Grace of Guile, 242. This practices does not reside solely in the sphere of religion fed by religious authorities, but is alive and well in the realm of nationalism, politics and factions fueled by their own propagandizing leaders.

116 There is a relationship between the nature of the stakes and the nature of the community. When the stakes are high, so to is the intensity. The greater the goal, the higher the hurdles, the more pressing the stakes, in turn the tighter and more cohesive is the social formation. Paul states this sociological axiom as: "for just as the sufferings of Christ are abundant for us, so also our consolation is abundant through Christ, 2 Cor 1.5, 6.
} 
prescribed conversion narratives embedded in the community they join, sociological analysis suggests that converts join new movements because they would rather associated in the new community than with their previous attachments. They join for the people first, they get comfortable with the doctrine later. ${ }^{117}$

Deception is one of the sharpest arrows in Paul's and Smith's respective quivers to achieve solidarity and to generate the emotional experiences that come with solidarity and conviction. If Paul has succeeded in building a number of communities pleasing to God, by his logic it follows that his means of doing so must have been appropriate in God's eyes. Paul's defiant query regarding the legitimacy of deception is justified on the rationale that deceiving can, does, and in fact has provided witness to God's glory. If the human construction of reality is a given, we are all deceived in some ways in the eyes of others who have constructed or embraced different realities for themselves.

When a group of individuals is organized under one sacred canopy by use of a powerful narrative, social cohesion has been achieved. If social cohesion is the goal, then Paul's defiant query to the Romans, as analyzed above, provides an apt analogy as he challenges the crux of the issue. The popularity, functionality and durability of the cohesive group proves to be a certain type of "truth" in its own right.

117 "Subsequently, doctrine often becomes a central aspect of commitment," Stark and Finke, Acts of Faith, 115-118, 137. One perhaps can assume that part of what made the group attractive initially, from a social perspective, was some type of alignment of general social values. 
This is a slippery slope. History provides numerous examples of the dangers of constructed realities that provide no room for internal reflection, opposition or dissent. Philemon may have been happy to give over his slave, and Martin Harris his farm, but such sacrifices to the interests of power will not always be warmly embraced. Power does not befriend its challengers. Those on the hierarchal bottom - whether due to financial means, political beliefs, country of origin, skin pigment, genitalia, sexual orientation, ideological perspective, foreskin-intactness, culture or any other measure have the right to weigh-in on the ostensible "functionality" of any system. The benefits of a totalizing system might not be beneficial to everyone caught up in its propagated reality. It is difficult to conceive of those without a voice, those who have been construed by society's construction to belong on the bottom or at the margins, to be happy or fulfilled on a personal levellet alone pleased with their relegation to the bottom or the lonely fringe. ${ }^{118}$ This is one important reason that power interests should always be questioned. This requires careful reflexivity on the part of every citizen, especially those at the top who otherwise perpetuate the status quo, and of whom it might fairly be said, have an implicit responsibility to their fellow humans.

Measures of social "functionality" are often based upon the perspective of those in control. Truly measuring human happiness is a tall, if not impossible, order. Undoubtedly Hitler saw his reich's mythic complex as the basis for something truly functional. The same could be said of Jim Jones and the theology he espoused.

118 Certainly those relegated to the margins can find cohesion, commonalities and sociality by virtue of the fact their collective relegation to marginal status. 
David "Emanuel" Mitchell believed he was fulfilling God's commandments when he violently abducted teen-aged Elizabeth Smart for his second bride. Undoubtedly Mitchell saw his theology and marriage as perfectly functional in addition to sanctioned by his god. Those who hold or participate in power are rarely capable of facing and grasping the violence their system does to those who do not fit the norms espoused or embrace the ideology promulgated. ${ }^{119}$

Dominant classes construct realities that keep them dominant. All too often the dominated accept the rhetoric of the dominant classes as simply the way it is and acquiesce to the soul-stripping burdens of domination. The role of deception in the construction of reality is powerful. Subordination need not always be the outcome.

\section{Just the Facts?}

Robert Price raises an appropriate question when he writes, “[w]hy defend a metaphor as if it were a literal fact when factually it is manifestly false and symbolically may be profoundly true?"120 The question is a great one and I believe that the answer lies once again in human notions of reality and deception. The perception of-or rather, the belief in the (exclusive) possession of-some greater

${ }^{119}$ As most traditional or conservative religions are governed by men, the most obvious example of prescribed marginalization perpetuated against a sub-group of the community is the status of women. Women comprise one half of the population, and yet are denied the spiritual authority enjoyed by their male co-religionists in the form of priesthood or leadership roles in their community. The discrimination is not based on individual merit, rather solely on the anatomical differences that facilitate human reproduction and survival. This type of visceral, simplistic bigotry is more appropriate to the stone-age than in the twenty-first century. Homosexuals are another category of people routinely marginalized by good God-fearing, Jesus-loving Christian congregations.

${ }^{120}$ Robert M. Price "Joseph Smith: Inspired Author of the Book of Mormon" in Dan Vogel and Brent Lee Metcalfe, editors, American Apocrypha: Essays on the Book of Mormon (Salt Lake City: Signature Books, 2002), 321-366, 337-338. 
"truth" is critical to exclusive social formations. Tightly woven communities thrive on tension, on a perception that they possess a knowledge that the "deceived" simply do not have. Compelling stories and powerful metaphors are simply not as potent or inspiring if they are not perceived as somehow grounded factually and existentially in history and reality. Theology and communal affiliation are high stakes affairs where temporal well being and perhaps even eternal destiny are at stake. Nobody wants to be deceived, no one wants to live in error, few intentionally seek eternal flames. Whether or not the charter myth of a community is factually true or not-it must be understood as profoundly true if it is to serve as the community's binding matrix and have the intended guiding impact on the cadre of followers. How could a high stakes society be centered around a charter narrative that everyone realizes is just a nice, even tremendously powerful, story if in fact there was not some legitimate, even factual, "truth" to the tale? "Nice stories" simply do not cut it. When what is perceived as reality is replaced with what is perceived as a fiction attempting to inspire, the power of attraction is lowered as are the stakes. "Nice" stories simply do not generate the required tension upon which high stakes, high commitment social formations thrive. Nice stories may work well for social clubs, but not social entities whose participants seek ultimate meaning.

So in response to Price's query above, one might respond with another question: "why quibble with the factuality versus symbolism if in fact a community finds the charter myths and its foundational texts profoundly true?" Texts as material artifacts, embraced by a community, function to support the truth claims they make. Undermining the perceived truth, not just the organizationally 
efficacious "truth" but the literal, historical and factual "truth" undermines the seriousness with which followers and partisans can embrace a way of life, a way of death and a constructed scenario of reality and meaning itself. In challenging the "literal fact" of a community's constructed reality, we gain insight into a method of human coping, and a vehicle for human community formation.

Critical excavation illuminates the crafty means of power. Texts serve to disseminate and reify the posited realities that manufacture, perpetuate and protect power interests. Their operation is so naturalized and normative that it generally escapes critical analysis. Power structures have no interest in subverting themselves. The business of critical history and the excavation of power interests is often left to those on the margins.

One reason one might want to quibble with the factuality and symbolism behind the development of Paul's Christianity and Joseph's Latter-day Saint movement is because they share similar patterns of the use of texts to develop power, community and authority. Understanding these patterns helps us to understand not just social formation, but humanity itself. 


\section{WORKS CITED AND CONSULTED}

Aberbach, David, Charisma in Politics, Religion and the Media. New York: New York University Press, 1996.

Abzug, Robert H., Cosmos Crumbling: American Reform and the Religious Imagination. New York: Oxford University Press, 1994.

Albanese, Catherine L., A Republic of Mind \& Spirit: A Cultural History of American Metaphysical Religion, New Haven and London: Yale University Press, 2007

Allen, James B., “The Significance of Joseph Smith's 'First Vision' in Mormon Thought," DIALOGUE: A Journal of Mormon Thought, Vol. 1, no. 3, Autumn 1966.

, "The Emergence of a Fundamental: The Expanding Role of Joseph Smith's First Vision in Mormon Religious Thought," \ournal of Mormon History, 7 (1980), 43-62.

Anderson, Lavina Fielding, ed. Lucy's Book, A Critical Edition of Lucy Mack Smith's Family Memoir. Salt Lake City, UT: Signature Books, 2001.

Anderson, Robert D., Inside the Mind of Joseph Smith, Psychobiography and the Book of Mormon. Salt Lake City, UT: Signature Books, 1999.

Angus, S., The Mystery Religions: A Study in the Religious Background of Early Christianity. New York: Dover Publications, Inc., 1975. Unabridged and unaltered from its second printing as The Mystery-Religions and Christianity. London: John Murray, 1928.

Arrington, Leonard J., and Davis Bitton, The Mormon Experience: A History of the Latter-day Saints. New York: Vintage Books, 1980.

Ashton, John, The Religion of Paul the Apostle. New Haven and London: Yale University Press, 2000.

Ashton, John and Tom Whyte, The Quest for Paradise: Visions of Heaven and Eternity in the World's Myths and Religions. San Francisco: HarperSanFrancisco, 2001.

Attridge, Harold, W., Editor, The Harper Collins Study Bible, Revised Edition, (San Francisco: HarperSanFrancisco), 2006. 
Aune, David E., The New Testament in Its Literary Environment, The Library of Early Christianity, Wayne A. Meeks, Editor. Philadelphia: Westminster Press, 1989.

, Prophecy in Early Christianity and the Ancient Mediterranean World. Grand Rapids, Michigan: William B. Eerdmans Publishing Company, 1983. Reprint 1991.

Austin-Broos, Diane, "The Anthropology of Conversion: An Introduction," in Andrew Buckser and Stephen D. Glazier, editors, The Anthropology of Religious Conversion. Lanham: Rowman and Littlefield, 2003.

Baggini, Julian, Atheism, A Very Short Introduction. Oxford: Oxford University Press, 2003.

Bansman, Joseph and Michael Givant, "Charisma and Modernity: The Use and Abuse of a Concept," in Ronald M. Glassman and William H. Swatos, Jr., Charisma, History and Social Structure. Contributions in Sociology, Number 58, New York: Greenwood Press, 1986.

Barclay, John M. G., The Jews in the Mediterranean Diaspora: From Alexander to Trajan (323 BCE - 117 CE). Berkeley: University of California Press, 1996.

Barker, Eileen, The Making of a Moonie: Choice or Brainwashing? Oxford: Basil Blackwell, 1984.

Barrett, C. K., Paul: An Introduction to His Thought. Lousiville, KY: Westminster/John Knox Press, 1994.

Batson, C. Daniel, Patricia Schoenrade, and W. Larry Ventis, Religion and the Individual: A Social-Psychological Perspective. New York: Oxford University Press, 1993.

Bauer, Walter, Orthodoxy and Heresy in Earliest Christianity. Mifflintown, PA: Sigler Press, 1996.

Baur, F. C., Paul: The Apostle of Jesus Christ, His Life and Work, His Epistles and His Doctrine, trans. Eduard Zeller, 2nd ed. Edinburgh: Williams and Norgate, 1876.

Beard, Mary, John North and Simon Price, Religions of Rome, Vol I - A History. Cambridge, U.K.: Cambridge University Press, 2000.

Religions of Rome, Vol II - A Sourcebook. Cambridge, U.K.: Cambridge University Press, 2000. 
Beckforth, James A., "The Continuum Between 'Cults' and 'Normal' Religions," in Cults and New Religious Movements, ed. Lorne L. Dawson (Oxford: Blackwell, 2003).

BeDuhn, Jason David, The Manichaean Body In Discipline and Ritual, Baltimore and London: The Johns Hopkins University Press, 2000.

Belsey, Catherine, Poststructuralism: A Very Short Introduction. Oxford: Oxford University Press, 2002.

Berger, Peter L., The Sacred Canopy: Elements of a Sociological Theory of Religion. New York: Anchor Books, 1969. Reprint, 1990.

Heretical Imperative: Contemporary Possibilities of Religious Affirmation, 1980.

, "Charisma and Religious Innovation: The Social Location of Israelite Prophecy," American Sociological Review, Vol. 28, No. 6, Dec. 1963, 940-950.

Berger Peter L., and Thomas Luckmann, The Social Construction of Reality: A Treatise in the Sociology of Knowledge. New York: Anchor Books, 1967.

Berlinerblau, Jacques, The Secular Bible: Why Nonbelievers Must Take religion Seriously. Cambridge: Cambridge University Press, 2005.

Bianchi, Ugo, "Initiations, Mysteres, Gnose: Pour l'histoire de la mystique dans le paganisme greco-oreintal' in C. J. Bleeker, ed Initiation (Leiden, 1965): 15471 in the series SHR, 10.

Bickerman, Elias J., The God of the Maccabees: Studies on the Meaning and Origin of the Maccabean Revolt. Leiden: E. J. Brill, 1979.

Bienert, Wolfgang A., "The Picture of the Apostle in Early Christian Tradition" in Wilhelm Schneemelcher, editor, New Testament Apocrypha: Volume Two: Writings Relating to the Apostles; Apocalypses and Related Subjects, Revised Edition, English translation edited by R. McL. Wilson. Louisville and London: James Clarke \& Co. and Westminster John Knox Press, 2003.

Black, Max, Models and Metaphors (Ithaca, 1962) 236-38 (Cited by JZS DD, 52)

Bloom, Harold, The American Religion, New York: Chu Hartley Publishers, 2006.

Borg, Marcus J. and John Dominic Crossan, The First Paul: Reclaiming the Radical Visionary Behind the Church's Conservative Icon. New York: HarperOne, 2009.

Bowden, Hugh, Mystery Cults of the Ancient World. Princeton: Princeton University Press, 2010. 
Bourdieu, Pierre, Homo Academicus, trans. Peter Collier, Stanford: Stanford University Press, 1988.

Outline of a Theory of Practice, Cambridge Studies in Social and Cultural Anthropology 16. Richard Nice, Translator, Cambridge: Cambridge University Press, 1977. Reprint, 2008.

Bourdieu, Pierre and Loic J. D. Wacquant, An Invitation to Reflexive Sociology, Chicago: The University of Chicago Press, 1992.

Boyarin, Daniel, Border Lines: The Partition of Judaeo-Christianity. Philadelphia: University of Pennsylvania Press, 2004.

A Radical Jew: Paul and the Politics of Identity. Berkeley: University of California Press, 1994. Reprint 1997.

Boyer, Pascal, The Naturalness of Religious Ideas: A Cognitive Theory of Religion. Berkeley: University of California Press, 1994.

Boyer, Pascal, Religion Explained: The Evolutionary Origins of Religious Thought. New York: Basic Books/Perseus Books Group, 2001.

Boyer, Paul, When Time Shall Be No More, Prophecy Belief in Modern American Culture. Cambridge, Massachusetts and London, England: The Belknap Press of Harvard University Press.

Braun, Willi and Russell McCutcheon (eds) Introducing Religion, Essays in Honor of Jonathan Z. Smith

Braun, Willi and Russell T. McCutcheon, editors, Guide to the Study of Religion, London and New York: Continuum, 2006 (2000).

Brodie, Fawn M., No Man Knows My History: the Life of Joseph Smith, New York: Vintage Books, 1995 (first printing 1945).

Bromley, David G., "Perspective: Whither New Religions Studies? Defining and Shaping a new Area of Study," Novo Religio: The Journal of Alternative and Emergent Religions, Volume 8, Issue 2, 83-97, 2004.

Bromley, David G. and Anson D. Shupe, Jr. Strange Gods: The Great American Cult Scare. Boston: Beacon Press, 1981.

Brook, John L. The Refiner's Fire: The Making of Mormon Cosmology, 1644-1844. Cambridge: Cambridge University Press, 1994. Reprint, 2001. 
Brown, Peter, "The Rise and Function of the Holy Man in Late Antiquity" Journal of Roman Studies, 61, 60-101.

Bruce, Steve, "Religion and Rational Choice: A Critique of Economic Explanations of Religious Behavior.” Sociology of Religion, 54:193-205 (1993).

Bryman, Alan, Charisma and Leadership in Organizations. London: SAGE Publications, 1992.

Buckser, Andrew and Stephen D. Glazier, editors, The Anthropology of Religious Conversion. Lanham, Maryland: Rowman and Littlefield Publishers, Inc., 2003.

Bultmann, Rudolf, Primitive Christianity: in its Contemporary Setting, Translated by the Reverend R. H. Fuller. New York: Meridian Books, 1956.

, Theology of the New Testament, Volume I. New York: Charles Scribner's Sons, 1951.

Burkert, Walter, Ancient Mystery Cults, Carl Newell Jackson Lectures. Cambridge, Massachusetts and London, England: Harvard University Press, 1987.

, Creation of the Sacred: Tracks of Biology in Early Religions. Cambridge, MA: Harvard University Press, 1998.

, Greek Religion. Cambridge, MA: Harvard University Press, 2000.

, Homo Necans, The Anthropology of Ancient Greek Sacrificial Ritual and Myth. Berkeley: University of California Press, 1983.

, The Orientalizing Revolution: Near Easter Influence on Greek Culture in the Early Archaic Age. Cambridge, MA: Harvard University Press, 1997.

Bushman, Richard Lyman, Joseph Smith, Rough Stone Rolling, A cultural biography of Mormonism's founder, New York: Alfred A. Knopf, 2006.

, Joseph Smith and the Beginnings of Mormonism. Urbana, IL: University of Illinois Press, 1988.

, “Joseph Smith as Translator," in Bryan Waterman, ed., The Prophet Puzzle: Interpretive Essays on Joseph Smith. Salt Lake City, UT: Signature Books, 1999.

_. "Joseph Smith's Many Histories," BYU Studies 44, no. 4 (2005): 3-20 
, "That Little Narrow Prison of Language" in Believing History: Latter-day Saint essays, Edited by Reid L. Neilson and Jed Woodworth. New York: Columbia University Press, 2004, 248-261.

, “The Visionary World of Joseph Smith," BYU Studies, 37, no. 1 (1997-98), 183204.

Butler, Jon, Awash in a Sea of Faith: Christianizing the American People. Cambridge, MA: Harvard University Press, 1992.

Cameron, Avril , Christianity and the Rhetoric of Empire: The Development of Christian Discourse, Slather Classical Lectures, Volume Fifty-five, Berkeley: University of California Press, 1994.

Cameron, Ron and Merrill P. Miller, editors, Redescribing Christian Origins, Society of Biblical Literature Symposium Series, No. 28. Atlanta: Society of Biblical Literature, 2004.

Campbell, Alexander, The Millennial Harbinger; A Monthly Publication Devoted to Primitive Christianity. February 7, 1831.

Campbell, Jeremy, The Liar's Tale: A History of Falsehood. New York: W. W. Norton \& Company, 2002.

Castelli, Elizabeth A., Imitating Paul: A Discourse of Power, Literary Currents in Biblical Interpretation. Louisville, Kentucky: Westminster/John Knox Press, 1991.

Castelli, Elizabeth A., "Interpretations of Power in 1 Corinthians." Semeia 54 (1991): 197-222.

Charlesworth, James H, From Messianology to Christology: Problems and Prospects in James H. Charlesworth, Editor, The Messiah: Developments in Earliest Judaism and Christianity, The First Princeton Symposium on Judaism and Christian Origins, Minneapolis, Minnesota: Fortress Press, 1992.

, The Old Testament Pseudepigrapha, Vol. 1: Apocalyptic Literatures \& Testaments. Anchor Bible Reference Library, New York: Doubleday, 1983.

, The Old Testament Pseudepigrapha, Vol. 2: Expansions of the "Old Testament" and Legends, Wisdom and Philosophical Literature, Prayers, Psalms and Odes, Fragments of Lost Judeo-Hellenistic Works. Anchor Bible Reference Library, New York: Doubleday, 1985.

Chaves, Mark "On the Rational Choice Approach to Religion." Journal for the Scientific Study of Religion (JSSR) 34:98-104 (1995). 
Chomsky, Noam, Necessary Illusions: Thought Control in Democratic Societies. Boston: South End Press, 1989.

, Understanding Power: The Indispensable Chomsky. Edited by Peter R. Mitchell and John Schoelffel. New York: The New York Press, 2002.

Churchland, Patricia S., Braintrust: What Neuroscience Tells Us about Morality. Princeton: Princeton University Press, 2011.

, Neurophilosophy: Toward a Unified Science of the Mind/Brain. Cambridge, MA: The MIT Press, A Bradford Book, 1989. MIT Paperback, 2000.

Cohn, Norman, Cosmos, Chaos and the World to Come: The Ancient Roots of Apocalyptic Faith, Second Edition. New Haven: Yale University Press, 2001.

Coleman, Simon, "Continuous Conversion? The Rhetoric, Practice, and Rhetorical Practice of Charismatic Protestant Conversion" in Buckster and Glazier, The Anthropology of Religious Conversion, 15-28.

Collins, Adella Yarbro, Cosmology and Eschatology in Jewish and Christian Apocalypticism, Brill's Scholars' List. Leiden: Brill, 2000.

Collins, John J. Between Athens and Jerusalem: Jewish Identity in the Hellenistic Diaspora, $2^{\text {nd }}$ ed. The Biblical Research Series. Grand Rapids, Michigan/Cambridge. U.K.: William B. Eerdmans Publishing Company, 2000.

, The Apocalyptic Imagination, An Introduction to Jewish Apocalyptic Literature, Second Edition. The Biblical Resource Series, Grand Rapids, MI: Eerdmans Publishing Company, 1998.

, The Encyclopedia of Apocalypticism, Volume 1: The Origins of Apocalypticism in Judaism and Christianity, New York: Continuum, 2000.

Compton, Todd, In Sacred Loneliness: The Plural Wives of Joseph Smith. Salt Lake City, UT: Signature Books, 1994.

Coogan, David M., Stories From Ancient Canaan. The Westminster Press, 1978.

Cook, James W., The Arts of Deception: Playing with Fraud in the Age of Barnum. Cambridge, MA: Harvard University Press, 2001.

Cook, Lyndon W., editor, David Whitmer Interviews: A Restoration Witness

Cooper, John M., Editor, Plato: Complete Works. Indianapolis, IN: Hackett Publishing Company, 1997. 
Cowan, Douglas E. and David G. Bromley, Cults and New Religions: A Brief History. Malden Mass: Blackwell Publishing, 2008.

Cross, Frank Moore, Canaanite Myth and Hebrew Epic. Cambridge, MA: Harvard University Press, 1997.

Cross, Whitney R., The Burned Over District: The Social and Intellectual History of Enthusiastic Religion in Western New York, 1800-1850. Ithaca and London: Cornell University Press, 1982.

Crossan, John Dominic and Marcus J. Borg, The First Paul: Reclaiming the Radical Visionary Behind the Church's Conservative Icon. HarperOne: New York, 2009.

Danker, William Frederick, A Greek-English Lexicon of the New Testament and Other Early Christian Literature, Third Edition, based on Walter Bauer's Griechischdeutsches Worterbuch zu den Schriften des Neuen Testaments unde der fruhchristlichen Literatur, sixth edition. Chicago: University of Chicago Press, 2000.

Davidson, James West, The Logic of Millennial Thought, Eighteenth-Century New England. New Haven and London: Yale University Press, 1977.

Dawkins, Richard, The God Delusion. Boston: Houghton Mifflin Company, A Mariner Book, 2008.

Dawson, Lorne, "Charismatic Leadership in Millennial Movements: Its Nature, Origins and Development" in Cathy Wessinger, ed., The Oxford Handbook of Millennialism. New York: Oxford University Press, forthcoming.

Comprehending Cults: The Sociology of New Religious Movements Toronto: Oxford University Press, 1998.

Deen, Jesse, “Joseph Knight's Recollection of Early Mormon History,” BYU Studies, vol 17, No 1 (1977), 29-39.

Detienne, Marcel and Jean-Pierre Vernant; Translator, Cunning Intelligence in Greek Culture and Society. Atlantic Highlands, NJ: Humanities Press Inc, 1978.

Dickie, Matthew, Magic and Magicians in the Greco-Roman World. London: Routledge, 2003.

Doan, Ruth Alden, "Millerism and Evangelical Culture" in The Disappointed, Millerism and Millenarianism in the Nineteenth Century, ed. Numbers and Butler. Knoxville: University of Tennessee Press, 1993. 
Douglas, Mary, How Institutions Think. Syracuse, NY: Syracuse University Press, 1986.

Drees, William B., Religion, Science and Naturalism. Cambridge: Cambridge University Press, 1998.

Dugan, David L., Constantine's Bible: Politics and the Making of the New Testament. Minneapolis, MN: Fortress Press, 2007.

Durkheim, Emile, The Elementary Forms of Religious Life, trans. Carol Cosman, abridged with an and introduction and notes by Mark S. Cladis. Oxford, Oxford University Press, 2001.

Eagleton, Terry, Ideology: An Introduction, New and Updated Edition. London: Verso 1991. Reprint, 2007.

, Literary Theory: An Introduction. Minneapolis, MN: University of Minnesota Press, 1983.

, Marxism and Literary Criticism. Berkeley: University of California Press, 1976.

, The Meaning of Life, A Very Short Introduction. Oxford: Oxford University Press, 2007.

Edwards, Mark, et al., eds. Apologetics in the Roman Empire, Pagans, Jews, and Christians. Oxford: Oxford University Press.

Ehrman, Bart, The New Testament: A Historical Introduction to the Early Christian Writings, Third Edition. New York: Oxford University Press, 2004.

Eisenbaum, Pamela, Paul Was Not a Christian: The Original Message of a Misunderstood Apostle. New York: HarperOne, 2010.

Eisenstadt, S. N. editor, Max Weber: On Charisma and Institution Building, The Heritage of Sociology Series. Chicago and London: University of Chicago Press, 1968.

Eliade, Mircea, Patterns in Comparative Religion, translated by Rosemary Sheed, Lincoln Nebraska and London: University of Nebraska Press, 1996 (1958).

Eusebius, History of the Church, translated by G. A. Williamson. London: Penguin Books, 1986.

Evans, Craig A. and W. Richard Stegner, editors, The Gospels and the Scriptures of Israel, Journal for the Study of the New Testament Supplement Series 104, 
Studies in Scripture in Early Judaism and Christianity 3, Sheffield, England: Sheffield Academic Press Ltd, 1994.

Early Christian Interpretation of the Scriptures of Israel: Investigations and Proposals, Journal for the Study of the New Testament Supplement Series 148, Studies in Scripture in Early Judaism and Christianity 5, Sheffield, England: Sheffield Academic Press Ltd, 1997.

Finkelstein, Israel and Neil Asher Silberman, The Bible Unearthed: Archaeology's New Vision of Ancient Israel and the Origin of Its Sacred Texts. New York: The Free Press, 2001.

Finlan, Stephen, The Apostle Paul and the Pauline Tradition. Collegeville, MN: Liturgical Press, 2008.

, Problems with Atonement: The Origins of, and Controversy about, the Atonement Doctrine. Collegeville, MN: Liturgical Press, 2005.

Fitzgerald, Timothy, The Ideology of Religious Studies, New York: Oxford University Press, 2000. (see p. 6-7)

Flanagan, Owen, The Really Hard Problem: Meaning in a Material World. Cambridge, MA: A Bradford Book, The MIT Press, 2009.

Flower, Michael Attyah, The Seer in Ancient Greece. Berkeley, CA: University of California Press, 2009.

Foster, Lawrence, "First Visions: Personal Observations on Joseph Smith's Religious Experience," Sunstone, September-October 39-43;

, James J. Strang: The Prophet Who Failed, Church History, Vol. 50, No. 2 (Jun., 1981), pp. 182-192 Published by: Cambridge University Press on behalf of the American Society of Church History Stable URL:

The Psychology of Prophetic Charisma: New Approaches to Understanding Joseph Smith and the Development of Charismatic Leadership, Cultic Studies Review (Online) 6, no. 1, 2007

"The Psychology of Prophetic Charisma: New Approaches to Understanding Joseph Smith and the Development of Charismatic Leadership," Dialogue, A Journal of Mormon Thought, Vol. 36, No. 4/Winter 2003, 1-14

, The Psychology of Religious Genius: Joseph Smith and the Origins of New Religious Movements, Dialogue: A Journal of Mormon Thought, 26 (Winter 1993): $1-22$ 
Foucault, Michel, History of Madness, Translated by Jonathan Murphy and Jean Khalfa, London and New York: Routledge, 2006 (1961).

Foucault, Michel, Religion and Culture, selected and edited by Jeremy R. Carrette, New York: Routledge, 1999.

__ "The Hermeneutics of the Self" in Religion and Culture. Selected and edited by Jeremy R. Carrette. New York: Routledge, 1999.

Freeden, Michael, What is Ideology: A Very Short Introduction. Oxford: Oxford University Press, 2003.

Freedman, David Noel, Editor-in-Chief, The Anchor Bible Dictionary, 6 volumes. New York: Doubleday, 1992.

Furseth, Inger and Pal Repstad, An Introduction to the Sociology of Religion: Clasical and Contemporary Perspectives, Hants England and Burlington Vermont: Ashgate, 2006.

Gager, John G., "Early Mormonism and Early Christianity: Some Parallels and Their Consequences For the Study of New Religions," Journal of Mormon History 9, $1982,53-60$.

, Kingdom and Community: The Social World of Early Christianity. Englewood Cliffs, NJ: Prentice-Hall, Inc., 1975.

Gamble, Harry Y., Books and Readers in the Early Church: A History of Early Christian Texts. New Haven: Yale University Press, 1995.

Gauchet, Marcel The Disenchantment of the World: A Political History of Religion, Translated by Oscar Burge. Foreword by Charles Taylor. Princeton, New Jersey: New French Thought/Princeton University Press, 1999.

Gaustad, Edwin S., ed. The Rise of Adventism, Religion and Society in Mid-NineteenthCentury America. New York: Harper \& Row Publishers, 1974.

Ghaemi, Nassir, A First Rate Madness: Uncovering the Links Between Leadership and Mental Illness. New York: Penguin, 2011.

Geertz, Clifford, The Interpretation of Cultures: Selected Essays by Clifford Geertz. Basic Books, HarperCollins Publishers, 1973.

Local Knowledge: Further Essays in Interpretive Anthropology, Third Edition. Basic Books, Perseus Books Group, 2000. 
Georgi, Deiter, The Opponents of Paul in Second Corinthians. Philadelphia, PA: Fortress Press, 1986.

Given, Mark D. Paul's True Rhetoric: Ambiguity, Cunning, and Deception in Greece and Rome, Emory Studies in Early Christianity. Harrisburg, PA: Trinity Press International, 2001.

editor, Paul Unbound: Other Perspectives on the Apostle. Grand Rapids, MI: Baker Academic, 2010.

Givens, Terryl, By the Hand of Mormon: The American Scripture that Launched a New World Religion. Oxford: Oxford University Press, 2002.

People of Paradox: A History of Mormon Culture. Oxford: Oxford University Press, 2007.

Glassman, Ronald M. and William H. Swatos, Jr., editors, Charisma, History, and Social Structure, Contributions in Sociology, Number 58. New York: Greenwood Press, 1986.

Gonzalez, Matilde Martin, "A Utopian America: Charlotte Perkins Gilman's "Herland"” in Jaap Verheul, editor, Dreams of Paradise, Visions of Apocalypse, Utopia and Dystopia in American Culture. Amsterdam: VU University Press, 2004.

Goodenough, Erwin R., Jewish Symbols in the Greco-Roman Period, Edited and abridged by Jacob Neusner, Bollington Series. Princeton, NJ: Princeton University Press, 1992.

Goody, Jack, The Logic of Writing and the Organization of Society, Studies in Literacy, Family, culture and the State, Cambridge: Cambridge University Press, 1986. Reprint, 1986.

, The Power of Written Tradition, Washington, DC: Smithsonian Institution Press, 2000.

Grant, Frederick C., Hellenistic Religions: The Age of Syncretism. The Library of Liberal Arts, Indianapolis, Bobbs-Merrill, 1953.

Green, Peter, Alexander to Actium: The Historical Evolution of the Hellenistic Age. Hellenistic Culture and Society Series. Berkeley: University of California Press, 1990.

Greenspan, Stephen, The Annals of Gullibility: Why We Get Duped and How to Avoid It. Westport, CT: Praeger Publishers, 2009. 
Gruen, Erich S., Diaspora: Jews Amidst Greeks and Romans. Cambridge, MA: Harvard University Press, 2002.

, Heritage and Hellenism: The Reinvention of Jewish Tradition. Berkeley, CA: University of California Press, 1998.

Gunther, John J., St. Paul's Opponents and Their Background, A Study of Apocalyptic and Jewish Sectarian Teachings. Leiden: E.J. Brill, 1973.

Halttunen, Karen, Confidence Men and Painted Women: A Study of Middle-class Culture in America, 1830-1870. New Haven: Yale University Press, 1982.

Harland, Phillip, A., Associations, Synagogues, and Congregations: Claiming a Place in Ancient Mediterranean Society. Minneapolis, MN: Fortress Press, 2003.

, Dynamics of Identity in the World of the Early Christians: Associations, Judeans, and Cultural Minorities. New York: T \& T Clark, 2009.

Harrison, John F. C., Quest for the New Moral World, Robert Owen and the Owenites in Britain and America, New York: Charles Scribner's Sons, 1969.

The Second Coming: Popular Millenarianism, 1780-1850, New Brunswick, NJ: Rutgers University Press, 1979.

Hatch, Nathan 0., Mormon and Methodist: Popular Religion in the Crucible of the Free Market, Journal of Mormon History, Spring 1994. (Tanner Lecture).

Hatch, Nathan O., and Mark A. Noll, eds., The Bible in America: Essays in Cultural History. New York: Oxford University Press, 1982.

Hayes, Richard B., The Conversion of the Imagination: Paul as Interpreter of Israel's Scripture: Grand Rapids, MI: William B. Eerdmans Publishing Company, 2005.

,Echoes of Scripture in the Letters of Paul, New Haven: Yale University Press, 1989

Hengle, Martin, The Charismatic Leader and His Followers, translated by James Greig. Eugene, OR: Wipf \& Stock, 2005. Previously published as Nachfolge und Charisma. Walter de Gruyter \& Co., 1968.

Judaism and Hellenism: Studies in their Encounter in Palestine during the Early Hellenistic Period. Philadelphia: Fortress Press, 1981.

Hengel, Martin and Anna Maria Schwemer, Paul-Between Damascus and Antioch, The Unknown Years. Louisville: Westminster John Knox Press, 1997. 
Hesiod, Theogony, Work and Days, Shield. Translation, Introduction, and Notes by Apostolos N. Athanassakis. Baltimore, MD: The Johns Hopkins University Press, 1983.

Holmberg, Bengt, Paul and Power: The Structure of Authority in the Primitive Church as Reflected in the Pauline Epistles. Eugene, Oregon: Fortress Press, 1978. Wipf \& Stock Publishers, 2004.

Holmes, Michael W., ed. Apostolic Fathers, Greek Texts and English Translations, Edited and Revised by Grand Rapids, Michigan: Baker Books, 1999.

Hopkins, Keith, A World Full of Gods: The Strange Triumph of Christianity. New York: PLUME/Penguin, 2001.

Horsely, Richard A., Bandits, Prophets and Popular Messiahs: Popular Movements in the Time of Jesus. Harrisburg, PA: Trinity Press International, 1999.

editor, Christian Origins: A People's History of Christianity, Vol. 1. Minneapolis, MN: Fortress Press, 2005.

Galilee: History, Politics People. Valley Forge, PA: Trinity Press International, 1995.

Sociology and the Jesus Movement, Second Edition. New York: Continuum, 1994.

Howard, Richard P., “Joseph Smith's First Vision: The RLDS Tradition,” \ournal of Mormon History 7 (1980) 23-29.

Howe, Eber. D., Mormonism Unveiled: or, A faithful account of that singular imposition and Delusion, from its rise to the present time, Painseville: Printed and Published by the Author, 1834. A Photo Reprint of the 1834 edition is available from Utah Lighthouse Ministry, Salt Lake City, n.d.

Hughes, Richard T., "Two Restoration Traditions: Mormons and Churches of Christ in the Nineteenth Century." Journal of Mormon History, Spring 1993, 34-51.

James, William, The Varieties of Religious Experiences: A Study in Human Nature. New York: Modern Library, 2002.

Jenkins, Philip, Mystics and Messiahs: Cults and New Religions in American History. New York: Oxford University Press, 2000.

Jensen, Tim and Mikael Rothstein, Secular Theories on Religion: Current Perspectives. Copenhagen: University of Tusculanum Press, 2000. 
Kassam, Tazim R., "Signifying Revelation in Islam" in Vincent Wimbush, editor, Theorizing Scriptures: New Critical Orientations to a Cultural Phenomenon. New Brunswick, NJ: Rutgers University Press, 2008, 29-40.

Kaufmann, Walter, Existentialism from Dostoevsky to Sartre, Revised and Expanded. New York: New American Library, A Meridian Book, 1975.

Kennedy, George Alexander, Classical rhetoric \& its Christian \& secular tradition from ancient to modern times, Chapel Hill: University of North Carolina Press, c1999.

, Comparative Rhetoric, A Historical and Cross Cultural Introduction, New York: Oxford University Press, 1998.

, Classical Rhetoric and its Christian and Secular Tradition from Ancient to Modern Times, Chapel Hill: University of North Carolina Press, 1980.

A New History of Classical Rhetoric, Princeton, New Jersey: Princeton University Press, 1994.

Kenney, Jeff, "The Politics of Sects and Typologies," Nova Religio 6.1 (October 2002)

King, Karen L., What Is Gnosticism. Cambridge, MA: The Belknap Press of Harvard University Press, 2003.

Klass, Morton, Ordered Universes: Approaches to the Anthropology of Religion. Boulder, CO: Westview Press, 1995.

Klauck, Hans-Josef, Magic and Paganism in Early Christianity: The World of the Acts of the Apostles. Minneapolis, MN: Fortress Press, 2000.

, The Religious Context of Early Christianity: A Guide to Graeco-Roman Religions, trans. Brian McNeil. Minneapolis: Fortress Press, 2003.

Kloppenborg, John, The Formation of Q: Trajectories in Ancient Wisdom Collections, Studies in Antiquity and Christianity. Harrisburg, PA: Trinity Press International, 1987.

,Excavating Q: The History and Setting of the Sayings Gospel. Minneapolis: Fortress Press, 2000.

Kloppenborg, John S. and Stephen G. Wilson, editors, Voluntary Associations in the Graeco-Roman World. London: Routledge, 1996. 
Koester, Helmut, Ancient Christian Gospels: Their History and Development. Harrisburg, PA: Trinity Press International, 1990.

, "GNOMAI DIAPHOROI: The Origin and Nature of Diversification in the History of Early Christianity, in James M. Robinson and Helmut Koester, Trajectories through Early Christianity. Philadelphia: Fortress Press, 1971, 114-157.

, Introduction to the New Testament, Volume One: History, Culture, and Religion of the Hellenistic Age, Second Edition. New York: Walter de Gruyter \& Co., 1995.

, Introduction to the New Testament, Volume Two: History and Literature of Early Christianity, Second Edition. New York: Walter de Gruyter \& Co., 2000.

Kramer, Joel and Diana Alstad, The Guru Papers: Masks of Authoritarian Power, Berkeley, California: Frog Ltd., 1993.

La Barre, Weston, Culture in Context: Selected writings of Weston La Barre. Durham, NC: Duke University Press, 1980.

Lalich, Janja, Bounded Choice: True Believers and Charismatic Cults. Berkeley, CA: University of California Press, 1988.

Launius, Roger D., "Mormon Memory, Mormon Myth, and Mormon History”, Journal of Mormon History, Presidential Address. Spring 1995, 1-24.

Lawson, Thomas E. "Theory and the New Comparativism, Old and New." Method and Theory in the Study of Religion 8:31-35.

Lee, Shayne and Phillip Luke Sinitiere, Holy Mavericks: Evangelical Innovators and the Spiritual Marketplace. New York and London: New York University Press, 2009.

Lentz, John Clayton Jr., Luke's Portrait of Paul. Cambridge: Cambridge University Press, 1993.

Levenson, Jon D., The Death and Resurrection of the Beloved Son: The Transformation of Child Sacrifice in Judaism and Christianity. New Haven, CT: Yale University Press, 1993.

Lewis, I. M., Ecstatic Religion: A Study of Shamanism and Spirit Possession, Third Edition. London: Routledge, 2003.

Religion in Context: Cults and Charisma. Cambridge: Cambridge University Press, 1989. 
Lewis, James R., and Olav Hammer, editors, The Invention of Sacred Tradition. Cambridge: Cambridge University Press, 2007. Paperback 2011.

Lincoln, Bruce, Authority: Construction and Corrosion, Chicago and London: University of Chicago Press, 1994.

, Discourse and the Construction of Society: Comparative Studies in Myth Ritual and Classification, New York: Oxford University Press, 1989

Theorizing Myth: Narrative, Ideology and Scholarship, Chicago and London: University of Chicago Press, 1999.

, “Thesis on Method" Method \& Theory in the Study of Religion vol. 8 (1996): 225-27.

Long, Anthony A., Hellenistic Philosophy: Stoics, Epicureans, Sceptics, Second Edition. Berkeley and Los Angeles: University of California Press, 1986.

Long, Fredrick J., Ancient Rhetoric and Paul's Apology: The Compositional Unity of 2 Corinthians, Cambridge: Cambridge University Press, 2004.

Ludwig, Arnold M., The Price of Greatness: Resolving the Creativity and Madness Controversy. New York: Guilford Press, 1995.

Maccoby, Hyam, The Mythmaker: Paul and the Invention of Christianity. New York, Barnes \& Noble, 1986, (1998).

MacDonald, Dennis Ronald, The Legend and the Apostle: The Battle for Paul in Story and Canon. Philadelphia: The Westminster Press, 1983.

Mack, Burton L., The Christian Myth, Origins, Logic, and Legacy. New York and London: Continuum, 2006.

, "The Christ and Jewish Wisdom" in James Charlesworth, ed., The Messiah: Developments in Earliest Judaism and Christianity. Minneapolis, MN: Ausburg Fortress Publishers, 2009.

, The Lost Gospel: The Book of $Q$ and Christian Origins. San Francisco, HarperSanFrancisco, 1993

, A Myth of Innocence: Mark and Christian Origins. Minneapolis, MN: Fortress Press, 1988.

MacMullen, Ramsay, Enemies of the Roman Order: Treason, Unrest, and Alienation in the Empire. Cambridge, Massachusetts, Harvard University Press, 1966. 
Malherbe, Abraham J., Paul and the Popular Philosophers. Minneapolis, Fortress Press, 2006.

Malina, Bruce and Jerome Neyrey, Portraits of Paul: An Archaeology of Ancient Personality. Louisville, KY: Westminster John Knox, 1996.

Malina, Bruce and John Pilch. Social-Science Commentary on the Letters of Paul. Minneapolis, MN: Fortress Press. 2006.

Maltby, Paul, The Visionary Moment: A Postmodern Critique, The SUNY Series in Postmodern Culture. Albany: State University of New York Press, 2002.

Mann, Michael, The Sources of Social Power, Vol. 1., A History of Power from the Beginning to A.D. 1760. Cambridge: Cambridge University Press, 1986.

Martin, Luther H., Hellenistic Religions: An Introduction. New York and Oxford: Oxford University Press, 1987.

Martinez, Florentino Garcia, The Dead Sea Scrolls Translated: The Qumran Texts in English, Second Edition. Leiden: E. J. Brill, 1996.

Martyn, J. Louis, History and Theology in the Fourth Gospel, Third Edition. The New Testament Library, Louisville \& London: Westminster John Knox Press, 2003.

Marquardt, H. Michael, The Joseph Smith Revelations, Text and Commentary. Salt Lake City, UT: Signature Books, 1999.

Marquardt, H. Michael and Wesley P. Walters, Inventing Mormonism: Tradition and the Historical Record. Smith Research Associates, 1998.

Martin, Luther H., "Akin to Gods or Simply One to Another? Comparison with Respect to Religions in Antiquity." In Hans-Joachim Klimkeit (ed.), Vergleichen und Verstehen in der Religionwissenschaft. Wiesbaden: Harrassowitz, 1997.

, "Introduction: The Post-Eliadean Study of Religion and the New Comparativism." The New Comparativism in the study of Religion: A Symposium. Method and Theory in the Study of Religion 8:1-3, 1996.

___, "Religious Syncretism, comparative Religion and Spiritual Quests." Method and Theory in the Study of Religion, 11, 1999.

Marty, Martin E., Religion and Republic: The American Circumstance. Boston: Beacon Press, 1989. 
Mauss, Armand L., The Angel and the Beehive, The Mormon Struggle with Assimilation, Urbana, IL: University of Illinois Press, 1994.

__ , In Search of Ephraim: Traditional Mormon Conceptions of Lineage and Race," Journal of Mormon History

May, Dean, “A Demographic Portrait of the Mormons, 1830-1980” in Michael Quinn, The New Mormon History, Revisionist Essays on . . Signature Books, 1992 (perhaps also in JMH or Dialogue?)

McCutcheon, Russell, T., Critics Not Caretakers: Redescribing the Public Study of Religion. Albany, NY: State University of New York Press, 2001.

Manufacturing Religion: The Discourse on Sui Generis Religion and The Politics of Nostalgia. Oxford: Oxford University Press, 1997.

, Studying Religion: An Introduction. London: Equinox, 2007.

McDonald, Lee Martin, The Biblical Canon: Its Origin, Transmission, and Authority. Peabody, MA: Hendrickson Publishers, 2007.

McIntyre, John, Children of Peace, McGill-Queen's Studies in the History of Religion. Montreal: McGill-Queen's University Press, 1994.

Meeks, Wayne A., The First Urban Christians, The Social World of the Apostle Paul. New Haven: Yale University Press, 1983.

Meinig, D. W., "The Mormon Nation and the American Empire," Journal of Mormon History, vol. 22 No. 1 Spring 1996.

Melville, Herman, The Confidence-Man: His Masquerade. Oxford: Oxford University Press, 2008.

Meyer, Marvin W., ed., The Ancient Mysteries: A Sourcebook of Sacred Texts. Philadelphia, PA: University of Pennsylvania Press, 1999.

Miles, H. Lyn, "How Can I Tell a Lie? Apes, Language, and the Problem of Deception" in Mitchell and Thompson, Perspectives on Human and Nonhuman Deceit, 245-266.

Mitchell, Margaret M., Paul and the Rhetoric of Reconciliation: An Exegetical Investigation of the Language and Composition of 1 Corinthians, Lousville, Kentucky: Westminster/John Knox Press, 1992. 
Mitchell, Robert W., and Nicholas S. Thompson, eds., Deception: Perspectives on Human and Nonhuman Deceit. Albany: State University of New York Press, 1986.

Mohanty, Satya P., Literary Theory and the Claims of History: Postmodernism, Objectivity, Multicultural Politics, Ithaca and London: Cornell University Press, 1997.

Moorhead, James H., "Between Progress and Apocalypse: A Reassessment of Millennialism in American Religious Thought, 1800-1880," Journal of American History 71, Dec. 1984.

Moreland, Kjell Arne, The Rhetoric of Curse in Galatian: Paul Confronts Another Gospel, Atlanta: Scholars Press, 1995.

Moerman, D. Max, "The Death of the Dharma: Buddhist Sura Burials in Early Medieval Japan," in Kristina Myrvold, The Death of Sacred Texts: Ritual Disposal and Renovation of Sacred Texts in World Religions. Surrey, England: Ashgate Publishers, 2010, 71-89. As found online at http://divinity.uchicago.edu/martycenter/publications/webforum/032011/ Moerman.pdf. Accessed April 28, 2011.

Mumford, Michael D., Pathways to Outstanding Leadership: A Comparative Analysis of Charismatic, Ideological, and Pragmatic Leaders (Applied Psychology) Mar 27, 2006

Murphy-O'Connor, Jerome, Paul: A Critical Life. Oxford: Oxford University Press, 1997.

Neilson, Reid L., and Terryl L. Givens, Joseph Smith Jr.: Reappraisals after Two Centuries. Oxford: Oxford University Press, 2009.

Neusner, Jacob, Take Judaism for Example: Studies toward the Comparison of Religions, South Florida Studies in the History of Judaism Number 51. Atlanta: Scholars Press, 1992.

The New Oxford Annotated Bible: New Revised Standard Version with the Apocrypha, An Ecumenical Study Bible, College Edition. Edited by Michael D. Coogan and others. Oxford and New York: Oxford University Press, 2001.

Nickelsburg, George W. E., Ancient Judaism and Christian Origins: Diversity, Continuity, and Transformation. Minneapolis, MN: Augsburg Fortress Publishers, 2003.

Nisetich, Frank J., Pindar Victory Songs. Baltimore, MD: The Johns Hopkins University Press, 1980. 
Norbeck, Edward, Religion in Human Life: Anthropological Views. New York: Holt, Rinehart and Winston, Inc., 1974

Numbers, Ronald L. and Jonathan M. Butler, editors, The Disappointed, Millerism and Millenarianism in the Nineteenth Century. Knoxville: University of Tennessee Press, 1993.

Oakes, Len, Prophetic Charisma: The Psychology of Revolutionary Religious Personalities, Syracuse, NY: Syracuse University Press, 1997.

Oats, Joan, Babylon, Revised Edition. New York: Thames and Hudson, 2000.

O'Dea, Thomas, The Mormons. Chicago: University of Chicago Press, 1965.

O’Donnell, John, J. Augustine: A New Biography. San Francisco: HarpersCollins, 2005

Origen, Contra Celsum, Translated with an Introduction \& Notes by Henry Chadwick. London, New York: Cambridge University Press, 1980.

Overholt, Thomas, W., Channels of Prophecy: The Social Dynamics of Prophetic Activity. Eugene, OR: Wipf and Stock Publishers, 1989.

, Prophecy in Cross-Cultural Perspective: A Sourcebook for Biblical Researchers, Society of Biblical Literature Sources for Biblical Study, Edited by Burke 0. Long, No. 17. Atlanta: Scholars Press, 1986.

Paden, William E., Religious Worlds: The Comparative Study of Religion, Second Edition. Boston: Beacon, 1994.

Pagels, Elaine, The Gnostic Gospels. New York: Vintage Books, 1989.

The Gnostic Paul: Gnostic Exegesis of the Pauline Letters, Harrisburg, Pennsylvania: Trinity Press International, 1975.

Palmer, Grant H., An Insider's View of Mormon Origins. Salt Lake City, UT: Signature Books, 2002.

Parker, Richard A., "The Joseph Smith Papyri: A Preliminary Report,” Dialogue: A Journal of Mormon Thought, Vol 3 no. 2, 1968, 86-87.

Pemberton, John, ed., Insight and Artistry in African Divination. Washington: Smithsonian Institution Press, 2000.

Pervo, Richard, I., Dating Acts: Between the Evangelists and the Apologists. Santa Rosa, CA: Polebridge Press, 2006. 
Luke's Story of Paul. Minneapolis, MN: Fortress Press, 1990.

, The Making of Paul: Constructions of the Apostle in Early Christianity,

, The Mystery of Acts: Unraveling Its Story. Santa Rosa, CA: Polebridge Press, 2008.

, Profit with Delight: The Literary Genre of the Acts of the Apostles. Philadelphia: Fortress Press, 1987.

Plato, Complete Works, Edited with Introduction and Notes by John M. Cooper. Indianapolis, IN: Hacket Publishing Company, 1997.

Poole, Fitz John Porter, "Metaphors and Maps: Towards Comparison in the Anthropology of Religion." Journal of the American Academy of Religion, vol. 54, no.3 Autumn 1986, 411-457.

Pollock, Sheldon, The Language of the Gods in the World of Men: Sanskrit, Culture, and Power in Premodern India. Berkeley: University of California Press, 2006. Paperback, 2009.

Pratt, Parley P., A Voice of Warning, Salt Lake City, Utah: The Deseret News Steam Printing Establishment, 1874 (1839).

Preus, Samuel, Explaining Religion: Criticism and Theory from Bodin to Freud. Yale University Press, 1987.

Price, Robert, M., "Joseph Smith: Inspired Author of the Book of Mormon" in Dan Vogel and Brent Lee Metcalfe, editors, American Apocrypha: Essays on the Book of Mormon. Salt Lake City: Signature Books, 2002, 321-366.

Price, S. R. F., Rituals and Power: The Roman Imperial Cult in Asia Minor, Cambridge: Cambridge University Press, 2002, (1984)

Prothero, Stephen, Religious Literacy: What Every American Needs to Know-And Doesn't. New York: HarperCollins, 2008.

Quinn, D. Michael, Early Mormonism and the Magic World View. Salt Lake City, UT: Signature Books, 1988.

The Mormon Hierarchy: Origins of Power. Salt Lake City, UT: Signature Books, 1994.

Rambo, Lewis R., Understanding Religious Conversion. New Haven, CT: Yale University Press, 1993. 
Ranger, Terence and Eric Hobsbawn, editors, The Invention of Tradition. Cambridge: Cambridge University Press, 1992.

Richardson, Cyril C., ed., Early Christian Fathers, Newly translated and edited. New York: Simon and Schuster, 1996.

Riley, Gregory J., One Jesus, Many Christs: How Jesus Inspired Not One True Christianity But Many. Minneapolis: Fortress Press, 2000.

, The River of God: A New History of Christian Origins. San Francisco: HarperSanFrancisco, 2001.

Riggio, Ronald, The Charisma Quotient: What It Is, How To Get It, How To Use It. New York: Dodd, Mead \& Company, 1987.

Rives, John B., Religion and Authority in Roman Carthage from Augustus to Constantine, Oxford: Clarendon Press, 1995.

Robbins, Vernon, The Tapestry of Christian Discourse: Rhetoric, Society and Ideology. London: Routledge, 1996.

Roberts, B. H., A Comprehensive History of The Church, 6 vols. Salt Lake City, UT: Corporation of the President, Church of Jesus Christ of Latter-day Saints, 1930. Reprint, Provo, UT: Brigham Young University Press, 1965.

Roberts, Alexander, James Donaldson and Arthur Cleveland Coxe, eds. The AnteNicene Fathers, Vol. I, The Apostolic Fathers with Justin Martyr and Irenaeus. Reprint, New York: Cosmo Publishing, 2007. (Originally published in 1885) eds. The Ante-Nicene Fathers, Vol. III, Latin Christianity. Reprint, New York: Cosmo Publishing, 2007. (Originally published in 1885)

Robinson, James M. "Kerygma and History in the New Testament," in Trajectories through Early Christianity, ed. James M. Robinson Philadelphia: Fortress Press, 1971.

,"LOGIO SOPHON, on the Gattung of Q," in Trajectories through Early Christianity. Philadelphia: Fortress Press, 1971.

Robinson, James M., and Helmut Koester, editors, Trajectories through Early Christianity. Philadelphia: Fortress Press, 1971.

Robinson, James, et. al, The Critical Edition of Q: A Synopsis Including the Gospels of Matthew and Luke, Mark and Thomas With English, German and French 
Translations of $Q$ and Thomas. Minneapolis: Fortress Press and Peeters Publishers, 2000.

Robinson, James M., ed. The Nag Hammadi Library. San Francisco: HarperSanFrancisco, 1990.

Roetzel, Calvin, The Letters of Paul: Conversations in Context, Fourth Edition. Louisville, KY: Westminster John Knox Press, 1998.

Paul: The Man and the Myth. Minneapolis: Fortress Press, 1999.

Rosner, Brian S., Paul, Scripture and Ethics: A Study of 1 Corinthians 5-7. Arbeiten zur Geschichte Des Antiken Judentums und des Urchristentums, Leiden: E.J. Brill, 1994.

Roth, Martha T., Law Collections from Mesopotamia and Asia Minor, Second Edition, SBL Writings from the Ancient World Series. Atlanta, GA: Scholars Press, 1997.

Rue, Loyal, By the Grace of Guile: The Role of Deception in Natural History and Human Affairs. Oxford: Oxford University Press, 1994.

Religion Is Not About God: How Spiritual Traditions Nurture Our Biological Nature and What to Expect When They Fail. New Brunswick, NJ: Rutgers University Press, 2005.

Ruthven, Malise, Fundamentalism, The Search for Meaning. Oxford: Oxford University Press, 2004.

Sagan, Carl, The Demon-Haunted World: Science as a Candle in the Dark. New York: Ballantine Books, 1996.

Samply, J. Paul, Paul in the Greco-Roman World: A Handbook. Harrisburg, PA: Trinity Press International, A Continuum imprint, 2003.

Schneemelcher, Wilhelm, New Testament Apocrypha, vol. 2: Writings Relating to the Apostles; Apocalypses and Related Subjects, revised edition, trans. by R. McL. Wilson. Louisville, KY: Westminster John Know Press, 2003.

Schuessler Fiorenza, Elisabeth and Kent H. Richards, editors, Transforming Graduate Biblical Studies. Atlanta, GA: Society of Biblical Literature, 2010.

Segal, Alan F., Paul the Convert: The Apostolate and Apostasy of Saul the Pharisee. New Haven: Yale University Press, 1990. 
Shaw, Graham, The Cost of Authority: Manipulation and Freedom in the New Testament. Philadelphia, PA: Fortress Press, 1983.

Sharpe, Eric J., Comparative Religion: A History, Second Edition. La Salle, IL: Open Court, 1986, (Duckworth, 1975).

Shipps, Jan, Mormonism, The Story of a New Religious Tradition. Urbana and Chicago: University of Illinois Press, 1987.

The Prophet Puzzle, Journal of Mormon History, vol. 1, 1974, 3-20.

Sojourner in the Promised Land, Forty Years among the Mormons, Urbana and Chicago: University of Illinois Press, 2000.

Smart, Ninian, The Science of Religion and the Sociology of Knowledge. Princeton: Princeton University Press, 1973.

Smith, Jonathan Z., Drudgery Divine: On the Comparison of Early Christianities and the Religions of Late Antiquity, Jordan Lectures on Comparative Religion, XIV, School of Oriental and African Studies. University of London, Chicago: The University of Chicago Press, 1994. Reprint, 1990.

, Imagining Religion, From Babylon to Jonestown. Chicago and London: The University of Chicago Press, 1982.

Smith, Joseph Jr., A Book of Commandments, For the Government of the Church of Christ. Zion: W. W. Phelps \& Co., 1833.

, The Book of Mormon: An Account Written By the Hand of Mormon, Upon Plates Taken From the Plates of Nephi. Palmyra, NY: Printed by E. B. Grandin, For the Author, 1830.

, The Book of Mormon, translated by Joseph Smith, Jr. Salt Lake City, Utah: The Church of Jesus Christ of Latter-day Saints, 1975.

, The Doctrine and Covenants of The Church of Jesus Christ of Latter-Day Saints, Containing Revelations Given to Jospeh Smith, The Prophet, With some Additions by his Successors in the Presidency of the Church. Salt Lake City, Utah: The Church of Jesus Christ of Latter-day Saints, 1974.

, Extracts from the History of Joseph Smith, The Prophet, in The Pearl of Great Price. Salt Lake City, UT: Church of Jesus Christ of Latter-day Saints, 1975.

, The Pearl of Great Price: A Selection from the Revelations, Translations, and Narrations of Joseph Smith, First Prophet, Seer and Revelator To the Church of 
Jesus Christ of Latter-day Saints. Salt Lake City, UT: Church of Jesus Christ of Latter-day Saints, 1975.

Smith, Lucy Mack, Biographical Sketches of Joseph Smith the Prophet, and His Progenitors for Many Generations. Liverpool: S. W. Richards, 1853. A photo reprint of the original 1853 edition. Salt Lake City: Lighthouse Ministry. n.d.

Smith, Morton, "The Common Theology of the Ancient Near East," Journal of Biblical Literature, 71 (1952), 135-47

Smith, Wilfred Cantwell, Faith and Belief: The Difference Between Them. Oxford: Oneworld Publications, 1998. (First published as Faith and Belief. Princeton: Princeton University Press, 1979).

, What Is Scripture? A Comparative Approach. Minneapolis, MN: Fortress Press, 2005.

Staker, Mark Lyman, Hearken, O Ye People: The Historical Setting of Joseph Smith's Ohio Revelations, Salt Lake City, UT: Greg Kofford Books, 2009.

Stanley, Chris D. Arguing with Scripture: The rhetoric of quotations in the letters of Paul, New York and London: T \& T Clark, 2004.

Stark, Rodney, "Extracting Social Scientific Models from Mormon History," Journal of Mormon History, Spring, 1999.

, The Rise of Christianity: How the Obscure, Marginal Jesus Movement Became the Dominant Religious Race in the Western World in a Few Centuries. San Francisco: HarperSanFrancisco, 1997.

, The Rise of Mormonism, edited by Reid L. Neilson. New York: Columbia University Press, 2005.

, "Why Religious Movements Succeed or Fail: A Revised General Model," Journal of Contemporary Religion, Vol. 11, No. 2, 1996, 133-146.

Stark, Rodney and William Bainbridge, The Future of Religion: Secularization, Revival and Cult Formation. Berkeley: University of California Press, 1985.

Stark, Rodney and William Sims Bainbridge, $A$ Theory of Religion, New Brunswick, New Jersey: Rutgers University Press, 1987. Reprint, 1996.

Stark, Rodney and Roger Finke, Acts of Faith, Explaining the Human Side of Religion. Berkeley: University of California Press, 2000.

Stendahl, Krister, Paul Among Jews and Gentiles, Philadelphia: Fortress Press, 1976. 
"The Sermon on the Mount and Third Nephi," in Reflections on Mormonism: Judaeo-Christian Parallels, ed. Truman G. Madsen (Provo, UT: Religious Studies Center, Brigham Young University, 1978), 139-54.

Storr, Anthony, Feet of Clay-Saints, Sinners and Madmen: A Study of Gurus. New York: Free Press, 1996.

Swartz, David, Culture and Power: The Sociology of Pierre Bourdieu. Chicago: University of Chicago Press, 1997.

Sweeney, Marvin, "Form Criticism" in Steven L. McKenzie and Stephen R. Haynes, editors, To Each Its Own Meaning: An Introduction to Biblical Criticisms and Their Application. Louisville, KY: Westminster John Knox Press, 1999, 58-89.

Taves, Ann, Fits, Trances and Visions: Experiencing Religion and Explaining Experience from Wesley to James. Princeton, NJ: Princeton University Press, 1999.

Taylor, Alan, The Free Seekers: Religious Culture in Upstate NY 1790-1835, Lournal of Mormon History, Spring, 2001.

Tcherikover, Victor, Hellenistic Civilization and the Jews. New York: Atheneum, A Temple Book, 1959.

Tenney, Elizabeth R., Robert J. MacCoun, Barbara A Spellman, and Reid Hastie, "Calibration Trumps Confidence as a Basis for Witness Credibility." Psychological Science vol. 18 no. 1. 46-50.

Thomassen, Einar, “Forgery' in the New Testament," in James R. Lewis and Olav Hammer, editors, The Invention of Sacred Tradition. Cambridge: Cambridge University Press, 2007. Paperback 2011.

Tiede, David L., Prophecy and History in Luke Acts. Fortress Press, PA, 1980.

Torjesen, Karen, When Women were Priests: Women's Leadership in the Early church and the Scandal of their Subordination in the Rise of Christianity. New York: HarperOne, 1995.

Toscano, Margret Merrill, “Are Boys More Important than Girls,” Sunstone: Mormon Experience, Scholarship, Issues and Art. Issue 146, June 2007, 19-29.

Tuckett, Christopher M., Q and the History of Early Christianity, Studies on Q. Peabody Massachusetts: Hendrickson Publishers, 1996. 
Turcan, Robert, The Cults of the Roman Empire. Oxford, UK: Blackwell Publishers, 2000.

Ulansey, David, The Origins of the Mithraic Mysteries: Cosmology and Salvation in the Ancient World. Oxford: Oxford University Press, 1989.

Underwood, Grant, The Millenarian World of Early Mormonism. Urbana, IL: University of Illinois, 1999.

, "Millenarianism and the Early Mormon Mind." Journal of Mormon History 9 (1982): 41-51.

Van Wagoner, Richard S., Sidney Rigdon: A Portrait of Religious Excess. Salt Lake City, UT: Signature Books, 1994.

Vogel, Dan, Early Mormon Documents, in Five Volumes. Salt Lake City, UT: Signature Books, 1996.

Joseph Smith, The Making of a Prophet. Salt Lake City: Signature Books, 2004.

, “The Location of Joseph Smith's Early Treasure Quests.” Dialogue: A Journal of Mormon Thought 27 (3) 197-231.

, "The Prophet Puzzle" Revisited, Dialogue: A Journal of Mormon Thought, vol. 31, No. 3, Fall, 1998. 49-68. Reprinted in Bryan Waterman, ed., The Prophet Puzzle: Interpretive Essays on Joseph Smith. Salt Lake City, UT: Signature Books, 1999.

, Religious Seekers and the Advent of Mormonism. Salt Lake City, UT: Signature Books, 1988.

Vogel, Dan and Brent Lee Metcalfe, eds., American Apocrypha, Essays on the Book of Mormon, Signature Books: Salt Lake City, 2002.

Wallace, Anthony F. C., "Revitalization Movements," American Anthropologist 38 (April 1956): 264-281.

Waterman, Bryan, ed., The Prophet Puzzle: Interpretive Essays on Joseph Smith. Salt Lake City, UT: Signature Books, 1999.

Watson, Duane F., Persuasive Artistry, Studies in New Testament Rhetoric in Honor of George A. Kennedy, Sheffield, England: Sheffield Academic Press, 1991.

Web, Thomas Smith, The Freemason's Monitor or: Illustrations of Masonry. Salem: Cushing and Appleton, 1818. 
Weber, Max, On Charisma and Institution Building, edited and introduced by S. N. Eisenstadt. Chicago, IL: University of Chicago Press, 1968.

, The Sociology of Religion, Introduction by Talcott Parsons, Foreword by Ann Swidler, Boston: Beacon Press, 1993 (1992).

, The Theory of Social and Economic Organization. New York: The Free Press, 1964.

Werth, Lucy Fontaine and Jenny Flaherty, "A Phenomenological Approach to Human Deception" in Robert W. Mitchell and Nicholas S. Thompson, Deception:

Perspectives on Human and Nonhuman Deceit, 293-312.

West, Martin L., Early Greek Philosophy and the Orient. Oxford: Clarendon Press, 1971.

Westergren, Bruce N., From Historian to Dissident: The Book of John Whitmer. Salt Lake City, UT: Signature Books, 1995.

Whitmer, David, An Address to All Believers in Christ By A Witness to the Divine Authenticity of the Book of Mormon. Richmond, Missouri: David Whitmer, 1887.

Wilken, Robert L., The Christians as the Romans Saw Them New Haven and London: Yale University Press, 1984.

Wilson, John A., “The Joseph Smith Egyptian Papyri, Translations and Interpretations, A Summary Report," Dialogue: A Journal of Mormon Thought, Vol 3 no. 2, 1968, 67-85.

Wilson, Robert R., Prophecy and Society in Ancient Israel. Philadelphia: Fortress Press, 1946. Reprint 1984.

Wimbush, Vincent L., ed., Editor, African Americans and the Bible: Sacred Texts and Social Textures, New York: Continuum, 2000.

, The Bible and African Americans: A Brief Hisotry. Minneapolis, MN: Fortress Press, 2003.

, The Bible and the American Myth: A Symposium on the Bible and Constructions of Meaning. Macon, GA: Mercer University Press, 1999.

, "Contemptus Mundi - Redux: The Politics of an Ancient Rhetorics and Worldview." Power, Powerlessness, and the Divine: New Inquiries in Bible and Theology. Cynthia L. Rigby, ed., 263-80. Atlanta, Georgia: Scholars Press 
Paul the Worldly Ascetic: Responses to the World and Self-Understanding according to 1 Corinthians 7. Macon, Georgia: Mercer University Press, 1987.

, A Response to D. Max Moerman's The Death of the Dharma: Buddhist Sutra Burials in Early Medieval Japan, Journal of Biblical Literature 130, no. 1 (2011) 5-24.

, Editor, Theorizing Scriptures: New Critical Orientations to a Cultural Phenomenon. New Brunswick, NJ: Rutgers University Press, 2008.

“The Work We Make Scriptures Do For Us: An Argument For Signifying (On) Scriptures As Intellectual Project," in Elisabeth Schuessler Fiorenza and Kent H. Richards, editors, Transforming Graduate Biblical Studies. Atlanta, GA: Society of Biblical Literature, 2010, 355-366.

Winters, Bruce W., Philo and Paul Among the Sophists: Alexandrian and Corinthian Responses to a Julio-Claudian Movement, Second Edition, Foreword by G. W. Bowersock. Grand Rapids, MI: William B. Eerdmans Publishing Company, 2002.

Witt, R. E. Isis in the Ancient World, Baltimore and London: Johns Hopkins University Press, 1997 (1971).

Wodak, Ruth and Michael Meyer, Methods of Critical Discourse Analysis, Second Edition. Los Angeles: SAGE Publishing, 2009.

Wood, Wilford C., Joseph Smith Begins His Work, Volume II. United States of America: Wilford C. Wood, 1958.

Zablocki, Benjamin and Thomas Robbins, Editors, Misunderstanding Cults: Searching for Objectivity in a Controversial Field. Toronto: University of Toronto Press, 2001.

Zizek, Slavoj, The Puppet and the Dwarf: The Perverse Core of Christianity, Cambridge MA: The MIT Press, 2003. 